\title{
Glycerolmetabolismus und Pathogenität Von
}

\section{Mycoplasma pneumoniae}

\author{
Dissertation zur Erlangung des Doktorgrades \\ der Mathematisch-Naturwissenschaftlichen Fakultäten \\ der Georg-August-Universität zu Göttingen
}

\author{
Vorgelegt von: \\ Claudine Hames \\ aus Luxemburg/Luxemburg
}

Göttingen 2008 
D7

Referent: Prof. Dr. Jörg Stülke

Korreferent: PD Dr. Michael Hoppert

Tag der mündlichen Prüfung: 29.04.2008 


\section{Danksagung}

$\mathrm{Zu}$ allererst möchte ich Prof. Jörg Stülke danken, dass ich bei ihm sowohl meine Diplomarbeit als auch meine Doktorarbeit in seiner Abteilung anfertigen durfte, für die schöne und leider zu kurze Stadtführung durch London und für einige gesellige Feierabendbierrunden. Auch möchte ich PD Dr. Michael Hoppert dafür danken, dass er Korreferent dieser Arbeit ist und für die Hilfe und die Tipps bei der Elektronenmikroskopie. Wolfgang Bohne und Diana Hippe danke ich für die gute Einführung in die Zellkultur.

Auch Sven möchte ich danken, dass er mir die Welt der Mykoplasmen näher gebracht hat und immer für Fragen jeglicher Art zur Verfügung stand. Ein großer Dank gilt auch den Praktikanten, Cécilia, Spencer und Meike, die zu dieser Arbeit beigetragen haben. Meinem Diplomanden Sebastian S. danke ich für die erfolgreiche und nette Zusammenarbeit, auch wenn wir in Sachen Fußball nicht immer der gleichen Meinung sind (Und der HSV wird doch Meister! $($ )). Der lieben Julia danke ich für die sehr gute Unterstützung im Labor und für unterhaltsame Gespräche. Unserer fleißigen guten Fee Bärbel gebührt auch ein großer Dank.

Allen Abteilungsmitgliedern danke ich für die gute Stimmung im Labor und für die lustigen Freitagnachmittage. Hierbei möchte ich Nico für die Einführung der Bloodhoundgangfreitagsmusiktradition danken, die jedem immer die Vorfreude auf das Wochenende versüßt. Auch möchte ich Katrin und Christoph danken, mit denen man immer lustige und interessante Gespräche führen kann. Falk und Sina möchte ich vor allem für die spaßigen Veteranentreffen beim Thailänder oder Mexikaner danken. Kalpana danke ich, dass sie immer mit mir zum Sport gegangen ist und wir uns gegenseitig motiviert haben. Maria, unserer spanischen Austauschdoktorandin, danke ich, dass sie mir Spanien näher gebracht hat und dafür, dass ihre immerwährende gute Laune so ansteckend war. Josef danke ich für die interessanten Gespräche. Fabian danke ich für die netten musikalischen Einlagen mit dem Laborschweinchen. Hinnerk danke ich auch für lustige Geschichten und für das näher bringen seines etwas anderen Musikgeschmacks. Oli danke ich, dass er mir immer meine Fragen beantwortet hat, obwohl er jetzt immer sehr beschäftigt ist. Auch ehemaligen Kollegen, darunter Matthias, Matti, Sarah und Eva danke ich zum einen für die nette Aufnahme im StülkeLab und zum anderen für unterhaltsame Gespräche. Den TAs Christina und Sabine 
danke ich, dass sie immer gute Tipps auf Lager hatten, wenn etwas mal nicht geklappt hat.

Jörn und Judith möchte ich für die lustigen Kneipen- und Partyabende während des Studiums und der Doktorarbeit danken. Bärbel und Peter danke ich, dass sie mich immer herzlich aufgenommen haben und mir den Norden Deutschlands näher gebracht haben.

E grousse Merci gebührt meine lieben Eltern und meiner Familie in Luxemburg. Sie haben mir mein Studium finanziert und mich in meinen Entscheidungen immer unterstützt. Vielen Dank!

Zum Schluss möchte ich Sebastian H., dem wichtigsten Menschen in meinem Leben, danken, dass er mich immer auf andere Gedanken gebracht hat, wenn es im Labor mal nicht so gut lief und dabei oftmals meine schlechte Laune ertragen musste. Danke, dass du immer für mich da bist. 


\section{Inhaltsverzeichnis}

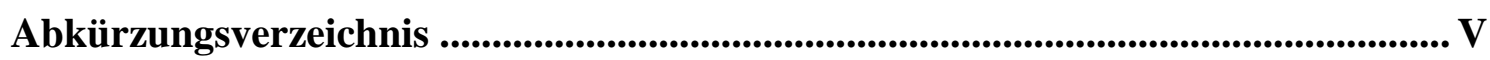

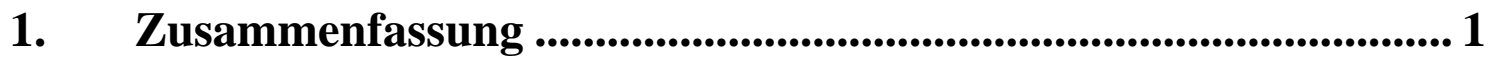

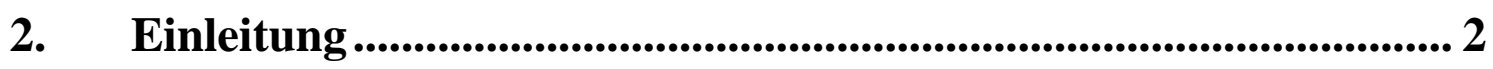

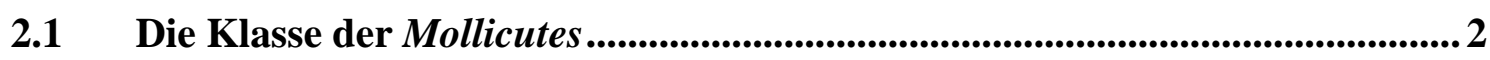

2.2 Der Organismus $M$. pneumoniae ..........................................................................2

2.3 Das PTS in Gram-positiven Bakterien.............................................................. 4

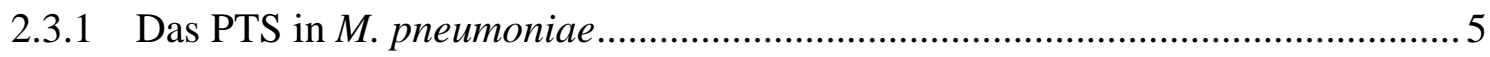

2.4 Glycerolstoffwechsel in Gram-positiven und Gram-negativen Bakterien..... 6

2.4.1 Die Rolle der Glycerol-3-phosphat-Oxidase bei der Pathogenität........................ 7

2.4.2 Glycerolstoffwechsel in M. pneumoniae..................................................... 9

2.5 Pathogenitätsmechanismen von Bakterien................................................. 10

2.5.1 Pathogenitätsmechanismen von Mykoplasmen ............................................... 12

2.6 Regulation in Bakterien............................................................................................ 14

2.6.1 Phosphorylierungen in Bakterien und deren Funktion...................................... 15

2.6.2 Die Ser/Thr/Tyr-Kinasen und deren Funktion ............................................... 16

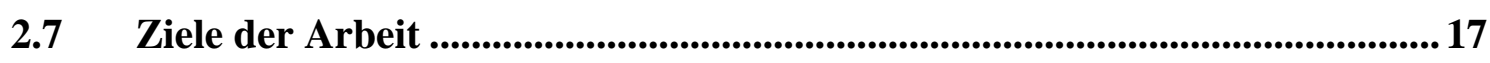

3. Material und Methoden ................................................................. 18

3.1 Bakterienstämme und Plasmide ............................................................... 18

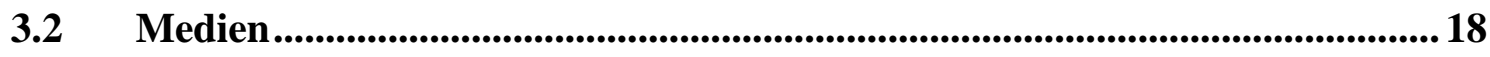

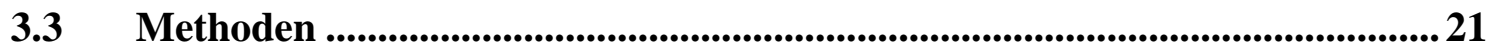

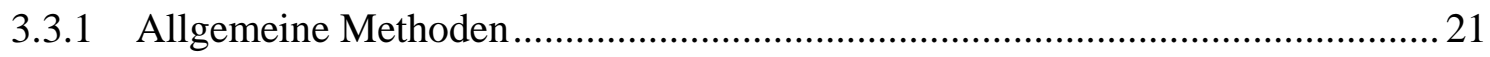

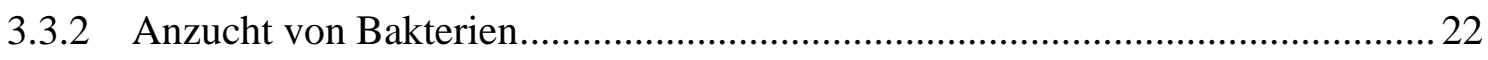




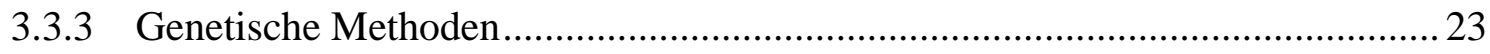

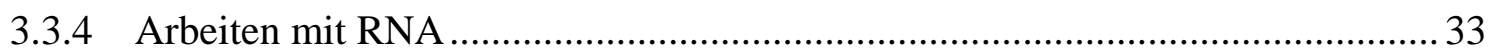

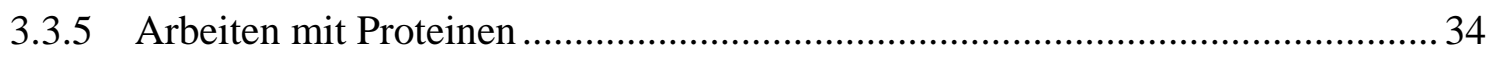

3.3.6 Bestimmung von Enzymaktivitäten ......................................................... 40

3.3.7 Messung der $\mathrm{H}_{2} \mathrm{O}_{2}$-Produktion von M. pneumoniae in vivo .............................. 43

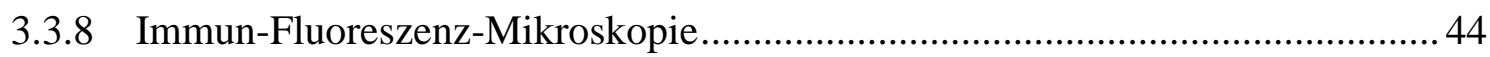

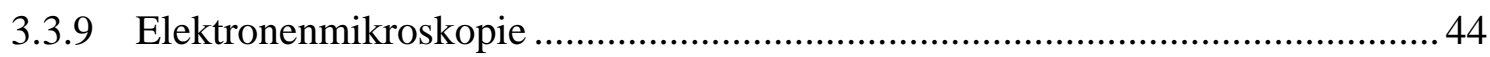

3.3.10 Radioaktive in vitro Phosphorylierung von Enzymen ..................................... 45

3.3.11 Infektion von HeLa-Zellen mit M. pneumoniae Mutanten ................................ 48

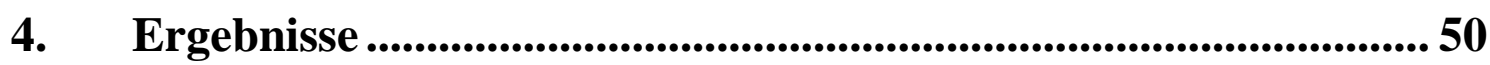

4.1 Untersuchung der Glycerol-3-phophat-Dehydrogenase aus

M. pneumoniae............................................................................................5 50

4.1.1 Expression der Glycerol-3-phosphat-Dehydrogenase bei verschiedenen

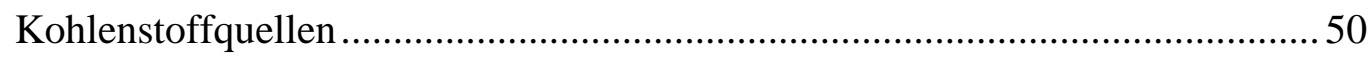

4.1.2 Kann die Glycerol-3-phosphat-Dehydrogenase NAD ${ }^{+}$reduzieren?................... 51

4.1.3 Ist glpD aus M. pneumoniae eine Glycerol-3-phosphat-Oxidase?...................... 52

4.1.4 Charakterisierung der GlpO aus M. pneumoniae in B. subtilis........................... 54

4.1.5 Lokalisierung der Glycerol-3-Phosphat-Oxidase............................................. 56

4.1.6 Wachstumsversuche mit der glpD::tn-Mutante GPM52 ................................... 61

4.1.7 Untersuchung der $\mathrm{H}_{2} \mathrm{O}_{2}$-Produktion in M. pneumoniae..................................... 62

4.1.8 Zytotoxizität der glpD::tn-Mutante gegenüber HeLa-Zellen ..............................63

4.1.9 Ist die $\mathrm{NADH} / \mathrm{H}^{+}$-Oxidase in der Lage Wasserstoffperoxid freizusetzen?......... 65

4.2 Untersuchung der Zytotoxizität von verschiedenen Transposonmutanten von M. pneumoniae .....................................................................................68

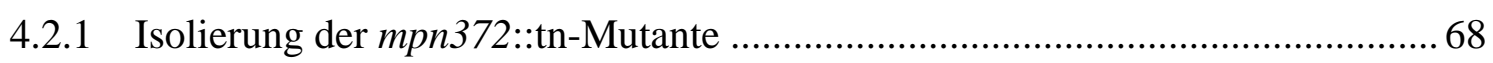

4.2.2 Zytotoxischer Effekt der mpn372::tn-Mutante (GPM8) ................................... 70

4.2.3 Zytotoxischer Effekt der mpn474::tn-Mutante (GPM70) und der

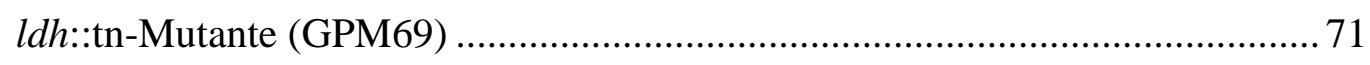

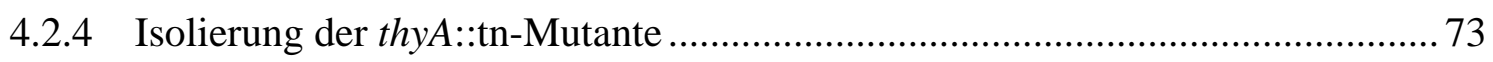

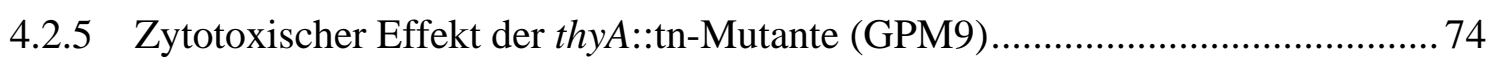

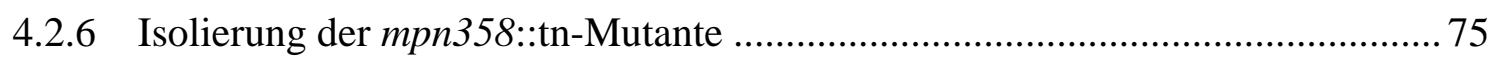


4.2.7 Zytotoxischer Effekt der mpn358::tn-Mutante (GPM10) ................................... 77

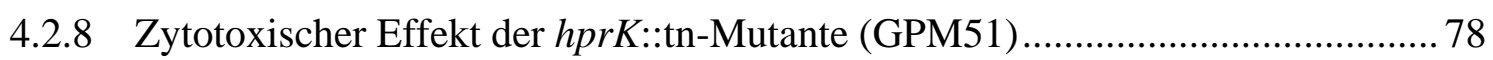

4.2.9 Zytotoxischer Effekt der prpC::tn-Mutante (GPM68)..................................... 79

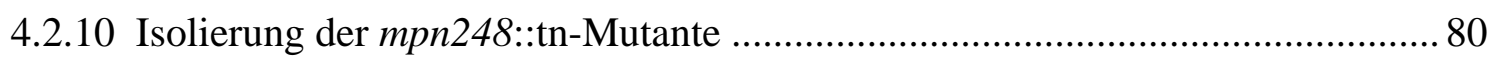

4.2.11 Zytotoxischer Effekt der mpn248::tn-Mutante ............................................... 82

4.3 Regulatorische Phosphorylierungen in M. pneumoniae .................................. 83

4.3.1 Wird der Glycerolstoffwechsel durch die HPrK reguliert?................................. 83

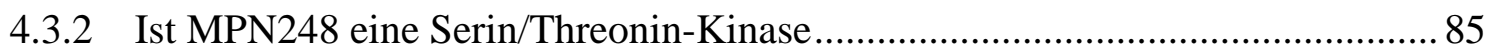

5. Diskussion ................................................................................... 87

5.1 Die Verbindung von Kohlenstoffmetabolismus und Pathogenität in M. pneumoniae......................................................................................................8 87

5.2 Der Glycerolstoffwechsel und seine Rolle bei der Virulenz .........................87

5.3 Die $\mathrm{NADH}_{2}$-Oxidase von $M$. pneumoniae ....................................................92

5.4 Proteinphosphorylierung: ein wichtiger Regulationsmechanismus in M. pneumoniae? ......................................................................................................95

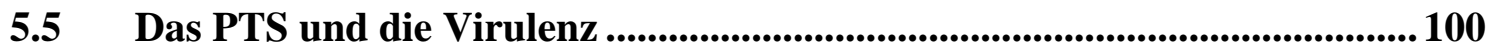

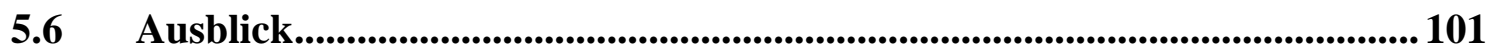

6. Literaturverzeichnis...................................................................... 103

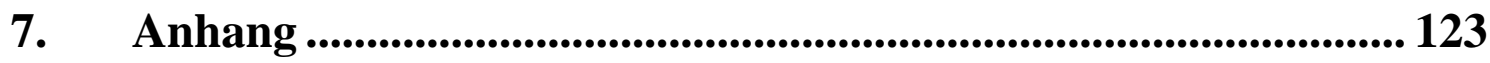

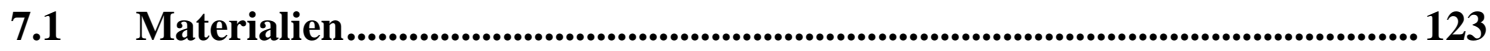

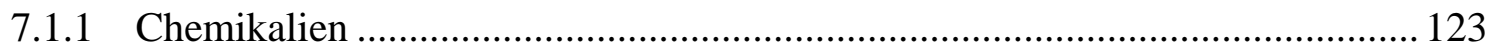

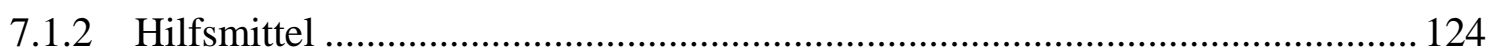

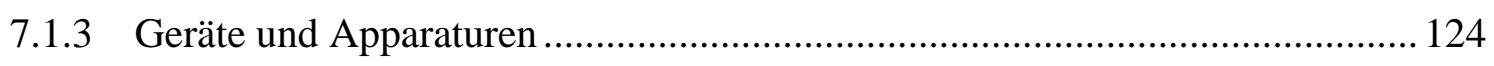

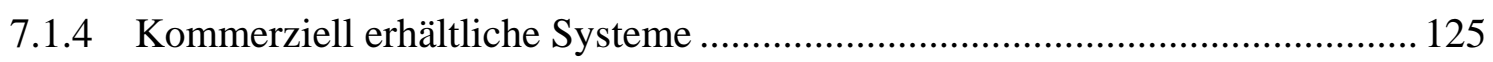

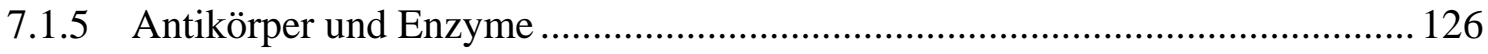

7.2 Oligonukleotide ................................................................................................................ 126

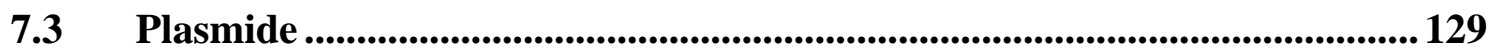

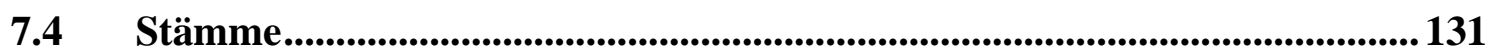




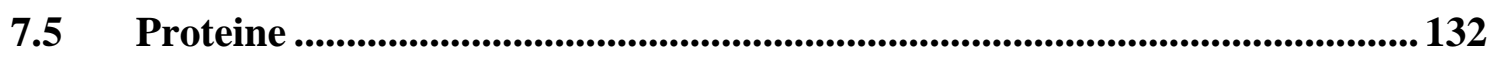

7.6 Verwendete Internetangebote und Computerprogramme......................... 133 


\section{Abkürzungsverzeichnis}

\begin{tabular}{|c|c|}
\hline$\%(\mathrm{v} / \mathrm{v})$ & $\%$ (volume/volume) (Volumenprozent) \\
\hline$\%(\mathrm{w} / \mathrm{v})$ & $\%$ (weight/volume) (Massenprozent) \\
\hline $\mathrm{Abb}$ & Abbildung \\
\hline APS & Ammoniumperoxoidsulfat \\
\hline ATP & Adenosintriphosphat \\
\hline BSA & bovine serum albumin (Rinderserumalbumin) \\
\hline CAPS & 3-(Cyclohexylamino)-1-propansulfonsäure \\
\hline CcpA & Catabolite control protein A \\
\hline CCR & Kohlenstoff-Katabolitenrepression \\
\hline $\mathrm{CDP} *$ & 2-Chlor-5-(4-Methoxyspiro\{1,2-Dioxetan-3,2‘-(5'-Chlor) \\
\hline & Tricyclo[3.3.1.13,7]Decan\}-4-yl)-1-Phenylphosphat, Dinatriumsalz \\
\hline Chrom. & chromosomal \\
\hline cre & Catabolite responsive element \\
\hline Deion. & Deionisiert \\
\hline DHAP & Dihydroxyacetonphosphat \\
\hline dNTP & Desoxyribonukleosidtriphosphat \\
\hline DTT & Dithiothreitol \\
\hline EI & Enzym I \\
\hline EII & Enzym II \\
\hline EDTA & Ethylendiamintetraacetat \\
\hline Glc & Glukose \\
\hline HABA & 2-(4'-hydroxybenzenazo)benzolsäure \\
\hline HEPES & 4-(2-Hydroxyethyl)-piperazin-1-ethan-sulfonsäure \\
\hline $\mathrm{HPr}$ & Hitzestabiles Protein \\
\hline $\mathrm{HPrK} / \mathrm{P}$ & HPr-Kinase/Phosphorylase \\
\hline IPTG & Isopropyl-1-thio- $\beta$-D-galaktosid \\
\hline $\mathrm{kb}$ & Kilobasenpaare \\
\hline LB & Luria Bertani (Medium) \\
\hline $\mathrm{MCS}$ & Multiple cloning site \\
\hline Mbp & Megabasenpaare \\
\hline MMR & Multiple mutation reaction \\
\hline MOI & Multiplicity of infection \\
\hline $\mathrm{NAD}^{+}$ & Nicotinamid-adenindinucleotid \\
\hline $\mathrm{NADH}_{2}$ & Nicotinamid-adenindinucleotid (reduzierte Form) \\
\hline $\mathrm{Ni}^{2+}-\mathrm{NTA}$ & Nickel-Nitrilotriessigsäure \\
\hline $\mathrm{OD}_{\mathrm{x}}$ & Optische Dichte, gemessen bei Wellenlänge $\lambda=\mathrm{x} \mathrm{nm}$ \\
\hline PAA & Polyacrylamid \\
\hline PAGE & Polyacrylamidgelelektrophorese \\
\hline PBS & phosphate buffered saline \\
\hline PCR & Polymerasekettenreaktion \\
\hline PEP & Phosphoenolpyruvat \\
\hline PPLO & pleuropneumoniae like organisms \\
\hline PTS & Phosphoenolpyruvat:Zucker Phosphotransferasesystem \\
\hline PVDF & Polyvinylidendifluorid \\
\hline RT & Raumtemperatur \\
\hline SDS & sodium dodecyl sulfate (Natriumdodecylsulfat) \\
\hline sec./sek. & Sekunde \\
\hline Tab. & Tabelle \\
\hline TEMED & $\mathrm{N}, \mathrm{N}, \mathrm{N}^{\prime}, \mathrm{N}^{\prime}$-Tetramethylethylendiamin \\
\hline Tris & Tris-(hydroxymethyl)-aminomethan \\
\hline WT & Wildtyp \\
\hline
\end{tabular}




\section{Zusammenfassung}

Mycoplasma pneumoniae, der Erreger der atypischen Pneumonie, kann neben Glukose und Fruktose auch Glycerol als Kohlenstoffquelle nutzen. Das Glycerol wird über erleichterte Diffusion in die Zelle geschleust und anschließend durch die GlycerolKinase phosphoryliert. Das Glycerol-3-phosphat wird dann zu Dihydroxyacetonphosphat umgewandelt, welches in der Glykolyse zur Gewinnung von Energie in Form von ATP weiter umgesetzt wird.

In dieser Arbeit sollte das Enzym, das für die Oxidation von Glycerol-3phosphat zuständig ist (annotiert als GlpD), in M. pneumoniae näher untersucht werden. Es stellte sich heraus, dass dieses Protein keine Dehydrogenase-, sondern eine OxidaseAktivität besitzt, d.h. Sauerstoff als Elektronenakzeptor verwendet. Hierbei wird dann Wasserstoffperoxid freigesetzt, welches als Virulenzfaktor die Wirtszellen nachweislich schädigen kann. Eine $g l p D$-Mutante ist weniger zytotoxisch gegenüber HeLa-Zellen als der Wildtyp. Die Glycerol-3-phosphat-Oxidase ist demnach der Produzent eines primären Virulenzfaktors in M. pneumoniae.

Neben der $g l p D$-Mutante wurden noch weitere Mutanten auf ihre Zytotoxizität untersucht. Es stellte sich heraus, dass die HPr-Kinase und eine Ser/Thr-Kinase (PrkC) wie GlpD einen Einfluss auf die Etablierung der Pathogenität von M. pneumoniae haben. Die Mutanten dieser Gene waren alle weniger zytotoxisch als der Wildtyp. Dies zeigt, dass Phosphorylierungen offensichtlich eine wichtige regulatorische Rolle für die Pathogenität in M. pneumoniae spielen.

Eine nähere Untersuchung der Kinase PrkC hat gezeigt, dass sie Ähnlichkeiten zu einer Ser/Thr-Kinase, die in vielen Gram-positiven Organismen zu finden ist, aufweist. Diese Kinase übernimmt wichtige regulatorische Funktionen in den Zellen. In dieser Arbeit konnte gezeigt werden, dass PrkC eine wichtige Eigenschaft, nämlich die Autophosphorylierung, mit den bereits beschriebenen PrkCs gemeinsam hat. Es war jedoch nicht möglich, Substrate der Kinase zu identifizieren. Aber die Isolierung einer prkC-Mutante war erfolgreich, die nicht mehr in der Lage ist, adhäsiv an Oberflächen zu wachsen und sich deshalb nicht mehr an die Wirtszellen anhaften kann. Dies gibt einen Hinweis darauf, dass PrkC eine wichtige Rolle bei dem Aufbau der so genannten Tipstruktur, dem Anhaftungsorganell von M. pneumoniae, spielen könnte. 


\section{Einleitung}

\subsection{Die Klasse der Mollicutes}

Pathogene Bakterien können Pflanzen, Tiere und auch Menschen befallen und Krankheiten auslösen. Die Mykoplasmen werden der Klasse der Mollicutes, was übersetzt weiche Haut bedeutet, zugeordnet. Die Mollicutes gehören zu den Grampositiven Bakterien mit niedrigem $\mathrm{G}+\mathrm{C}-$ Gehalt, obwohl sie keine echte Zellwand besitzen. Zu dieser Klasse gehören neben der Gattung Mycoplasma noch die Gattungen Acholeplasma, Anaeroplasma, Asteroleplasma, Spiroplasma, Mesoplasma, Phytoplasma und Ureaplasma (Woese et al., 1980).

Die Bakterien der Gattungen Acholeplasma, Phytoplasma und Spiroplasma sind Phytopathogene, welche die Pflanzen befallen und schädigen können. Die für die Human- und Veterinärmedizin relevanten Mollicutes gehören zu den Gattungen Mycoplasma und Ureaplasma.

Die Mykoplasmen gehören zu den Krankheitserregern mit den kleinsten Genomen. Die Genomgröße kann zwischen 0,58 Mbp bei Mycoplasma genitalium und 1,36 Mbp bei M. penetrans variieren (Su und Baseman, 1990; Fraser et al., 1995; Sasaki et al., 2002). Die kleine Genomgröße der Mykoplasmen rührt von einer regressiven Evolution mit einer graduellen Verkleinerung des Genoms her (Maniloff, 1992). Obwohl Woese et al. beschrieben haben, dass die Mollicutes vor etwa 605 Millionen Jahren von dem Streptococcen-Zweig der Gram-positiven Bakterien abzweigten, konnte ein neuer Stammbaum anhand von sequenzierten Genomen dies widerlegen (Woese et al., 1980). Der Stammbaum zeigt, dass die Mollicutes, die Lactobacilli, die Streptococcen, die Staphylococcen, die Listerien und die Bacilli aus einem gemeinsamen Vorfahren entstanden sind. Von diesem Vorfahren haben sich zwei unabhängige Zweige entwickelt: die Mollicutes und die anderen vorher genannten Organismen (Ciccarelli et al., 2006).

\subsection{Der Organismus M. pneumoniae}

M. pneumoniae wurde erstmals im Jahre 1944 entdeckt und beschrieben (Meiklejohn et al., 1944). Die Krankheitserreger wurden aus dem Sputum eines Patienten mit einer primären atypischen Lungenentzündung isoliert. Mykoplasmen befallen einen Wirt 
durch Tröpfcheninfektion und siedeln sie sich dann an dem unteren respiratorischen Trakt der Lunge an. Vor allem Kinder, ältere oder immungeschwächte Menschen sind von diesen Infektionen betroffen (Chanock et al., 1963). Neben dem klassischen Krankheitsbild, der Lungenentzündung, können noch erhebliche Komplikationen auftreten, wie zum Beispiel Meningoencephalitis, Myocarditis, hämolytische Anämie und rheumatische Arthritis (Taylor et al., 1967; Mackay et al., 1975; Ramirez et al., 2005, Wilson et al., 2007).

Der parasitäre Lebensstil von M. pneumoniae wird vor allem durch die Fähigkeit, adhäsiv an glatten Oberflächen zu wachsen, ermöglicht (Somerson et al., 1967). Die Anhaftung findet mit Hilfe eines Organells statt, der so genannten Tipstruktur. Diese Struktur befindet sich an einem Pol der Zelle und besteht aus vielen verschiedenen Proteinen wie zum Beispiel dem P1-Protein und den HMW-Proteinen (Leith und Baseman, 1984; Krause, 1996; Balish et al., 2003). Die Tipstruktur ermöglicht es den Mykoplasmen, sich an Epithelzellen anzulagern und somit eine Infektion auszulösen (Wilson und Collier, 1976). Des Weiteren ist die Tipstruktur an der Zellteilung und der Gleitbewegung beteiligt (Krause und Balish, 2001).

Im Jahr 1996 wurde die vollständige Genomsequenz von M. pneumoniae veröffentlicht und ermöglichte die Untersuchung einer minimalen Genausstattung (Himmelreich et al., 1996; Dandekar et al., 2000). Bei einer Größe von 816 kb wurden 688 offene Leserahmen identifiziert. Die parasitäre Lebensweise spiegelt sich auch darin wieder, dass der Organismus nicht zur Aminosäuresynthese befähigt ist und Gene für spezifische Transportsysteme für die Aufnahme von Aminosäuren und Kofaktoren vorhanden sind (Miles, 1992). Auch die Gene für die Nukleotidsynthese sind nicht vollständig vorhanden. Hier scheint jedoch die Funktion der Nukleosiddiphosphatkinase (ndk) von Enzymen aus der Glykolyse übernommen zu werden (Pollack et al., 2002).

Für die Aufnahme von Glukose, Fruktose und Mannitol besitzt M. pneumoniae ein Phosphotransferasesystem (PTS). Dieses System dient der aktiven Aufnahme und gleichzeitigen Phosphorylierung der Zucker. Das PTS besteht aus EI, HPr sowie den zuckerspezifischen Permeasen für Glukose, Fruktose und Mannitol (Himmelreich et al., 1996). Es stellte sich jedoch später heraus, dass M. pneumoniae nicht in der Lage ist, mit Mannitol als C-Quelle zu wachsen (Halbedel et al., 2004). Die Aufnahme des Glycerols erfolgt nicht über ein aktives Aufnahmesystem, sondern mit Hilfe eines Facilitators. Die Zucker werden allesamt an die Glykolyse zur Gewinnung von ATP und 
Pyruvat weitergeleitet. Der Pentose-Phosphat-Weg ist nur noch rudimentär vorhanden. Die Ribulose-5-phosphat-3-Epimerase und die Transketolase sind von diesem Weg noch in M. pneumoniae zu finden. Der ATP-Bedarf der Zelle kann nur durch Substratkettenphosphorylierung abgedeckt werden, da die Enzyme für den Zitronensäurezyklus sowie Chinone und Cytochrome fehlen (Razin et al., 1998)

Eine weitere Besonderheit der Mykoplasmen ist, dass UGA nicht für ein Stopcodon, sondern für ein Tryptophan kodiert (Schaper et al., 1987; Renaudin et al., 1987).

\subsection{Das PTS in Gram-positiven Bakterien}

In Gram-positiven Bakterien ist das Phosphotransferasesystem für die aktive Aufnahme sowie die Phosphorylierung von verschiedenen Zuckern zuständig. Dieses System bildet eine Phosphorylierungskaskade, die mit der Autophosphorylierung von EI durch PEP beginnt. Das EI gibt das Phosphat dann an das Histidin-15 von HPr weiter, welches in der Lage ist, die Permease EII zu phosphorylieren. In B. subtilis wie in anderen Grampositiven Bakterien mit niedrigem $\mathrm{G}+\mathrm{C}$-Gehalt besitzt das HPr neben der Histidin- auch eine Serin-Phosphorylierungsstelle (Reizer et al., 1989; Reizer et al., 1998). Während das am Histidin-15 phosphorylierte HPr für die Aufnahme PTS-abhängiger Kohlenhydrate benötigt wird, hat das am Serin-46, durch die HPr-Kinase/Phosphorylase (HPrK/P), phosphorylierte HPr eine regulatorische Funktion (Reizer et al., 1998; Kravanja et al., 1999). Die zuckerspezifische Permease EII wird durch HPr(His P) phosphoryliert und ermöglicht so die Aufnahme und Phosphorylierung der PTS-Zucker (Stülke und Hillen, 1999; Titgemeyer und Hillen, 2002).

Die HPrK/P phosphoryliert HPr am Serin-46. Die Kinaseaktivität der HPrK/P wird durch ATP und Fruktose-1,6-bisphosphat stimuliert (Jault et al., 2000). Das so von

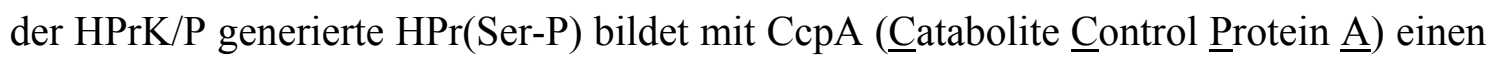
Komplex und dieser inhibiert oder aktiviert die Transkription von katabolen Operons, die eine so genannte cre-Sequenz in der Promotorregion besitzen (C

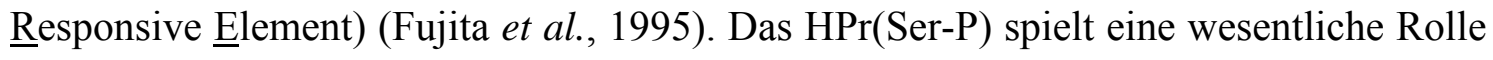
bei der Kohlenstoffkatabolitenrepression (CCR). Eine Zusammenfassung des PTS und der CCR sind in Abb. 2.1. dargestellt. 


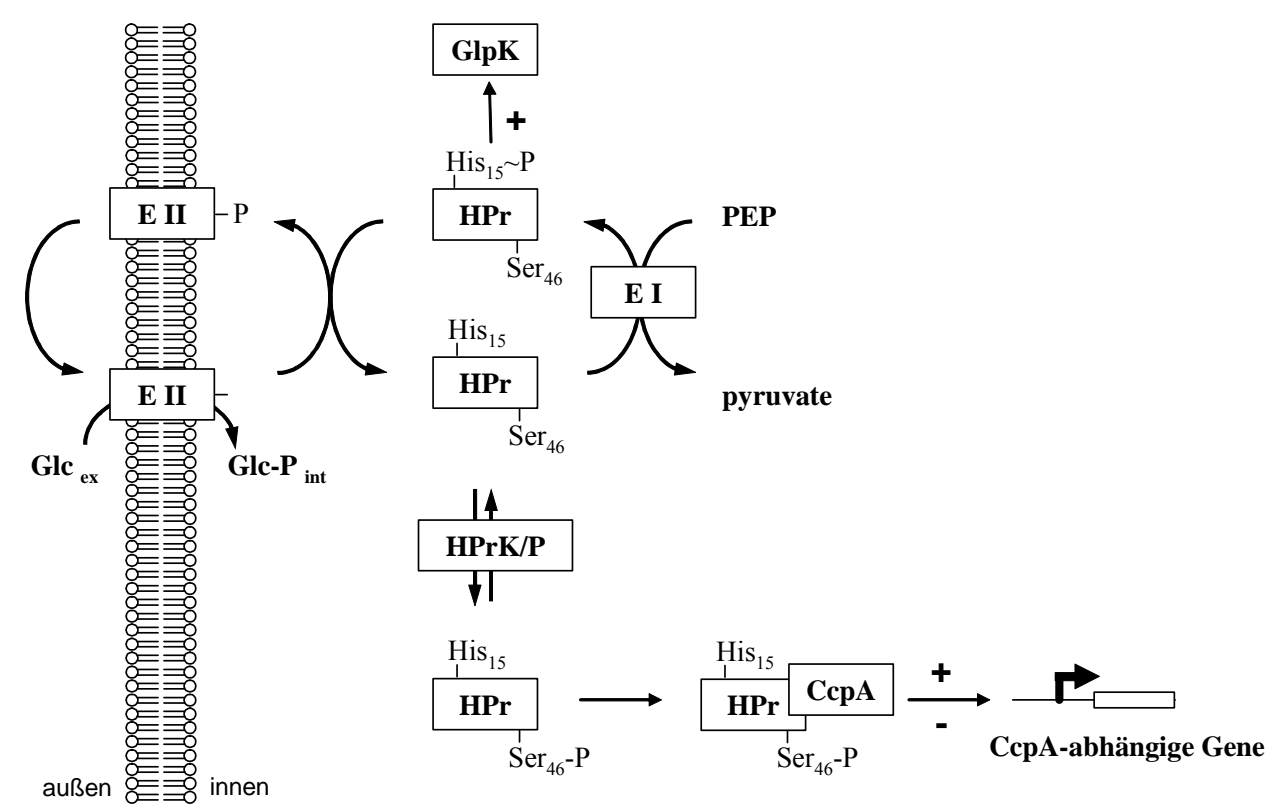

Abb. 2.1.: Schematische Darstellung des PTS und der CCR in B. subtilis.

\subsubsection{Das PTS in M. pneumoniae}

M. pneumoniae kann nur die Kohlenstoffquellen Glukose und Fruktose über das PTS aufnehmen (Halbedel et al., 2004). Die Komponenten des PTS EI, HPr, EIIABC und HPrK/P sind in den Mykoplasmen vorhanden. Die Regulation durch diese Komponenten unterscheidet sich jedoch stark von der, die in B. subtilis zu finden ist. Bisher konnte in M. pneumoniae kein CcpA oder ein CcpA-homologes Gen identifiziert werden (Himmelreich et al., 1996). Auch cre-Sequenzen wurden noch nicht in Mykoplasmen entdeckt.

In vitro-Untersuchungen der HPrK/P von $M$. pneumoniae haben gezeigt, dass die HPrK/P bereits bei niedrigen ATP-Konzentrationen als Kinase aktiv ist. Die HPrK/P von $B$. subtilis hingegen benötigt für ihre Aktivität neben hohen ATP-Konzentrationen noch die Anwesenheit von Fruktose-1,6-bisphosphat. Man geht davon aus, dass dies auf die unterschiedlichen Lebensräume dieser Organismen zurückzuführen ist (Steinhauer et al., 2002). Die HPrK/P in B. subtilis zeigt vorrangig eine Phosphatase-Aktivität und verhindert so die CCR.

Das in vivo-Phosphorylierungsmuster von HPr in M. pneumoniae wurde ebenfalls untersucht. In der Anwesenheit von Glukose oder Fruktose wurde nur HPr(His $\sim$ P) gebildet. Durch die Zugabe von Glycerol ins Medium traten zu jeweils einem Drittel 
$\operatorname{HPr}($ His $\sim \mathrm{P}), \operatorname{HPr}($ Ser-P) und HPr(His $\sim \mathrm{P})($ Ser-P) auf. Die Kinase-Aktivität der HPrK ist am höchsten, wenn Glycerol im Medium vorhanden ist (Halbedel et al., 2004). Die CQuelle Glycerol hat demnach einen Einfluss auf das PTS, obwohl dieser Zucker nicht über dieses System aufgenommen wird. Eine allosterische Aktivierung der Kinaseaktivität beziehungsweise eine Inhibierung der Phosphorylaseaktivität durch Glycerol oder Glycerol-3-phosphat konnte bereits ausgeschlossen werden (Halbedel, Doktorarbeit). Die heterologe Expression von der HPrK und HPr aus M. pneumoniae in B. subtilis hat gezeigt, dass die Kinase unabhängig von der angebotenen C-Quelle konstitutiv aktiv ist (Schmidl, Diplomarbeit). Die Annahme, dass die Glycerolkinase einen Einfluss auf die HPrK-Aktivität haben könnte, konnte nicht bestätigt werden. Die Koexpression von HPrK, HPr und GlpK in B. subtilis hatte keinen Einfluss auf die Kinaseaktivität (Schmidl, Diplomarbeit). Der Zusammenhang zwischen PTS und Glycerolstoffwechsel in M. pneumoniae konnte bisher nicht geklärt werden.

\subsection{Glycerolstoffwechsel in Gram-positiven und Gram-negativen Bakterien}

In Gram-positiven wie auch in Gram-negativen Bakterien erfolgt die Aufnahme von Glycerol durch erleichterte Diffusion mit Hilfe des Facilitators GlpF (Lin, 1976; Heller et al., 1980). Der Glycerolstoffwechsel unterliegt einer strengen Regulation. Hierbei wird die Aktivität der Glycerolkinase über Komponenten des PTS kontrolliert. Die Mechanismen der Regulation unterscheiden sich jedoch.

Die Glycerolkinase in E. coli wird durch EIIA und durch Fruktose-1,6bisphosphat inhibiert und kann so Glycerol nicht mehr zu Glycerol-3-phosphat umsetzen (Berman und Lin, 1971; DeBoer et al., 1986; Hurley et al., 1993; Pettigrew et al., 1996).

In Gram-positiven Bakterien wird die Aktivität der Glycerolkinase ebenfalls durch Fruktose-1,6-bisphosphat inhibiert (Deutscher und Sauerwald, 1986). Im Gegensatz zu Gram-negativen Bakterien kann hier die Aktivität der Glycerolkinase jedoch auch erhöht werden. Hierbei spielt das PTS eine wichtige Rolle (Reizer et al., 1984). Das $\operatorname{HPr}($ His $\sim \mathrm{P})$ hat einen aktivierenden Effekt auf die Glycerolkinase. Sie wird von $\operatorname{HPr}($ His $\sim \mathrm{P})$ phosphoryliert und zeigt eine zehnfach höhere Aktivität als die unphosphorylierte Glycerolkinase in Enterococcus faecalis (Deutscher und Sauerwald, 1986). Dies scheint aber nicht für alle Glycerolkinasen der Fall zu sein. In Thermus 
flavus hat die Phosphorylierung der Kinase nur einen geringen Effekt auf die Aktivität (Darbon et al., 1999).

Mit Hilfe von Aminosäurensequenzen der Glycerolkinasen konnte die Phosphorylierungsstelle am Histidin an der Position 232 identifiziert werden (Charrier et al., 1997). Dieses Histidin sowie die umliegenden Aminosäuren sind in Grampositiven Bakterien stark konserviert und es konnte folgende Konsensussequenz ermittelt werden: (Y/F)HF(Y/F)G. Wie erwartet, ist diese Phosphorylierungsstelle nicht in Gram-negativen Organismen zu finden.

Bei B. subtilis wird der Glycerolstoffwechsel auch noch auf Transkriptionsebene durch die Kohlenstoffkatabolitenrepression (CCR) sowie durch einen so genannten Riboswitch reguliert. Ein Inverted Repeat vor der Leadersequenz von $g l p D$ bildet einen Transkriptionsterminator aus und verhindert die vollständige Transkription dieses Genes (Holmberg und Rutberg, 1991; Holmberg und Rutberg, 1992; Glatz et al., 1998). Bei Anwesenheit von Glycerol bindet das aufgenommene und phosphorylierte Glycerol-3phosphat an den Antiterminator GlpP und aktiviert diesen, damit er an die Leadersequenz binden kann (Glatz et al., 1996; Glatz et al., 1998; Rutberg, 1997). Dies führt dann zur Antitermination, das heißt zur vollständigen Transkription des Gens. Außerdem spielt GlpP noch eine Rolle bei der Stabilisierung der glpD mRNA (Glatz et al., 1996). Man findet die Regulation durch GlpP auch am glpFK-Operon, welches zusätzlich durch die CCR bei Anwesenheit durch Glukose reguliert wird (Darbon et al., 2002). Die Bindung des HPr(Ser-P) + CcpA-Komplexes an der cre-Sequenz bewirkt eine Repression dieses Operons. Damit wird die Aufnahme des Glycerols verhindert, wenn Glukose verfügbar ist.

Bei den Mykoplasmen wurde bisher noch keine Regulation des Glycerolstoffwechsels beschrieben. In $M$. capricolum, einem der wenigen Grampositiven Organismen, der lösliches EIIA $^{\text {Glc }}$ besitzt, wird die Aktivität der Glycerolkinase nicht durch dieses PTS-Protein inhibiert (Zhu et al., 1997).

\subsubsection{Die Rolle der Glycerol-3-phosphat-Oxidase bei der Pathogenität}

Die Umsetzung von Glycerol-3-phosphat zu Dihydroxyacetonphosphat, einem Substrat für die Glykolyse, erfolgt in vielen Bakterien und Säugerzellen durch eine Glycerol-3phosphat-Dehydrogenase (Burton und Kaplan, 1953; Wiame et al., 1954; Kormann et 
al., 1972). Dieses Enzym verwendet $\mathrm{NAD}^{+}$als Elektronenakzeptor und setzt bei der Reaktion $\mathrm{NADH}_{2}$ frei (Asnis und Brodie, 1953).

Jedoch gibt es auch Bakterien, die ein anderes Enzym für diese Reaktion verwenden, eine so genannte Glycerol-3-phosphat-Oxidase. Es ist in der Lage, statt $\mathrm{NAD}^{+}$Sauerstoff als Elektronenakzeptor zu verwenden. Bei dieser Reaktion wird Wasserstoffperoxid freigesetzt. Bisher wurde dieses Protein in E. faecium (Gunsalus und Umbreit, 1945; Esders und Michrina, 1979), Lactobacillus casei (Strittmatter, 1959), M. sp. bovine (Djordjevic et al., 2003) und M. mycoides subsp. mycoides (Wadher et al., 1990; Pilo et al., 2005) beschrieben. Hierbei fällt auf, dass alle Organismen, bis auf L. casei, zu den pathogenen Bakterien gehören.

E. faecium, dem, wie den Mykoplasmen, die bekannten Virulenzfaktoren fehlen, kann mit Glycerol als alleinige C-Quelle wachsen und dabei große Mengen an Wasserstoffperoxid freisetzen. Dabei kann E. faecium den Nematoden Caenorhabditis elegans, welcher als Modellorganismus zur Untersuchung der Virulenzfaktoren verwendet wird, töten (Moy et al., 2004).

Auch in $M$. mycoides subsp. mycoides konnte gezeigt werden, dass der Glycerolstoffwechsel eine große Rolle bei der Pathogenität spielt. Bei diesen Mykoplasmen gibt es einen hochvirulenten afrikanischen Stamm, welcher neben dem Facilitator noch über ein aktives Transportsystem (ABC-Transporter) für die Aufnahme von Glycerol verfügt. Dadurch ist der Stamm auch in der Lage, mehr Glycerol zu verwerten und auch mehr Wasserstoffperoxid freizusetzen (Vilei und Frey, 2001). Der europäische Stamm, der nur einen Facilitator zur Aufnahme von Glycerol verwendet, ruft hingegen nur ein schwaches Krankheitsbild bei den Rindern hervor.

Mit elektronenmikroskopischen Aufnahmen konnte gezeigt werden, dass die Glycerol-3-phosphat Oxidase an der Oberfläche der Zelle lokalisiert ist. Durch die Inhibierung der GlpO mit Hilfe von Antikörpern konnte die Zytotoxizität der Mykoplasmen gegenüber Epithelzellen von Rindern unterbunden werden (Pilo et al., 2005). Dies zeigt, dass GlpO für die Produktion des primären Virulenzfaktors Wasserstoffperoxid zuständig ist und diesen gleich an die Wirtszelle weiterleitet, um ihr Schaden zuzufügen. 


\subsubsection{Glycerolstoffwechsel in $M$. pneumoniae}

Glycerol ist neben Glukose und Fruktose eine der wenigen Kohlenstoffquellen, die M. pneumoniae verwerten kann (Halbedel et al., 2004). Die Aufnahme von Glycerol erfolgt über einen Facilitator, der eine erleichterte Diffusion ermöglicht. Anschließend phosphoryliert die Glycerolkinase das Glycerol, damit es nicht wieder aus der Zelle diffundieren kann. Glycerol-3-phosphat wird dann von der Glycerol-3-phosphatDehydrogenase zu Dihydroxyacetonphosphat (DHAP) umgewandelt (Abb. 2.2.). Das DHAP wird in die Glykolyse eingeschleust und weiter verwertet, um ATP zu gewinnen. Neben der Energiegewinnung wird Glycerol-3-phosphat für den Phospholipidmetabolismus benötigt.

Die Regulationsmechanismen, wie sie bei Gram-negativen und Gram-positiven Bakterien beschrieben sind, konnten bisher nicht in Mykoplasmen nachgewiesen werden. Die Glycerolkinase wird in M. pneumoniae konstitutiv exprimiert (Hames, 2005). Die Phosphorylierungsstelle, das Histidin an der Position 232, die in vielen Gram-positiven Organismen zu finden ist, ist auch in M. pneumoniae vorhanden. Jedoch sind die umliegenden Aminosäuren bei den Mykoplasmen nicht konserviert und stimmen nicht mit der Konsensussequenz überein. Die Aktivität der Glycerolkinase in Anwesenheit von HPr(His $\sim$ P) zeigte keinen Unterschied $\mathrm{zu}$ der normalen Enzymaktivität (Hames, Diplomarbeit). Es konnte bisher nicht gezeigt werden, dass die Glycerolkinase von M. pneumoniae am His-232 phosphoryliert wird. Es bleibt noch zu erwähnen, dass es in der Transposonbank keine glpK::tn-Mutante und keine glpF::tnMutante gibt (Halbedel, 2006). Dies ist sehr verwunderlich, da die Transposonmutanten auf Platten mit Glukose angezogen wurden und die Gene für die Aufnahme und Phosphorylierung von Glycerol unter diesen Bedingungen nicht essentiell sein sollten. Die beiden Proteine GlpF und GlpK scheinen demnach noch andere Funktionen in der Zelle zu übernehmen. 


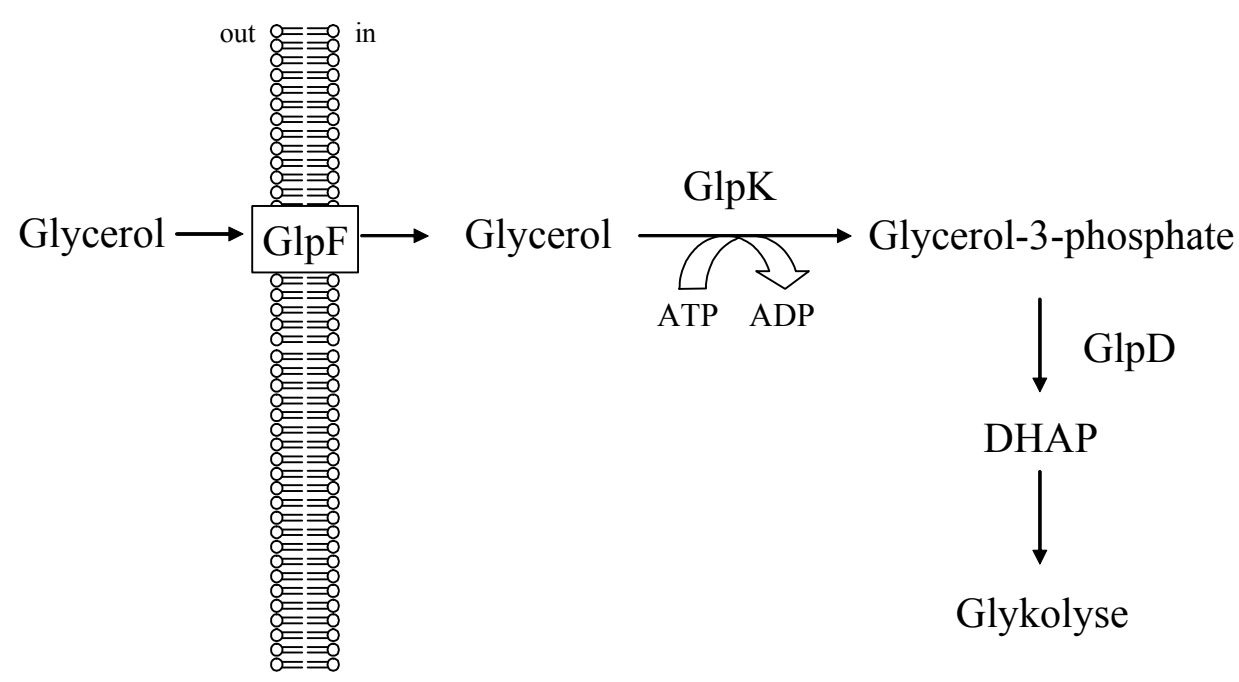

Abb. 2.2. Schematische Darstellung der Aufnahme und der Verwertung von Glycerol in M. pneumoniae

Die Glycerol-3-phosphat-Dehydrogenase spielt wie bereits erwähnt, eine wichtige Rolle bei der Pathogenität in M. mycoides subsp. mycoides SC. Die Rolle dieses Enzyms in M. pneumoniae ist bisher nicht untersucht worden. Dieses Gen ist im Gegensatz zu glpF und $g l p K$ nicht essentiell, da es gelungen ist, eine Mutante zu isolieren, welche ein Transposoninsertion in $g l p D$ trägt.

Der Glycerolstoffwechsel scheint auch in M. pneumoniae eine wichtige Rolle bei der Pathogenität zu spielen. Es konnte bereits gezeigt werden, dass in Anwesenheit von Glycerol die Wasserstoffperoxid-Produktion sehr stark ansteigt (Low, 1971).

\subsection{Pathogenitätsmechanismen von Bakterien}

Im Laufe der Zeit haben die pathogenen Bakterien unterschiedliche Mechanismen zur Schädigung des Wirtsorganismus entwickelt, wie z.B. Staphylococcus aureus, Corynebacterium diphteriae und Pseudomonas aeruginosa. Die Organismen S. aureus und C. diphteriae verwenden Toxine und P. aeruginosa ein spezielles Sekretionssystem als Virulenzfaktoren.

Es gibt eine Vielzahl an Toxinen, die unterschiedliche Wirkungsweisen haben. Die poren-bildenden Toxine sind sowohl in Gram-positiven als auch in Gram-negativen Bakterien beschrieben worden. In $S$. aureus greift das so genannte $\alpha$-Toxin viele verschiedene Zelltypen des Menschen an, wie zum Beispiel Erythrocyten, Endothelzellen, Plättchen usw. (Bhakdi und Tranum-Jensen, 1991; Suttorp et al., 1985; Bhakdi et al., 1988). Das Toxin bindet an die Wirtszellmembran, bildet eine Pore und 
bewirkt einen irreparablen Riss in der Membran, aus dem Ionen und kleine Moleküle austreten (Bhakdi und Tranum-Jensen, 1988). Das Gram-negative Bakterium Actinobacillus actinomycetemcomitans bildet das porenformende Leukotoxin, welches die Apoptose bei Monocyten und polymorphonuklearen Neutrophilen auslöst (Tsai et al., 1979; Taichman et al., 1980; Mangan et al., 1991; Welch, 1991). Auch das Hämolysin aus E. coli ist in der Lage, Poren in viele kernhaltige Zellen einzufügen und den Zelltod herbeizuführen (Welch, 1991).

S. aureus produziert neben dem $\alpha$-Toxin auch noch ein sehr stabiles Enterotoxin B, welches nicht von den Enzymen des Magens oder des Dünndarms abgebaut werden kann. Dieses Toxin ist verantwortlich für Lebensmittelvergiftungen und für das toxische Schock Syndrom (Marples und Wieneke, 1993). Es bindet an die $\mathrm{V}_{\beta}$ T-Zellrezeptoren und stimuliert dabei die T-Zellproliferation (White et al., 1989; Kappler et al., 1989). Bei unreifen Thymocyten induziert die Bindung an $\mathrm{V}_{\beta}$-Elemente die Apoptose, also den Zelltod (Jenkinson et al., 1989; Lin et al., 1992).

Eine weitere Art der Toxine wirkt inhibierend auf die Translation der eukaryotischen Zellen. C. diphteriae produziert das Diphterietoxin, das den Elongationsfaktor eEF-2 durch ADP-Ribosylierung in seiner Funktion inhibiert und damit die Translation neuer Proteine verhindert (Choe et al., 1992). Dies führt meist zu einer massiven Zelllyse (Morimoto und Bonavida, 1992). Das Exotoxin A von $P$. aeruginosa und das Shiga Toxin von Shigella dysenteriae sind weitere Beispiele für ADP-ribosylierende Toxine (Tesh und O'Brien, 1991; Morimoto und Bonavida, 1992).

Bei Gram-negativen Bakterien haben sich spezielle Sekretionssysteme entwickelt, die eine Rolle bei der Pathogenität spielen. Ein Beispiel hierfür ist das Typ III Sekretionssystem (TTSS). Mit dessen Hilfe können die Toxine direkt in die Wirtszelle injiziert werden (Rosqvist et al., 1994). Dieses System hat eine sehr komplexe Struktur mit über 20 verschiedenen Proteinen und bildet eine Nadel aus, die direkt in die Wirtszelle eindringt (Aizawa, 2001; Kubori et al., 2000). Das Typ IV Sekretionssystem, welches vor allem durch die Rolle bei der Konjugation bekannt ist, kann neben DNA auch Toxine sekretieren (Winans et al., 1996; Christie, 1997). Hierbei wird ein so genannter Pilus ausgebildet, der den Kontakt zwischen dem pathogenen Organismus und dem Wirt herstellt. Das Pertussistoxin bildet dabei eine Ausnahme, weil es von dem Typ IV Sekretionssystem in das extrazelluläre Milieu abgegeben wird (Farizo et al., 2002; Burns, 2003). Vor kurzem hat man noch ein weiteres Sekretionssystem, Typ VI, 
in P. aeruginosa und Vibrio cholerae beschrieben, welches Ähnlichkeiten zu dem Injektionsapparat des E. coli Bakteriophagen T4 aufweist (Mougous et al., 2006; Pukatzki et al., 2006). Hier wird ebenfalls vermutet, dass die Effektorproteine direkt über dieses „Zellpunktierungssystem“ in die Wirtszelle gelangen (Pukatzki et al., 2007).

In Mycobakterien konnte erstmals in einem Gram-positiven Organismus ein Sekretionssystem beschrieben werden, das Typ VII Sekretionssystem, welches Ähnlichkeiten zu dem T4SS aufweist (Pallen, 2002; Abdallah et al., 2007). Das T7SS wurde auch in weiteren Gram-positiven Bakterien gefunden, es spielt jedoch nicht immer eine Rolle bei der Virulenz wie zum Beispiel bei Listeria monocytogenes (Gey van Pittius et al., 2001; Way und Wilson, 2005). Dem Impfstamm Mycobacterium bovis BCG fehlen dieses Sekretionssystem sowie das Toxin. Dies gab schon sehr früh einen Hinweis darauf, dass das T7SS eine wichtige Rolle in der Virulenz von Mycobakterien spielt (Pym et al., 2002; Lewis et al., 2003; Majlessi et al., 2005).

Das Wasserstoffperoxid wird von manchen Bakterien auch genutzt, um bei den Wirtszellen oxidativen Stress auszulösen. Auf diesen Virulenzfaktor wurde bereits in dem Kapitel 2.4.1 eingegangen. Das Wasserstoffperoxid reagiert mit den Zellmembranen der Wirtszellen und löst dann den programmierten Zelltod, die Apoptose, in tracheobronchalen Epithelzellen aus (Goldkorn et al., 1998).

Die pathogenen Bakterien haben außerdem noch Mechanismen entwickelt, um einem Angriff des Immunsystems des Menschen zu entgehen. Dies gelingt ihnen zum Beispiel durch die so genannte Antigenvariation. Die Oberflächenproteine werden dabei durch Neuordnung der DNA verändert, damit die Immunzellen die Bakterien nicht mehr erkennen und nicht mehr angreifen können (Dybvig, 1993). Andere pathogene Organismen können dem Immunsystem entfliehen, indem sie in die Wirtszelle eindringen und sich dort auch weiter vermehren. Diesen Mechanismus verwendet zum Beispiel Mycobacterium tuberculosis, der sich in den Phagosomen der Makrophagen einnistet oder L. monocytogenes, der sich im Cytosol der Wirtszelle verbreitet (Armstrong und Hart, 1971; Gaillard et al., 1987).

\subsubsection{Pathogenitätsmechanismen von Mykoplasmen}

Die Antigenvariation von Oberflächenproteinen, meist Lipoproteine, ist auch in Mykoplasmen weit verbreitet. Sie wurde bereits in M. pulmonis, M. gallisepticum, M. hyorhinis, M. bovis und vielen anderen beschrieben (Watson et al., 1988; Thomas 
und Sharp, 1988; Boyer und Wise, 1989; Behrens et al., 1994). Auch das P1 Protein aus M. pneumoniae, ein wichtiges Zytadhärenzprotein, weist Variationen auf, die dazu führen, dass es von Immunzellen nicht mehr erkannt wird (Kenri et al., 1999).

Einige Mykoplasmen, darunter M. pulmonis, M. pneumoniae und M. mycoides sind in der Lage, Wasserstoffperoxid als Virulenzfaktor zu produzieren (Cohen und Somerson, 1967; Brennan und Feinstein, 1968; Cherry und Taylor-Robinson, 1970). Am besten ist dieser Mechanismus in M. mycoides untersucht. Hier ist die Glycerol-3phosphat-Oxidase, die in der Membran verankert ist, für die Produktion von Wasserstoffperoxid zuständig und gibt dieses in die Umgebung ab (Pilo et al., 2005). Des Weiteren konnte gezeigt werden, dass ein enger Kontakt zu den Wirtszellen wichtig ist, damit Wasserstoffperoxid die Zellen schädigen kann (Bischof et al., 2008).

Überhaupt spielen Adhäsionsproteine eine wichtige Rolle bei den Mykoplasmen. Die Tipstruktur kann mit spezifischen Antikörpern behandelt werden, die verhindern, dass die $M$. pneumoniae-Zellen an Wirtszellen binden. Dies bewirkt, dass die Lungenläsionen in Hamstern weniger ausgeprägt sind als bei der Infektion mit Wildtyp M. pneumoniae (Brunner et al., 1984). Auch bei M. genitalium und M. gallisepticum führt das Fehlen von Zytadhärenzproteinen $\mathrm{zu}$ einer verringerten Virulenz (Dhandayuthapani et al., 2001; Papazisi et al., 2002).

Bei manchen Mykoplasmen konnte ein intrazelluläres Wachstum nachgewiesen werden. Die Invasion von unterschiedlichen Zellkulturen, darunter auch HeLa-Zellen, wurde in M. pneumoniae, M. genitalium, M. fermentans, M. gallisepticum, M. penetrans und M. hominis gezeigt (Taylor-Robinson et al., 1991; Jensen et al, 1994; Andreev et al., 1995; Dallo und Baseman, 2000; Winner et al., 2000; Meseguer et al., 2003; Yavlovich et al., 2004). Die genauen Mechanismen, die Mykoplasmen verwenden, um in die Wirtszelle zu gelangen, sind jedoch weitestgehend unbekannt. Man hat festgestellt, dass die Bindung von Plasminogen an M. fermentans im Gegensatz zu anderen extrazellulären Matrixproteinen der Wirtszelle, die Adhärenz und die Invasionsrate erhöht (Yavlovich et al., 2001; Yavlovich und Rottem, 2007). Es bleibt jedoch unklar, ob die Mykoplasmen diesen Mechanismus auch in vivo verwenden und ob sie diesen zur Virulenz benötigen oder als Schutz vor dem Immunsystem nutzen. Für M. gallisepticum konnte vor kurzem gezeigt werden, dass das invasive Wachstum auch in vivo genutzt wird (Vogl et al., 2008). Die degenerative Evolution der Genome der Mykoplasmen gibt jedoch ein Hinweis auf die parasitäre Lebensweise, wie sie auch bei 
anderen invasiv wachsenden Bakterien zu finden ist. M. hominis scheint diese Fähigkeit zu nutzen, um an seinen Wirkungsort zu gelangen. Er kann in Trichomonas vaginalis, einen parasitischen Einzeller, eindringen, ihn als Vektor nutzen und verlässt ihn wieder bei der Ankunft am Ziel, um den Urogenitaltrakt zu besiedeln (Vancini und Benchimol, 2008).

In M. pneumoniae konnte erstmals ein Zytotoxin identifiziert werden. Es handelt sich hierbei um ein so genanntes ADP-ribosylierendes Toxin, welches Homologien zum Pertussistoxin aufweist. Diese Toxine haben einen massiven Einfluss auf die Translation und regulatorische Proteine der eukaryotischen Zellen und lösen dadurch die Apoptose aus (Honjo et al., 1968; Iglewski und Kabat, 1975; Krueger und Barbieri, 1995). Das Toxin aus M. pneumoniae, MPN372, weist 3 Motive auf, die für diese Toxine spezifisch sind. An der Position 10 befindet sich ein konserviertes Arginin, das für die NAD-Bindung in vielen ADP-ribosylierenden Toxinen benötigt wird. Das SerinThreonin-Serin Motif (STS) befindet sich an der Position 49-51 und gewährleistet die strukturelle Integrität der NAD-Bindestelle. Außerdem findet man noch an der Position 132 ein potentiell katalytisches Glutamat (Kannan und Baseman, 2006).

Das aufgereinigte Protein MPN372 weist ADP-ribosylierende Aktivität auf und hat einen zytotoxischen Effekt auf Zellkulturen. Jedoch konnte nicht gezeigt werden, dass dieses Toxin von den Mykoplasmen sekretiert wird. Der Großteil des Proteins scheint im Zytoplasma vorzuliegen und nur 7\% sind an der Membran lokalisiert. In Patientenisolaten konnte die Anwesenheit von MPN372 mit Antikörpern nachgewiesen werden (Kannan und Baseman, 2006). Es bleibt unklar, wie die Mykoplasmen dieses Toxin in die Wirtszelle bringen und diese damit schädigen können.

\subsection{Regulation in Bakterien}

Bakterien haben unterschiedliche Mechanismen entwickelt, um auf ihre Umwelt zu reagieren und sich anzupassen. Sehr weit verbreitet ist die Regulation auf Ebene der Transkription, die anhand des lac-Operons erstmals beschrieben wurde (Beckwith, 1967). In Mykoplasmen ist nur wenig über diese Art der Regulation bekannt. Vor kurzem konnte jedoch gezeigt werden, dass HrcA, ein Repressor der Hitzeschockgene, mit CIRCE-Elementen in M. hyopneumoniae interagieren kann (Chang et al., 2007). Die Expression von ackA und ldh ist invers und scheint auch reguliert zu sein, jedoch 
konnte der Mechanismus dieser Regulation bisher nicht aufgeklärt werden (Halbedel et al., 2007).

Eine weitere Möglichkeit ist die Regulation auf Ebene der RNA. Hier sind die so genannten Riboswitches zu nennen, bei denen Metabolite oder Proteine die Transkription verhindern oder ermöglichen können. Ein Beispiel wurde bereits im Kapitel 2.4 anhand des Glycerolstoffwechsels in B. subtilis beschrieben.

Auch die Enzymaktivität kann reguliert werden. Manche Enzyme besitzen neben dem aktiven Zentrum noch ein allosterisches Zentrum an das Effektormoleküle binden können, die einen Einfluss auf die Aktivität haben. Die Bindung des Effektors kann die Aktivität hemmen oder aktivieren. In B. subtilis inhibieren aromatische Aminosäuren die Enzyme, die am Anfang des Syntheseweges stehen (Nester et al., 1966). Somit wird verhindert, dass die Zellen keine Energie zur Synthese von Aminosäuren aufwenden, die ausreichend vorhanden sind. Die Kinaseaktivität der HPrK/P aus dem PTS wird hingegen in Anwesenheit des Effektors Fruktose-1,6-Bisphosphat stimuliert (Jault et al., 2000). In M. pneumoniae hat die Anwesenheit von FBP nur einen sehr schwachen Effekt auf die HPrK (Merzbacher et al., 2004).

Enzyme können außerdem noch posttranslational durch Adenylierung, Methylierung oder Phosphorylierung modifiziert werden, was dann einen Einfluss auf die Aktivität hat.

\subsubsection{Phosphorylierungen in Bakterien und deren Funktion}

Phosphorylierte Proteine können unterschiedliche Funktionen in Bakterien übernehmen. Das HPr kann an zwei Stellen phosphoryliert werden und führt je nach Phosphorylierung andere Aufgaben durch. Das $\operatorname{HPr}(\mathrm{His} \sim \mathrm{P})$ ist wichtig für die Aufnahme und Phosphorylierung von Zuckern, während HPr(Ser-P) zusammen mit CcpA an der Regulation der Genexpression beteiligt ist (Reizer et al., 1998; Kravanja et al., 1999). Die Enzymaktvität der Isocitratdehydrogenase (IDH) aus E. coli wird durch Phosphorylierung gehemmt, während die phosphorylierte GlpK aus E. faecalis aktiviert wird (Garnak und Reeves, 1979; Deutscher und Sauerwald, 1986).

Das PTS für die Aufnahme von Zuckern ist auch in Mykoplasmen weit verbreitet (Cirillo und Razin, 1973). Die Tipstruktur in M. pneumoniae spielt eine wichtige Rolle bei der Adhärenz und hat einen komplexen Aufbau. Es konnte gezeigt werden, dass viele von den Proteinen, die das Zytoskelett bilden, phosphoryliert werden (Dirksen et 
al., 1994; Krebes et al., 1995). Eine globale Studie der phosphorylierten Proteine in M. genitalium und M. pneumoniae hat gezeigt, dass neben vielen Zytadhärenzproteinen auch Transkriptionsfaktoren, Hitzeschockproteine und die Laktatdehydrogenase phosphoryliert werden ( $\mathrm{Su}$ et al., 2007). Bisher wurde nur die HPr-Kinase aus M. pneumoniae näher charakterisiert. Eine weitere Kinase, die regulatorische Funktionen übernehmen könnte, wurde bisher nicht beschrieben (Steinhauer et al., 2002; Halbedel et al., 2004).

\subsubsection{Die Ser/Thr/Tyr-Kinasen und deren Funktion}

In Eukaryoten wie auch in Bakterien findet man Kinasen, die die Aminosäuren Serin, Threonin und Tyrosin phosphorylieren können (de Verdier, 1952; Deutscher und Saier, 2005). Diese Phosphorylierungen sind im Gegensatz zu Histidinphosphorylierungen sehr stabil. Die Ser/Thr/Tyr-Kinasen und die dazugehörenden Phosphatasen wurden zuerst in Eukaryoten beschrieben (Ben-David et al., 1991; Rossomando et al., 1992). In B. subtilis konnte eine Proteinphosphatase (PrpC) isoliert werden, die Ähnlichkeit zu der menschlichen Proteinphosphatase PP2C aufweist. Hinter dem Gen für die Phosphatase konnte noch eine Kinase (PrkC) identifiziert werden, die in ihrer phosphorylierten Form ein Substrat für die Phosphatase ist (Obuchowski et al., 2000). Sequenzalignments haben gezeigt, dass diese Phosphatasen auch in anderen Bakterien zu finden sind, darunter auch M. genitalium (Bork et al., 1996; Fraser et al., 1995) und M. pneumoniae (Halbedel, 2006).

Über die Rolle von PrkC und PrpC ist bisher nur wenig bekannt. In B. subtilis hat eine $\operatorname{prpC-Mutante~in~der~späten~stationären~Phase~eine~sehr~hohe~Zelldichte,~während~}$ die Zellmasse bei der prkC-Mutante im Gegensatz zum Wildtyp stark abnimmt. Außerdem konnte ein Substrat für die Kinase und die Phosphatase identifiziert werden. Es handelt sich hierbei um den Elongationsfaktor EF-G. Wahrscheinlich wird durch die Phosphorylierung von EF-G dessen Aktivität herabgesetzt und somit auch die Translationsrate (Gaidenko et al., 2002). PrkC und PrpC haben auch einen Einfluss auf die Sporen- und Biofilmbildung (Madec et al., 2002).

Die Kinase wurde auch in einem pathogenen Organismus, E. faecalis, gefunden und untersucht. Es stellte sich heraus, dass eine prkC-Mutante empfindlicher auf Antibiotika reagiert, die die Zellwand angreifen. Die Persistenz in Darm von Mäusen war ebenfalls herabgesetzt. PrkC reguliert demnach wichtige physiologische Prozesse, 
die E. faecalis zu einem erfolgreichen nosokomialen Erreger macht (Kristich et al., 2007).

In $M$. pneumoniae sowie in B. subtilis wurde $\mathrm{HPr}(\operatorname{Ser}-\mathrm{P})$ als Substrat für die Phosphatase identifiziert (Halbedel et al., 2006; Singh et al., 2007). Bei den Bacillen spielt diese Dephosphorylierung jedoch in vivo keine Rolle.

\subsection{Ziele der Arbeit}

Die Untersuchung des Glycerolstoffwechsels aus M. pneumoniae beschränkte sich bisher auf die Bestimmung der Enzymaktivität der Glycerolkinase und den Zusammenhang mit dem PTS. In dieser Arbeit sollte untersucht werden, ob die Glycerolkinase durch Komponenten des PTS phosphoryliert werden kann. Außerdem sollte die Rolle der Glycerol-3-phosphat-Dehydrogenase in der Pathogenität näher betrachtet werden.

Es sollten auch Transposonmutanten von M. pneumoniae isoliert und untersucht werden, die eventuell einen Einfluss auf die Zytotoxizität gegenüber HeLa-Zellen aufweisen. Hierzu sollte ein Test entwickelt werden, der es ermöglicht, die Zytotoxizität der Mykoplasmen gegenüber Wirtszellen zu bestimmen.

Nachdem PrpC in $M$. pneumoniae identifiziert worden ist, sollte untersucht werden, ob es sich bei dem dahinter liegenden Gen um PrkC handelt. Hierzu sollte eine Mutante dieses Gens isoliert werden. Des Weiteren sollte die PrkC rekombinant exprimiert werden und für in vitro Phosphorylierungen eingesetzt werden. Dabei sollten Substrate für die Kinase identifiziert werden. 


\section{Material und Methoden}

Materialien: Chemikalien, Hilfsmittel, Geräte, Apparaturen, kommerziell erhältliche Systeme sowie Proteine, Antikörper, Enzyme und Oligonukleotide (Tab. 7.1.) sind im Anhang aufgeführt.

\subsection{Bakterienstämme und Plasmide}

Siehe Anhang dieser Arbeit

\subsection{Medien}

Puffer, Lösungen und Medien wurden mit deionisiertem Wasser angesetzt und $20 \mathrm{~min}$ im Dampfdrucktopf bei $121^{\circ} \mathrm{C}$ und 2 bar autoklaviert. Thermolabile Substanzen wurden gelöst und steril filtriert. Alle Angaben beziehen sich auf Wasser, andere Lösungsmittel sind angegeben. Dem LB-Medium wurde zur Verfestigung bei Herstellung von Platten $15 \mathrm{~g} / 1$ Agar zugesetzt.

\section{Bakterienmedien und fakultative Zusätze}

LB-Medium (11)

$10 \mathrm{~g}$ Trypton

$5 \mathrm{~g}$ Hefeextrakt

$10 \mathrm{~g} \mathrm{NaCl}$

MP-Medium (400ml)

$7,35 \mathrm{~g}$ PPLO broth

11,92 g HEPES

$2 \mathrm{ml}$ Phenolrot $0,5 \%$

$14 \mathrm{ml} 2 \mathrm{~N} \mathrm{NaOH}$

ad. $400 \mathrm{ml}$ deionisiertes Wasser

$\mathrm{pH} 7,6-7,8$

20 min. autoklavieren

Abkühlen auf $56^{\circ} \mathrm{C}$

anschließend Zugabe von:

$100 \mathrm{ml}$ Pferdeserum (hitzeinaktiviert) 
$5 \mathrm{ml}$ Penicillin $100000 \mathrm{U} / \mathrm{ml}$

C-Quellen wurden mit einer Endkonzentration von $1 \%$ eingesetzt

$5 \mathrm{~g}$ Agar für Platten

5 x C-Salze (11)

$20 \mathrm{~g} \quad \mathrm{KH}_{2} \mathrm{PO}_{4}$

$80 \mathrm{~g}_{2} \mathrm{~K}_{2} \mathrm{HPO}_{4} \times 3 \mathrm{H}_{2} \mathrm{O}$

$16,5 \mathrm{~g}\left(\mathrm{NH}_{4}\right)_{2} \mathrm{SO}_{4}$

III'-Salze (11)

$0,232 \mathrm{~g}^{\mathrm{MnSO}} 4 \mathrm{X} 4 \mathrm{H}_{2} \mathrm{O}$

$12,3 \mathrm{~g}_{\mathrm{MgSO}_{4}} \times \mathrm{H}_{2} \mathrm{O}$

1x C-Minimalmedium

$100 \mathrm{ml} 1 \times \mathrm{C}$-Salze

$1 \mathrm{ml}$ Tryptophan $\left(5 \mathrm{mg} \mathrm{ml}^{-1}\right)$

$1 \mathrm{ml}$ Ammoniumeisencitrat $\left(2,2 \mathrm{mg} \mathrm{ml}^{-1}\right)$

$1 \mathrm{ml}$ III'-Salze

1x CSE-Medium

$100 \mathrm{ml} 1$ x C-Salze

$1 \mathrm{ml}$ Tryptophan $\left(5 \mathrm{mg} \mathrm{ml}^{-1}\right)$

$1 \mathrm{ml}$ Ammoniumeisencitrat $\left(2,2 \mathrm{mg} \mathrm{ml}^{-1}\right)$

$1 \mathrm{ml}$ III'-Salze

$2 \mathrm{ml}$ Kaliumglutamat (40\%)

$2 \mathrm{ml}$ Natriumsuccinat (30\%)

SP-Medium (11)

$8 \mathrm{~g}$ Nutrient Broth

$0,25 \mathrm{~g} \mathrm{MgSO}_{4} \times \mathrm{MH}_{2} \mathrm{O}$

$1 \mathrm{~g} \mathrm{KCl}$

ad. $1000 \mathrm{ml}$ deion. Wasser anschließende Zugabe von:

$1 \mathrm{ml} \mathrm{CaCl}_{2}(0,5 \mathrm{M})$ 
$1 \mathrm{ml} \mathrm{MnCl}_{2}(10 \mathrm{mM})$

$2 \mathrm{ml}$ Ammoniumeisencitrat $\left(2,2 \mathrm{mg} \mathrm{ml}^{-1}\right)$

$\operatorname{MNGE}(10 \mathrm{ml})$

$$
\begin{aligned}
& \text { 9,2 ml 1x MN-Medium } \\
& 1 \mathrm{ml} \text { Glukose (20\%) } \\
& 50 \mu 1 \text { Kaliumglutamat (40\%) } \\
& 50 \mu \mathrm{l} \text { Ammoniumeisencitrat }\left(2,2 \mathrm{mg} \mathrm{ml}^{-1}\right) \\
& 100 \mu \mathrm{l} \text { Tryptophan }\left(5 \mathrm{mg} \mathrm{ml}^{-1}\right) \\
& 30 \mu \mathrm{l} \mathrm{MgSO}_{4}(1 \mathrm{M}) \\
& \text { +/- } \quad 100 \mu \mathrm{l} \text { CAA }(10 \%)
\end{aligned}
$$

$10 \times$ MN-Medium (11)

$136 \mathrm{~g} \mathrm{~K}_{2} \mathrm{HPO}_{4} \times 3 \mathrm{H}_{2} \mathrm{O}$

$60 \mathrm{~g} \mathrm{KH}_{2} \mathrm{KO}_{4}$

$10 \mathrm{~g}$ Natriumcitrat $\times 2 \mathrm{H}_{2} \mathrm{O}$

DMEM

$$
\begin{aligned}
& 500 \mathrm{ml} \text { DMEM } \\
& 50 \mathrm{ml} \text { FCS } \\
& 5 \mathrm{ml} \quad 1 \% \text { nicht essentielle Aminosäuren } \\
& 5 \mathrm{ml} \quad 1 \% \text { Na-Pyruvat } \\
& 500 \mu \mathrm{l} \text { Penicillin (100000 U) }
\end{aligned}
$$

\section{Antibiotika}

Die verwendeten Antibiotika wurden als 1000-fach konzentrierte Stammlösungen angesetzt. Ampicillin, Kanamycin, Spectinomycin, Lincomycin, Penicillin und Gentamycin wurden dazu in deionisiertem Wasser gelöst, Erythromycin in 70\% EtOH. Alle Lösungen wurden steril filtriert und bei $-20^{\circ} \mathrm{C}$ aufbewahrt. Nach Abkühlung der Medien auf ca. $50^{\circ} \mathrm{C}$ wurden die Antibiotika in den entsprechenden Endkonzentrationen zugegeben. 
Selektionskonzentration für E. coli:

$\begin{array}{lr}\text { Ampicillin } & 100 \mu \mathrm{g} \mathrm{ml}^{-1} \\ \text { Kanamycin } & 50 \mu \mathrm{g} \mathrm{ml}^{-1}\end{array}$

Selektionskonzentration für M. pneumoniae:

Penicillin $1000 \mathrm{U} \mathrm{ml}^{-1}$

Gentamycin

$80 \mu \mathrm{g} \mathrm{ml}^{-1}$

$\underline{\text { Selektionskonzentration für B. subtilis: }}$

$\begin{array}{lc}\text { Kanamycin } & 5 \mu \mathrm{g} \mathrm{ml}^{-1} \\ \text { Erythromycin }^{1} & 2 \mu \mathrm{g} \mathrm{ml}^{-1} \\ \text { Lincomycin }^{1} & 25 \mu \mathrm{g} \mathrm{ml}^{-1} \\ \text { Spectinomycin } & 100 \mu \mathrm{g} \mathrm{ml}^{-1} \\ { }^{1} \text { Zur Selektion auf ermC wurde eine Mischung aus Erythromycin und Lincomycin in den oben } \\ \text { angegebenen Konzentrationen verwendet. }\end{array}$

\subsection{Methoden}

\subsubsection{Allgemeine Methoden}

Eine Zusammenfassung der allgemeinen Methoden, die in der Literatur beschrieben sind und in dieser Arbeit angewendet wurden, ist in Tab. 3.1. aufgeführt.

\section{Tab. 3.1. Allgemeine Methoden}

\begin{tabular}{ll}
\hline Methode & Referenz \\
\hline Absorptionsmessung & Sambrook et al., 1989 \\
Ethidiumbromidfärbung von DNA & Sambrook et al., 1989 \\
Gelelektrophorese von Proteinen (denaturierend) & Laemmli, 1970 \\
Proteinmengenbestimmung & Bradford, 1976 \\
Plasmidpräparation aus E. coli & Sambrook et al., 1989 \\
Sequenzierung nach der Kettenabbruchmethode & Sanger et al., 1977 \\
\hline
\end{tabular}




\subsubsection{Anzucht von Bakterien}

Anzucht von E. coli

Soweit nicht anders angegeben, wurde E. coli in LB-Medium bei $37^{\circ} \mathrm{C}$ und $180 \mathrm{U} \mathrm{min}^{-1}$ in Reagenzgläsern oder Schikanekolben angezogen. Beimpft wurde von frischen Vereinzelungsplatten bzw. aus Übernachtkulturen. Das Wachstum wurde durch Messung der optischen Dichte bei $\lambda=600 \mathrm{~nm}$ verfolgt.

\section{Anzucht von M. pneumoniae}

$\mathrm{Zu} 500 \mathrm{ml}$ MP-Medium wurden $10 \mathrm{ml}$ einer $M$. pneumoniae Stammkultur hinzugegeben. Je $100 \mathrm{ml}$ werden auf $150 \mathrm{~cm}^{2}$ Zellkulturflaschen verteilt und für $96 \mathrm{~h}$ bei $37^{\circ} \mathrm{C}$ inkubiert.

\section{Stammhaltung von M. pneumoniae}

Der Überstand einer $100 \mathrm{ml}$ Kultur wurde nach $96 \mathrm{~h}$ Inkubation bei $37^{\circ} \mathrm{C}$ weggeschüttet. Anschließend gab man $20 \mathrm{ml}$ frisches MP-Medium auf die Zellen und schabte diese von der Oberfläche der Zellkulturflasche. Je $10 \mathrm{ml}$ dieser Suspension wurde in sterile Vorkulturröhrchen gegeben und bei $-70^{\circ} \mathrm{C}$ weggefroren.

\section{Nassgewichtbestimmung von M. pneumoniae Kulturen}

Der Überstand von $100 \mathrm{ml}$ Kulturen wurde aus der Kulturflasche abgegossen und die adhärierten Zellen zweimal mit 1 x PBS-Puffer gewaschen. Anschließend wurden die Zellen mit Hilfe eines Zellspatels und 1,5 ml 1 x PBS abgeschabt. Die Zellen wurden mit einer Pasteurpipette in ein zuvor abgewogenes Eppendorfgefäß überführt und abzentrifugiert $\left(10000 \mathrm{xg}, 4^{\circ} \mathrm{C}\right)$. Der Überstand wurde vollständig mit der Pipette abgenommen und das Pellet in dem Eppendorfgefäß auf der Feinwaage abgewogen. Das Nassgewicht ergab sich aus der Differenz der Gewichte des Eppendorfgefäßes mit und ohne Zellen. Zum Erstellen einer Wachstumskurve wurde das Nassgewicht jeweils einer $100 \mathrm{ml}$ Kultur nach 2, 4, 6 und 8 Tagen bestimmt.

\section{Anzucht von B. subtilis}

B. subtilis wuchs in LB-Medium, CSE-Medium oder MNGE-Medium bei $37^{\circ} \mathrm{C}$ oder $28^{\circ} \mathrm{C}$ in Reagenzgläsern oder Erlenmeyerkolben. Beimpft wurde von frischen 
Vereinzelungsplatten bzw. aus Übernachtkulturen. Das Wachstum wurde durch Messung der optischen Dichte bei $\lambda=600 \mathrm{~nm}$ verfolgt.

\section{Anzucht von HeLa-Zellen}

Der Überstand einer konfluent bewachsenen $25 \mathrm{ml}$ Kultur wurde nach 4 Tagen Inkubation bei $37^{\circ} \mathrm{C}$ und $5 \% \mathrm{CO}_{2}$ mit einer sterilen Pasteurpipette abgenommen. Nach der Zugabe von $5 \mathrm{ml}$ frischem DMEM-Medium wurden die adhärierten Zellen mit dem Zellschaber abgeschabt. Die HeLa-Zellen wurden in einem spitzen $50 \mathrm{ml}$ Falcon tube bei 1400 Upm für 5 min abzentrifugiert. Das Pellet wurde in $2 \mathrm{ml}$ frischem DMEMMedium aufgenommen und die Zellen durch Resuspendieren vereinzelt. Man gab 100 $200 \mu \mathrm{l}$ der Zellsuspension in eine Kulturflasche mit $25 \mathrm{ml}$ frischem DMEM-Medium. Die Inkubation erfolgte wieder für 4 Tage bei $37^{\circ} \mathrm{C}$ und $5 \% \mathrm{CO}_{2}$.

\section{Zellzahlbestimmung von HeLa-Zellen}

Mit Hilfe einer Neubauer Zählkammer (Tiefe 0,1 mm, Fläche 0,0025 $\mathrm{mm}^{2}$ ) wurde die Zellzahl bestimmt. Hierzu wurden $10 \mu \mathrm{l}$ der Zellsuspension mit $10 \mu \mathrm{l}$ Trypanblau vermischt und $10 \mu \mathrm{l}$ dieser Lösung zwischen Deckglas und Kammer pipettiert. Das Trypanblau ermöglicht das Unterscheiden zwischen lebenden und toten Zellen, da diese blau angefärbt werden. Ausgezählt wurden nur lebende Zellen. Es wurden immer 4 Großquadrate à 16 Quadraten ausgezählt. Die Zellzahl pro ml Zellsuspension wurde aus dem Mittelwert der ausgezählten Zellen pro Großquadrat berechnet, mit dem Verdünnungsfaktor 2 und dem Volumenfaktor 1 x $10^{4}$ multipliziert.

\subsubsection{Genetische Methoden}

\section{Präparation chromosomaler DNA aus M. pneumoniae}

Der Überstand einer $100 \mathrm{ml}$ M. pneumoniae Kultur wurde abgenommen und die Zellen wurden dreimal mit 1 x PBS gewaschen. Das Abschaben der Zellen erfolgte mit 1,5 ml 1x PBS. Anschließend wurden die Zellen in einem Eppendorfgefäß abzentrifugiert $\left(10000 \mathrm{x} \mathrm{g}, 5 \mathrm{~min}, 4^{\circ} \mathrm{C}\right)$. Der Überstand wurde verworfen und das Pellet in $750 \mu 150$ $\mathrm{mM}$ Tris- $\mathrm{HCl} \mathrm{pH}$ 8,0 und 25 mM EDTA resuspendiert. Nach der Zugabe von $19 \mu 1$ RNaseA (1 mg/ml) wurden die Zellen für 15 Minuten bei $37^{\circ} \mathrm{C}$ inkubiert. Dann wurden $50 \mu 1$ Proteinase K $(25 \mathrm{mg} / \mathrm{ml})$ und $75 \mathrm{ml} \mathrm{10 \%} \mathrm{SDS} \mathrm{hinzugegeben} \mathrm{und} \mathrm{der} \mathrm{Ansatz} \mathrm{für}$ 
$2 \mathrm{~h}$ bei $50^{\circ} \mathrm{C}$ inkubiert. Nach der Zugabe von $300 \mu \mathrm{l} 5 \mathrm{M} \mathrm{NaCl}$ wurde der Ansatz gemischt und für 5 Minuten auf Eis gestellt. Die Suspension wurde dann für 25 Minuten bei $10000 \mathrm{x} \mathrm{g}\left(4^{\circ} \mathrm{C}\right)$ zentrifugiert. Der Überstand wurde mit $1 \mathrm{ml}$ eiskaltem Isopropanol gemischt und über Nacht bei $-20^{\circ} \mathrm{C}$ gelagert. Die Lösung wurde am nächsten Tag für 15 Minuten bei $10000 \times \mathrm{g}\left(4^{\circ} \mathrm{C}\right)$ abzentrifugiert, das Pellet mit $500 \mu 170 \%$ Ethanol gewaschen und wieder zentrifugiert $\left(10000 \mathrm{xg}, 15 \mathrm{~min}, 4^{\circ} \mathrm{C}\right)$. Das Pellet wurde bei RT unter der Sterilbank getrocknet. Anschließend löste man die DNA in $300 \mu 1$ sterilem $\mathrm{H}_{2} \mathrm{O}$.

\section{Isolierung von chromosomaler DNA aus B. subtilis}

Die Isolation der chromosomalen DNA aus B. subtilis erfolgte mit Hilfe des QIAamp Tissue Kits. Hierzu wurden 1,5 ml einer in LB-Medium gewachsenen Übernachtkultur 2 min bei $13000 \mathrm{U} \mathrm{min}^{-1}$ abzentrifugiert. Anschließend wurde das Zellpellet in $180 \mu \mathrm{l}$ Lyse-Puffer resuspendiert und $60 \mathrm{~min}$ bei $37^{\circ} \mathrm{C}$ inkubiert. Die weiteren Schritte zur Isolation der chromosomalen DNA erfolgten nach den Angaben des Herstellers.

\section{DNA-Gelelektrophorese}

Zur Größenbestimmung und zur präparativen Auftrennung von DNARestriktionsfragmenten wurde eine Gelelektrophorese mit 1\%-igen Agarosegelen durchgeführt. Die Proben wurden mit DNA-Farbmarker versetzt und auf das Gel aufgetragen. Der Gellauf erfolgte bei 100-150 V, bis die Bromphenolblaubande das untere Drittel des Gels erreicht hatte. Danach wurden die Gele in einer Ethidiumbromidhaltigen Lösung $(0,5 \mu \mathrm{g} / \mathrm{ml}) 10 \mathrm{~min}$ gefärbt, kurz in Wasser entfärbt und anschließend unter UV-Licht $(254 \mathrm{~nm})$ fotografiert. Zur Abschätzung der Größe von DNAFragmenten wurde EcoRI und HindIII verdaute $\lambda$-DNA verwendet. Bei $\lambda=366 \mathrm{~nm}$ konnte präparativ verdaute DNA aus Gelen ausgeschnitten und mit Hilfe des Gelextraktionskits von Qiagen nach Anleitung des Herstellers eluiert werden.

\section{Southern Blot}

Die chromosomale DNA wurde mit einem oder zwei Restriktionsenzymen über Nacht bei $37^{\circ} \mathrm{C}$ verdaut. Am nächsten Tag wurden die verdaute DNA sowie ein DIGmarkierter DNA-Marker (DNA molecular weight marker III DIG-labeled, Roche) auf ein 1\%-iges Agarose-Gel aufgetragen. Nach dem Gellauf wurde das Gel in einer 
Ethidiumbromid-haltigen Lösung gefärbt, in Wasser entfärbt und unter UV-Licht fotografiert.

Der Transfer der DNA auf eine positiv geladene Nylonmembran wurde mit einer Vakuum-Blot-Anlage (VacuGene ${ }^{\mathrm{TM}} \mathrm{XI}$ ) durchgeführt. Die positiv geladene Nylonmembran (Roche) mit einer Größe von 12 x $11 \mathrm{~cm}$ wurde zunächst mit sterilem deion. Wasser getränkt. Anschließend wurde die Membran möglichst luftblasenfrei auf die gut mit deion. Wasser durchfeuchtete poröse Trägerplatte aufgelegt. Mit einer Plastikmaske wurde der Blot abgedichtet und das Agarosegel luftdicht abschließend auf die Membran und die Plastikmaske aufgelegt. Ein Vakuum von 80 mbar wurde an die Vakuum-Kammer angelegt und das Gel nacheinander mit den folgenden Lösungen überschichtet:

1. Depurinisierungspuffer $15 \mathrm{~min}$

2. Denaturierungspuffer $20 \mathrm{~min}$

3. Neutralisierungspuffer $20 \mathrm{~min}$

4. $20 \mathrm{x}$ SSPE 4-5 h

Beim Wechsel der Lösungen wurden Reste der vorherigen Lösung durch Abkippen entfernt. Die DNA wurde mittels UV-Licht (90 sek) an der Membran fixiert. Bis zur Hybridisierung wurde die Membran bei RT trocken und vor Staub geschützt gelagert.

\section{Hybridisierung membrangebundener DNA mit DIG-markierten RNA-Sonden}

Die Nylonmembran, die die UV-fixierte DNA trägt, wurde mit $20 \mathrm{ml}$ Prähybridisierungslösung in Hybridisierungsröhrchen transferiert und bei $68^{\circ} \mathrm{C}$ eine Stunde im Hybridisierungsofen inkubiert. Anschließend wurde die Prähybridisierungslösung durch die Sonde ersetzt. Die Hybridisierung erfolgte ÜN bei $68^{\circ} \mathrm{C}$. Am nächsten Tag wurde die Sonde entfernt und bis zum weiteren Gebrauch bei $-20^{\circ} \mathrm{C}$ aufbewahrt. Die Membran wurde zweimal für $15 \mathrm{~min}$ bei RT in $50 \mathrm{ml} 2 \mathrm{x}$ SSC und $0,1 \%$ SDS Waschlösung sowie zweimal $15 \mathrm{~min}$ bei $68^{\circ} \mathrm{C}$ in $50 \mathrm{ml} 0,1 \times \mathrm{SSC}$ und 0,1\% SDS Waschlösung inkubiert, um unspezifisch gebundene RNA-Sonden zu entfernen. Anschließend konnte die Membran zur Detektion der DIG-markierten DNARNA Hybride eingesetzt werden. 


\section{Detektion von DNA-RNA-Hybriden}

Der Nachweis der DNA schloss sich direkt an die Hybridisierung an. Zunächst wurde die Membran für 5 min in 1 x Puffer I, danach für weitere 30 min in Puffer II inkubiert. Es folgte die Detektion der hybridisierten Sonden mittels Anti-DIG-Antikörper gekoppelt mit Alkalischer Phosphatase (30 min), die im Verhältnis 1:10000 in Puffer II gelöst waren. Anschließend wurde die Membran dreimal 10 min in Puffer I und danach 5 min in Puffer III gewaschen. Im letzten Schritt wurde die Membran zwischen eine Klarsichtfolie gelegt und mit $1 \mathrm{ml}$ Puffer III, der $5 \mu \mathrm{l}$ des Substrats CDP* enthielt, 5 min im Dunkeln inkubiert. Nach Überführung der Membran in eine frische Folie, wurde diese sofort in die Belichtungskassette gelegt. Abschließend erfolgte die Belichtung von Filmen, wobei je nach Bandenintensität unterschiedliche Belichtungszeiten (15 - 45 min) angewandt wurden. Dabei wurde die Chemilumineszenz detektiert, die bei der enzymatischen Spaltung von CDP* durch die Alkalische Phosphatase entsteht.

\section{Restriktion und Ligation von DNA}

Die Restriktionen mit Endonukleasen wurden in den vom Hersteller empfohlenen Puffern durchgeführt. Die Ligation von DNA-Fragmenten wurde mit T4-DNA-Ligase unter Verwendung des vom Hersteller mitgelieferten Puffers durchgeführt. Es wurden zwischen 10 und 100 ng Vektor-DNA und ein fünffacher Überschuss an Fragment eingesetzt. Die Ligationsreaktion erfolgte für $1 \mathrm{~h}$ bei Raumtemperatur.

\section{Dephosphorylierung von DNA}

Die Dephosphorylierung des 5'-Endes von DNA-Fragmenten wurde mit Hilfe von CalfIntestinal Alkalischer-Phosphatase (CIAP) unter Einsatz des vom Hersteller mitgelieferten Puffers durchgeführt. Einem Ansatz mit einer DNA-Endkonzentration von ca. 3-10 ng/ $\mu 1$ wurde $1 \mu$ CIAP (1000 Units/ $\mu$ l) zugesetzt. Anschließend wurde 30 min bei $37^{\circ} \mathrm{C}$ inkubiert und danach erneut $1 \mu$ CIAP zugegeben. Es erfolgte eine weitere Inkubation bei $37^{\circ} \mathrm{C}$ für $30 \mathrm{~min}$. Anschließend wurde das Enzym $30 \mathrm{~min}$ bei $65^{\circ} \mathrm{C}$ hitzeinaktiviert. Danach konnte der Ansatz direkt für eine Ligation verwendet werden. 


\section{Polymerasekettenreaktion (PCR)}

Die Polymerasekettenreaktion wurde stets mit chromosomaler DNA oder zirkulärer Plasmid-DNA als Matrize durchgeführt.

$\underline{\text { Reaktionsansatz für die Pfu-Polymerase }(100 \mu 1) \text { : }}$

$1 \mu 1$ Primer forward $(100 \mu \mathrm{M})$

$1 \mu 1$ Primer reverse complement $(100 \mu \mathrm{M})$

$3 \mu 1$ Matrizen-DNA (ca. 100 ng)

$10 \mu 110$ x Pfu-Polymerase Puffer

$1 \mu 1$ Pfu-Polymerase $\left(2,5{\left.\mathrm{U} \mu 1^{-1}\right)}^{-1}\right.$

$4 \mu \mathrm{dNTPs}\left(12,5 \mu \mathrm{mol} \mathrm{ml} \mathrm{d}^{-1}\right)$

$80 \mu 1$ deionisiertes Wasser

$\underline{\text { Reaktionsansatz für die Taq-Polymerase }(100 \mu 1) \text { : }}$

$1 \mu 1$ Primer forward $(100 \mu \mathrm{M})$

$1 \mu 1$ Primer reverse complement $(100 \mu \mathrm{M})$

$3 \mu 1$ Matrizen-DNA (ca. $100 \mathrm{ng}$ )

$10 \mu 110 \times$ Taq-Polymerase Puffer

$10 \mu 110 \times \mathrm{MgCl}_{2}$

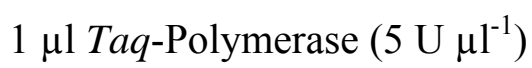

$4 \mu \mathrm{dNTPs}\left(12,5 \mu \mathrm{mol} \mathrm{ml}^{-1}\right)$

$70 \mu 1$ deionisiertes Wasser

Der Ansatz wurde gemischt und die Reaktion im Thermocycler mit folgendem Programm durchgeführt:

\begin{tabular}{|c|c|c|c|}
\hline Anzahl der Zyklen & Reaktion & Temperatur & Dauer der Reaktion \\
\hline \multirow[t]{2}{*}{1} & Vorlauf & $95^{\circ} \mathrm{C}$ & $5 \mathrm{~min}$ \\
\hline & Denaturierung & $95^{\circ} \mathrm{C}$ & $1 \mathrm{~min}$ \\
\hline \multirow[t]{2}{*}{30} & Anlagerung & $49-60^{\circ} \mathrm{C}$ & $1 \mathrm{~min}$ \\
\hline & Elongation & $72^{\circ} \mathrm{C}$ & $1-4 \min$ \\
\hline
\end{tabular}

Nach Abschluss des Programms wurde der Reaktionsansatz auf $15^{\circ} \mathrm{C}$ abgekühlt. 


\section{Multiple Mutation Reaction (MMR)}

Die Multiple Mutation Reaction ist eine Weiterentwicklung der „Kombinierten Kettenreaktion“ (CCR) (Bi und Stambrook, 1998) zur simultanen Einführung von mehreren Punktmutationen (Hames et al., 2005). Da bei dieser Methode die Einführung der Mutationen und die Amplifikation des mutagenisierten Fragments in nur einem Schritt erfolgt, entfallen dazwischenliegende Aufreinigungsschritte. Es erfolgt sowohl eine Polymerasekettenreaktion als auch eine Ligation. Zur Ligationsreaktion werden am 5'-Ende phosphorylierte Oligonukleotide und eine thermostabile Ligase (Ampligase, Biozym) benötigt.

Reaktionsansatz $(50 \mu \mathrm{l})$ :

$2 \mu 1$ Primer CH9 $(5 \mu \mathrm{M})$

$2 \mu 1$ Primer CH10 $(5 \mu \mathrm{M})$

je $3 \mu 15^{\prime}$-phosphorylierte Mutageneseprimer (CH11-CH19) (3,3 $\left.\mu \mathrm{M}\right)$

$1 \mu 1$ Matrizen-DNA (ca. $100 \mathrm{ng}$ )

$5 \mu 110$ x MMR-Polymerase Puffer

$1 \mu$ Pfu-Polymerase $\left(2,5 \mathrm{U}^{-1} \mathrm{l}^{-1}\right)$

$3 \mu$ Ampligase

$1 \mu \mathrm{dNTPs}\left(12,5 \mu \mathrm{mol} \mathrm{ml}^{-1}\right)$

$2 \mu \mathrm{BSA}\left(10 \mathrm{mg} \mathrm{ml}^{-1}\right)$

$30 \mu 1$ deionisiertes Wasser

Der Ansatz wurde gemischt und die Reaktion im Thermocycler mit folgendem Programm durchgeführt:

\begin{tabular}{|c|c|c|c|}
\hline Anzahl der Zyklen & Reaktion & Temperatur & Dauer der Reaktion \\
\hline \multirow[t]{2}{*}{1} & Vorlauf & $95^{\circ} \mathrm{C}$ & $5 \mathrm{~min}$ \\
\hline & Denaturierung & $95^{\circ} \mathrm{C}$ & $30 \mathrm{~s}$ \\
\hline \multirow[t]{2}{*}{35} & Anlagerung & $57^{\circ} \mathrm{C}$ & $30 \mathrm{~s}$ \\
\hline & Elongation & $65^{\circ} \mathrm{C}$ & $6 \mathrm{~min}$ \\
\hline 1 & Endlauf & $65^{\circ} \mathrm{C}$ & $10 \mathrm{~min}$ \\
\hline
\end{tabular}

Nach Abschluss des Programms wurde der Reaktionsansatz auf $15^{\circ} \mathrm{C}$ abgekühlt. 


\section{Long Flanking Homolgy PCR (LFH-PCR)}

Für die Konstruktion einer glpD-Deletionsmutante von B. subtilis wurde die LFH-PCR angewandt. Zunächst wurde eine Spec-Resistenzkassette vom Vektor pDG1727 amplifiziert. Des Weiteren wurden zwei Primerpaare abgeleitet, mit denen die flankierenden Bereiche des zu glpD-Gens amplifiziert werden konnten. Diese Fragmente mit einer Größe von circa 1000 bp mussten so gewählt werden, dass die Expression der angrenzenden Gene nicht beeinflusst wurde. An das strangaufwärts und an das strangabwärts liegende DNA-Fragment wurde mit dem reverse Primer bzw. forward Primer jeweils eine 25 Nukleotide lange Sequenz angehängt. Diese Sequenz ist komplementär zum 5'- bzw. 3'-Ende der Resistenzkassette. Die PCR-Fragmente wurden mit dem QIAquick PCR Purification Kit aufgereinigt. In einer zweiten PCR wurden die strangaufwärts und strangabwärts liegenden DNA-Fragmente und die Resistenzkassette über die 25 Nukleotide lange Sequenz miteinander verbunden und amplifiziert. Die eingesetzte DNA-Menge des oberen und unteren Fragmentes betrug jeweils 150 ng, die der Resistenzkassette etwa 300 ng. Die Amplifikation der einzelnen Fragmente erfolgte mit Hilfe der Pfu-DNA-Polymerase (MBI Fermentas). Der TripleMaster Polymerase Mix (Eppendorf) wurde für die Verbindung der einzelnen Fragmente verwendet. Der Wildtypstamm von B. subtilis wurde direkt mit den erhaltenen PCR-Produkten transformiert. Die erhaltenen Transformanten wurden mittels PCR überprüft. Um sicherzustellen, dass bei den beiden PCR-Schritten keine Mutationen eingebaut wurden, wurden die bei den Kontroll-PCRs erhaltenen DNAFragmente sequenziert.

\section{Isolierung von M. pneumoniae Transposonmutanten}

Die Isolierung der Transposonmutanten erfolgte aus einer Transposonmutantenbank mit Hilfe der so genannten Haystack-Methode (Halbedel et al., 2006). Die Pools der Mutantenbank wurden verwendet, um Mutanten zu finden, in denen ein bestimmtes Gen durch ein Transposon unterbrochen wurde. Dazu wurde eine PCR durchgeführt mit einem Primer der sich in dem vorderen Bereich des Genes anlagert und ein reverser Primer, der sich im vorderen Bereich des Transposons anlagert. Ein PCR-Produkt in einem der Pools gab einen Hinweis darauf, dass hier eine Mutante enthalten sein könnte. Die PCR wurde dann noch mal mit jedem Klon dieses Pools durchgeführt und 
der Klon, der ein PCR-Produkt lieferte, wurde isoliert und in flüssigem Medium angezogen. Die Überprüfung der Mutante auf ihre Reinheit fand mit einem Southern Blot statt.

\section{Herstellung kompetenter E. coli Zellen}

Zur Herstellung kompetenter Zellen wurde über Nacht eine $4 \mathrm{ml}$ Kultur angezogen. Am nächsten Tag wurden $100 \mathrm{ml}$ LB-Medium mit $2 \mathrm{ml}$ der Übernachtkultur beimpft. Die Kultur wurde bei $37^{\circ} \mathrm{C}$ bis zu einer $\mathrm{OD}_{600}$ von 0,8 geschüttelt und für 10 min bei $9000 \mathrm{x}$ g abzentrifugiert $\left(4^{\circ} \mathrm{C}\right)$. Das Pellet wurde in $20 \mathrm{ml}$ Lösung 1 resuspendiert und wieder für $10 \mathrm{~min}$ bei $4^{\circ} \mathrm{C}$ abzentrifugiert. Dann wurde das Pellet in $20 \mathrm{ml}$ Lösung 2 resuspendiert und $30 \mathrm{~min}$ bei $4^{\circ} \mathrm{C}$ inkubiert. Es folgte wieder eine Zentrifugation für 10 min bei $4{ }^{\circ} \mathrm{C}$. Anschließend wurde das Pellet in $5 \mathrm{ml}$ Lösung 2 und 1,3 $\mathrm{ml} 50 \%$ Glycerin aufgenommen. Die Suspension wurde aliquotiert, in flüssigem Stickstoff schockgefroren und bei $-70^{\circ} \mathrm{C}$ gelagert.

\section{Transformation von $E$. coli}

Die kompetenten Zellen wurden auf Eis aufgetaut. Es wurden $200 \mu 1$ der Zellsuspension zu 10-100 ng DNA gegeben und der Ansatz für 30 min auf Eis gestellt. Danach wurde das Reaktionsgefäß 1 min auf $42^{\circ} \mathrm{C}$ erwärmt, für 5 min auf Eis gestellt und nach Zugabe von $900 \mu \mathrm{l}$ LB-Medium für $1 \mathrm{~h}$ bei $37^{\circ} \mathrm{C}$ im Brutraum inkubiert. Von den Transformationsansätzen wurden jeweils $100 \mu 1$ und der abzentrifugierte Rest auf LBSelektionsplatten (mit Ampicillin oder Kanamycin) ausplattiert. Die Platten wurden über Nacht bei $37^{\circ} \mathrm{C}$ bebrütet.

\section{Herstellung kompetenter B. subtilis Zellen}

In 10 ml MNGE-Medium (mit CAA) wurde mit einer Übernachtkultur eine $\mathrm{OD}_{600}$ von 0,1 eingestellt und unter Schütteln bei $37^{\circ} \mathrm{C}$ inkubiert. Das Wachstum der Zellen wurde durch Messung der $\mathrm{OD}_{600}$ verfolgt. Bei einer $\mathrm{OD}_{600}$ von 1,3 wurden die Zellen mit gleicher Menge an MNGE-Medium ohne CAA verdünnt. Danach wurden die Zellen für eine weitere Stunde bei $37^{\circ} \mathrm{C}$ geschüttelt. Die anschließende Zentrifugation der Zellen erfolgte bei $5000 \mathrm{U} \mathrm{min}^{-1}$ und RT für $5 \mathrm{~min}$. Der Überstand wurde in ein steriles Greinergefäß dekantiert. Das Pellet wurde in $1 / 8$ des Überstandes resuspendiert und eine 
Glycerinkonzentration von 10\% eingestellt. Aliquots von $300 \mu 1$ wurden in flüssigem Stickstoff eingefroren und bei $-70^{\circ} \mathrm{C}$ gelagert.

\section{Transformation von $B$. subtilis}

Die zu $300 \mu \mathrm{l}$ aliquotierten Zellen wurden im Wasserbad bei $37^{\circ} \mathrm{C}$ aufgetaut und mit folgender vorpipettierter Lösung versetzt: $\quad 1,7 \mathrm{ml} 1 \mathrm{x} \mathrm{MN}$

$$
\begin{aligned}
& 43 \mu 120 \% \text { Glukose } \\
& 34 \mu 11 \mathrm{M} \mathrm{MgSO}_{4}
\end{aligned}
$$

$\mathrm{Zu} 400 \mu \mathrm{l}$ dieser Zellsuspension wurde $0,1-1 \mu \mathrm{g}$ DNA gegeben und $30 \mathrm{~min}$ bei $37^{\circ} \mathrm{C}$ geschüttelt. Anschließend wurden $100 \mu$ l Expressionslösung (500 $\mu 1$ Hefeextrakt (5\%), $250 \mu \mathrm{l} \mathrm{CAA} \mathrm{(10 \% ),} 250 \mu 1$ deion. Wasser, $50 \mu 1$ Tryptophan $(5 \mathrm{mg} / \mathrm{ml}))$ zupipettiert und für weitere $60 \mathrm{~min}$ bei $37^{\circ} \mathrm{C}$ geschüttelt. Dann wurden die Zellen auf Selektionsmedium mit Antibiotika ausplattiert.

\section{Lösungen für das Arbeiten mit DNA}

Agarosegel 1\%

$1 \%(\mathrm{w} / \mathrm{v})$ Agarose in $1 \times \mathrm{TAE}$

für DNA-Gelelektrophorese

Denaturierungspuffer

Depurinisierungslösung

DNA-Probenpuffer $5 \mathrm{x}$

für DNA-Gelelektrophorese

Lösung 1

für kompetente Zellen
1,5 $\mathrm{M} \mathrm{NaCl}$

$0,5 \mathrm{M} \mathrm{NaOH}$

ad. 11 mit deionisiertem Wasser

$250 \mathrm{mM} \mathrm{HCl}$

$5 \mathrm{ml}$ Glycerin

$200 \mu 150 \times \mathrm{TAE}$

$10 \mathrm{mg}$ Bromphenolblau

$10 \mathrm{mg}$ Xylencyanol

4,5 $\mathrm{ml}$ deionisiertes Wasser

$10 \mathrm{mM}$ MOPS

$10 \mathrm{mM} \mathrm{RbCl}$ 


\section{Lösung 2}

für kompetente Zellen

Lyse-Puffer

für Isolation chromosomaler DNA

aus $B$. subtilis

MMR-Puffer

Neutralisierungspuffer

PBS 10x

SSPE $20 \mathrm{x}$
$100 \mathrm{mM}$ MOPS pH 6,5

$10 \mathrm{mM} \mathrm{RbCl}$

$50 \mathrm{mM} \mathrm{CaCl}_{2}$

50 mg Lysozym

$50 \mu 1$ Tris- $\mathrm{HCl}$ pH 8,0 (1 M)

$10 \mu 1$ EDTA pH 8,0 (0,5 M)

2,5 ml Millipore-Wasser

$20 \mathrm{mM}$ Tris-HCl pH 8,5

$3 \mathrm{mM} \mathrm{MgCl}_{2}$

$50 \mathrm{mM} \mathrm{KCl}$

0,5 mM NAD

$1 \mathrm{M}$ Tris- $\mathrm{HCl} \mathrm{pH} 7,5$

$1,5 \mathrm{M} \mathrm{NaCl}$

ad. 11 mit deionisiertem Wasser

$2 \mathrm{~g} \mathrm{KCl}$

$2 \mathrm{~g} \mathrm{KH}_{2} \mathrm{PO}_{4}$

14,24 $\mathrm{g} \mathrm{Na}_{2} \mathrm{HPO}_{4}$ × $2 \mathrm{H}_{2} \mathrm{O}$

$80 \mathrm{~g} \mathrm{NaCl}$

ad. 11 mit deionisiertem Wasser auf $\mathrm{pH}$ 7,4 einstellen

$3 \mathrm{M} \mathrm{NaCl}$

$0,2 \mathrm{M} \mathrm{NaH}_{2} \mathrm{PO}_{4}$

0,02 M EDTA

pH 7,4 mit 10N NaOH einstellen 
TAE-Puffer $50 \mathrm{x}$

für DNA-Gelelektrophorese
$242 \mathrm{~g}$ Tris

$57,1 \mathrm{ml}$ Essigsäure

$100 \mathrm{ml}$ 0,5 M EDTA pH 8,0

ad. 11 mit deionisiertem Wasser

\subsubsection{Arbeiten mit RNA}

\section{In-vitro Transkription zur Herstellung von RNA-Sonden}

Als Matrize für die Herstellung von Digoxigenin-markierten Transkripten dienten PCRProdukte (als template-DNA für die PCR wurde genomische DNA von M. pneumoniae M129 eingesetzt), welche ca. 500 bis 800 bp lange, interne Bereiche der interessierenden Gene abdeckten. Durch entsprechendes Primerdesign besaßen diese PCR-Produkte am 5'-Ende des nicht-kodierenden Stranges eine Erkennungsstelle für die T7-RNA-Polymerase. Dadurch war die synthetische Herstellung von antisenseTranskripten möglich.

Folgende Komponenten wurden dazu auf Eis in einem Eppendorf-Reaktionsgefäß zusammen pipettiert:

- $1 \mu \mathrm{g}$ DNA

- $2 \mu 110$ x DIG RNA labeling Mix (Roche Diagnostics)

- $\quad 2 \mu 110 \times$ Transkritionspuffer

- Ad. $18 \mu 1$ steriles deionisiertes Wasser

- $2 \mu 1$ T7-RNA-Polymerase (Roche Diagnostics)

- $\quad 1 \mu 1$ RNAse Inhibitor (Amersham)

Die in-vitro-Transkription erfolgte während einer zweistündigen Inkubation bei $37^{\circ} \mathrm{C}$. Die Reaktion wurde nach Ablauf der Inkubationszeit durch Zugabe von $1 \mu 1$ 0,5 M EDTA pH 8,0 abgestoppt und die markierte RNA-Sonde durch Zugabe von 2,5 $\mu 14$ $\mathrm{M} \mathrm{LiCl}$ und $75 \mu \mathrm{l}$ eiskaltem $96 \%$ (v/v) Ethanol ÜN bei $-20^{\circ} \mathrm{C}$ präzipitiert. Durch Zentrifugation $\left(10000 \mathrm{x} \mathrm{g}, 4^{\circ} \mathrm{C}, 15 \mathrm{~min}\right)$ wurde die markierte RNA pelletiert und der Überstand konnte abgenommen werden. Das gewonnene Pellet wurde mit $50 \mu 1$ eiskaltem 70\% (v/v) Ethanol gewaschen. Nach Zentrifugation für $15 \min$ bei $4^{\circ} \mathrm{C}$ und $10000 \mathrm{x}$ g wurde der Überstand abgenommen und das restliche Ethanol bei RT abgedampft. Das erhaltene Pellet wurde in $100 \mu \mathrm{l}$ sterilem deionisiertem Wasser durch 
Inkubation für $30 \mathrm{~min}$ bei $37^{\circ} \mathrm{C}$ nach Zugabe von $1 \mu$ RNAse Inhibitor gelöst und die so hergestellte Sondenstammlösung bei $-80^{\circ} \mathrm{C}$ aufbewahrt.

\subsubsection{Arbeiten mit Proteinen}

\section{Überproduktion von Proteinen und Zellaufschluss mit der French Press}

Zur Überexpression von Proteinen wurden $800 \mathrm{ml} \mathrm{LB} /$ Ampicillin-Medium mit $20 \mathrm{ml}$ einer Übernachtkultur von einem E. coli-Stamm, der das entsprechende Überexpressionsplasmid trug, angeimpft und bei $37^{\circ} \mathrm{C}$ geschüttelt. Bei einer OD 600 von 0,8 wurde die Expression mit $1 \mathrm{mM}$ IPTG induziert. Zur Überprüfung der Überproduktion wurde vor der Induktion und vor der Zellernte je eine Probe entnommen. Die Kultur wurde $2 \mathrm{~h}$ nach der Induktion zur Ernte für $10 \mathrm{~min}$ bei $9000 \mathrm{x} \mathrm{g}$ abzentrifugiert. Die Zellen wurden mit Hilfe der French Press aufgeschlossen. Der Aufschluss erfolgte bei einem Zellinnendruck von 1400 bar (20000 psi) und wurde viermal durchgeführt. Die Suspension wurde für $10 \mathrm{~min}$ bei $10800 \mathrm{x}$ g abzentrifugiert. Der Überstand wurde zum Abtrennen der Zelltrümmer in der Ultrazentrifuge für $1 \mathrm{~h}$ bei $4^{\circ} \mathrm{C}$ und $15000 \mathrm{x}$ g zentrifugiert.

\section{Zellaufschluss durch Ultraschall}

Bakterienkulturen wurden für 5 min bei $16000 \mathrm{x}$ g und $4^{\circ} \mathrm{C}$ abzentrifugiert. Das Pellet wurde in Zellaufschlusspuffer resuspendiert. Der Aufschluss erfolgte mit einer Ultraschallsonde bei $60 \mathrm{~W}$ sechsmal für je 10 Sekunden. In den Pausen wurde die Probe auf Eis gekühlt. Das Gemisch wurde anschließend zum Abtrennen der Zelltrümmer abzentrifugiert $\left(16000 \mathrm{x} \mathrm{g}, 30 \mathrm{~min}, 4^{\circ} \mathrm{C}\right)$.

\section{Aufreinigung von Proteinen über $\mathrm{Ni}^{2+}$-NTA Säule}

Zur Aufreinigung der Proteine mit einer N-terminalen Hexahistidin-Sequenz wurden Poly-Prep-Chromatographie-Säulen (BIO-RAD) verwendet. Dabei wurde die Säule zunächst mit $4 \mathrm{ml} \mathrm{Ni}{ }^{2+}$-NTA Superflow (QIAGEN) beladen und dann mit $10 \mathrm{ml}$ ZAP äquilibriert. $20 \mathrm{ml}$ Proteinrohlysat wurde zweimal über die Matrix gegeben. Dann wurde sechsmal mit je $5 \mathrm{ml}$ ZAP gewaschen. Mit steigender Imidazolkonzentration im Puffer (10 mM, 20 mM, 50 mM, 100 mM, $200 \mathrm{mM}$ und $500 \mathrm{mM}$ Imidazol) wurden mit je $5 \mathrm{ml}$ zunächst unspezifisch bindende Proteine abgewaschen und danach das $\mathrm{His}_{6}$-tag- 
tragende Protein eluiert. Die dabei erhaltenen Fraktionen wurden auf einem SDS-PAAGel mit anschließender Färbung mit Coomassie-Brilliantblau auf Zusammensetzung und Reinheit überprüft. Die Fraktionen, die aufgereinigtes Protein enthielten, wurden über Nacht in ZAP dialysiert und anschließend mittels Bradford-Reagenz auf ihre Proteinkonzentration getestet.

\section{Aufreinigung über Strep-Tactin-Sepharose ${ }^{\circledR}$ Säule}

Die Überexpression und der Zellaufschluss mittels French Press wurden wie oben beschrieben durchgeführt. Für die Aufreinigung des Proteins wurde eine Strep-Tactin Sepharose ${ }^{\circledR}$ Säule (IBA) mit einem Matrixvolumen von $1 \mathrm{ml}$ verwendet. Diese Matrix bindet spezifisch eine Sequenz von acht Aminosäuren (WSHPQFEK). Die Bindung kann durch eine Verdrängungsreaktion mit D-Desthiobiotin wieder aufgehoben werden. Dadurch können Proteine, die mit dieser Aminosäuresequenz versehen sind, aus einem Proteingemisch getrennt werden. Zuerst wurde die Säule mit $3 \mathrm{ml}$ Puffer W äquilibriert. Dann konnte die Säule mit $10 \mathrm{ml}$ Proteinrohextrakt beladen werden. Zum Waschen der Säule wurden 5 x $1 \mathrm{ml}$ Puffer W verwendet. Das gebundene Protein konnte dann mit 3 $\mathrm{ml}$ Puffer $\mathrm{E}$ in Fraktionen von je $500 \mu \mathrm{l}$ eluiert werden. Zur Regeneration der Säulenmatrix wurden dreimal $5 \mathrm{ml}$ Puffer R und zweimal mit $4 \mathrm{ml}$ Puffer W auf die Säule gegeben. Die bei der Elution erhaltenen Fraktionen wurden wie oben beschrieben überprüft.

\section{Dialyse von Proteinen}

Bei der Aufreinigung eines Proteins über eine N-terminale Hexahistidin-Sequenz oder Strep-TagII-Sequenz ist zum Ablösen des an die Säule gebundenen Proteins Imidazol bzw. Desthiobiotin notwendig, welches weitere Versuche negativ beeinflussen kann. Um das Imidazol bzw. das Desthiobiotin aus der Proteinpräparation zu entfernen, wurden die Elutionsfraktionen in einem Dialyseschlauch (Ausschlussgröße: 12-14 kDa für die Glycerolkinase und 3,5 kDa für HPr) gegen Zellaufschlusspuffer dialysiert. Das Volumen des Dialysepuffers betrug das 1000-fache der zu dialysierenden Proteinlösung. 


\section{Herstellung von Proteinextrakten aus Mycoplasma pneumoniae}

Zellen aus einer $100 \mathrm{ml}$ Kultur wurden zweimal mit 1 x PBS gewaschen. Anschließend gab man 1,5 ml 1 x PBS zu den Zellen und löste diese mit Hilfe eines Zellschabers vom Boden der Zellkulturflasche ab. Die Zellen wurden in ein $2 \mathrm{ml}$ Eppendorfgefäß überführt und für 4 min bei $16000 \mathrm{x} \mathrm{g}\left(4^{\circ} \mathrm{C}\right)$ abzentrifugiert. Das Pellet wurde in $500 \mu 1$ $10 \mathrm{mM}$ Tris/ $\mathrm{HCl} \mathrm{pH}$ 7,5, $600 \mathrm{mM} \mathrm{NaCl}$ resuspendiert. Die Zellen wurden mit der Ultraschallsonde aufgeschlossen $\left(3 \times 10 \mathrm{~s}, 4^{\circ} \mathrm{C}, 50 \mathrm{~W}\right)$ und die Zelltrümmer wurden abzentrifugiert $\left(10 \mathrm{~min}, 16000 \mathrm{xg}, 4^{\circ} \mathrm{C}\right)$.

\section{Herstellung von Cytoplasma- und Membran-Fraktion aus Proteinextrakten von M. pneumoniae}

Von einer $100 \mathrm{ml}$ Kultur wurde der Überstand entnommen und die Zellen wurden $3 \mathrm{x}$ mit kaltem PBS gewaschen. Die adhärierten Zellen wurden mit 1,5 ml PBS abgeschabt und für $5 \mathrm{~min}$ bei $10000 \mathrm{x} \mathrm{g}\left(4^{\circ} \mathrm{C}\right)$ abzentrifugiert. Der Überstand wurde verworfen und das Pellet wurde in $1 \mathrm{ml}$ 0,5\% TritonX-114 in PBS resuspendiert. Der Ansatz wurde für 1 Stunde auf Eis inkubiert und alle 15 min mehrmals geschwenkt. Anschließend wurde der Ansatz wieder für 5 min bei 10000 x g $\left(4^{\circ} \mathrm{C}\right)$ zentrifugiert. Der Überstand wurde vorsichtig auf 0,5 ml Saccharose Puffer (20 ml PBS, 1,2 g Saccharose, $100 \mu 1$ TritonX114) pipettiert und für 4 min bei $37^{\circ} \mathrm{C}$ inkubiert. Es folgte eine Zentrifugation für $3 \mathrm{~min}$ bei 10000 x g (RT). Danach wurden Überstand und Pellet getrennt behandelt.

Das Pellet wurde in $1 \mathrm{ml}$ PBS resuspendiert, bei $37^{\circ} \mathrm{C} 4 \mathrm{~min}$ inkubiert und 3 min bei RT und 10000 x g zentrifugiert. Der Überstand wurde verworfen und das Pellet noch zwei weitere Male wie gerade beschrieben behandelt. Zum Schluss wurde das Pelletvolumen abgeschätzt und in dem dreifachen Pelletvolumen mit PBS resuspendiert. Dies war dann die Membran-Fraktion.

Der Überstand wurde in ein neues Eppendorfgefäß überführt und mit $150 \mu 1$ 11,4\% TritonX-114 gemischt. Der Ansatz wurde für 4 min bei $37^{\circ} \mathrm{C}$ inkubiert und dann bei 10000 x g (RT) für 3 min abzentrifugiert. Der Überstand wurde wieder in ein neues Eppendorfgefäß überführt und die Prozedur wurde noch zwei Mal wiederholt. Dies war die Cytoplasma-Fraktion. 


\section{Westernblot}

Der Transfer von Proteinen auf die PVDF-Membran erfolgte in einer Semi-Dry Blot Apparatur. Die PVDF-Membran wurde kurz in Methanol (100\%) aktiviert und anschließend für $5 \mathrm{~min}$ in Transferpuffer äquilibriert. Nach einem einstündigen Transfer bei $0,8 \mathrm{~mA} / \mathrm{cm}^{2}$ wurde die PVDF-Membran über Nacht in Blotto geschwenkt, um unspezifische Bindungsstellen zu blockieren. Der GlpK-Antikörper wurde 1:1000 in Blotto verdünnt eingesetzt und für $3 \mathrm{~h}$ mit der PVDF-Membran inkubiert. Nach drei Waschschritten von je 30 min mit Blotto erfolgte die Inkubation mit dem sekundären Antikörper (Anti-Kaninchen IgG, Alkalische Phosphatase gekoppelt), der 1:100000 in Blotto verdünnt zum Einsatz kam. Nach drei weiteren 30-minütigen Waschschritten mit Blotto wurde die Membran in deion. Wasser gespült und anschließend zur Erhöhung des pH-Wertes 5 min in Puffer III inkubiert. Der Nachweis der Proteine erfolgte unter Verwendung des Chemilumineszenz-Substrates CDP* (1:100 verdünnt in Puffer III). Das Chemilumineszenz-System ChemiSmart (peqlab) wurde zur Dokumentation der Signale verwendet.

\section{Lösungen zum Arbeiten mit Proteinen}

Blotto

für Westernblot
$100 \mathrm{ml} 10 \times \mathrm{TBS}$

25 g Magermilchpulver

$1 \mathrm{ml}$ Tween 20

ad. $1000 \mathrm{ml}$ mit deionisiertem Wasser

$10 \%$ Essigsäure

\section{Entfärbelösung}

für Proteingelelektrophorese

\section{Färbelösung}

für Proteingelelektrophorese
0,2\% Coomassie Brillant Blue R250

$10 \%(\mathrm{v} / \mathrm{v})$ Essigsäure

45\%(v/v) Methanol

ad 11 mit deionisiertem Wasser 
Proteinlaufpuffer 10x

für SDS-PAGE

\section{Puffer III}

für Westernblot

Puffer E

Puffer R

Puffer W

Probenpuffer $5 \mathrm{x}$

für native Proteingelelektrophorese
1,92 M Glycerin

$0,5 \mathrm{M}$ Tris

$10 \%$ SDS

$0,1 \mathrm{M}$ Tris

$0,1 \mathrm{M} \mathrm{NaCl}$

ad. 11 mit deionisiertem Wasser

pH 9,5 mit $\mathrm{HCl}$ eingestellt

100 mM Tris-HCl pH 8,0

$150 \mathrm{mM} \mathrm{NaCl}$

1 mM EDTA

2,5 mM Desthiobiotin

100 mM Tris-HCl pH 8,0

$150 \mathrm{mM} \mathrm{NaCl}$

$1 \mathrm{mM}$ EDTA

1 mM HABA

100 mM Tris-HCl pH 8,0

$150 \mathrm{mM} \mathrm{NaCl}$

1 mM EDTA

50\% Glycerin

0,25\% Bromphenolblau 


\section{Sammelgel}

für denaturierende

Proteingelelektrophorese

SDS-Probenpuffer $2 x$

für denaturierende

Proteingelelektrophorese

TBS $10 x$

Trenngel (12\%) für denaturierende

Proteingelelektrophorese
1,3 $\mathrm{ml} \mathrm{30 \%} \mathrm{Acrylamid-Bisacrylamid}$

$(37,5: 1)$

$0,87 \mathrm{ml}$ 1,5 M Tris-HCl pH 6,8

6,83 $\mathrm{ml}$ deionisiertes Wasser

$50 \mu 120 \%$ SDS

$100 \mu 110 \%$ APS

$20 \mu 1$ TEMED

1,4 ml 1 M Tris-HCl pH 7,0

$3 \mathrm{ml}$ Glycerin

$2 \mathrm{ml} \mathrm{20 \%} \mathrm{SDS}$

1,6 $\mathrm{ml} \mathrm{100 \%} \beta$-Mercaptoethanol

0,01 g Bromphenolblau

$2 \mathrm{ml}$ deionisiertes Wasser

$60 \mathrm{~g}$ Tris

$90 \mathrm{~g} \mathrm{NaCl}$

pH 7,6 mit $\mathrm{HCl}$ einstellen

ad 11 mit deionisiertem Wasser

$4 \mathrm{ml} \mathrm{30 \%}$ Acrylamid-Bisacrylamid (37,5:1)

2,6 ml 1,5 M Tris-HCl pH 8,8

3,3 $\mathrm{ml}$ deionisiertes Wasser

$50 \mu 120 \%$ SDS

$100 \mu 110 \%$ APS

$10 \mu 1$ TEMED 
Transferpuffer

für Westernblot auf PVDF-Membran

Waschlösung

für Proteingelelektrophorese
$15,1 \mathrm{~g}$ Tris

72,1 g Glycin

$750 \mathrm{ml}$ Methanol

ad 51 mit deionisiertem Wasser

$45 \%(\mathrm{v} / \mathrm{v})$ Methanol

$10 \%(\mathrm{v} / \mathrm{v})$ Essigsäure

$10 \mathrm{mM}$ Tris- $\mathrm{HCl} \mathrm{pH} 7,5$

$200 \mathrm{mM} \mathrm{NaCl}$

\subsubsection{Bestimmung von Enzymaktivitäten}

\section{Messung der $\mathrm{NAD}^{+}$-abhängigen Glycerol-3-phosphat-Dehydrogenase-Aktivität}

Die Aktivität der Glycerol-3-phosphat-Dehydrogenase wurde nach der Methode von Deutscher und Sauerwald (1986) bestimmt. Die Messung beruht auf der Umsetzung von Glycerol-3-Phosphat zu Dihydroxyacetonphosphat. Die Zunahme von $\mathrm{NADH}_{2}$, welches dabei gebildet wird, kann photometrisch bei einer Wellenlänge von $340 \mathrm{~nm}$ bestimmt werden (siehe Abb. 3.1.).

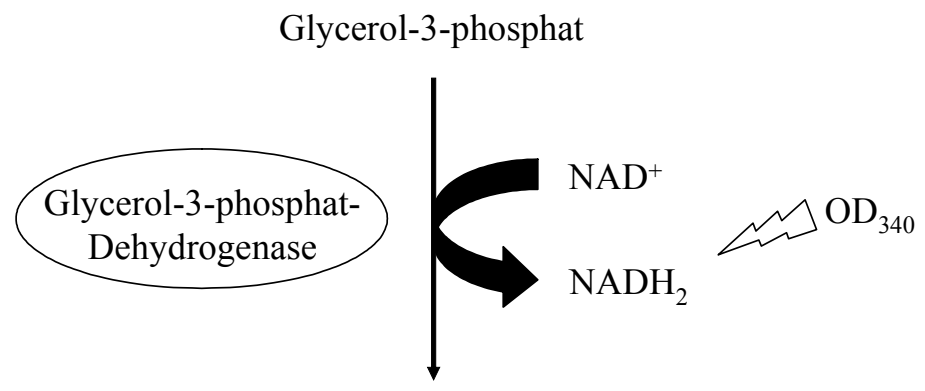

Dihydroxyacetonphosphat

Abb. 3.1. Schematische Darstellung des Enzymassays für die Glycerol-3-phosphat-Dehydrogenase

Nach der Aufreinigung der Glycerol-3-phosphat-Dehydrogenase konnte die Enzymaktivität bestimmt werden. In einer Küvette wurden $3 \mathrm{mM}$ sn-Glycerol-3phosphat, $3 \mathrm{mM} \mathrm{MgCl} 2,0,5 \mathrm{mM} \mathrm{NAD}^{+}$mit einem $100 \mathrm{mM}$ Glycin-Hydrazin Puffer 
vermischt. Die Aktivitätsmessung wurde durch die Zugabe von $4 \mu \mathrm{g}$ Glycerol-3phosphat-Dehydrogenase in einem Endvolumen von $1000 \mu \mathrm{l}$ gestartet. Die Absorptionszunahme wurde für $2 \mathrm{~min}$ bei $340 \mathrm{~nm}$ aufgezeichnet.

\section{Messung der $\mathrm{O}_{2}$-abhängigen $\mathrm{H}_{2} \mathrm{O}_{2}$-Produktion durch die Glycerol-3-phosphat- Dehydrogenase}

Die Messung der Entstehung von Wasserstoffperoxid durch die Glycerol-3-phosphatDehydrogenase kann photometrisch bei $\lambda=405 \mathrm{~nm}$ mit Hilfe der Meerrettichperoxidase (HRP) und dem Chromogen o-Dianisidin erfolgen. Die HRP ist unter Verbrauch von Wasserstoffperoxid in der Lage, das farblose o-Dianisidin zu einem braunen Farbstoff zu oxidieren (siehe Abb. 3.2.).

Zur Bestimmung der Menge an Wasserstoffperoxid wurde eine Standardkurve erstellt. Hierzu wurde die Absorption definierter Wasserstoffperoxidmengen gemessen und daraus die Steigung abgeleitet. In einem Ansatz wurden 0,5 mM o-Diansidin, $5 \mu \mathrm{M}$ $\mathrm{H}_{2} \mathrm{O}_{2}$ (bzw. 10, 50, 100, 200, $300 \mu \mathrm{M} \mathrm{H}_{2} \mathrm{O}_{2}$ ) und $10 \mathrm{mM}$ Kalium-Phosphat-Puffer $\mathrm{pH}$ 7,5 gut gemischt und nach der Zugabe von 2,5 U HRP konnte die Absorption bei $\lambda=405 \mathrm{~nm}$ bestimmt werden.

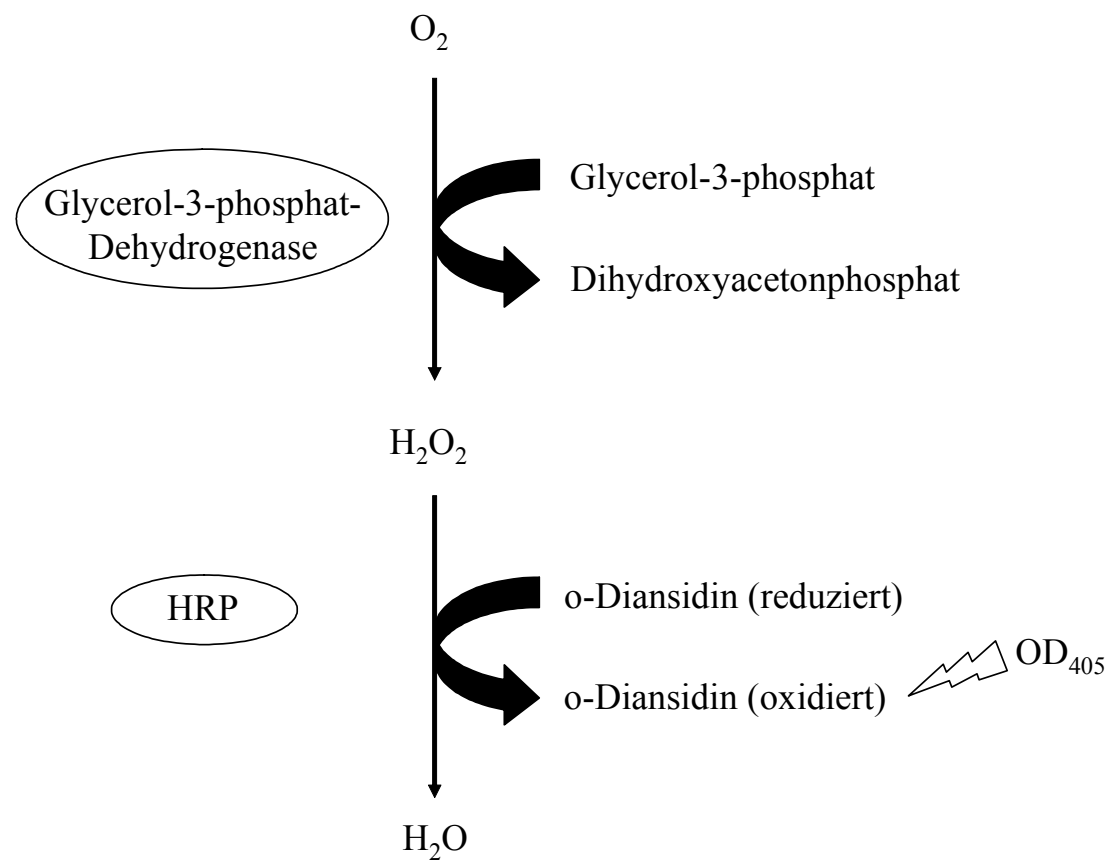

Abb. 3.2. Schematische Dartellung des Enzymassays zur Bestimmung der gebildeten Wasserstoffperoxidmenge 
Die Glycerol-3-phosphat-Dehydrogenase setzt Glycerol-3-phosphat zu Dihydroxyacetonphosphat um und überträgt dabei die Elektronen auf den Sauerstoff. Hierbei entsteht dann Wasserstoffperoxid. Um die Menge an freigesetztem Wasserstoffperoxid bei dieser Reaktion zu ermitteln, wurden erstmal $1 \mu$ g Glycerol-3phosphat-Dehydrogenase, $10 \mathrm{mM}$ Kalium-Phosphat-Puffer $\mathrm{pH} 7,5$ und $0,1 \mathrm{mM}$ Glycerol-3-phosphat in einem Gesamtvolumen von $1000 \mu$ für 1 Stunde bei $37^{\circ} \mathrm{C}$ inkubiert. Anschließend wurden 0,5 mM o-Diansidin und 2,5 U HRP zugesetzt und die Absorption bei $\lambda=405 \mathrm{~nm}$ gemessen. Anhand der Standardkurve konnte die entstandene Wasserstoffperoxidmenge abgelesen werden.

\section{Messung der $\mathrm{NADH}_{2}$-Oxidase-Aktivität}

Die Enzymaktivität der $\mathrm{NADH}_{2}-\mathrm{Oxidase}$ wurde nach der Methode von Hummel und Riebel (2003) bestimmt. Hierbei wird der Umsatz von $\mathrm{NADH}_{2} \mathrm{zu} \mathrm{NAD}{ }^{+}$durch die $\mathrm{NADH}_{2}$-Oxidase gemessen. Die Abnahme der Absorption bei der Bildung von NAD ${ }^{+}$ kann photometrisch bei einer Wellenlänge von $360 \mathrm{~nm}$ ermittelt werden (siehe Abb. 3.3.).

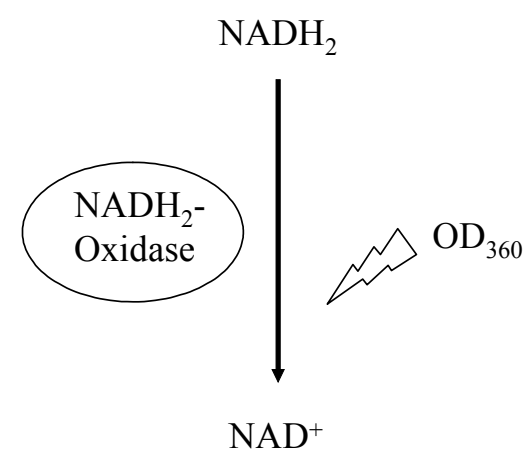

Abb. 3.3. Schematische Darstellung des Enymassays für die $\mathrm{NADH}_{2}$-Oxidase

Nach der Aufreinigung der $\mathrm{NADH}_{2}$-Oxidase konnte die Enzymaktivität bestimmt werden. In einer Küvette wurden $0,1 \mathrm{mM} \mathrm{NADH}_{2}$ und $100 \mathrm{mM}$ KaliumPhosphat-Puffer pH7,5 gemischt und der Enzymassay durch die Zugabe von $5 \mu \mathrm{g}$ $\mathrm{NADH}_{2}$-Oxidase in einem Endvolumen von $1000 \mu 1$ gestartet. Die Absorptionszunahme wurde für $2 \mathrm{~min}$ bei $360 \mathrm{~nm}$ aufgezeichnet. 


\section{Lösungen für Enzymaktivitätsmessungen}

$100 \mathrm{mM}$ sn-Glycerol-3-phosphat

100 mM Glycin-Hydrazin-Puffer

100 mM Kalium-Phosphat-Puffer pH 7,5 in $50 \mathrm{mM}$ Tris geben und bis zum Erreichen des $\mathrm{pH}$ 4,0 mit $1 \mathrm{~N} \mathrm{HCl}$ titrieren

7,507 g Glycin

5,1 g Hydrazin

ad. $100 \mathrm{ml}$ deionisiertes Wasser

$16 \mathrm{ml} \mathrm{0,2} \mathrm{M} \mathrm{KH}_{2} \mathrm{PO}_{4}$

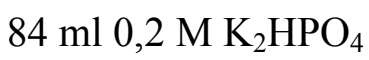

$100 \mathrm{ml}$ deionisiertes Wasser

\subsubsection{Messung der $\mathrm{H}_{2} \mathrm{O}_{2}$-Produktion von $M$. pneumoniae in vivo}

Der Überstand einer $100 \mathrm{ml}$ Kultur wurde abgegossen und die Zellen zweimal mit Puffer (67,6 mM HEPES pH 7,3, $140 \mathrm{mM} \mathrm{NaCl,} 7 \mathrm{mM} \mathrm{MgCl}_{2}$ ) gewaschen. Die adhärierten Zellen wurden mit 1,5 ml Puffer von der Oberfläche geschabt und in ein $2 \mathrm{ml}$ Eppendorfgefäß überführt. Es folgte eine Zentrifugation von $10 \mathrm{~min}$ bei $10000 \mathrm{xg}$ bei $4^{\circ} \mathrm{C}$. Der Überstand wurde verworfen und das Pellet wurde noch mal mit $1 \mathrm{ml}$ Puffer gewaschen. Die Zellen wurden noch mal für 10 min abzentrifugiert. Das Pellet wurde in $4 \mathrm{ml}$ Puffer resuspendiert und $1 \mathrm{ml}$ dieser Lösung wurde zur Messung der Absorption bei einer Wellenlänge von $550 \mathrm{~nm}$ eingesetzt. Für die Messung der $\mathrm{H}_{2} \mathrm{O}_{2}$ Produktion wurden je 1,0 $\mathrm{OD}_{550}$-Einheiten in einem Gesamtvolumen von $1 \mathrm{ml}$ eingesetzt. Der Ansatz wurde für 1 Stunde bei $37^{\circ} \mathrm{C}$ inkubiert. Anschließend erfolgte die Zugabe von $1 \mu 100$ mM Glycerol oder Glucose. Die $\mathrm{H}_{2} \mathrm{O}_{2}$-Produktion wurde zum Zeitpunkt der Zugabe der Kohlenstoffquelle gestartet (Zeitpunkt 0) und nach 1 min, $2 \mathrm{~min}, 5 \mathrm{~min}, 10 \mathrm{~min}, 20 \mathrm{~min}$ und $120 \mathrm{~min}$. Dabei wurden Analysestäbchen (PeroxidTest, Merck) 1 sek in die Lösung eingetaucht und nach 15 sek wurde die Farbe der Reaktionszone mit dem Farbfeld verglichen. Anhand des Farbfeldes konnte die entstandene Menge an $\mathrm{H}_{2} \mathrm{O}_{2}$ bestimmt werden. 


\subsubsection{Immun-Fluoreszenz-Mikroskopie}

Die Zellen einer $100 \mathrm{ml}$ Kultur wurden mit $2 \mathrm{ml}$ frischem Medium abgeschabt und anschließend mit einer 0,4 x 20 mm Kanüle vereinzelt. Von der Zellsuspension wurden $200 \mu \mathrm{l}$ auf ein Deckgläschen getropft, wobei beachtet wurde, dass keine Flüssigkeit über den Rand läuft. Das Deckgläschen wurde in einer geschlossenen Petrischale für 30 min bei $37^{\circ} \mathrm{C}$ inkubiert. Danach wurden das Deckgläschen zwei Mal mit PBS überschichtet und geschwenkt. Darauf folgte die Fixierung der Zellen mit 0,25\% Glutaraldehyd und 3,7\% Formaldehyd in PBS. Das Deckgläschen wurden mit dieser Lösung überschichtet und $30 \mathrm{~min}$ bei $4^{\circ} \mathrm{C}$ inkubiert. Die fixierten Zellen wurden anschließend 3 x 5 min mit PBS bei RT leicht geschwenkt.

Der primäre Antikörper $\alpha$-GlpD wurde in PBS-BSA (2\% BSA in PBS) 1:1000 verdünnt und $200 \mu 1$ der Lösung wurden auf dem Deckgläschen verteilt. Es folgte eine zweistündige Inkubation bei RT in einer geschlossenen Petrischale.

Danach wurde das Deckgläschen 3 x 10 min mit PBS bei RT leicht geschwenkt. Das Deckgläschen wurde mit einer Pinzette herausgenommen und die Unterseite wurde mit einem fusselfreien Tuch abgewischt. In einer neuen Petrischale wurden die Zellen dann mit dem sekundären Antikörper $\alpha$-Rabbit IgG-FITC (1:1000) 30 min bei RT im Dunkeln inkubiert. Das Deckgläschen wurde wieder 3 x 10 min mit PBS geschwenkt, die Unterseite trocken gewischt und auf einen Objektträger gelegt.

Die Zellen wurden unter einem Fluoreszenzmikroskop betrachtet und fotografiert.

\subsubsection{Elektronenmikroskopie}

Der Überstand einer $100 \mathrm{ml}$ Kultur wurde abgenommen, die Zellen wurden mit 3 x mit kaltem PBS gewaschen und mit 1,5 ml kaltem PBS abgeschabt. Die Zellen wurden 5 min bei $10000 \times \mathrm{g}\left(4^{\circ} \mathrm{C}\right)$ abzentrifugiert und der Überstand verworfen. Die Fixierung der Zellen erfolgte für 1 Stunde mit 2,5\% Glutaraldehyd. Dann wurden sie 2 x mit PBS gewaschen und für $3 \mathrm{~min}$ bei $10000 \mathrm{x} \mathrm{g}\left(4^{\circ} \mathrm{C}\right)$ abzentrifugiert. Die fixierten Zellen wurden in $1 \mathrm{ml}$ PBS resuspendiert und ein Tropfen dieser Lösung wurde auf Parafilm pipettiert. Ein Grid wurde für 3 min auf dem Tropfen inkubiert und kurz auf einem Filterpapier getrocknet. Der primäre Antikörper, $\alpha-\mathrm{P} 01$ oder $\alpha-\mathrm{GlpD}$, wurde 1:100 verdünnt, ein Tropfen dieser Lösung auf Parafilm pipettiert und das Grid für 1 Stunde aufgelegt. Anschließend wurde das Grid 3 x 5 min mit PBS gewaschen, in dem man das 
Grid auf die Tropfen gelegt hat und danach mit Filterpapier getrocknet hat. Der sekundäre Antikörper $\alpha$-Rabbit IgG-5nmGold (1:100) wurde $30 \mathrm{~min}$ mit dem Grid inkubiert. Danach wurde das Grid 2 x 5 min auf PBS-Tropfen gewaschen und zum Schluss kurz auf deionisiertes Wasser gelegt. Das Grid wurde mit der Unterseite nach oben auf dem Filterpapier trocknen gelassen.

Die fixierten und markierten Zellen wurden unter einem Elektronenmikroskop betrachtet und fotografiert.

\subsubsection{Radioaktive in vitro Phosphorylierung von Enzymen}

\section{Herstellung von radioaktivem $\gamma-\left[{ }^{32} \mathrm{P}\right]-$ Phosphoenolpyruvat (PEP)}

Für die Herstellung von radiaktivem $\gamma-\left[{ }^{32} \mathrm{P}\right]$-PEP wurden folgende Komponenten pipettiert:

$100 \mu 1250 \mathrm{mM}$ Triethylamine/ $\mathrm{HCl} \mathrm{pH}$ 7,6

$25 \mu \mathrm{l} \quad 150 \mathrm{mM} \mathrm{KCl}$

$25 \mu \mathrm{l} \quad 30 \mathrm{mM} \mathrm{MgCl}_{2}$

12,5 $\mu 1$ 3,3 mM PEP

$25 \mu 1 \quad 10 \mathrm{mM}$ Pyruvat

$25 \mu \mathrm{l}$ Pyruvatkinase $(400 \mathrm{U} / \mathrm{ml})$

$12,5 \mu 1100 \mu \mathrm{M}$ ATP

$25 \mu 1 \quad{ }^{32} \mathrm{P}-\mathrm{ATP}(3000 \mathrm{Ci} / \mathrm{mmol})$

Dieser Ansatz wurde für 30 min bei $30^{\circ} \mathrm{C}$ inkubiert. $\mathrm{Zu}$ den Phosphorylierungansätzen wurde jeweils $1 \mu 1$ der Lösung zugegeben. Das radioaktive $\gamma-\left[{ }^{32} \mathrm{P}\right]$-PEP wurde bei $\quad-20^{\circ} \mathrm{C}$ aufbewahrt.

\section{Herstellung von HPr-Ser46-P}

Zur Herstellung von HPr(His15 P)(Ser46-P) musste vorab das HPr-Ser46-P in vitro synthetisiert werden. Hierzu wurden 4,5 $\mu \mathrm{g}$ HPr, 0,3 $\mu \mathrm{g}$ HPrK, $2 \mu 1$ Master Mix Puffer $10 \mathrm{x}$ und $2 \mu 10 \mathrm{mM}$ ATP in einem Gesamtvolumen von $20 \mu \mathrm{l}$ für 1 Stunde bei $37^{\circ} \mathrm{C}$ inkubiert. Für die Phosphorylierungsansätze wurden je $4 \mu 1$ dieser Lösung eingesetzt. 


\section{In vitro Phosphorylierung der aufgereinigten Glycerolkinase aus M. pneumoniae}

Für die Phosphorylierungsexperimente wurden aus E. coli aufgereinigte Proteine von M. pneumoniae verwendet. Einzige Ausnahme war das Enzym I (EI) welches von B. subtilis stammte. Die Ansätze wurden wie folgt zusammen pipettiert:

\section{Phosphorylierungsansatz von GlpK mit HPr-Ser46-P:}

$100 \mathrm{pmol} \mathrm{HPr}$

100 pmol HPrK

100 pmol GlpK

$2 \mu 1$ Master Mix Puffer $10 \mathrm{x}$

ad. $19 \mu$ d deionisiertes Wasser

2. Phosphorylierungsansatz von GlpK mit HPr-His15 P:

100 pmol HPr

80 pmol EI

100 pmol GlpK

$2 \mu 1$ Master Mix Puffer $10 \mathrm{x}$

ad. $19 \mu$ deionisiertes Wasser

3. Phosphorylierungsansatz von GlpK mit HPr(His15 P)(Ser46-P):

100 pmol HPr-Ser46-P

80 pmol EI

100 pmol GlpK

$2 \mu 1$ Master Mix Puffer $10 \mathrm{x}$

ad. $19 \mu \mathrm{l}$ deionisiertes Wasser

Die Ansätze wurden im Labor pipettiert und anschließend auf $4^{\circ} \mathrm{C}$ gehalten. Im Isotopenlabor erfolgte die Zugabe von $1 \mu \mathrm{l}$ ATP-Gemisch ( 0,4 mM) zu den Ansätzen, in denen HPr am Ser46 phosphoryliert werden sollte (Ansatz 1). Das ATP-Gemisch bestand aus nicht-radioaktiv markiertem ATP (,,kalt") und dem radioaktiv markierten $\gamma$ $\left[{ }^{32} \mathrm{P}\right]$-ATP (6000 Ci/mmol). Es wurden $11,5 \mu \mathrm{l}$, ,kaltes“ ATP (10 mM), zur Absättigung von unspezifischen Phosphorylierungsstellen, mit $1 \mu \mathrm{l} \gamma-\left[{ }^{32} \mathrm{P}\right]-\mathrm{ATP}$ und 7,5 $\mu 1 \mathrm{H}_{2} \mathrm{O}$ 
gemischt. Zu den Ansätzen (Ansatz 2 und 3), in denen HPr am His15 phosphoryliert werden sollte, wurde $1 \mu 1$ radioaktiv markiertes $\gamma-\left[{ }^{32} \mathrm{P}\right]$-PEP gegeben.

Nach der ATP bzw. PEP-Zugabe wurden die Ansätze 30 und 60 min bei $37^{\circ} \mathrm{C}$ inkubiert. Nach Zugabe von SDS-Probenpuffer wurden die Phosphorylierungsansätze auf ein $12 \%$ SDS-PAA-Gel aufgetragen.

Master Mix Puffer $10 x$

$250 \mathrm{mM}$ Tris-HCl pH 7,5

$100 \mathrm{mM} \mathrm{MgCl} 2$

$10 \mathrm{mM}$ DTT

\section{In vitro Phosphorylierung der Laktatdehydrogenase durch eine Serin/Threonin-} Kinase aus M. pneumoniae

Für die Untersuchung der Phosphorylierung wurden die Laktatdehydrogenase (Ldh) und die Serin/Threonin-Kinase $(\operatorname{PrkC})$ von $M$. pneumoniae aus E. coli aufgereinigt. Die Ansätze wurden wie folgt zusammen pipettiert:

45 pmol PrkC

295 pmol Ldh

$2 \mu 1$ Master Mix $10 \mathrm{x}$

ad. $19 \mu 1$ deionisiertes Wasser

Im Isotopenlabor wurde $1 \mu 1$ von dem ATP-Gemisch zu dem Ansatz pipettiert und für $30 \mathrm{~min}$ bei $37^{\circ} \mathrm{C}$ inkubiert. Nach Zugabe von SDS-Probenpuffer wurden die Phosphorylierungsansätze auf ein 12\% SDS-PAA-Gel aufgetragen.

\section{Identifizierung von ${ }^{32}$ P-markierten Proteinen}

Nach dem Gellauf wurden die Gele auf Whatman®-Papier überführt und mit durchsichtiger, hitzebeständiger Folie abgedeckt und für 2 Stunden auf dem Gel Dryer 583 (Bio-Rad) bei $80^{\circ} \mathrm{C}$ unter Vakuum getrocknet. Es erfolgte die Exposition auf einem Schirm (,Screen“) für mindestens $18 \mathrm{~h}$. Der Schirm ist mit BaFBrEu-Kristallen beschichtet. Bei der Exposition mit radioaktiven Isotopen werden die Kristalle der ionisierenden Strahlung ausgesetzt, wodurch das $\mathrm{Eu}$ zum stabileren $\mathrm{Eu}^{2+}$ angeregt wird. Nach der Exposition wurde der hybridisierte Schirm im PhosphorImager ${ }^{\mathrm{TM}}$ (Molecular Dynamics) durch einen Laserstrahl abgelesen. Beim Auftreffen der Lichtenergie auf 
$\mathrm{Eu}^{2+}$ wird dieses $\mathrm{zu}$ instabilem $\mathrm{Eu}^{3+}$ überführt, woraufhin die Elektronen in ihren Grundzustand zurückfallen und ein Lichtsignal abgeben, das vom Gerät detektiert wird. Das Vorhandensein von ${ }^{32} \mathrm{P}$ an bestimmen Positionen im Gel, war als Schwärzung auf dem Bildschirm erkennbar. Die Proteingrößen konnten mit Hilfe des Größenmarkers auf dem Coomassie-Blau-Bild, den Signalen im Autoradiogramm zugeordnet werden.

\subsubsection{Infektion von HeLa-Zellen mit M. pneumoniae Mutanten}

\section{Vorbereitung der HeLa-Zellen}

Die Versuche wurden in 24 Well Titerplatten durchgeführt. Hierzu wurden die geernteten HeLa-Zellen erst mal mit einer Neubauer Zählkammer ausgezählt. Um die gewünschte Menge an Zellen pro Well $\left(2,5 \times 10^{4}\right)$ für den Versuch einsetzen zu können, wurde folgende Formel verwendet:

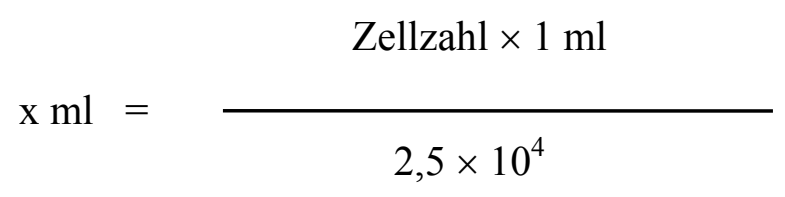

Die berechnete Menge an Zellen wurden in die Wells pipettiert und mit frischem DMEM auf $700 \mu \mathrm{l}$ Gesamtvolumen aufgefüllt. Anschließend wurden die Titerplatten für 24 Stunden bei $37^{\circ} \mathrm{C}$ und $5 \% \mathrm{CO}_{2}$ inkubiert.

\section{Infektion der HeLa-Zellen}

Die M. pneumoniae Kulturen wurden für $96 \mathrm{~h}$ bei $37^{\circ} \mathrm{C}$ inkubiert. Der Überstand der Kulturen wurde abgeschüttet und die adhärierenden Zellen dreimal mit 67,6 mM Hepes, $140 \mathrm{mM} \mathrm{NaCl}$ und $7 \mathrm{mM} \mathrm{MgCl}_{2}$ gewaschen. Die Zellen wurden dann mit 1,5 $\mathrm{ml}$ von diesem Puffer abgeschabt und bei $4^{\circ} \mathrm{C}$ und 10000 x g für 5 min abzentrifugiert. Das Pellet wurde in $1 \mathrm{ml}$ Puffer mit einer 0,4 x $20 \mathrm{~mm}$ Kanüle resuspendiert. Je nach Größe des Pellet wurde es mit 5-8 ml Puffer verdünnt. Anschließend wurde $1 \mathrm{ml}$ dieser Suspension zur Bestimmung der optischen Dichte bei $\lambda=550 \mathrm{~nm}$ verwendet.

Die entsprechende Menge von 0,1 $\mathrm{OD}_{550}$-Einheiten wurde der Suspension entnommen und bei $4^{\circ} \mathrm{C}$ und 10000 x g für 5 min abzentrifugiert. Das Pellet wurde in $125 \mu 1$ frischem MP-Medium mit einer 0,4 x 20 mm Kanüle resuspendiert. Die Zellen 
wurden dann zu den HeLa-Zellen pipettiert und die Titerplatte für $2 \mathrm{~h}$ bei $37^{\circ} \mathrm{C}$ und $5 \%$ $\mathrm{CO}_{2}$ inkubiert. Nach dieser Inkubationszeit wurde der Überstand abgenommen und durch $700 \mu 1$ frisches DMEM ersetzt. Der Versuch wurde über 6 Tage verfolgt.

Zur Bestimmung der MOI (multiplicity of infection) wurden Verdünnungsreihen der von $0,1 \mathrm{OD}_{550}$-Einheiten vor der Infektion und der Überstand $2 \mathrm{~h}$ nach der Infektion auf MP-Platten ausplattiert und für 14 Tage bei $37^{\circ} \mathrm{C}$ inkubiert. Der MOI entsprach 1000000 M. pneumoniae-Zellen pro HeLa-Zelle.

\section{Anfärben und fotografieren der HeLa-Zellen}

Das Medium wurde aus den Wells entnommen, die HeLa-Zellen wurden mit $100 \mu 1$ Kristallviolett-Lösung überschichtet und für $10 \mathrm{~min}$ bei RT inkubiert. Anschließend wurden die Zellen durch zweimalige Zugabe von $600 \mu 1$ sterilem deionisiertem Wasser gewaschen, um Reste der Kristallviolett-Lösung zu entfernen. Die Färbelösung fixiert die Zellen und färbt diese blau an. In diesem Zustand wurden die Zellen mit einer Digital-Kamera fotografiert (Belichtungszeit $15 \mathrm{~ms}$ ).

Kristallviolett-Lösung

$0,75 \%$ Kristallviolett

$0,25 \% \mathrm{NaCl}$

$1,75 \%$ Formaldehyd

$50 \%$ Ethanol 


\section{Ergebnisse}

\subsection{Untersuchung der Glycerol-3-phosphat-Dehydrogenase aus M. pneumoniae}

\subsubsection{Expression der Glycerol-3-phosphat-Dehydrogenase bei verschiedenen Kohlenstoffquellen}

In den meisten Prokaryoten ist die Aufnahme von Zuckern streng reguliert. Bei Grampositiven Bakterien wird die Expression der Gene, die für die Aufnahme und Verwertung alternativer Zucker zuständig sind, reprimiert, sobald die am besten verwertbare Kohlenstoffquelle Glukose verfügbar ist. Diese Form der Regulation wird Kohlenstoffkatabolitenrepression genannt (Stülke und Hillen, 1999; Brückner und Titgemeyer, 2002; Warner und Lolkema, 2003). Somit wird gewährleistet, dass nur die Enzyme gebildet werden, die zu dem Zeitpunkt gerade benötigt werden. Da M. pneumoniae ebenfalls in der Lage ist, verschiedene Kohlenstoffquellen zu verwerten, sollte mittels Western Blot untersucht werden, ob die Expression der Glycerol-3-phosphat-Dehydrogenase (GlpD) unter verschiedenen Bedingungen reguliert wird.

Für die Herstellung eines Antikörpers gegen die Glycerol-3-phosphatDehydrogenase wurde das Protein in den Überexpressionsvektor pWH844 kloniert, der es ermöglicht, die GlpD mit einem N-terminalen $\mathrm{His}_{6}$-Tag aufzureinigen. Mit Hilfe der MMR wurden die vier UGA-Codons in UGG-Codons umgewandelt, um eine vollständige Translation des Proteins in E. coli zu gewährleisten. Das Plasmid erhielt die Bezeichnung pGP266 und E. coli DH5 $\alpha$ wurde mit diesem transformiert. Nach der Überexpression wurde die rekombinante GlpD mit einer $\mathrm{Ni}^{+2}$-NTA-Säule aufgereinigt und $1 \mu \mathrm{g}$ wurde für die Immunisierung eines Kaninchens verwendet (Institut für Veterinär-Bakteriologie, Universität Bern). Nach Erhalt des Antikörpers $\alpha$-GlpD wurden die Mykoplasmen mit verschiedenen Kohlenstoffquellen, Glukose, Glycerol und Glukose und Glycerol angezogen. Aus diesen Kulturen wurden die Proteinextrakte gewonnen, welche für die Western Blot Untersuchung (Abb. 4.1.) eingesetzt werden konnten. In der Abbildung 4.1. ist in der ersten Spur rekombinante GlpD aufgetragen. Die Spuren 2, 3 und 4 stellen die Proteinextrakte mit Glukose, Glycerol und Glukose und Glycerol da. Die Menge an Glycerol-3-phosphat-Dehydrogenase ist unter allen 
Bedingungen gleich. Dies zeigt, dass keine Regulation der Expression von glpD auf der Transkriptions- und Translationsebene stattfindet. Somit ist höchstens eine Regulation durch Proteinmodifikation wie zum Beispiel Phosphorylierung denkbar. Es konnte in vorherigen Experimenten bereits gezeigt werden, dass auch im Fall der Glycerolkinase die Proteinmenge unter verschiedenen Kohlenstoffbedingungen konstant ist (Hames, 2005).

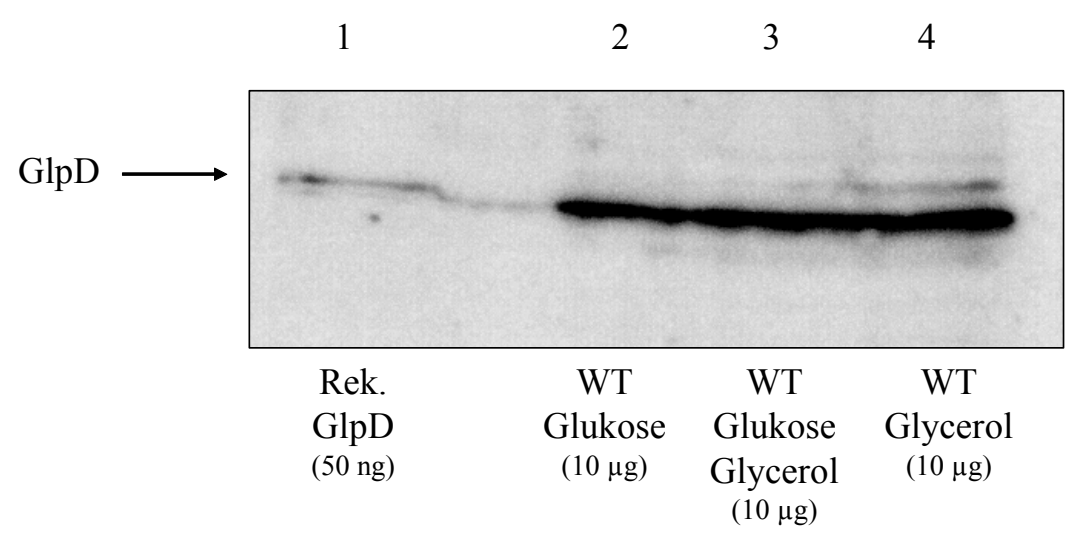

\section{Abb. 4.1. Western Blot mit Proteinextrakten aus M. pneumoniae}

Zur Kontrolle wurden $50 \mathrm{ng}$ rekombinante GlpD aufgetragen (Spur 1). In Spur 2 wurde $10 \mu \mathrm{g}$ Proteinextrakt von WT mit Glukose, in Spur 3 WT mit Glukose und Glycerol und in Spur 4 WT mit Glycerol aufgetragen und in einem 12\% Polyacrylamidgel aufgetrennt. Zur Detektion der Glycerol-3phosphat-Dehydrogenase wurde ein $\alpha$-GlpD-Antikörper verwendet.

\subsubsection{Kann die Glycerol-3-phosphat-Dehydrogenase $\mathrm{NAD}^{+}$reduzieren?}

Mit Hilfe eines Enzymassays sollte die Aktivität des rekombinanten Enzyms His $_{6}-\mathrm{GlpD}$ überprüft werden. Hierzu wurde eine Methode verwendet, die von Deutscher und Sauerwald (1986) beschrieben wurde. Dabei wird die Reduktion von $\mathrm{NAD}^{+}$zu NADH photometrisch $(\lambda=340 \mathrm{~nm})$ verfolgt, wenn die GlpD Glycerol-3-phosphat zu Dihydroxyacetonphosphat umsetzt.

Bei der Negativkontrolle ohne Zugabe der Glycerol-3-phosphat-Dehydrogenase konnte wie erwartet keine Absorptionsänderung festgestellt werden (Abb. 4.2.). Die Zugabe von $4 \mu \mathrm{g}$ GlpD sollte die Umsetzung des Substrats auslösen, wenn NAD $^{+}$zu $\mathrm{NADH}_{2}$ reduziert wird. Hierbei wäre eine Zunahme der Absorption bei einer Wellenlänge von $340 \mathrm{~nm}$ zu erwarten gewesen. Jedoch konnte bei der photometrischen Messung keine Absorptionsänderung festgestellt werden. 


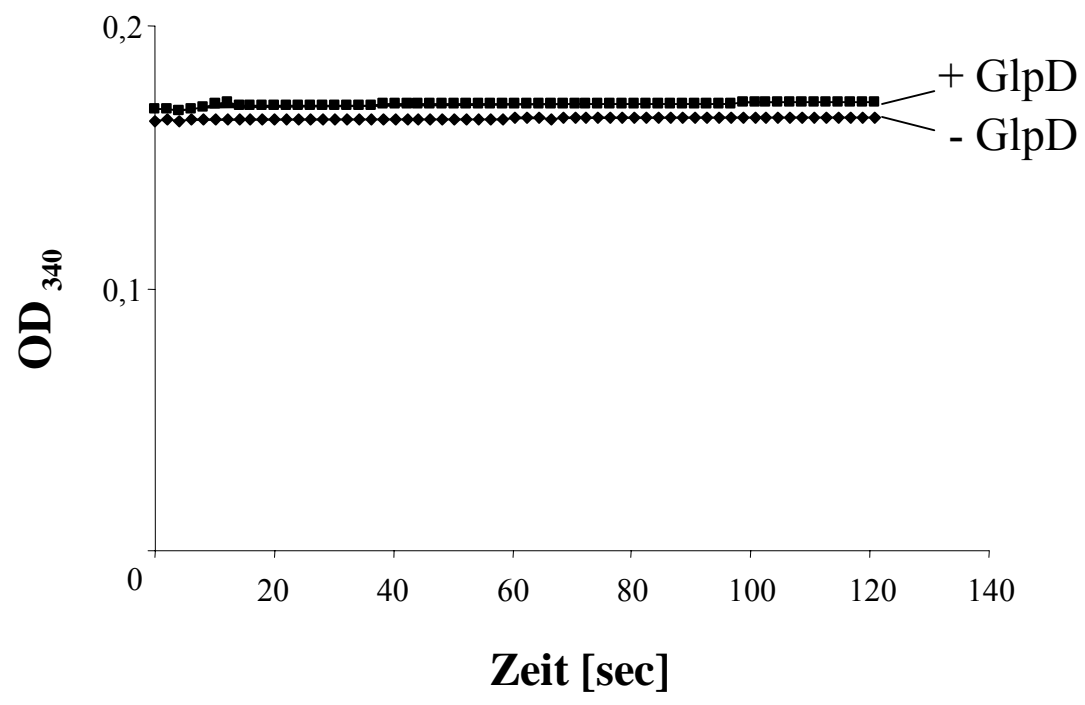

\begin{abstract}
Abb. 4.2. Graphische Darstellung der Messung der Enzymaktivität der Glycerol-3-phosphatDehydrogenase

Die Absorptionsänderung bei einer Wellenlänge von $340 \mathrm{~nm}$ wurde über 2 Minuten verfolgt. Der Enzymassay wurde durch die Zugabe von $4 \mu \mathrm{g}$ Glycerol-3-phosphat-Dehydrogenase gestartet. Als Negativkontrolle wurde kein Enzym zu dem Assay hinzugegeben.
\end{abstract}

Eine mögliche Erklärung wäre, dass das rekombinante Protein durch den angehängten Tag nicht mehr richtig gefaltet ist und damit die Enzymreaktion nicht mehr ablaufen kann. Die andere Möglichkeit wäre, dass das Enzym keine Dehydrogenase sondern eine Oxidase ist, bei der nicht $\mathrm{NAD}^{+}$sondern Sauerstoff als Elektronenakzeptor fungiert. Eine Glycerol-3-phosphat-Oxidase konnte bereits in M.mycoides subsp. mycoides nachgewiesen werden (Pilo et al., 2005).

\title{
4.1.3 Ist glpD aus M. pneumoniae eine Glycerol-3-phosphat-Oxidase?
}

Bei der Umsetzung des Substrats Glycerol-3-phosphat durch die Glycerol-3-phosphatOxidase wird Sauerstoff reduziert und es entsteht Wasserstoffperoxid (Wadher et al., 1990). Das Wasserstoffperoxid kann mit Hilfe eines Enzymassays bestimmt werden.

In diesem Fall wurde die rekombinante His 6 -GlpD zusammen mit dem Substrat Glycerol-3-phosphat für eine Stunde bei $37^{\circ} \mathrm{C}$ inkubiert. Dann gab man die MeerrettichPeroxidase und das Chromogen o-Dianisidin zu dem Ansatz und verfolgte die Absorption bei einer Wellenlänge von $405 \mathrm{~nm}$ über die Zeit. Anschließend konnte die 
Menge an entstandenem Wasserstoffperoxid ermittelt werden, in dem man die Werte anhand einer Standardkurve abgeglichen hat. Die Standardkurve ist in Abbildung 4.3. dargestellt.

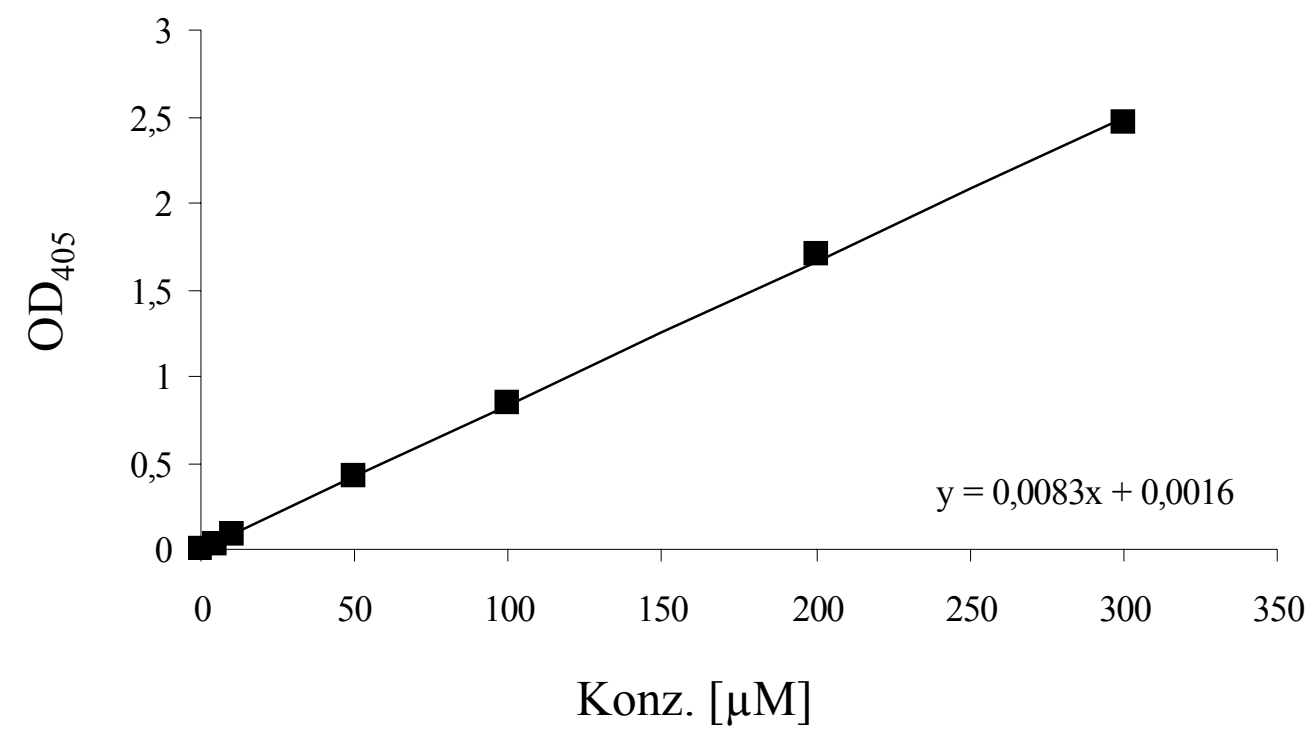

\section{Abb. 4.3. Standardkurve zur photometrischen Bestimmung der Wasserstoffperoxidmenge}

Die Umsetzung von bestimmten Mengen Wasserstoffperoxid durch die Meerrettich-Peroxidase konnte mit dem Photometer bei einer Wellenlänge von $405 \mathrm{~nm}$ durch die Farbreaktion des Chromogens o-Dianisidin bestimmt werden. Es wurde die Absorption von 0, 5, 10, 50, 100, 200 und $300 \mu \mathrm{M} \mathrm{H}_{2} \mathrm{O}_{2}$ (ש) gemessen. Die $\mathrm{OD}_{405}$ wurde gegen die Konzentration des $\mathrm{H}_{2} \mathrm{O}_{2}$ aufgetragen und mit Hilfe einer Trendlinie konnte die Geradengleichung bestimmt werden.

Die Standardkurve wurde mit definierten Mengen $\mathrm{H}_{2} \mathrm{O}_{2}(5,10,50,100,200,300$ $\mu \mathrm{M})$ bestimmt. Die gemessene Absorption bei einer Wellenlänge von $405 \mathrm{~nm}$ wurde gegen die eingesetzte Konzentration von $\mathrm{H}_{2} \mathrm{O}_{2}$ aufgetragen und es konnte eine Geradengleichung anhand der Ausgleichsgeraden ermittelt werden. Man konnte nun mit Hilfe der Gleichung $(\mathrm{x}=(\mathrm{y}-0,0016) / 0,0083)$ das entstandene $\mathrm{H}_{2} \mathrm{O}_{2}(\mathrm{x})$ berechnen, welches bei Einsatz unterschiedlicher Mengen Substrat nach einer Stunde Inkubation bei $37^{\circ} \mathrm{C}$ entstanden ist. Hierzu wurde bei y in der Gleichung die gemessene Absorption bei einer Wellenlänge von $405 \mathrm{~nm}$ eingesetzt und $\mathrm{x}$ berechnet.

Die Messungen der Absorption bei Zugabe von 0,1 und 0,5 mM Glycerol-3phosphat zu der Glycerol-3-phosphat-Dehydrogenase ist in der Abbildung 4.4. dargestellt. Ohne die Zugabe von Substrat verändert sich die Absorption nicht und bleibt konstant (•). Bei der Zugabe von 0,1 mM Glycerol-3-phosphat ( $\mathbf{\Delta}$ ) steigt die gemessene $\mathrm{OD}_{405}$ leicht an und erreicht einen Wert von 0,15 nach 5 Minuten. Dies 
entspricht einer freigesetzten Wasserstoffperoxidmenge von 17,7 $\mu \mathrm{M} \mathrm{H}_{2} \mathrm{O}_{2}$. Die Zugabe von 0,5 mM Substrat (a) bewirkt einen Anstieg der Absorption von 0,8 nach 5 Minuten. Hier wurden 90,1 $\mu \mathrm{M} \mathrm{H}_{2} \mathrm{O}_{2}$ Wasserstoffperoxid freigesetzt.

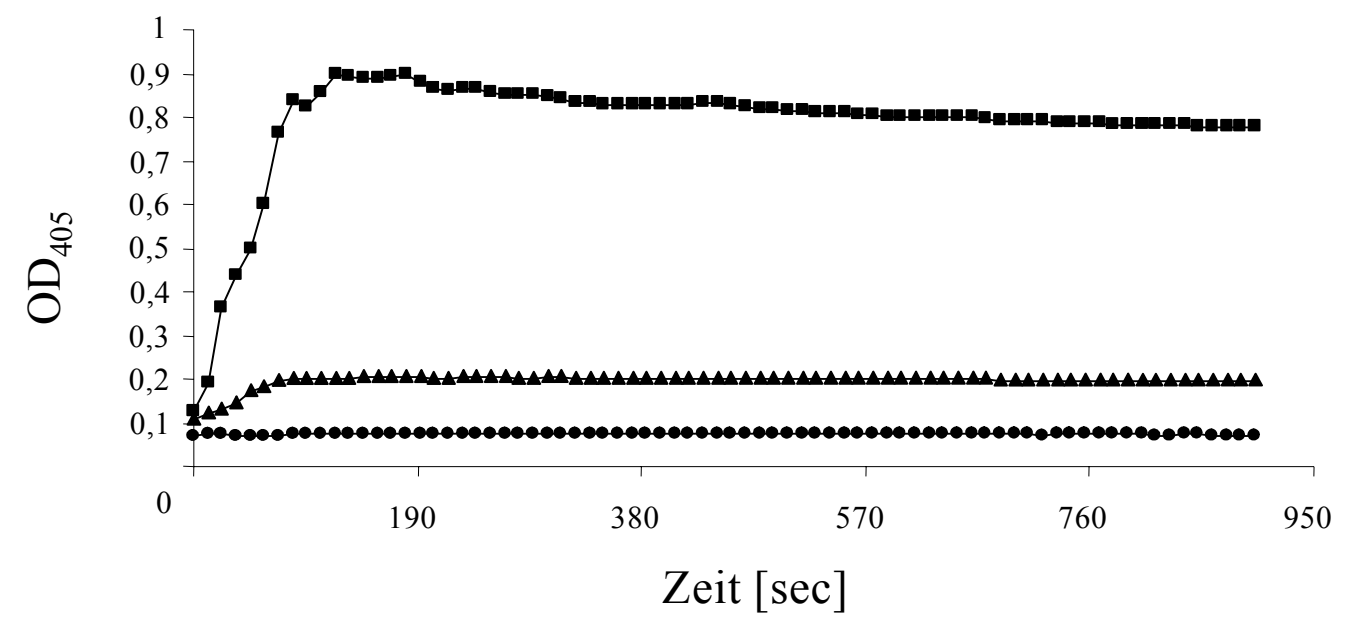

Abb. 4.4. Enzymassay zur Bestimmung der freigesetzten Wasserstoffperoxidmenge durch die rekombinante Glycerol-3-phosphat-Dehydrogenase

Die Glycerol-3-phosphat-Dehydrogenase wurde mit dem Substrat Glycerol-3-phosphat für eine Stunde bei $37^{\circ} \mathrm{C}$ inkubiert. Anschließend konnte durch die Zugabe von der Meerrettich-Peroxidase und dem Chromogen o-Dianisidin die entstandene Menge Wasserstoffperoxid photometrisch bei einer Wellenlänge von $405 \mathrm{~nm}$ bestimmt werden. In der Graphik sind die Daten der Kontrolle ohne Zugabe des Proteins $(\bullet)$, der Zugabe von 0,1 mM Glycerol-3-phosphat ( $\mathbf{\Delta}$ ) und der Zugabe von 0,5 mM Glycerol-3-phosphat (-) dargestellt.

Der Vergleich der entstandenen Wasserstoffperoxidmengen zeigt, dass die freigesetzten Mengen von der eingesetzten Menge Substrat, Glycerol-3-phosphat, abhängig ist. Die Zugabe von 0,5 mM Substrat bewirkt einen ungefähr 5-fach höheren Anstieg der Absorption beziehungsweise der Wasserstoffperoxidmenge gegenüber der Zugabe von 0,1 mM Substrat. Mit Hilfe dieses Versuches konnte gezeigt werden, dass das Gen $g l p D$ für eine Glycerol-3-phosphat-Oxidase kodiert.

\subsubsection{Charakterisierung der GlpO aus M. pneumoniae in B. subtilis}

Es gibt nur sehr wenige genetische Werkzeuge zur Manipulation von M. pneumoniae. Es gibt zum Beispiel keine replikativen Plasmide für diesen Organismus mit welchen man Mutanten komplementieren oder Enzyme näher charakterisieren könnte. Daher 
sollten die Versuche zur Charakterisierung der GlpO aus M. pneumoniae in dem gut untersuchten Gram-positiven Modellorgansimus B. subtilis durchgeführt werden.

Die Glycerol-3-phosphat-Oxidase wurde mit den Primern CH59 und CH60 aus dem Plasmid pGP266 amplifiziert. In diesem Plasmid war das Gen glpD enthalten, bei welchem die UGA-Codons in UGG-Codons mutiert wurden, um eine vollständige Synthese des Proteins in B. subtilis zu gewährleisten. Außerdem wurde mit dem Primer CH59 die Ribosomenbindestelle von gltC aus B. subtilis eingeführt, welche eine Translation des rekombinanten Proteins ermöglicht. Für die Klonierung wurde der Vektor pBQ200 verwendet, ein replikatives Plasmid, welches einen starken Promotor besitzt und somit eine hohe Expression des Gens ermöglicht. Mit den Primern wurden die Schnittstellen BamHI und SalI eingeführt, um das PCR-Fragment mit dem geschnittenen Vektor pBQ200 ligieren zu können. Mit dem Ligationsansatz konnte E. coli DH5 $\alpha$ transformiert werden und die Selektion fand auf LB-Platten mit Kanamycin statt. Das fertige Plasmid bekam nach der Sequenzierung die Bezeichnung pGP267.

Die Versuche sollten in einer $\Delta g l p D$-Mutante von $B$. subtilis durchgeführt werden. Hierzu wurde die LFH-PCR-Methode verwendet. Dabei wird das ganze Gen, in diesem Fall glpD, durch eine Resistenzkassette ersetzt. Daher wurden erstmal strangaufund strangabwärts je 1000 bp des flankierenden Bereichs mit den Primern CH64/CH65 und CH66/CH67 amplifiziert. Den Primern CH65 und CH66 war eine 25 Nukleotide lange Sequenz angehängt, welche komplementär zum 5'- bzw. 3'-Ende der Resistenzkassette ist. Für die Amplifizierung der Spectinomycin-Resistenzkassette wurden die Primer TM0141 und TM0142 und das Plasmid pDG1727 als Template verwendet. Alle drei PCR-Fragmente wurden dann mit Hilfe einer PCR-Reaktion zusammengefügt. Dieses Fragment wurde dann eingesetzt, um den Wildtyp Stamm B. subtilis $168 \mathrm{zu}$ transformieren. Die $\Delta g l p D$-Mutante bekam nach der Sequenzierung der flankierenden Bereiche die Bezeichnung GP60.

Der Wildtyp 168 und die $\Delta g l p D$-Mutante von B. subtilis sollten nun mit dem Plasmid pGP267 transformiert werden, welches ihnen eine Erythromycin/LincomycinResistenz verleihen sollte. Jedoch war es nicht möglich, Transformanten zu isolieren. Zur Kontrolle wurden der Wildtyp und die $\Delta g l p D$-Mutante mit dem Plasmid pBQ200 (Vektor ohne $g l p D$ ) transformiert. Hierbei wurden immer Transformanten erhalten. Das Einbringen des Gens glpD aus M. pneumoniae hatte demnach eine letale Wirkung auf 
den Rezeptorstamm B. subtilis. Obwohl den Platten kein Glycerol zugesetzt wurde, ist es möglich, dass dem Enzym Glycerol-3-phosphat zur Verfügung stand und somit Wasserstoffperoxid freigesetzt wurde. Das entstandene Wasserstoffperoxid könnte die letale Wirkung auf die Bacillen gehabt haben. Somit konnte die Domäne, welche für die $\mathrm{H}_{2} \mathrm{O}_{2}$-Produktion wichtig ist, nicht identifiziert werden.

\subsubsection{Lokalisierung der Glycerol-3-phosphat-Oxidase}

Bei M. mycoides konnte gezeigt werden, dass die Glycerol-3-phosphat-Oxidase (GlpO) an der Cytoplasmamembran lokalisiert ist (Pilo et al., 2005). Die Glycerol-3-phosphatOxidase aus M. pneumoniae übernimmt die gleiche Funktion wie GlpO, nämlich die Umwandlung von Glycerol-3-phosphat zu Dihydroxyacetonphosphat. Es stellte sich die Frage, ob sich das Protein GlpO ebenfalls in der Membran befindet oder ob es im Cytoplasma anzutreffen ist.

Hierzu wurden die Proteinextrakte von $M$. pneumoniae Wildtyp und einer glpD::tn-Mutante (GPM52) in die Cytoplasma-Fraktion und die Membran-Fraktion getrennt. Die gewonnenen Fraktionen wurden mittels Western Blot mit einem $\alpha$-GlpDAntikörper untersucht (Abb. 4.5.).

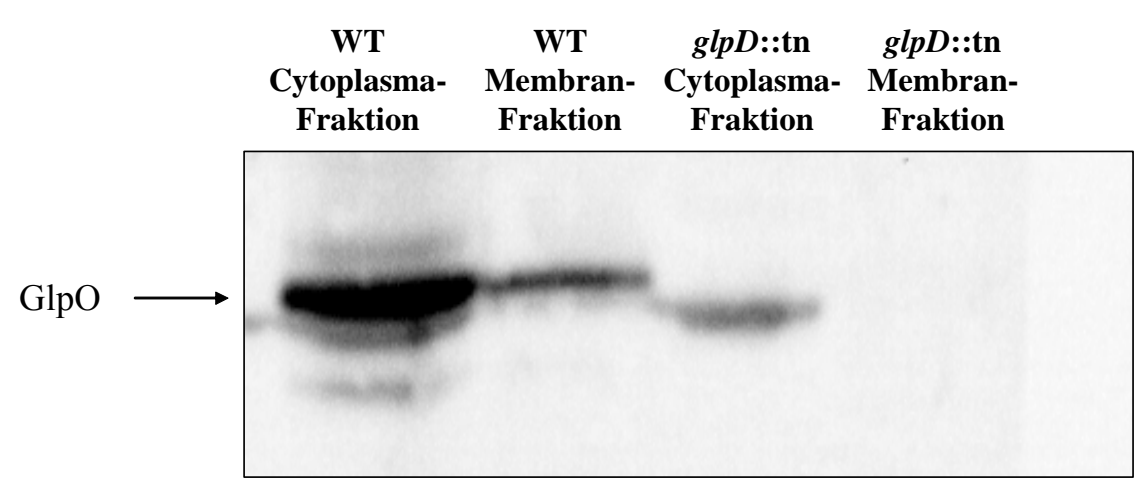

Abb. 4.5. Western Blot von Cytoplasma- und Membran-Fraktionen aus M. pneumoniae WT und einer glpD::tn-Mutante

Das $12 \%$ Polyacrylamidgel wurde wie folgt von links nach rechts beladen: 1 . WT Cytoplasma-Fraktion, 2. WT Membran-Fraktion, 3. glpD::tn-Mutante Cytoplasma-Fraktion, 4. glpD::tn-Mutante MembranFraktion. Der Western Blot wurde mit einem $\alpha$-GlpD-Antikörper durchgeführt.

In M. pneumoniae befindet sich der Großteil der Glycerol-3-phosphat-Oxidase im Cytoplasma und nur wenig Protein kann in der Membran detektiert werden. Mit der Immunfluoreszenzmikrokopie sollte noch mal bestätigt werden, dass die GlpO auch auf 
der Membran zu finden ist. Hierzu wurden der Wildtyp und die glpD::tn-Mutante auf Deckgläschen für eine halbe Stunde inkubiert, damit sie sich anheften können. Anschließend wurden ein $\alpha$-GlpD-Antikörper und danach ein sekundärer FITCgekoppelter Antikörper zu den Zellen gegeben. Im Anschluss konnten die markierten Zellen im Fluoreszenzmikroskop angesehen werden (Abb. 4.6.). Die Pfeile auf den Lichtmikroskopiebildern zeigen auf die Mykoplasmen. Daneben sieht man den gleichen Bildausschnitt in der Fluoreszenzmikroskopie. An den Wildtyp-Zellen hat der $\alpha$-GlpDAntikörper an die Membran gebunden und der sekundäre FITC-gekoppelte Antikörper fluoresziert grün. Man sieht, dass die Fluoreszenz nur dort zu finden ist, wo sich auch Mykoplasmen befinden. Zur Kontrolle wurde der Versuch mit einer glpD::tn-Mutante durchgeführt. Das Protein wird nicht exprimiert und der Antikörper kann demnach nicht binden. Die Auflösung des Mikroskops war zu gering, um eine Aussage darüber zu treffen, wo genau die Antikörper an der Membran gebunden hatten. Für die exakte Lokalisierung des Proteins sollte die Elektronenmikroskopie eingesetzt werden.

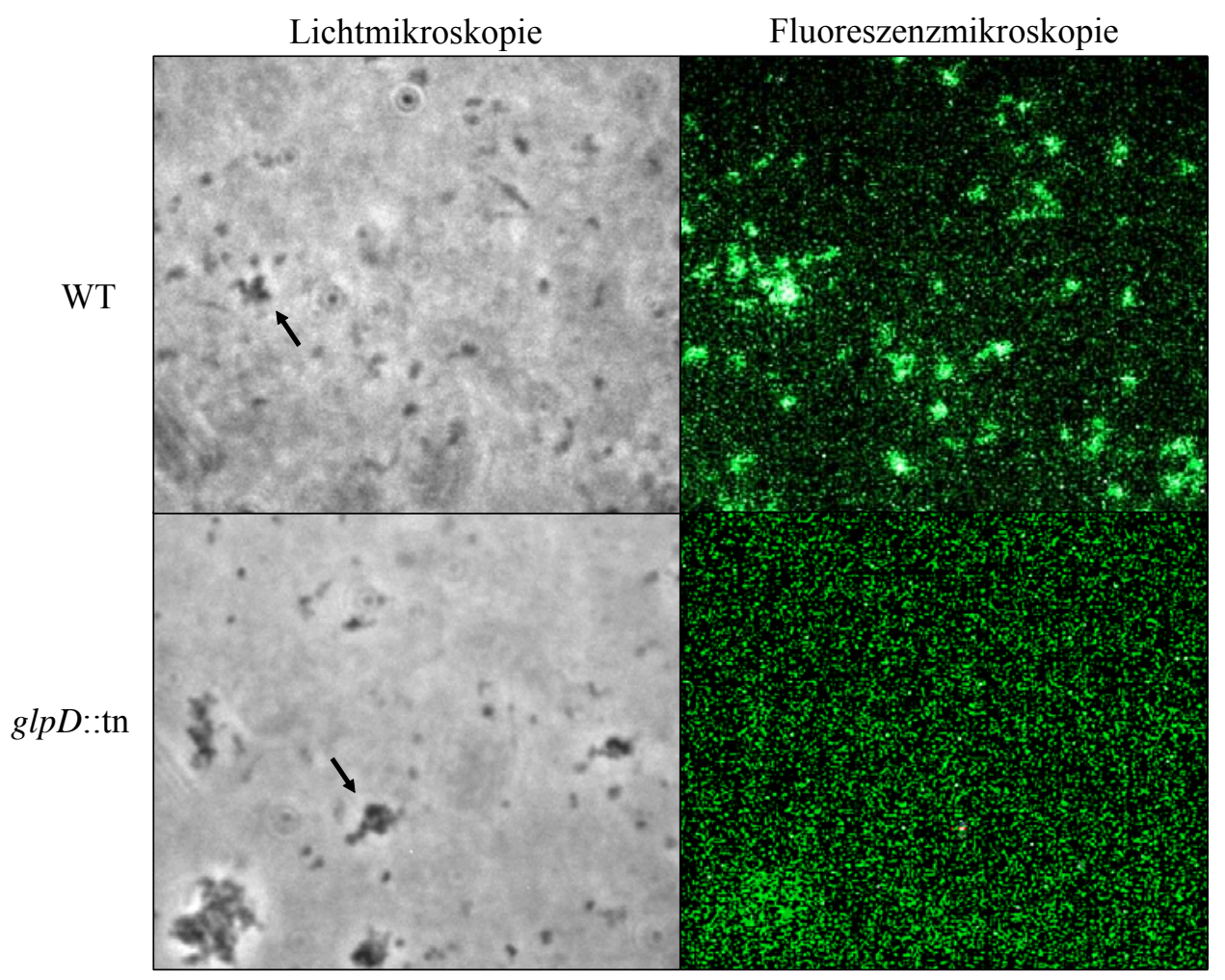

Abb. 4.6. Immunfluoreszenzmikroskopie mit M. pneumoniae WT und glpD::tn-Mutante

In der linken Spalte sind jeweils die Lichtmikroskopieausschnitte gezeigt. In der rechten Spalte sind die gleichen Ausschnitte zu sehen. Hier wurde der Laser eingeschaltet, um das FITC des sekundären 
Antikörpers anzuregen, damit dieses mit in Grün fluoresziert. In der oberen Spalte sind die Ergebnisse des Wildtyps und in der unteren Spalte sind die Ergebnisse der glpD::tn-Mutante dargestellt. Die Pfeile zeigen auf Mykoplasmen.

Die Ergebnisse des Western Blots zeigen, dass die GlpO von M. pneumoniae sowohl im Cytoplasma als auch an der Membran vorhanden ist. Daraus kann man schließen, dass die GlpO von M. mycoides subsp. mycoides SC zwar die gleiche Funktion hat jedoch andere Eigenschaften besitzt, da man dieses Enzym nur in der Membran detektieren kann (Pilo et al., 2005).

Die GlpO von $M$. mycoides subsp. mycoides SC produziert während ihrer katabolen Funktion Wasserstoffperoxid und ist somit ein primärer Pathogenitätsfaktor (Pilo et al., 2005). In Kapitel 4.1.7. wird näher auf die Wasserstoffperoxidproduktion von M. pneumoniae eingegangen. Im Gegensatz zu M. mycoides besitzt M. pneumoniae die so genannte Tip-Struktur, welche diesen Bakterien eine flaschenartige Form verleiht. Mit dieser Struktur, welche aus vielen Adhäsionsproteinen besteht, steht M. pneumoniae in Kontakt mit der eukaryotischen Wirtszelle und kann sich an diesen festsetzen (Wilson und Collier, 1976). Mit Hilfe der Elektronenmikroskopie sollte der Frage nachgegangen werden, ob die GlpO an dieser Tip-Struktur lokalisiert ist und somit das Wasserstoffperoxid direkt an die Wirtszelle abgeben kann.

Bevor mit diesem Versuch begonnen werden konnte, wurden erstmal Kontrollen durchgeführt. Diese sind in Abb. 4.7. aufgeführt. In der Elektronenmikroskopie werden jeweils zwei Antikörper verwendet, ein spezifischer primärer Antikörper für das Protein und ein sekundärer Antikörper, an den ein $5 \mathrm{~nm}$ großer Goldpartikel gekoppelt ist.

Als Negativkontrolle (Abb. 4.7.A) wurde nur der sekundäre Antikörper ( $\alpha$-Rabbit IgG $5 \mathrm{~nm}$ Gold) eingesetzt, um zu sehen, ob dieser unspezifisch an die Mykoplasmen binden kann. Die Antikörper sind nur vereinzelt in der Umgebung der Zelle zu erkennen und binden somit nicht unspezifisch an diese.

Anschließend wurde Positivkontrolle mit dem $\alpha$-P01-Antikörper durchgeführt. P01 ist ein Oberflächenprotein, welches stark exprimiert wird. In den Abbildungen B) und C) ist zu erkennen, dass der Antikörper das Protein spezifisch erkennt und auf der ganzen Zelloberfläche vorhanden ist. Die Abbildung C) ist ein vergrößerter Ausschnitt der Abbildung B), damit man die Goldpartikel besser sehen kann. Da die Negativ- und die Positivkontrollen die erwarteten Ergebnisse geliefert hatten, konnte nun mit der GlpO-Markierung begonnen werden. 
A

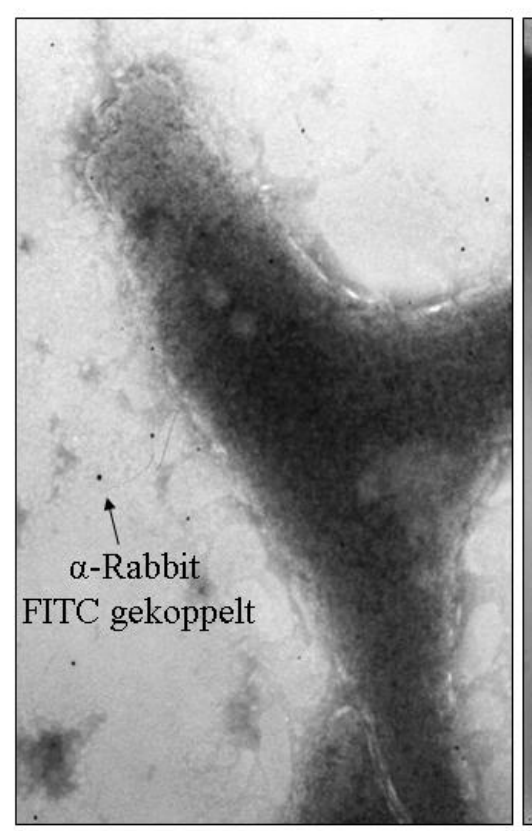

$\mathrm{B}$

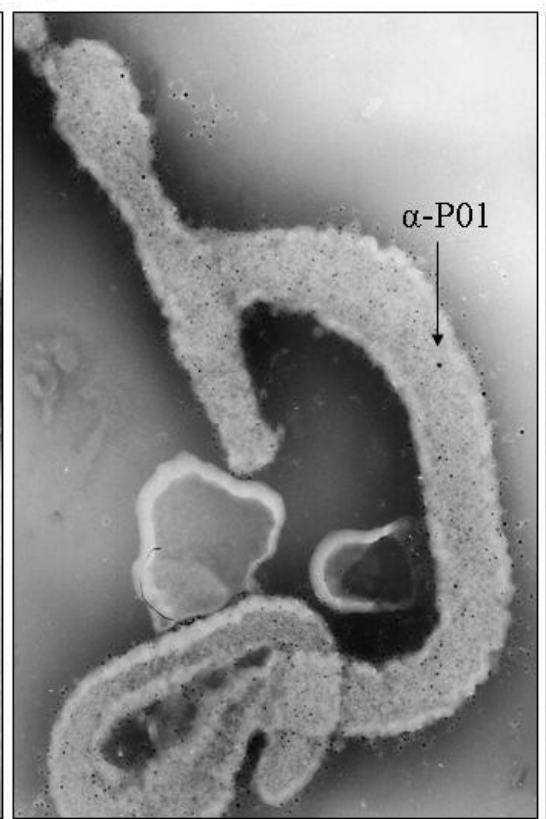

$\mathrm{C}$

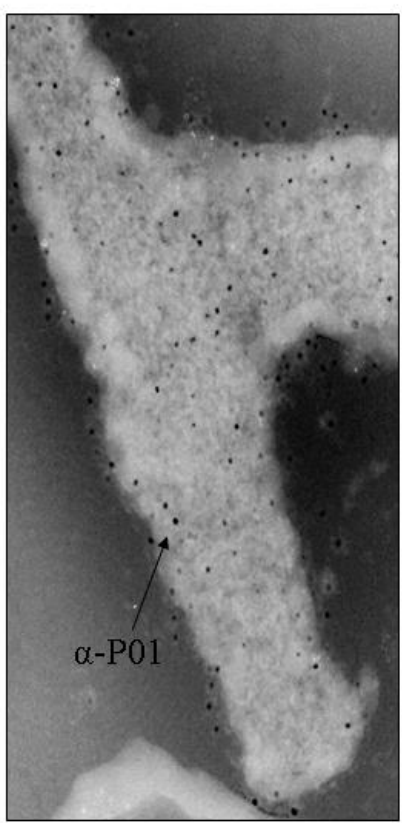

Abb. 4.7. Elektronenmikroskopiebilder von M. pneumoniae mit A) der Negativkontrolle und B), C) der Positivkontrolle

In der Abbildung A), der Negativkontrolle, wurden die Mykoplasmen nur mit den sekundären $\alpha$-Rabbit $5 \mathrm{~nm}$ Gold gekoppelten Antikörpern inkubiert. Ein ungebundener Antikörper wurde mit einem Pfeil markiert. Die Positivkontrollen sind in den Abbildungen B) und C) dargestellt. Hier wurden $\alpha$-P01Antikörper verwendet, welche ein prominentes Oberflächenprotein erkennen. Die spezifisch gebundenen Antikörper wurden mit einem Pfeil markiert. Die Abbildung C) zeigt noch mal einen vergrößerten Ausschnitt aus der Abbildung B).

In der Abbildung 4.8. ist das Ergebnis der GlpO-Markierung zu sehen. Zum Vergleich wurde noch mal die Positivkontrolle mit dem $\alpha$-P01-Antikörper durchgeführt (Abb. 4.8. A). Auf diesem Bild kann man die Tip-Struktur sehr gut erkennen. Der $\alpha$ P01-Antikörper ist wie erwartet über der ganzen Zelle verteilt. Die Markierung der Glycerol-3-phosphat-Oxidase ist in der Abbildung 4.8. B zu sehen. 


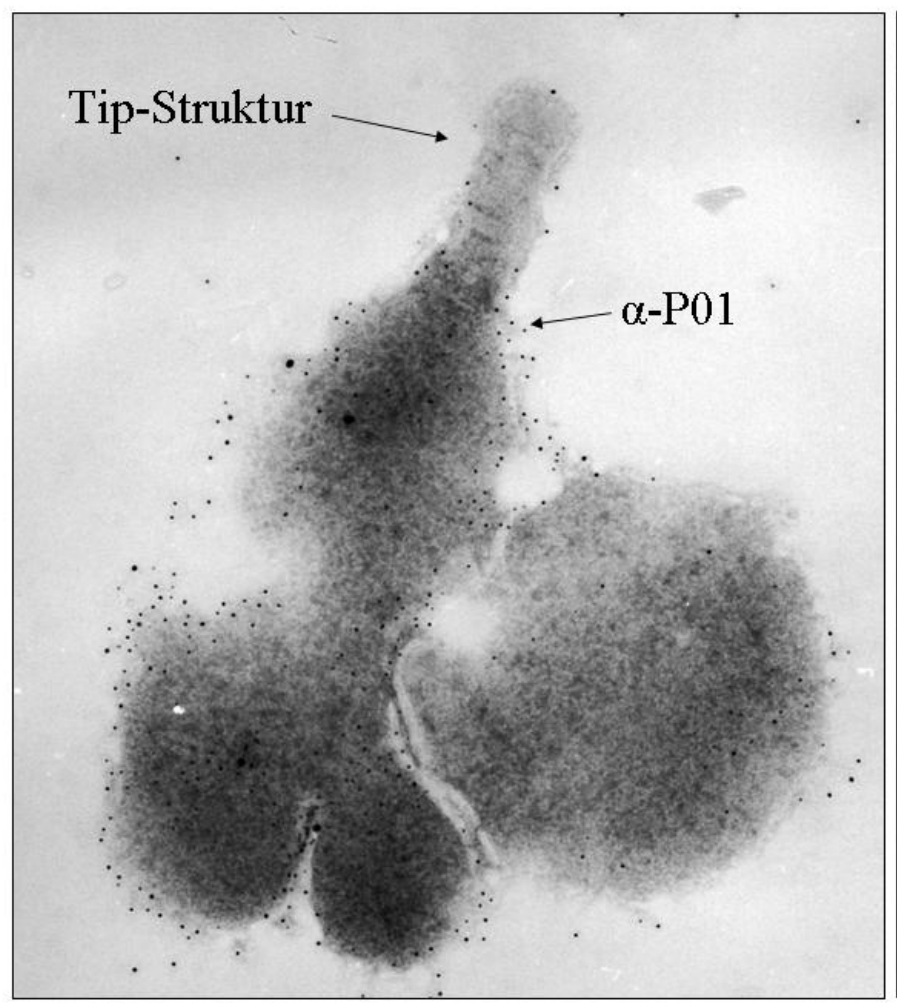

A) P01-Markierung

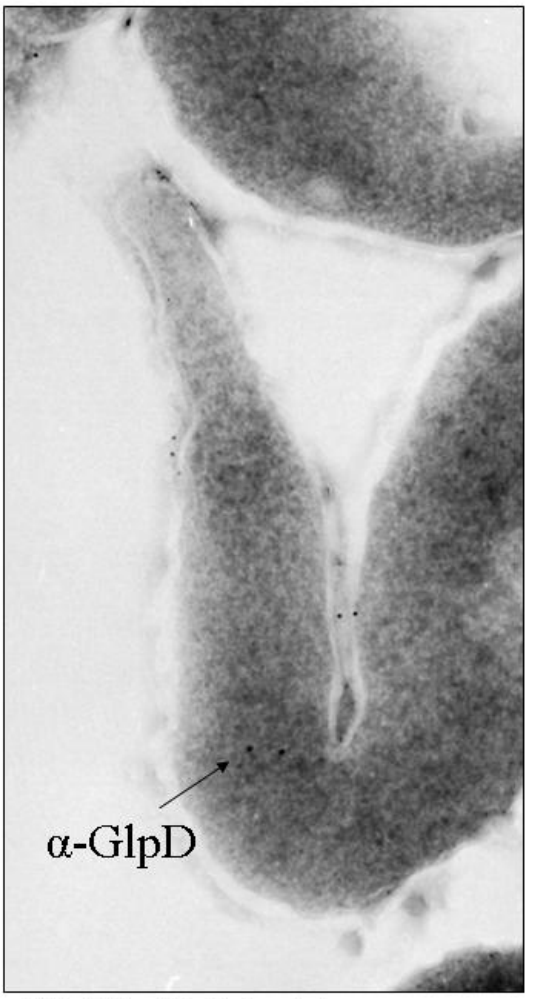

B) GlpO-Markierung

Abb. 4.8. Die Abbildungen A) und B) stellen die P01-Markierung, die Positivkontrolle, und die GlpO-Markierung dar.

In der Abbildung A) wurden die Zellen mit einem $\alpha$-P01-Antikörper (Positivkontrolle) markiert. Zum einen wurde die Tipstruktur, zum anderen ein gebundener $\alpha$-P01-Antikörper, welcher von einem $5 \mathrm{~nm}$ Gold gekoppelten sekundären Antikörper erkannt wurde, mit einem Pfeil hervorgehoben. In der Abbildung B) wurden die Zellen mit einem $\alpha$-GlpD-Antikörper inkubiert und der Pfeil zeigt auf einen gebundenen Antikörper, an dem ein 5 nm Gold gekoppelter sekundärer Antikörper hängt.

Man erkennt nur sehr wenig gebundene Goldpartikel, was darauf hindeutet, dass nur wenig Enzym an der Oberfläche zu finden ist. Dieses Ergebnis stimmt mit der Western Blot Untersuchung überein, wo auch nur wenig Protein in der MembranFraktion detektiert werden konnte. Offensichtlich befindet sich der Großteil der GlpO im Cytoplasma. Die Proteine, die sich in der Membran befinden, sind über die ganze Zelle verteilt. Die Hypothese, dass die Glycerol-3-phosphat-Oxidase an der Tipstruktur konzentriert ist, konnte nicht bestätigt werden. 


\subsubsection{Wachstumsversuche mit der glpD::tn-Mutante GPM52}

Die Isolierung einer $g l p D:$ :tn-Mutante aus einer Transposon-Bank war erfolgreich. Die Transposonmutanten wurden auf MP-Platten mit Glukose und Gentamycin selektiert. Dies zeigt, dass GlpO unter diesen Bedingungen nicht essentiell ist. Die glpD::tnMutante sollte auf ihr Wachstumsverhalten bei Anwesenheit verschiedener Kohlenstoffquellen untersucht werden. Hierzu wurde die Mutante in Gegenwart von Glukose und Glycerol angezogen.

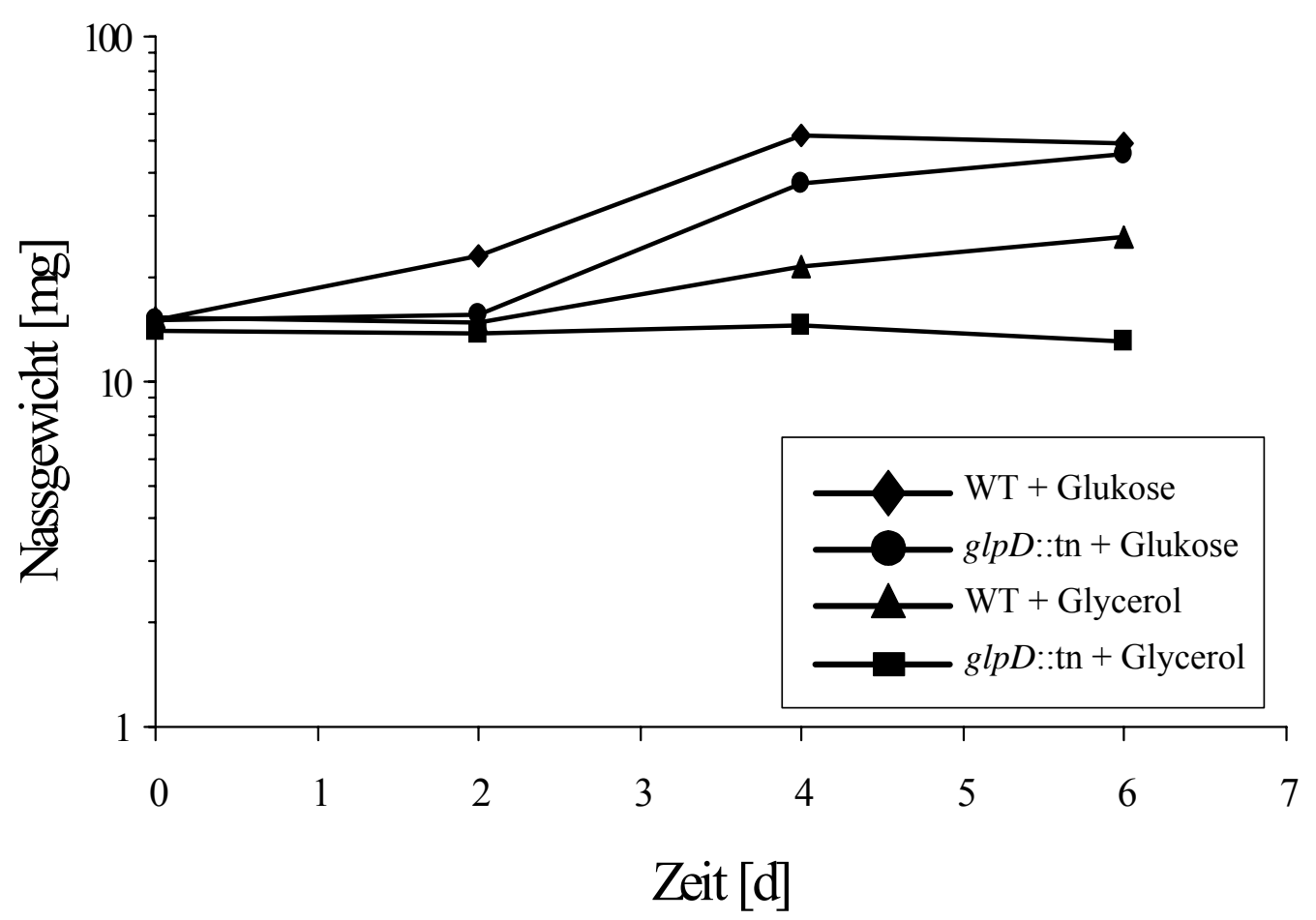

Abb. 4.9. Wachstumskurve des Wildtyps und der glpD::tn-Mutante bei Anwesenheit von Glukose und Glycerol

Der Wildtyp und die glpD::tn-Mutante wurden mit 1\% Glukose oder 1\% Glycerol angezogen. Nach 2, 4 und 6 Tagen wurden die Zellen einer $100 \mathrm{ml}$ Kulturflasche abgeschabt und das Nassgewicht bestimmt. Das Nassgewicht in mg wurde gegen die Zeit in Tagen aufgetragen.

Die Ergebnisse der Wachstumskurve sind in der Abbildung 4.9. dargestellt. In Anwesenheit von Glukose wachsen der Wildtyp und die glpD::tn-Mutante gleich gut und erreichen die größte Zellmasse. Wie bereits beschrieben wurde, stellt Glukose die beste verwertbare Kohlenstoffquelle dar (Halbedel et al., 2004). Bei der Zugabe von Glycerol in das Medium wächst der Wildtyp nur noch halb so schnell wie bei der Zugabe von Glukose. Glycerol kann im Gegensatz zur Glukose, die aktiv über das PTS 
aufgenommen wird, nur durch erleichterte Diffusion in die Zelle gelangen. Dies erklärt, wieso die Zellen mit Glycerol langsamer wachsen. Die glpD::tn-Mutante kann mit Glycerol als C-Quelle nicht mehr wachsen. In Abbildung 4.9. kann man sehen, dass das Nassgewicht sich nach dem Animpfen nicht mehr verändert. Dies zeigt, dass die Transposoninsertion die Funktion der Glycerol-3-phosphat-Oxidase unterbindet. Das Glycerol, welches durch die Glycerol-Kinase zu Glycerol-3-phosphat umgesetzt wird, kann von der GlpO nicht mehr zu Dihydroxyacetonphosphat umgewandelt werden. Somit kann dieses nicht in die Glykolyse weitergeleitet werden, um ATP zu gewinnen.

\subsubsection{Untersuchung der $\mathrm{H}_{2} \mathrm{O}_{2}$-Produktion in $M$. pneumoniae}

In M. mycoides konnte ein Zusammenhang zwischen dem Glycerolstoffwechsel und der Wasserstoffperoxid-Produktion hergestellt werden (Vilei und Frey, 2001). Der hochvirulente M. mycoides subsp. mycoides SC Stamm Afadé ist in der Lage, bis zu 6,5 $\mu \mathrm{g} / \mathrm{ml} \mathrm{H}_{2} \mathrm{O}_{2}$ freizusetzen und somit auch die Wirtszellen zu schädigen (Vilei und Frey, 2001; Pilo et al., 2005). Des Weiteren konnte man die Glycerol-3-phosphat-Oxidase als Wasserstoffperoxid produzierendes Enzym identifizieren.

Es sollte nun in M. pneumoniae überprüft werden, ob die Glycerol-3-phosphatOxidase ebenfalls in der Lage ist, Wasserstoffperoxid frei zu setzen. Hierzu wurde die freigesetzte Menge an Wasserstoffperoxid mit Hilfe von Indikatorstäben in Kulturen gemessen, denen man Glukose oder Glycerol zugesetzt hatte. Zur Kontrolle wurde einer Kultur keine Kohlenstoffquelle zugegeben. Die Versuche wurden mit dem Wildtyp und dem Stamm GPM52 (glpD::tn) durchgeführt.

Die Ergebnisse der $\mathrm{H}_{2} \mathrm{O}_{2}$-Messungen sind in Abbildung 4.10. dargestellt. Ohne CQuelle werden nur 0,5 $\mu \mathrm{g} / \mathrm{ml}$ Wasserstoffperoxid von den beiden Stämmen freigesetzt. Die Zugabe von $100 \mu \mathrm{M}$ Glukose $\mathrm{zu}$ den Zellen bewirkt einen Anstieg der Wasserstoffperoxidmenge auf 1,5-2 $\mu \mathrm{g} / \mathrm{ml}$. Dieses wird wahrscheinlich von der $\mathrm{NADH}_{2}-\mathrm{Oxidase}$ freigesetzt, wenn $\mathrm{NADH}_{2}$ zu NAD ${ }^{+}$umgesetzt wird (Low und Zimkus, 1973). In Kapitel 4.1.9. wird näher auf dieses Enzym eingegangen. 


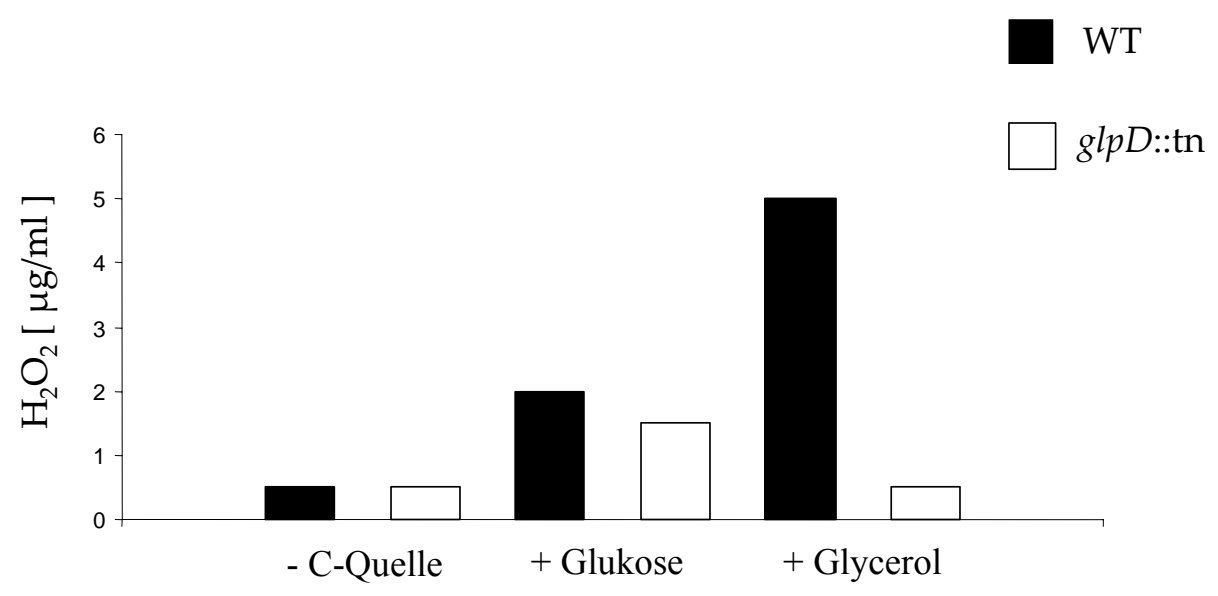

Abb. 4.10. $\mathrm{H}_{2} \mathrm{O}_{2}$-Bestimmung beim Wildtyp und der glpD::tn-Mutante bei Anwesenheit verschiedener C-Quellen

Die schwarzen Balken stellen die Wasserstoffperoxidmenge in $\mu \mathrm{g} / \mathrm{ml}$ da, welche vom Wildtyp freigesetzt wird. Die weißen Balken stellen die freigesetzte Wasserstoffperoxidmenge der glpD::tn-Mutante da. Links wurde den Zellen keine Kohlenstoffquelle, in der Mitte $100 \mu \mathrm{M}$ Glukose und rechts $100 \mu \mathrm{M}$ Glycerol zugesetzt.

Die Zugabe von $100 \mu \mathrm{M}$ Glycerol zu den Wildtyp-Zellen bewirkt einen hohen Anstieg des Wasserstoffperoxids. Hier konnten $5 \mu \mathrm{g} / \mathrm{ml}$ gemessen werden. Dieser Wert kommt sehr nah an die 6,5 $\mu \mathrm{g} / \mathrm{ml}$ des hochvirulenten M. mycoides subsp. mycoides SC Afadé Stamms heran.

Der Stamm GPM52 kann nach der Zugabe von Glycerol nur noch sehr wenig $\mathrm{H}_{2} \mathrm{O}_{2}$ produzieren. Der Wert ist mit der Kontrolle ohne Kohlenstoffquelle zu vergleichen und liegt bei $0,5 \mu \mathrm{g} / \mathrm{ml}$. Der Versuch zeigt, dass das Transposon die Funktion der Glycerol-3-phosphat-Oxidase unterbindet. Des Weiteren konnte bewiesen werden, dass die Gycerol-3-phosphat-Oxidase in Anwesenheit von Glycerol für die hohe Wasserstoffperoxidfreisetzung in den Überstand zuständig ist. Der Glycerolstoffwechsel scheint demnach auch in M. pneumoniae eng mit der Produktion eines Virulenzfaktors zusammen zu hängen.

\subsubsection{Zytotoxizität der glpD::tn-Mutante gegenüber HeLa-Zellen}

Bei M. mycoides subsp. mycoides SC wird die Zytotoxizität herabgesetzt, wenn man mit $\alpha$-GlpO-Antikörpern die Funktion dieses Enzyms inhibiert (Pilo et al., 2005). Mit Hilfe 
von HeLa-Zellkulturen sollte untersucht werden, ob die Transposoninsertion im glpDGen von M. pneumoniae ebenfalls einen Einfluss auf die Zytotoxizität hat.

Die HeLa-Zellen (2,5 x 104) wurden mit 1000000 Mykoplasmen pro HeLa-Zelle inkubiert beziehungsweise infiziert und das Wachstum der HeLa-Zellen wurde über mehrere Tage verfolgt. Die HeLa-Zellen wurden mit einer Kristallviolettlösung fixiert und angefärbt. Anschließend konnte man diese mittels eines inversen Mikroskops fotografieren.

A

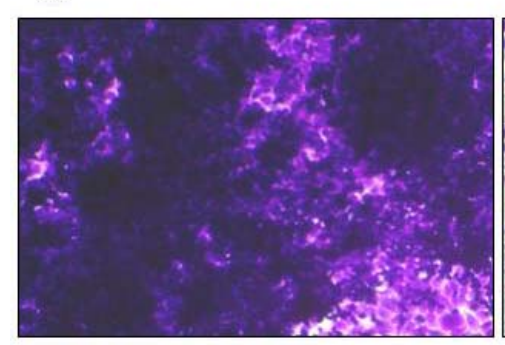

B

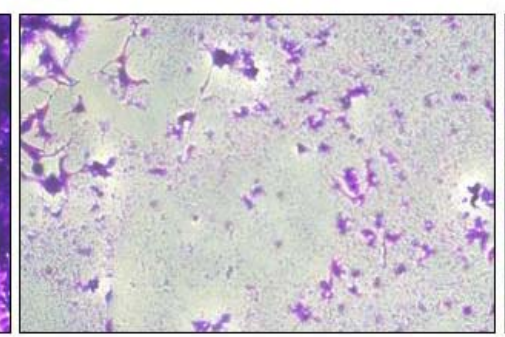

$\mathrm{C}$

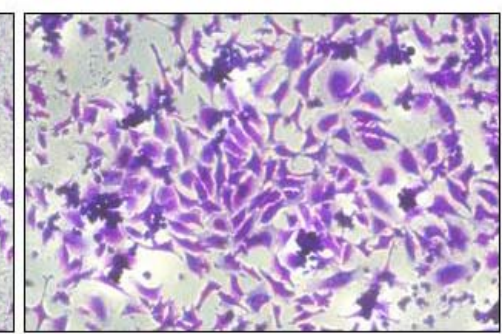

Abb. 4.11. Zytotoxizität von $M$. pneumoniae gegenüber HeLa-Zellen: A) HeLa-Zellen ohne M. pneumoniae; B) HeLa-Zellen mit Wildtyp M. pneumoniae; C) HeLa-Zellen mit glpD::tnMutante

Die HeLa-Zellen wurden am Tag 6 nach der Infektion mit Mykoplasmen mit Kristallviolett angefärbt und fotografiert. In Abbildung A) wurden die Zellen zur Kontrolle ohne Mykoplasmen inkubiert. In Abbildung B) wurden die Zellen mit Wildtyp M. pneumoniae inkubiert und in Abbildung C) wurde die $g l p D:$ :tn-Mutante von M. pneumoniae hinzugegeben.

In der Abbildung 4.11. sind die HeLa-Zellen am Tag 6 nach der Infektion dargestellt. Die Positivkontrolle, das heißt HeLa-Zellen die ohne Mykoplasmen inkubiert wurden, wachsen wie erwartet sehr gut und zu einem dichten Rasen an (Abb. 4.11. A). Die Inkubation der Zellen mit Wildtyp M. pneumoniae bewirkt ein massives Absterben der Wirtszellen (Abb. 4.11. B). Es gibt keine lebenden HeLa-Zellen mehr und es werden nur noch Zellüberreste angefärbt. Dies zeigt, dass die Anwesenheit von Mykoplasmen einen zytotoxischen Effekt auf die eukaryotischen Wirtszellen hat. Die Zytotoxizität gegenüber den HeLa-Zellen nimmt jedoch ab, wenn man diese zusammen mit der $g l p D::$ tn-Mutante inkubiert (Abb. 4.11. C). Diese Mutante ist, wie bereits erwähnt, nicht mehr in der Lage, in Anwesenheit von Glycerol Wasserstoffperoxid freizusetzen. Dies bedeutet, dass einer der primären Virulenzfaktoren, die Glycerol-3phosphat-Oxidase, nicht mehr aktiv ist und somit den HeLa-Zellen weniger Schaden zugefügt werden kann. Obwohl die Zytotoxizität des GPM52 herabgesetzt ist, wachsen 
die HeLa-Zellen nicht so dicht wie bei der Positivkontrolle. Dies gibt einen Hinweis darauf, dass noch andere Virulenzfaktoren für die Zytotoxizität der Mykoplasmen zuständig sind.

\subsubsection{Ist die $\mathrm{NADH} / \mathrm{H}^{+}$-Oxidase in der Lage Wasserstoffperoxid freizusetzen?}

Die Messungen des freigesetzten Wasserstoffperoxids bei der Zugabe von Glukose zu dem Wildtyp und der glpD::tn-Mutante in Kapitel 4.1.7 haben gezeigt, dass noch ein anderes Enzym an in der Lage sein muss, geringe Mengen $\mathrm{H}_{2} \mathrm{O}_{2}$ zu produzieren. Als möglicher Kandidat kam die NADH/ $\mathrm{H}^{+}$-Oxidase in Frage, die für die Regeneration von $\mathrm{NAD}^{+}$zuständig ist und dabei eventuell Wasserstoffperoxid freisetzen kann. Hierzu wurde das Gen nox mit den Primern CH54 und CH58 aus der chromosomalen DNA amplifiziert. Mit Hilfe der MMR wurden die drei internen UGA-Codons mit den Primern CH55, CH56 und CH57 in UGG-Codons mutiert, um eine vollständige Translation des Proteins in E. coli DH5 $\alpha$ zu gewährleisten. Das mutierte PCR-Fragment wurde mit den Schnittstellen SalI und HindIII in den IPTG-induzierbaren Überexpressionsvektor pWH844 kloniert, welcher dem rekombinanten Protein einen Nterminalen His $_{6}$-Tag verleiht. Das Protein Nox konnte schließlich über eine $\mathrm{Ni}^{2+}$-NTASäule aufgereinigt werden und für einen Enzymassay eingesetzt werden. Dieser sollte zeigen, ob das rekombinante Nox enzymatisch aktiv ist.

Für die Bestimmung der Enzymaktivität $\mathrm{NADH}_{2}$-Oxidase wurde die Methode von Hummel und Riebel (2003) verwendet. Hierbei wird der Umsatz von $\mathrm{NADH}_{2}$ zu $\mathrm{NAD}^{+}$durch die $\mathrm{NADH}_{2}$-Oxidase gemessen. Die Abnahme der Absorption bei der Bildung von $\mathrm{NAD}^{+}$kann photometrisch bei einer Wellenlänge von $360 \mathrm{~nm}$ bestimmt werden. In einer Küvette wurden $0,1 \mathrm{mM} \mathrm{NADH} \mathrm{N}_{2}$ und $100 \mathrm{mM}$ Kalium-PhosphatPuffer pH7,5 gemischt und der Enzymassay durch die Zugabe von $5 \mu \mathrm{g} \mathrm{NADH}_{2}$ Oxidase in einem Endvolumen von $1000 \mu 1$ gestartet. Anschließend wurde die Absorptionsänderung wurde für $2 \mathrm{~min}$ bei $360 \mathrm{~nm}$ gemessen (Abb. 4.12.). 


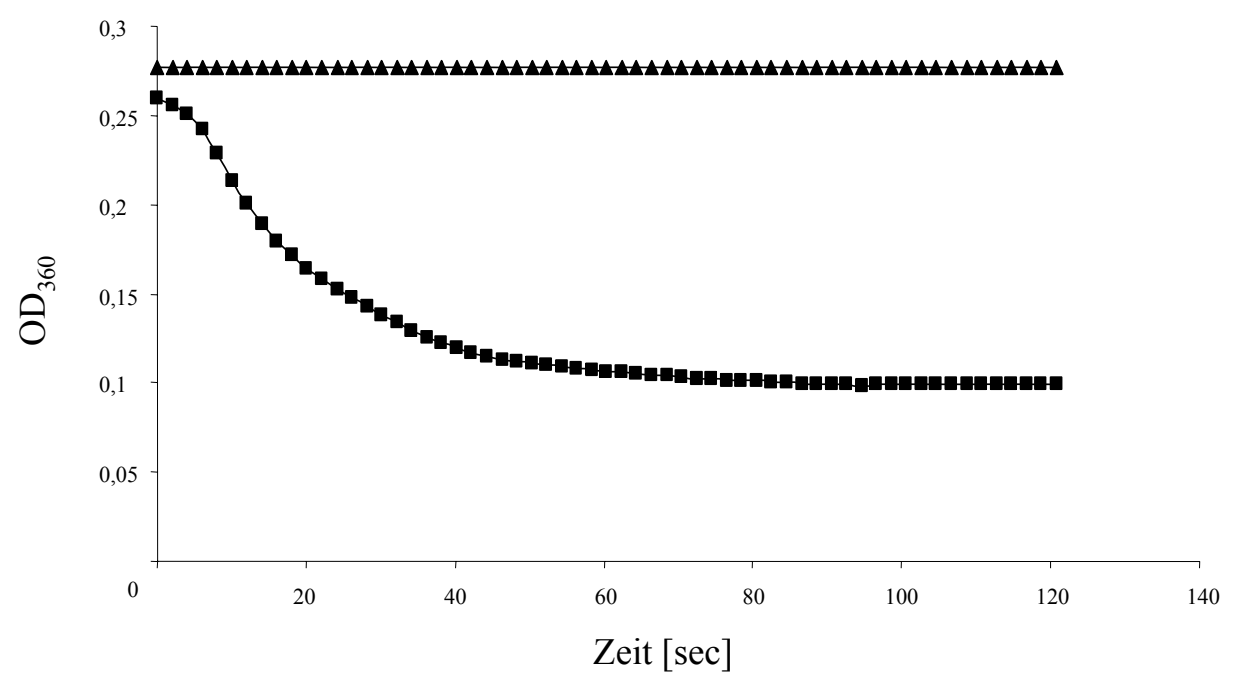

Abb. 4.12. Graphische Darstellung der photometrischen Bestimmung der Enzymaktivität der $\mathrm{NADH}_{2}$-Oxidase

Die Absorptionsänderung bei einer Wellenlänge von $360 \mathrm{~nm}$ wurde über 2 Minuten verfolgt. Der Enzymassay wurde durch die Zugabe von $5 \mu \mathrm{g} \mathrm{NADH}_{2}$-Oxidase zu $0,1 \mathrm{mM} \mathrm{NADH} \mathrm{N}_{2}$ und $100 \mathrm{mM}$ Kalium-Phosphat-Puffer pH7,5 gestartet (a). Als Negativkontrolle wurde kein Enzym zu dem Assay hinzugegeben $(\boldsymbol{\Delta})$.

Mit Hilfe der Absorptionsänderung konnte die spezifische Aktivität 4,7 U/mg des Enzyms Nox bestimmt werden. Der Enzymassay hat gezeigt, dass das rekombinante Protein aktiv ist. Es sollte nun, wie auch schon für die GlpO, gezeigt werden, dass die $\mathrm{NADH}_{2}$-Oxidase ebenfalls in der Lage ist, in Anwesenheit von Glukose Wasserstoffperoxid freizusetzen.

Hierzu wurde wieder der gleiche Assay verwendet wie bereits in Kapitel 4.1.3. beschrieben. Die $\mathrm{NADH}_{2}$-Oxidase wurde für eine Stunde bei $37^{\circ} \mathrm{C}$ mit dem Substrat $\mathrm{NADH}_{2}$ inkubiert und die Messung erfolgte nach der Zugabe der MeerrettichPeroxidase und des Chromogens o-Dianisidin. Es konnte jedoch keine Absorptionsänderung gemessen werden, was bedeutet, dass unter diesen Bedingungen kein Wasserstoffperoxid entstanden ist. Dies könnte daran liegen, dass die Nox nicht wie erwartet Sauerstoff zu Wasserstoffperoxid sondern zu Wasser reduziert. Man kann jedoch das Wasser, welches bei der Reduktion von Sauerstoff entsteht, nicht im Assay nachweisen. Da das Enzym Nox unter den oben genannten Bedingungen enzymatisch aktiv ist, kann eigentlich ausgeschlossen werden, dass der Assay zum Nachweis von Wasserstoffperoxid unter diesen Bedingungen nicht funktioniert. 
Folglich kann die gemessene Menge Wasserstoffperoxid nach der Zugabe von Glukose eventuell von einem anderen, bisher nicht charakterisierten Enzym freigesetzt werden.

Um die Frage $\mathrm{zu}$ klären, ob Nox aus $M$. pneumoniae für die Wasserstoffperoxidproduktion in Anwesenheit von Glukose zuständig ist, sollte eine Mutante isoliert werden. Hierzu wurde die Transposonmutantenbank (Halbedel et al., 2006) mit spezifischen Primern für nox gescreent (Halbedel, Doktorarbeit). Es konnte jedoch keine Transposoninsertion in diesem Gen gefunden werden, was darauf hindeutet, dass dieses Gen in M. pneumoniae essentiell ist. 


\subsection{Untersuchung der Zytotoxizität von verschiedenen Transposonmutanten von M. pneumoniae}

\subsubsection{Isolierung der mpn372::tn-Mutante}

Das Gen mpn372 kodiert für ein ADP-ribosylierendes und vakuolisierendes Zytotoxin (Kannan und Baseman, 2006). Es konnte gezeigt werden, dass das rekombinante Protein einen zytotoxischen Effekt auf CHO-Zellen (Zellen aus den Ovarien chinesischer Hamster) und das Trachealepithelium von Pavianen hat.

Es sollte nun untersucht werden, ob bei einer mpn372::tn-Mutante der zytotoxische Effekt gegenüber HeLa-Zellen verloren geht. Hierzu musste erstmal die Mutante aus der Transposonbank isoliert werden. Die Primer CH61/SH29 und CH62/SH30 wurden zum Screening der Transposonbank mittels PCR verwendet. Es konnte eine Mutante isoliert werden, welche ein Transposon an der Position 522 bp integriert hat. Die schematische Darstellung der Transposoninsertion ist in Abb. 4.13. dargestellt.

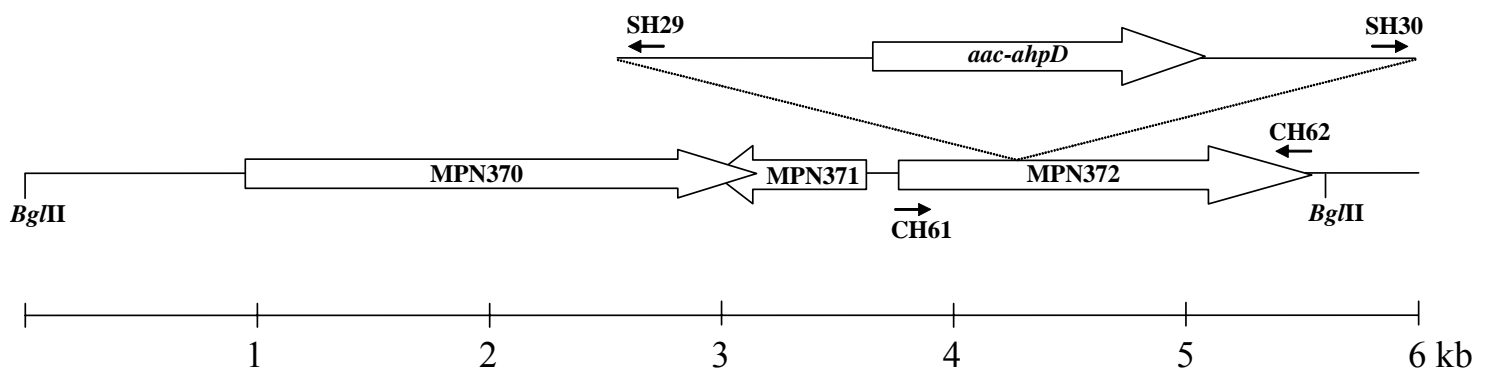

Abb. 4.13. Schematische Darstellung der Transposoninsertion in mpn372 im genetischen Hintergrund

Die Darstellung der Transposoninsertion ist maßstabsgetreu. Die für das Screening verwendeten Primer sind abgebildet sowie die Restriktionsstellen für das Enzym BglII, welche für den Verdau der chromosomalen DNA für den Southern Blot verwendet wurden.

Nach der Isolierung der Mutante musste überprüft werden, ob es sich um eine reine Kultur handelt und ob das Transposon nur einmal im Genom vorhanden ist. Dazu musste die chromosomale DNA nach geeigneten Schnittstellen durchsucht werden, um beim Southern Blot einen Unterschied zwischen WT und Mutante feststellen zu können. Das Restriktionsenzym BglII wurde für den Verdau der DNA eingesetzt (Abb. 4.13.). 
Beim Southern Blot wurden zwei unterschiedliche Sonden verwendet, zum einen eine Sonde gegen die Gentamycin-Kassette, zum anderen eine Sonde gegen mpn372. Das Ergebnis des Southern Blots ist in der Abbildung 4.14. dargestellt.

A

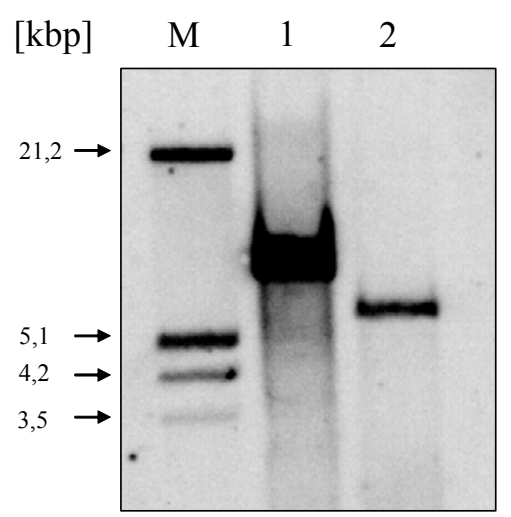

B

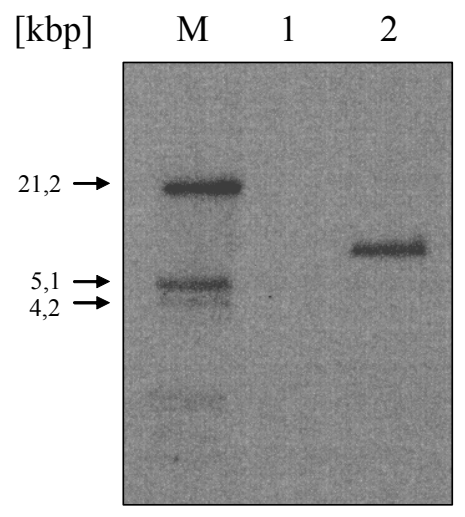

Abb. 4.14. Southern Blot mit einer Sonde gegen mpn372 (A) und gegen die Gentamycin-Kassette (B)

In der Abb. A wurde in Spur 1 die BglII-geschnittene chrom. DNA der Mutante und in Spur 2 des Wildtyps aufgetragen. Hier wurde die Sonde gegen mpn372 verwendet. Das detektierte Fragment in der Mutante ist durch die Integration des Transposons um 3,5 kb größer als das Fragment des Wildtyps. In der Abb. B wurde in Spur 1 die BglII-geschnittene chrom. DNA des Wildtyps und in Spur 2 der Mutante aufgetragen. Es wurde eine Sonde gegen die Gentamycin-Kassette verwendet. In Spur 1 konnte kein Signal detektiert werden und in Spur 2 wurde nur eine Bande sichtbar.

Mit der mpn372-Sonde konnte gezeigt werden, dass die Integration des Transposons in das Gen mpn372 erfolgreich war. Sie bewirkt einen Bandenshift im Southern Blot, da sich durch das Transposon die Größe des DNA-Fragmentes um ungefähr 3,5 kb verändert (Abb. 4.14. A Spur 1). Außerdem konnte mit der Sonde gegen die Gentamycin-Kassette gezeigt werden, dass das Transposon nur einmal in das Genom integriert wurde (Abb. 4.14. B Spur 2). Die mpn372::tn-Mutante erhielt die Bezeichnung GPM8. 


\subsubsection{Zytotoxischer Effekt der mpn372::tn-Mutante (GPM8)}

Nach der erfolgreichen Isolierung einer Mutante, welche das Gen mpn372 nicht mehr vollständig exprimieren kann, konnte nun der zytotoxische Effekt auf HeLa-Zellen untersucht werden.

Zuerst wurden die HeLa-Zellen mit 2,5 x $10^{4}$ Zellen pro Well in eine 24-WellPlatte in $700 \mu 1$ DMEM-Medium pipettiert. Die Platte wurde dann für 24 Stunden in dem $\mathrm{CO}_{2}$-Inkubator bei $37^{\circ} \mathrm{C}$ inkubiert. Am nächsten Tag wurden die Mykoplasmen (WT und GPM8) geerntet und durch Waschen mit einem Puffer von dem MP-Medium befreit. Anschließend wurde die Absorption bei einer Wellenlänge von $550 \mathrm{~nm}$ bestimmt. Die HeLa-Zellen wurden dann mit 0,1 OD-Einheiten infiziert. Nach zwei Stunden Inkubation wurde der Überstand aus den Wells entnommen und somit auch alle Mykoplasmen, die sich nicht angehaftet haben. Den Zellen wurde daraufhin frisches DMEM-Medium zugegeben und für maximal sieben Tage im $\mathrm{CO}_{2}$-Inkubator bei $37^{\circ} \mathrm{C}$ inkubiert. Ab dem zweiten Tag nach der Infektion wurden die HeLa-Zellen jeweils eines Wells mit Kristallviolett fixiert und unter einem Mikroskop fotografiert. Zu jeder Versuchsreihe wurden als Kontrolle nicht infizierte sowie mit dem M. pneumoniae Wildtyp infizierte HeLa-Zellen mitgeführt.

A

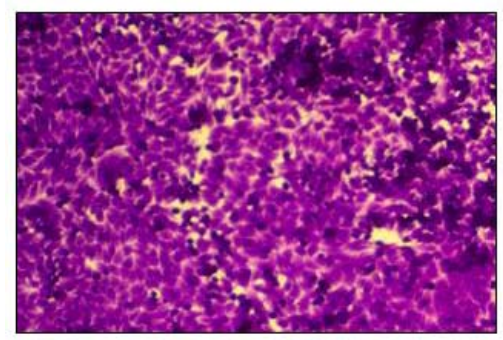

B

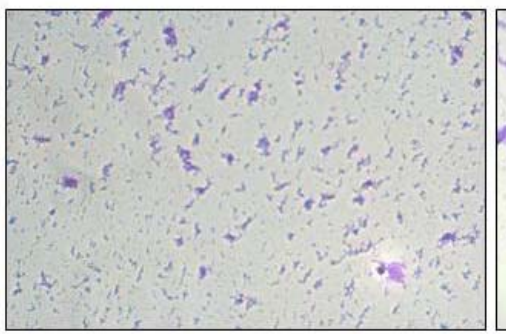

$\mathrm{C}$

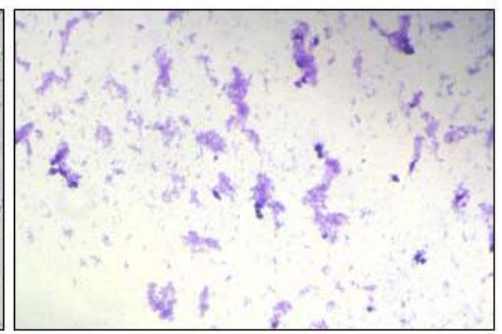

Abb. 4.15. Zytotoxizität von $M$. pneumoniae gegenüber HeLa-Zellen: A) HeLa-Zellen ohne M. pneumoniae; B) HeLa-Zellen mit Wildtyp M. pneumoniae; C) HeLa-Zellen mit der mpn372::tnMutante

In der Abb. 4.15. sind die fixierten Zellen nach 6 Tagen Inkubation mit den Mykoplasmen zu sehen. Es wird deutlich, dass der zytotoxische Effekt gegenüber dem Wildtyp nicht vermindert ist. Die HeLa-Zellen sind sowohl bei Anwesenheit des Wildtyps als auch bei Anwesenheit der Mutante GPM8 vollständig lysiert (Abb. 4.15. B 
und C). Man sieht nur noch vereinzelt Zelltrümmer. Die Kontrolle hingegen ist wie erwartet zu einem dichten Zellrasen gewachsen (Abb. 4.15. A).

Dieser Versuch lieferte nicht das erwartete Ergebnis. Die Unterbrechung des Gens mpn372 ab der Base 522 führt zu keinem verminderten zytotoxischen Effekt der Mutante GPM8 gegenüber den HeLa-Zellen. Es könnte demnach sein, dass die ersten 500 Basen des Proteins vor dem Transposon ausreichen, um die Funktionalität beziehungsweise die Zytotoxizität zu gewährleisten.

Es besteht auch die Möglichkeit, dass es ein weiteres Cytotoxin gibt oder der Effekt des Wasserstoffperoxids zu stark ist und daher kaum ein Unterschied zu dem Wildtyp festzustellen ist.

\subsubsection{Zytotoxischer Effekt der mpn474::tn-Mutante (GPM70) und der Idh::tn- Mutante (GPM69)}

Da die Mutanten des Gens mpn474 und der Laktatdehydrogenase zur Verfügung standen, sollten sie ebenfalls auf ihre Zytotoxizität untersucht werden.
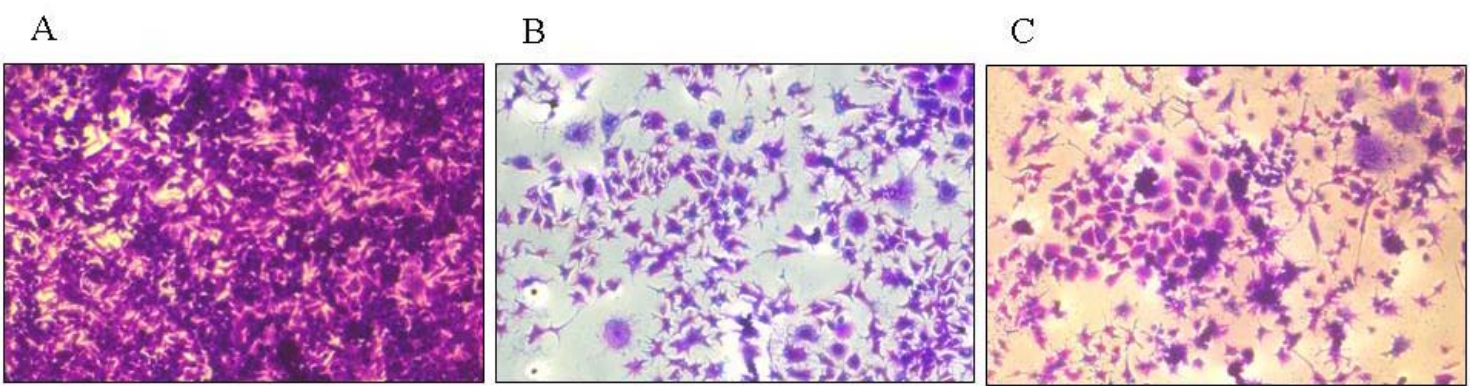

Abb. 4.16. Zytotoxizität von $M$. pneumoniae gegenüber HeLa-Zellen: A) HeLa-Zellen ohne M. pneumoniae; B) HeLa-Zellen mit Wildtyp M. pneumoniae; C) HeLa-Zellen mit der mpn474::tnMutante

Das Gen mpn474 kodiert für ein putatives Strukturgen und ist bisher nicht untersucht. Die Abbildung 4.16. zeigt die Ergebnisse des Versuches und man kann feststellen, dass die Transposoninsertion in mpn474 keinen Einfluss auf die Zytotoxizität hat. Dieser Stamm GPM70 verhält sich genauso wie der Wildtyp.

Dies gibt einen Hinweis darauf, dass das Protein MPN474 nicht notwendig ist, um den Kontakt zwischen der Wirtszelle und den Mykoplasmen herzustellen. Man kann daher nicht voraussagen, welche Rolle MPN474 in M. pneumoniae spielt. 
Die Laktatdehydrogenase ermöglicht den Mykoplasmen bei Anwesenheit von Glycerol durch die Reduktion von Pyruvat Laktat zu gewinnen und dabei wieder den $\mathrm{NAD}^{+}$-Pool für die Glykolyse neu aufzufüllen (Neimark und Lemecke, 1972). In Anwesenheit von Glukose wird das Pyruvat zu Acetat abgebaut, wobei noch zwei weitere ATP-Moleküle gewonnen werden können. In dem Fall wird NAD ${ }^{+}$durch die $\mathrm{NADH}_{2}$-Oxidase zurück gewonnen.

Es sollte untersucht werden, ob eine Transposoninsertion in $l d h$, einem Stoffwechselgen, einen Einfluss auf die Zytotoxizität hat. In der Abbildung 4.17. sind die Ergebnisse dargestellt.

A

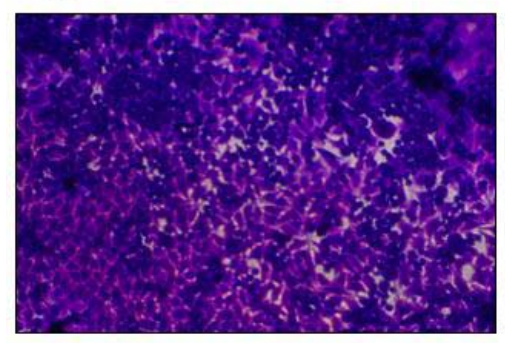

B

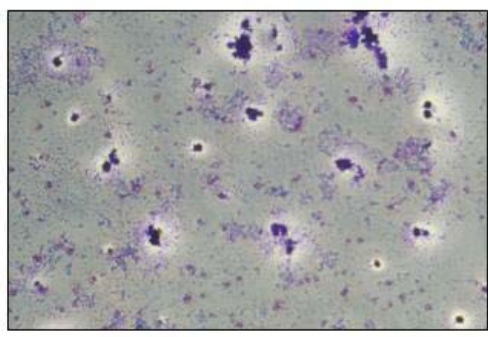

$\mathrm{C}$

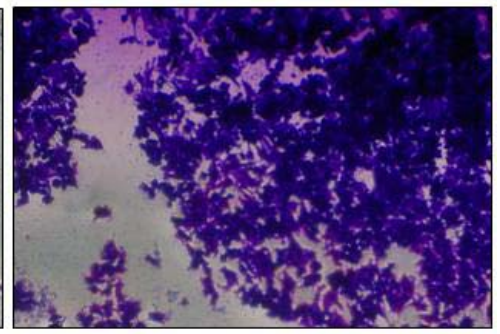

Abb. 4.17. Zytotoxizität von M. pneumoniae gegenüber HeLa-Zellen: A) HeLa-Zellen ohne M. pneumoniae; B) HeLa-Zellen mit Wildtyp M. pneumoniae; C) HeLa-Zellen mit der Idh::tnMutante

Wenn man die Ergebnisse der Inkubation mit dem Wildtyp und mit der ldh::tnMutante vergleicht, wird deutlich, dass die Zytotoxizität der Mutante deutlich herabgesetzt ist. Beim Wildtyp sind die HeLa-Zellen abgestorben (Abb. 4.17. B) wohingegen bei Anwesenheit der Mutante die HeLa-Zellen (Abb. 4.17. C) noch ein deutlicher Wachstum zu vermerken ist. Jedoch ist die Zahl der HeLa-Zellen geringer als bei den Kontrollzellen (Abb. 4.17. A).

Die Unterschiede in der Zytotoxizität rühren wahrscheinlich daher, dass die Mutante in ihrem Wachstum beeinträchtigt ist und sich deshalb der Effekt auf die HeLaZellen verzögert. Man kann schon erkennen, dass die Lyse der HeLa-Zellen langsam anfängt (Abb. 4.17. C). Es ist eher unwahrscheinlich, dass die Laktatdehydrogenase ein Pathogenitätsfaktor ist oder dass sie eine regulatorische Funktion übernimmt. 


\subsubsection{Isolierung der thyA::tn-Mutante}

Bei M. pneumoniae fehlen viele Gene für die Nukleotidsynthese. Sie verhalten sich wie Parasiten und erhalten die Nukleotide oder deren Vorstufen von den Wirtszellen beziehungsweise aus dem Medium. Die Desoxythymidin 5'-monophosphat (dTMP) Synthese erfolgt in Bakterien entweder de novo über eine Thymidylatsynthaseabhängige Methylierung von dUMP oder mit Hilfe der Thymidinkinase, welche Thymidinkomponenten aus dem Medium verwendet (Neuhard und Kelln, 1996).

Die Sequenzierung des Genoms von $M$. pneumoniae ermöglichte die Identifizierung einer Thymidylatsynthase thyA. Die Transposonmutantenbank wurde nach einer thyA::tn-Mutante durchsucht. Hierzu wurden die Primer CH69/SH29 und CH70/SH30 verwendet (Abb. 4.18.).

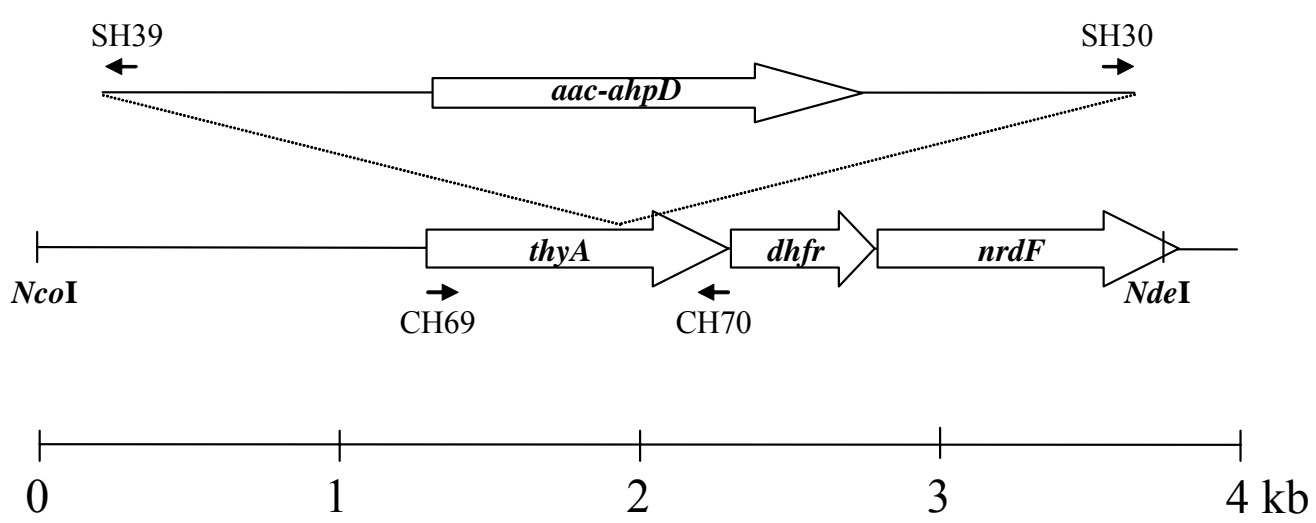

\section{Abb. 4.18. Schematische Darstellung der Transposoninsertion in thy $A$ im genetischen Hintergrund}

Die Darstellung der Transposoninsertion ist maßstabsgetreu. Die für das Screening verwendeten Primer sind abgebildet sowie die Restriktionsstellen für die Enzyme NcoI und NdeI, welche für den Verdau der chromosomalen DNA für den Southern Blot verwendet wurden.

Nach der erfolgreichen Isolierung der Mutante wurde durch Sequenzierung die Position des Transposons bestimmt. Die Insertion erfolgte an der Base 653. Dies sollte gewährleisten, dass die Funktion der Thymidylatsynthase beeinträchtigt ist.

Anschließend wurde ein Southern Blot durchgeführt mit einer Sonde gegen thyA und gegen die Gentamycin-Kassette (aac-ahpD). Hierzu wurde die chromosomale DNA mit den Restriktionsenzymen NcoI und NdeI verdaut (Abb. 4.18.). Der Southern Blot ist in Abbildung 4.19. dargestellt. 
A

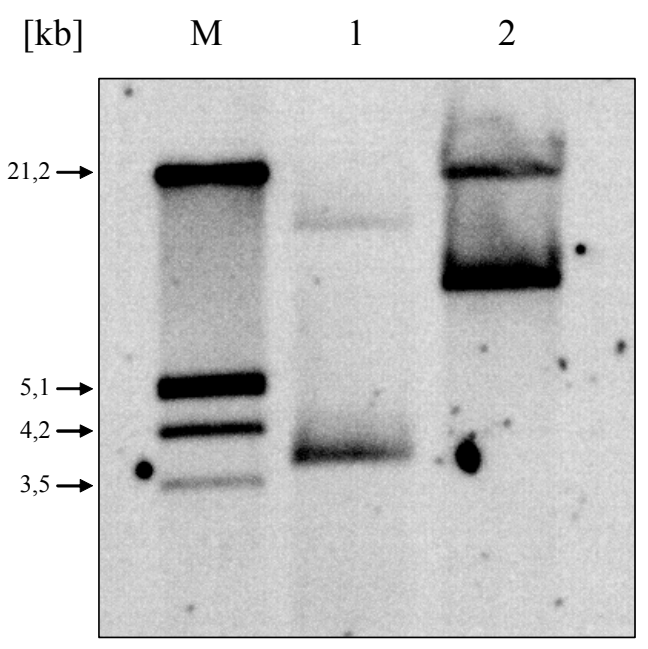

B

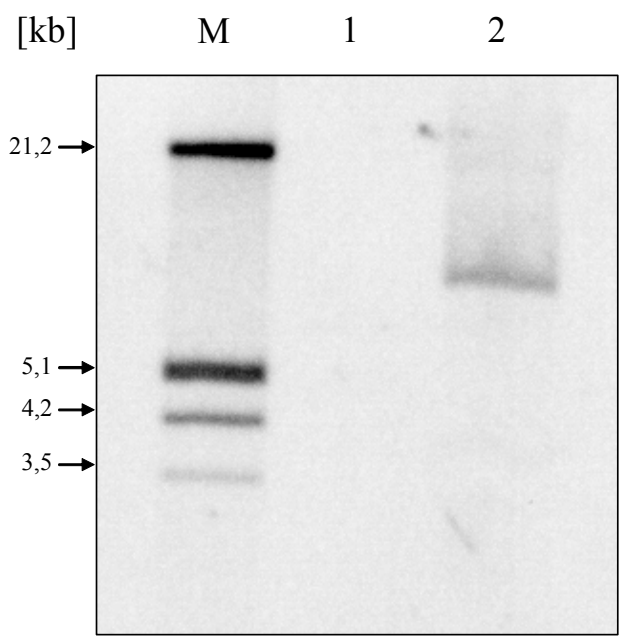

Abb. 4.19. Southern Blot mit einer Sonde gegen thyA (A) und gegen die Gentamycin-Kassette (B) In der Abb. A wurde in Spur 1 die NcoI-NdeI-geschnittene chrom. DNA des Wildtyps und in Spur 2 der Mutante aufgetragen. Hier wurde die Sonde gegen MPN372 verwendet. Das detektierte Fragment in der Mutante ist durch die Integration des Transposons um 3,5 kb größer als das Fragment des Wildtyps. In der Abb. B wurde in Spur 1 die NcoI-NdeI-geschnittene chrom. DNA des Wildtyps und in Spur 2 der Mutante aufgetragen. Es wurde eine Sonde gegen die Gentamycin-Kassette verwendet. In Spur 1 konnte kein Signal detektiert werden und in Spur 2 wurde nur eine Bande sichtbar.

Mit der thyA-Sonde konnte gezeigt werden, dass die Integration des Transposons in das Gen thyA erfolgreich war. Sie bewirkt einen Bandenshift im Southern Blot, da sich durch das Transposon die Größe des DNA-Fragmentes um ungefähr 3,5 kb verändert (Abb. 4.19. A Spur 2). Die oberste Bande stellt ungeschnittene DNA dar. Die Bande von etwa 3,9 kb entspricht der erwarteten Größe des Wildtyp-Fragments (Abb. 4.19. A Spur 1). Des Weiteren konnte mit der Sonde gegen die Gentamycin-Kassette gezeigt werden, dass das Transposon nur einmal in das Genom der Mutante integriert wurde (Abb. 4.19. B Spur 2). Mit der chromosomalen DNA des Wildtyps erhält man wie erwartet kein Signal, wenn man die Gentamycin-Sonde verwendet. Die thyA::tnMutante erhielt die Bezeichnung GPM9.

\subsubsection{Zytotoxischer Effekt der thyA::tn-Mutante (GPM9)}

Die Thymidylatsynthase ist ein wichtiges Enzym für die de novo Synthese des Thymidins (dTMP). Darum sollte untersucht werden, ob eine Mutante, in welcher das Gen thyA durch ein Transposon unterbrochen wurde, noch zytotoxisch gegenüber 
HeLa-Zellen ist. In der Abbildung 4.20. sind die Ergebnisse dieses Versuches zusammengefasst.
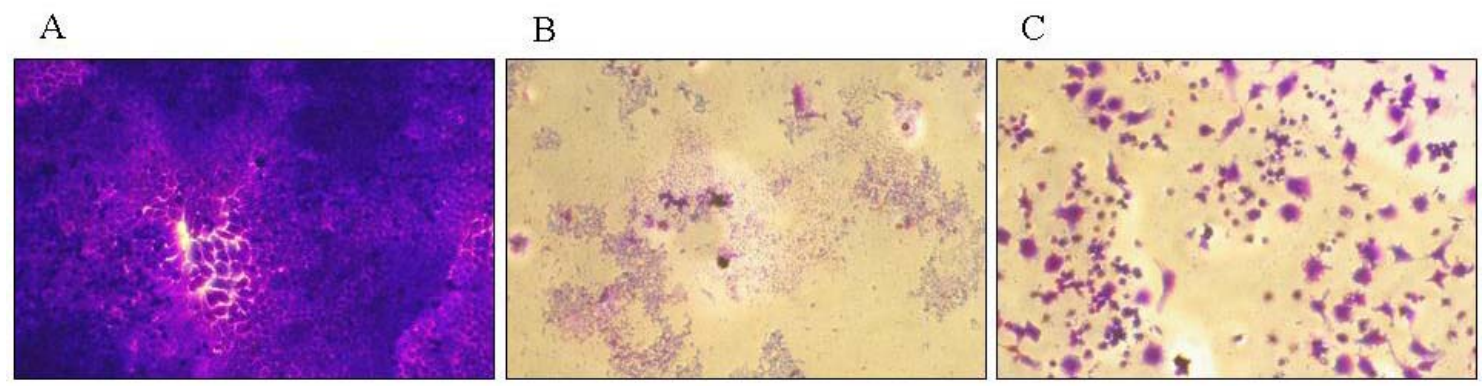

Abb. 4.20. Zytotoxizität von $M$. pneumoniae gegenüber HeLa-Zellen: A) HeLa-Zellen ohne M. pneumoniae; B) HeLa-Zellen mit Wildtyp M. pneumoniae; C) HeLa-Zellen mit der thyA::tnMutante

Man kann klar erkennen, dass der Wildtyp von $M$. pneumoniae einen starken zytotoxischen Effekt zeigt, wenn man die Abbildungen 4.20. A und B vergleicht. Die Mutante GPM9 ist ebenfalls nicht in ihrer Zytotoxizität vermindert. Sie verhält sich ebenso wie der Wildtyp. Somit hat die Transposoninsertion in das Gen, welches für die Thymidylatsynthase kodiert, keinen Einfluss auf die Zytotoxizität.

Man hätte eventuell erwarten können, dass diese Mutanten in ihrem Wachstum beeinträchtigt sind, weil nicht mehr so viel dTMP gebildet werden kann. Jedoch haben Wachstumskurven bei Anwesenheit verschiedener C-Quellen im Vergleich zum Wildtyp keine Unterschiede gezeigt. Der Stamm GPM9 wächst genauso wie der Wildtyp. Wahrscheinlich kann ein anderes Enzym die Funktion der Thymidylatsynthase übernehmen.

\subsubsection{Isolierung der mpn358::tn-Mutante}

Viele Prokaryoten, vor allem pathogene Organismen, besitzen keine ThyA, aber dafür eine Thymidylat-Synthase (ThyX), die einen völlig anderen Reaktionsmechanismus hat. ThyX ist eine Flavin-abhängige Thymidylatsynthase (Myllykallio et al., 2002). In Ureaplasma und in M. mycoides konnten bereits Flavin-abhängige ThymidylatSynthasen identifiziert werden (persönliche Mitteilung, Wang L.). Ein Homolog dieses Enzyms wurde auch in M. pneumoniae gefunden, es handelt sich dabei um das Gen mpn358. 
Dieses Gen sollte nun näher untersucht werden und es wurde nach einer Transposonmutante gesucht, welche eine Insertion einer Gentamycinkassette in mpn358 trägt. Die Suche war auch erfolgreich und die Mutante wurde sequenziert, um den genauen Insertionsort des Transposons herauszufinden. Die Transposoninsertion erfolgte nach 158 Basen (Abb. 4.21.).

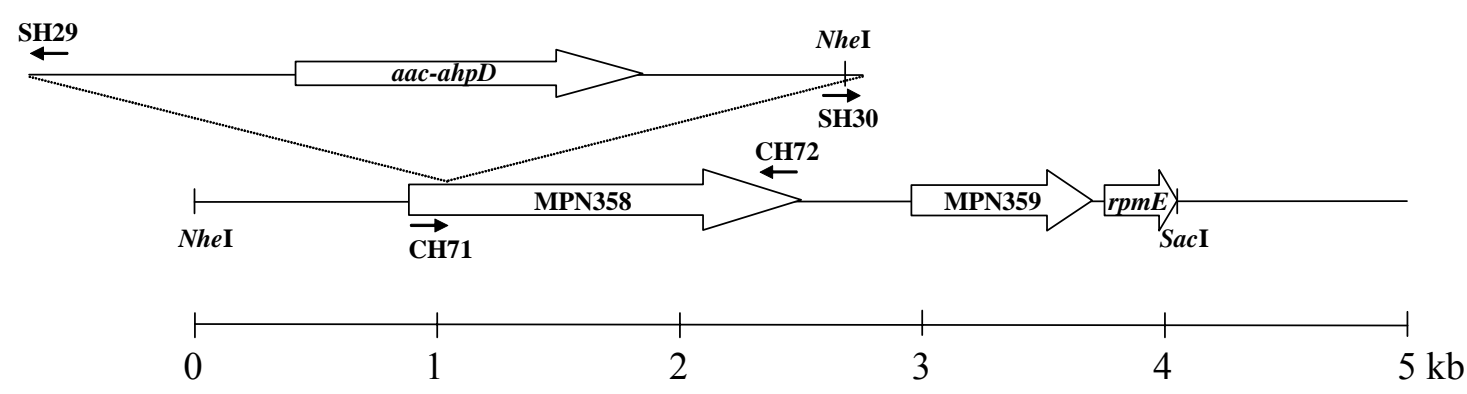

Abb. 4.21. Schematische Darstellung der Transposoninsertion in mpn358 im genetischen Hintergrund

Die Darstellung der Transposoninsertion ist maßstabsgetreu. Die für das Screening verwendeten Primer sind abgebildet sowie die Restriktionsstellen für die Enzyme NheI und SacI, welche für den Verdau der chromosomalen DNA für den Southern Blot verwendet wurden.

Nach der erfolgreichen Isolierung der Mutante erfolgte ein Southern Blot. Hierzu wurde die chromosomale DNA mit den Restriktionsenzymen NheI und SacI geschnitten. Anschließend erfolgte die Hybridisierung mit der Sonde gegen mpn358.

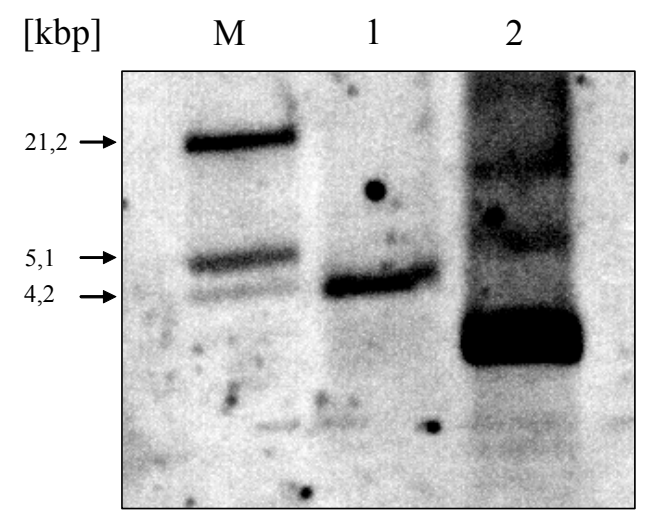

\section{Abb. 4.22. Southern Blot mit einer Sonde gegen mpn358}

In der Spur 1 wurde die NheI-SacI-geschnittene chrom. DNA des Wildtyps und in Spur 2 die chrom. DNA der Mutante aufgetragen. Hier wurde die Sonde gegen mpn358 verwendet. Die Bande in Spur 1 entspricht dem Wildtypfragment von etwa $4 \mathrm{~kb}$. Mit der chromosomalen DNA der Mutante erhält man 3 verschiedene Banden. Die Bande von etwa 7,5 kb welche die DNA zwischen der NheI-Schnittstelle vor mpn358 und der SacI-Schnittstelle umfasst. Die mittlere Bande hat eine Größe von 4,4 kb und ist somit 
das Fragment zwischen den beiden NheI-Schnittstellen. Die unterste Bande hat eine Größe von etwa $3 \mathrm{~kb}$ und entspricht dem Fragment zwischen der zweiten NheI-Schnittstelle (innerhalb des Transposons) und der SacI-Schnittstelle.

Das Ergebnis des Southern Blot ist in Abbildung 4.22. zu sehen. Die DNA des Wildtyps wurde mit den Restriktionsenzymen NheI und SacI geschnitten und im Blot taucht wie erwartet eine Fragmentgröße von 4 kb auf (Abb. 4.21. und Abb. 4.22. Spur 1). Die DNA der mpn358::tn-Mutante wurde mit den gleichen Enzymen verdaut und es konnten drei verschiedene Banden detektiert werden (Abb. 4.22. Spur 2). Dieses Bandenmuster entsteht, weil es zwei NheI-Schnittstellen gibt, nämlich eine vor dem Gen mpn358 und eine innerhalb des Transposons. Die größte Bande von 7,5 kb entsteht, wenn die DNA an der ersten NheI-Schnittstelle und an der SacI-Schnittstelle verdaut wird. Die mittlere Bande entspricht dem DNA-Fragment zwischen den beiden NheISchnittstellen und hat eine Größe von etwa 4,4 kb. Das kleinste Fragment von $3 \mathrm{~kb}$ wird gebildet, wenn die zweite NheI-Schnittstelle und die SacI-Schnittstelle von den entsprechenden Enzymen verdaut werden. Somit konnte gezeigt werden, dass die mpn358::tn-Mutante nicht mit Wildtyp-Zellen kontaminiert ist. Der Stamm, welcher eine Transposoninsertion im Gen mpn358 enthielt, erhielt die Bezeichnung GPM10.

\subsubsection{Zytotoxischer Effekt der mpn358::tn-Mutante (GPM10)}

Die Funktion des Genes mpn358 ist bisher noch nicht ganz klar. Wie schon bereits in dem vorherigen Kapitel erwähnt, besteht eine Homologie zu einer neuartigen Thymidylat-Synthase. Demnach würde M. pneumoniae zwei Enzyme besitzen, welche die gleiche Funktion übernehmen, nämlich die Synthese von dTMP. Dies ist umso erstaunlicher wenn man davon ausgeht, dass Mykoplasmen nur sehr kleine Genome besitzen und daher mit einem minimalen Set an Genen auskommen müssen.

Es sollte nun untersucht werden, ob die Transposoninsertion in dieses Gen einen Einfluss auf die Zytotoxizität hat. Hierzu wurden HeLa-Zellen sowohl mit dem Wildtyp als auch mit dem Stamm GPM10 inkubiert und die Zytotoxizität dokumentiert (Abb. 4.23.).

Das Ergebnis dieses Versuches zeigt, dass es zwischen dem Wildtyp und der mpn358::tn-Mutante keinen Unterschied in der Zytotoxizität gibt (Abb. 4.23. B und C). Der Wildtyp und der Stamm GPM10 bewirken, dass die HeLa-Zellen lysiert werden 
und gegenüber der Kontrolle, in welcher nur HeLa-Zellen vorhanden sind, keinen dichten Zellrasen mehr bilden können.
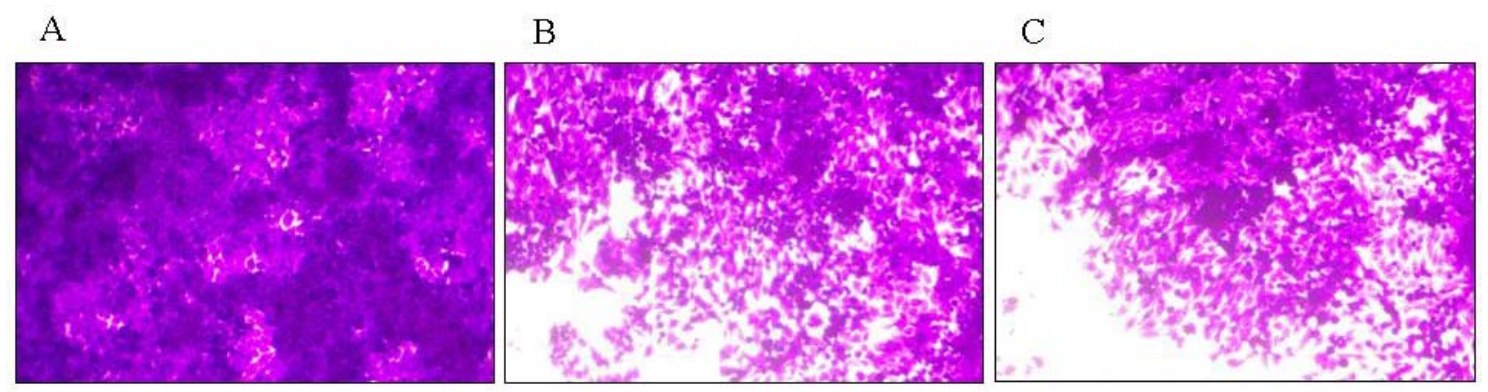

Abb. 4.23. Zytotoxizität von $M$. pneumoniae gegenüber HeLa-Zellen: A) HeLa-Zellen ohne M. pneumoniae; B) HeLa-Zellen mit Wildtyp M. pneumoniae; C) HeLa-Zellen mit der mpn358::tnMutante

Somit bleibt unklar, welche Funktion das Gen mpn358 in M. pneumoniae übernimmt. Es kann durchaus sein, dass ThyA die Funktion übernimmt, wenn MPN358 nicht mehr funktionsfähig ist und andersrum. Dies würde auch erklären, wieso die Mutanten GPM9 und GPM10 keine Unterschiede aufweisen sowie keinen Wachstumsdefekt zeigen.

\subsubsection{Zytotoxischer Effekt der hprK::tn-Mutante (GPM51)}

Die HPr-Kinase spielt in Gram-positiven Bakterien eine wichtige Rolle in der Regulation. Sie phosphoryliert das HPr aus dem PTS am Serin46, welches zusammen mit CcpA einen Komplex bildet. Dieser Komplex ist an der Kohlenstoffkatabolitenrepression beteiligt.

In M. pneumoniae konnte der $\mathrm{HPrK}$ beziehungsweise dem $\operatorname{HPr}(\mathrm{Ser}-\mathrm{P})$ bisher keine konkrete Rolle zugewiesen werden. Daher sollte untersucht werden, ob eine hprK::Mutante einen Einfluss auf die Zytotoxizität hat. Hierzu wurden HeLa-Zellen sowohl mit dem Wildtyp als auch mit dem Stamm GPM51 inkubiert und die Zytotoxizität dokumentiert (Abb. 4.24.).

Der Versuch macht deutlich, dass die hprK::Mutante nicht mehr zytotoxisch ist. Der Vergleich zwischen den Kontrollzellen (Abb. 4.24. A) und den HeLa-Zellen (Abb. 4.24. C), die mit der Mutante inkubiert wurden, zeigt keinen Wachstumsunterschied. In Anwesenheit des Wildtyps sind wie erwartet die HeLa-Zellen größtenteils lysiert. 
A

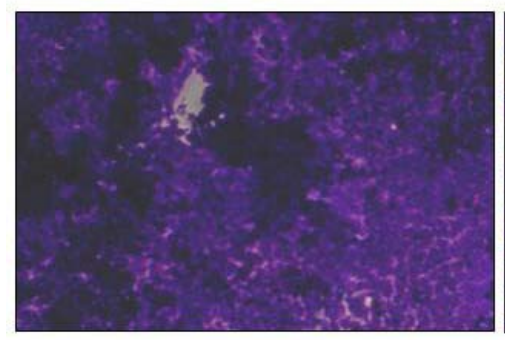

B

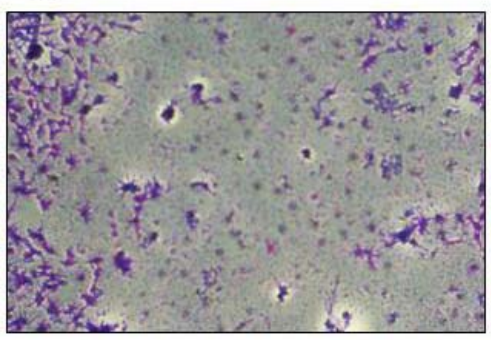

$\mathrm{C}$

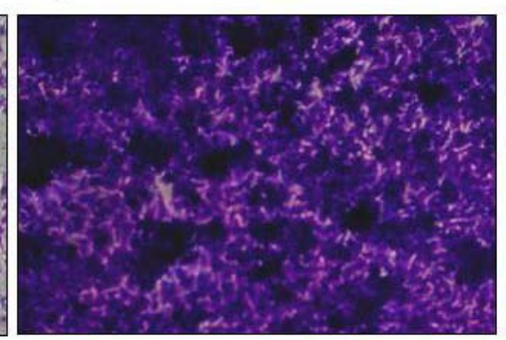

Abb. 4.24. Zytotoxizität von $M$. pneumoniae gegenüber HeLa-Zellen: A) HeLa-Zellen ohne M. pneumoniae; B) HeLa-Zellen mit Wildtyp M. pneumoniae; C) HeLa-Zellen mit der hprK::tnMutante

Dieses Ergebnis gibt einen Hinweis darauf, dass die HPr-Kinase auch in M. pneumoniae eine wichtige Rolle spielt. Es bleibt jedoch unklar, ob das Fehlen der Kinase Probleme im Stoffwechsel hervorruft oder ob sie an der Regulierung von Pathogenitätsmechanismen beteiligt ist.

\subsubsection{Zytotoxischer Effekt der prpC::tn-Mutante (GPM68)}

Das Gen prpC kodiert für eine Phosphatase, die der PP2C Familie angehört, zu der auch viele eukaryotische Phosphatasen gezählt werden. In M. pneumoniae ist $\operatorname{PrpC}$ in der Lage, das $\operatorname{HPr}($ Ser-P) zu dephosphorylieren.

Es sollte untersucht werden, ob eine prpC::tn-Mutante noch zytotoxisch auf HeLa-Zellen wirken kann. Die HeLa-Zellen wurden zusammen mit dem Wildtyp oder der $\operatorname{prpC}:$ :tn-Mutante von M. pneumoniae inkubiert und dokumentiert. (Abb. 4.25.)

A

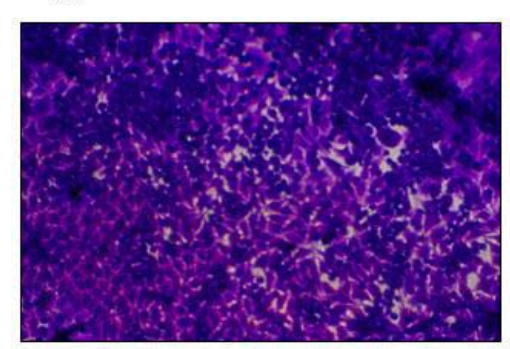

B

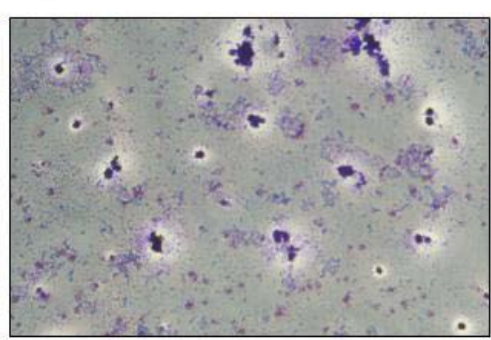

$\mathrm{C}$

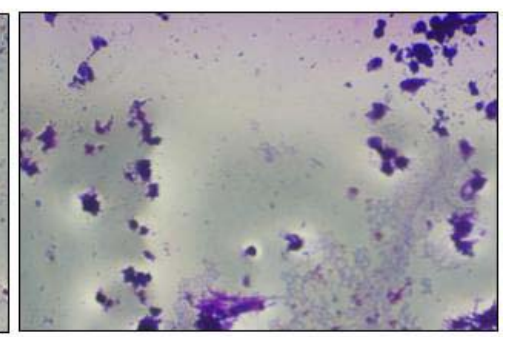

Abb. 4.25. Zytotoxizität von $M$. pneumoniae gegenüber HeLa-Zellen: A) HeLa-Zellen ohne M. pneumoniae; B) HeLa-Zellen mit Wildtyp M. pneumoniae; C) HeLa-Zellen mit der prpC::tnMutante 
Es wird deutlich, dass die prpC::Mutante (Abb. 4.25. C) noch genauso zytotoxisch auf die HeLa-Zellen wirkt wie der Wildtyp (Abb. 4.25. B). Demnach hat die Phosphatase keinen direkten Einfluss auf die Pathogenität von M. pneumoniae.

\subsubsection{Isolierung der mpn248::tn-Mutante}

Das Gen mpn248 (prkC) liegt hinter dem prpC-Gen und wird wahrscheinlich zusammen mit dieser transkribiert. Diese Genorganisation findet man in vielen Gram-positiven Organismen (Iwanicki et al., 2005). Üblicherweise befindet sich hinter der Phosphatase ein Gen, welches für eine Serin/Threonin Kinase kodiert. Es sollte untersucht werden, ob es sich bei mpn248 ebenfalls um eine Kinase handelt.

Um das Gen mpn248 näher zu charakterisieren, wurde die Transposonbank nach einer Mutante durchsucht, welche eine Insertion in dem Gen trägt. Es konnte eine Mutante isoliert werden und der Insertionsort wurde durch Sequenzierung bestimmt. Das Transposon befindet sich hinter der Base 313 (Abb. 4.26.).

Anschließend wurde die chromosomale DNA des Wildtyps und der mpn248::tnMutante isoliert und mit dem Restriktionsenzym XhoI geschnitten. Diese DNA wurde für einen Southern Blot eingesetzt. Die Detektion wurde mit einer Sonde gegen mpn248 und einer Sonde gegen die Gentamycin-Kassette durchgeführt.

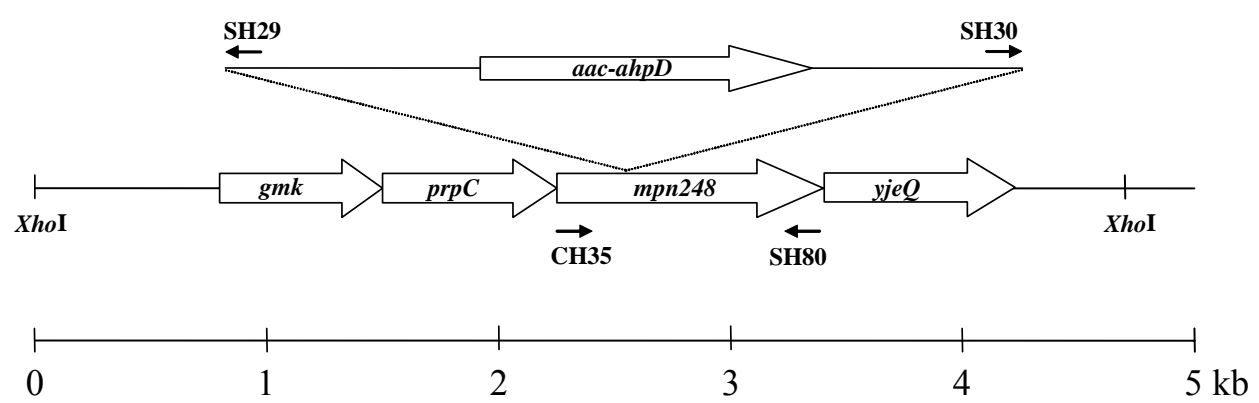

\footnotetext{
Abb. 4.26. Schematische Darstellung der Transposoninsertion in mpn248 im genetischen Hintergrund

Die Darstellung der Transposoninsertion ist maßstabsgetreu. Die für das Screening verwendeten Primer sind abgebildet sowie die Restriktionsstellen für das Enzym XhoI, welches für den Verdau der chromosomalen DNA für den Southern Blot verwendet wurde.
}

In der Abbildung 4.27. A ist der Southern Blot mit einer Sonde gegen mpn248 zu sehen. Die XhoI geschnittene chromosomale DNA des Wildtyps zeigt ein Signal bei der 
Größe von etwa 4,8 kb (Abb. 4.27. A Spur 1). Das DNA-Fragment, welches bei dem Verdau der chromosomalen DNA der Mutante entsteht, ist durch die Transposoninsertion etwa 3,5 kb größer und hat eine Länge von 8,3 kb (Abb. 4.27. A Spur 2).

A

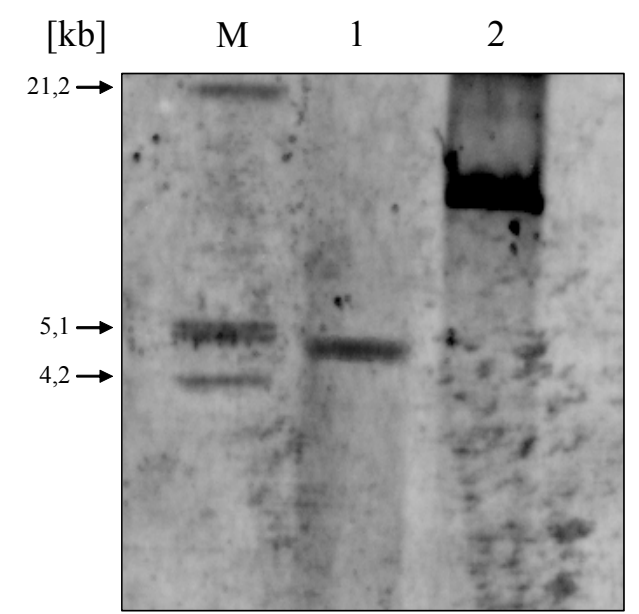

B

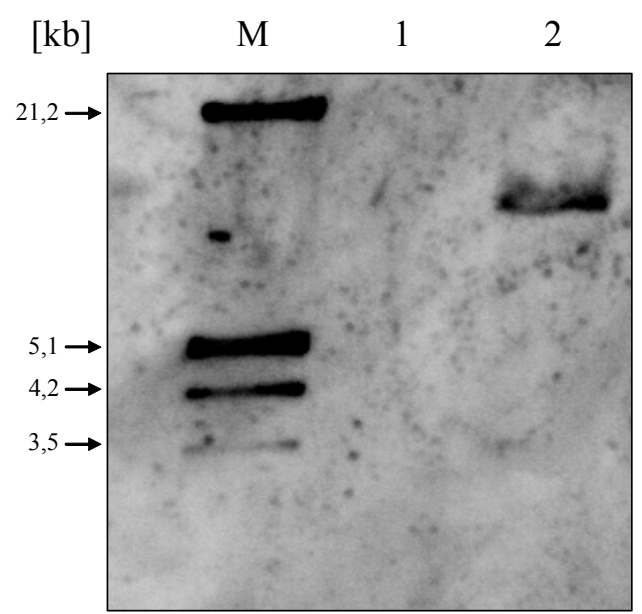

Abb. 4.27. Southern Blot mit einer Sonde gegen mpn248 (A) und gegen die Gentamycin-Kassette (B)

In der Abb. A wurde in Spur 1 die XhoI-geschnittene chrom. DNA des Wildtyps und in Spur 2 der Mutante aufgetragen. Hier wurde die Sonde gegen mpn248 verwendet. Das detektierte Fragment in der Mutante ist durch die Integration des Transposons um 3,5 kb größer als das Fragment des Wildtyps. In der Abb. B wurde in Spur 1 die XhoI -geschnittene chrom. DNA des Wildtyps und in Spur 2 der Mutante aufgetragen. Es wurde eine Sonde gegen die Gentamycin-Kassette verwendet. In Spur 1 konnte kein Signal detektiert werden und in Spur 2 wurde wie erwartet eine Bande sichtbar.

Der Southern Blot in Abbildung 4.27. B wurde mit einer Sonde gegen die Gentamycin-Kassette durchgeführt, um zu zeigen, dass das Transposon nur einmal in das Genom integriert wurde. Die geschnittene chromosomale DNA des Wildtyps gibt wie erwartet kein Signal (Abb. 4.27. B Spur 1) wohingegen bei der Mutante wieder ein Signal bei 8,3 kb detektiert werden kann (Abb. 4.27. B Spur 2).

Die Mutante erhielt die Bezeichnung GPM11. Diese Transposoninsertion in das Gen mpn248 bewirkt, dass die Mykoplasmen nicht mehr adhäsiv an Oberflächen wachsen können. Es ist die erste isolierte Mutante, welche einen Phänotyp aufweist. Dies gibt einen Hinweis darauf, dass MPN248 eine wichtige Rolle bei der Adhäsion spielt. 


\subsubsection{Zytotoxischer Effekt der mpn248::tn-Mutante (GPM11)}

Nachdem die Mutante erfolgreich isoliert werden konnte, sollte der zytotoxische Effekt auf HeLa-Zellen untersucht werden. Hierzu wurden die HeLa-Zellen für mehrere Tage zusammen mit der mpn248::tn-Mutante inkubiert. Mit der Hilfe mikroskopischer Aufnahmen konnte man feststellen, ob die Mutante sich anders verhält als der Wildtyp. 4.28.
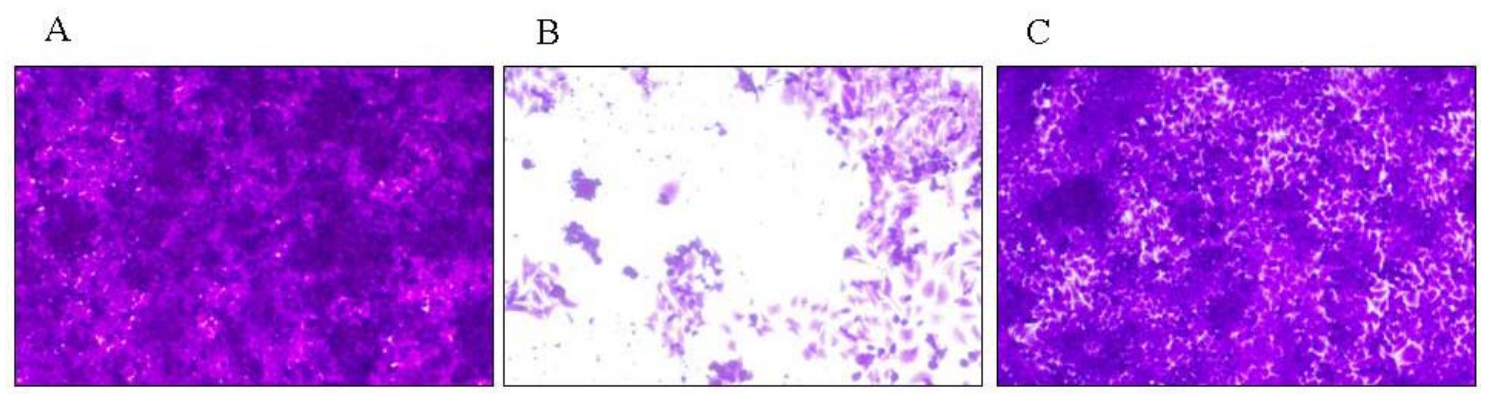

Abb. 4.28. Zytotoxizität von $M$. pneumoniae gegenüber HeLa-Zellen: A) HeLa-Zellen ohne M. pneumoniae; B) HeLa-Zellen mit Wildtyp M. pneumoniae; C) HeLa-Zellen mit der prkC::tnMutante

Dieser Versuch zeigt, dass die prkC::tn-Mutante im Gegensatz zu dem Wildtyp keine Zytotoxizität mehr gegenüber den HeLa-Zellen aufweist (Abb. 4.28. B und C). Offensichtlich ist diese Kinase an wichtigen regulatorischen Prozessen beteiligt. Möglicherweise ist die PrkC an der direkten oder indirekten Phosphorylierung der Adhäsionsproteine beteiligt und ihr Fehlen bewirkt, dass die Zellen nicht mehr an den Wirtszellen anhaften können. 


\subsection{Regulatorische Phosphorylierungen in M. pneumoniae}

\subsubsection{Wird der Glycerolstoffwechsel durch die HprK reguliert?}

Der Glycerolstoffwechsel und das Phosphotransferase-System scheinen in M. pneumoniae miteinander verknüpft zu sein. In Anwesenheit von Glycerol entsteht neben dem $\operatorname{HPr}($ His $\sim \mathrm{P})$, welches für die Aufnahme von Glukose notwendig ist, ebenfalls $\operatorname{HPr}(\operatorname{His} \sim \mathrm{P})($ Ser-P). Die Rolle des doppelt phosphorylierten $\mathrm{HPr}$ in M. pneumoniae ist bisher völlig unklar. In anderen Firmicutes spielen $\operatorname{HPr}(\operatorname{Ser}-\mathrm{P})$ beziehungsweise $\operatorname{HPr}($ His $\sim \mathrm{P})($ Ser-P) eine wichtige Rolle in der Kohlenstoffkatabolitenrepression.

Das PTS nimmt in Gram-positiven Bakterien ebenfalls Einfluss auf den Glycerolstoffwechsel, obwohl die Aufnahme dieser C-Quelle unabhängig von diesem System ist (Darbon et al., 2002). In E. faecalis stimuliert $\operatorname{HPr}(\mathrm{His} \sim \mathrm{P})$ durch die Phosphorylierung der Glycerolkinase deren Aktivität um das zehnfache (Deutscher und Sauerwald, 1986).

Es sollte nun die Frage geklärt werden, ob die phosphorylierten Formen des HPr als Phosphatdonor für die Glycerolkinase dienen können. Für diesen Versuch mussten zuerst alle Komponenten des PTS (EI, HPr, HPrK) sowie die Glycerolkinase rekombinant aufgereinigt werden. In vorherigen Untersuchungen wurde bereits gezeigt, dass diese rekombinanten Proteine enzymatisch aktiv sind. Die Phosphorylierungskaskade des PTS konnte mit Hilfe des radioaktiven Phosphoenolpyruvats oder des radioaktiven ATPs durchgeführt werden.

In der Abbildung 4.29. sind die Ergebnisse dieses Versuchs dargestellt. In der ersten Spur wurden EI, HPr und radioaktives PEP zusammen inkubiert. Hierbei entstehen zwei Phosphorylierungen, zum einen wird EI autophosphoryliert, zum anderen kann dieses wiederum HPr am Histidin phosphorylieren. Die Spur 2 zeigt die Phosphorylierung wenn HPr zusammen mit HPrK und radioaktivem ATP inkubiert wird. Die Phosphorylierung der HPrK ist nur sehr schwach, wohingegen man ein starkes Signal für $\mathrm{HPr}(\mathrm{Ser}-\mathrm{P})$ erhält. Diese beiden Spuren wurden zur Kontrolle mitgeführt. 
A

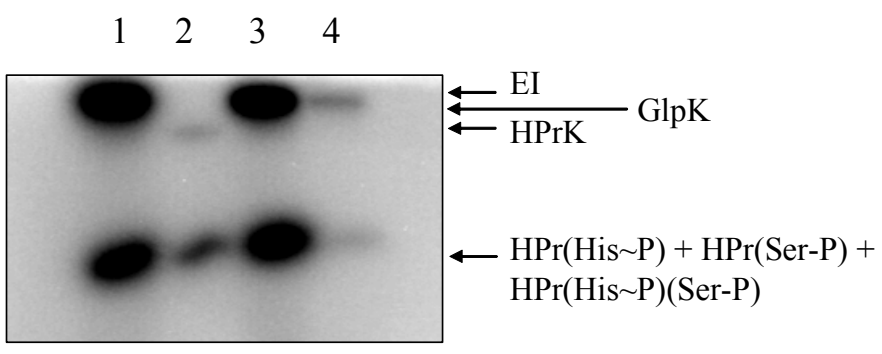

B

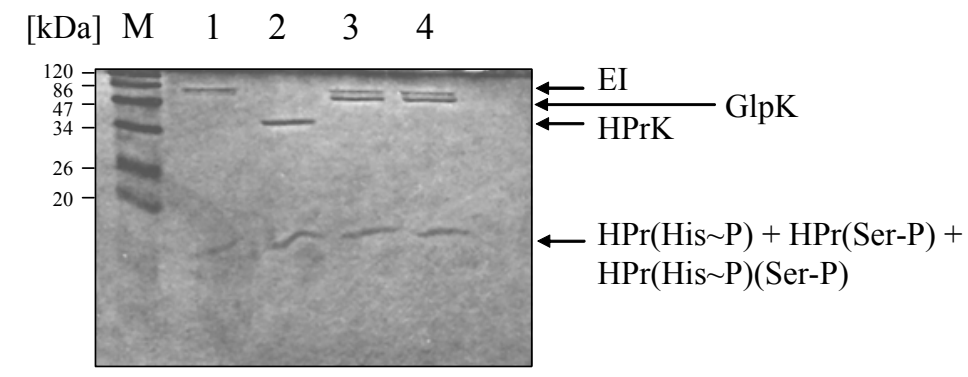

\section{Abb. 4.29. Radioaktive Phosphorylierung der Glycerolkinase durch PTS-Komponenten}

In der Spur 1 wurden EI, HPr und $\gamma-\left[{ }^{32} \mathrm{P}\right]-\mathrm{PEP}$ zusammen inkubiert. Bei diesem Ansatz wird EI auto- und HPr am Histidinrest phosphoryliert. In Spur 2 wurden die HPrK, HPr und ${ }^{32}$ P-ATP inkubiert und man erhielt eine schwache Phosphorylierung der HPrK und ein stärkeres Signal, welches HPr(Ser-P) darstellt. Die Spur 3 enthält EI, HPr, GlpK und $\gamma-\left[{ }^{32} \mathrm{P}\right]-\mathrm{PEP}$ und zeigt keine zusätzliche Bande gegenüber Spur 1. In der Spur 4 wurden $\operatorname{HPr}(\operatorname{Ser}-\mathrm{P})$, EI, GlpK und $\gamma-\left[{ }^{32} \mathrm{P}\right]-\mathrm{PEP}$ zusammen inkubiert. Die Autophosphorylierung von EI sowie die Phosphorylierung von $\operatorname{HPr}(\operatorname{Ser}-\mathrm{P})(\mathrm{His} \sim \mathrm{P})$ sind zu sehen.

In der Spur 3 wurde zu den Komponenten des PTS, EI, HPr und $\gamma-\left[{ }^{32} \mathrm{P}\right]-\mathrm{PEP}$, zusätzlich die Glycerolkinase hinzugegeben. Die Glycerolkinase (56 kDa) hat ein geringeres Molekulargewicht als EI (61 kDa) und man hätte erwartet, dass unterhalb des phosphorylierten EI eine zweite Bande auftaucht beziehungsweise, dass sich das Signal gegenüber der Spur 1 verstärkt. Dies ist jedoch nicht der Fall, so dass eine Phosphorylierung von GlpK durch HPr(His $\sim$ P) ausgeschlossen werden kann.

In der Spur 4 wurden EI, HPr(Ser-P), GlpK und $\gamma-\left[{ }^{32} \mathrm{P}\right]$-PEP eingesetzt. Auch hier sieht man nur die Autophosphorylierung von EI sowie die Phosphorylierung der $\operatorname{HPr}($ SerP) am Histidin. Bei diesem Ansatz wird das Phosphat nicht vom Histidinrest des HPr auf die Glycerolkinase übertragen.

Somit kann ausgeschlossen werden, dass das PTS, durch die Phosphorylierung der Glycerolkinase, einen Einfluss auf den Glycerolstoffwechsel nehmen kann. 


\subsubsection{Ist MPN248 eine Serin/Threonin Kinase?}

Der Stamm GPM11 zeigte bei seiner Isolierung einen für Mykoplasmen besonderen Phänotyp. Die Mutanten sind nicht mehr in der Lage, adhäsiv auf der Oberfläche zu wachsen und schwimmen im Medium.

Damit die Mykoplasmen adhärent wachsen können, sind sie auf die Bildung der Tipstruktur angewiesen. Diese Struktur besteht aus vielen verschiedenen Proteinen, die sehr gut untersucht sind, wie zum Beispiel das P1-Protein und die HMW-Proteine. Eine globale Studie der Phosphoproteine von M. pneumoniae hat gezeigt, dass viele dieser Proteine an Serin- oder Threonin-Resten phosphoryliert werden ( $\mathrm{Su}$ et al., 2007). Außerdem hat man in dieser Studie festgestellt, dass die Laktatdehydrogenase phosphoryliert wird.

Diese Ergebnisse gaben einen Hinweis darauf, dass es neben der HPr-Kinase noch eine weitere Kinase geben muss, welche Serin- und Threonin-Reste phosphorylieren kann. Da vor mpn248 ein Gen für eine Phosphatase ( $p r p C)$ vorhanden ist, gab dies einen Hinweis darauf, dass es sich bei diesem Gen um prkC handelt. In anderen Grampositiven Bakterien liegen die Phosphatase und die Serin/Threonin Kinase immer in einem Operon (Iwanicki et al., 2005). Des Weiteren kann PrkC sich autophosphorylieren wenn ATP vorhanden ist (Obuchowski et al., 2000).

Um der Frage nachzugehen, ob MPN248 eine Serin/Threonin Kinase ist, wurde das Gen in den Überexpressionsvektor pGP172, welcher dem Protein einen Strep-Tag verleiht, kloniert. Damit die Überexpression des Proteins in E. coli durchgeführt werden konnte, musste mit Hilfe der MMR ein UGA-Codon in ein UGG-Codon mutiert werden. Das fertige Plasmid erhielt die Bezeichnung pGP271.

Die Phosphorylierungen wurden wieder mit radioaktivem ATP durchgeführt. Die Ergebnisse sind in der Abbildung 4.30. zu sehen. In der ersten Spur wurde HPrK mit ${ }^{32} \mathrm{P}$-ATP inkubiert und man sieht die Autophosphorylierung dieses Proteins. Die Zugabe von HPr zu der HPr-Kinase und dem ${ }^{32}$ P-ATP führt zu einem weiteren Signal, welches HPr(Ser-P) darstellt (Abb. 4.30. Spur 2). Inkubiert man die HPrK und die Laktatdehydrogenase zusammen mit dem radioaktiven ATP, taucht nur eine Phosphorylierungsbande auf. Die beiden Proteine laufen auf der gleichen Höhe in dem SDS-Gel und es ist daher nicht möglich eine Aussage darüber zu treffen, ob die Laktatdehydrogenase durch die HPr-Kinase phosphoryliert werden kann (Abb. 4.30. 
Spur 3). In der Spur 4 wurde die Laktatdehydrogenase mit ${ }^{32}$ P-ATP inkubiert. Dies sollte eine Autophosphorylierung des Enzyms ausschließen.

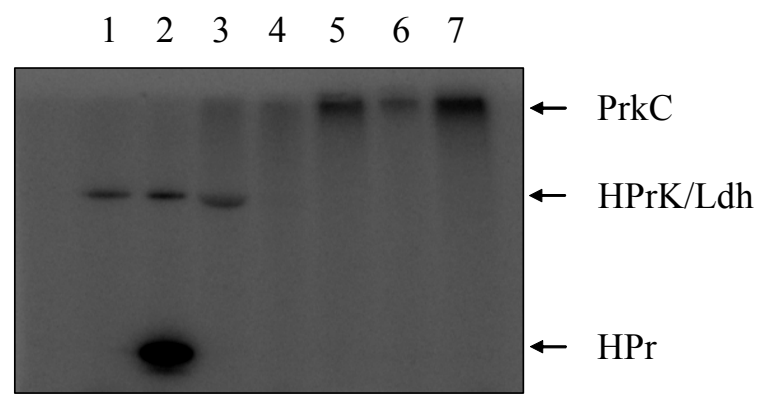

\section{Abb. 4.30. Phosphorylierungsexperimente mit PrKC und putativen Phosphorylierungskandidaten}

Allen Phosphorylierungsansätzen wurde ${ }^{32} \mathrm{P}$-ATP zugegeben und es folgte eine Inkubation von 30 Minuten bei $37^{\circ} \mathrm{C}$. In der Spur 1 ist die Autophosphorylierung von HPrK zu sehen. In der Spur 2 wurden HPrK und HPr aufgetragen und in Spur 3 wurde noch zusätzlich Ldh hinzugegeben. In der vierten Spur wurde zur Kontrolle Ldh mit ${ }^{32}$ P-ATP inkubiert. Die Spur 5 zeigt die Inkubation von PrkC mit HPr. In der Spur 6 wurde nur PrkC aufgetragen. Das Ergebnis der Inkubation von PrkC und Ldh ist in Spur 7 zu sehen.

Nun wurden PrkC und HPr zusammen mit ${ }^{32}$ P-ATP inkubiert (Abb. 4.30. Spur 5). Im Gegensatz zu PrkC aus B. subtilis ist PrkC aus M. pneumoniae nicht in der Lage HPr zu phosphorylieren (Nico Pietack, 2007). Man sieht jedoch deutlich, dass die Kinase autophosphoryliert wird. Dieses Ergebnis wird noch mal in Spur 6 bestätigt, in der PrkC mit ${ }^{32}$ P-ATP inkubiert wurde. In der letzten Spur wurden PrkC und die Laktatdehydrogenase zusammen mit radioaktivem ATP inkubiert. Auch hier sieht man nur die Autophosphorylierung der Kinase.

Es konnte gezeigt werden, dass MPN248 sich wie eine Serin/Threonin Kinase verhält. Jedoch konnte noch kein Substrat für diese Kinase identifiziert werden. Des Weiteren bleibt unklar, ob die HPr-Kinase an der Phosphorylierung der Laktatdehydrogenase beteiligt ist. 


\section{Diskussion}

\subsection{Die Verbindung von Kohlenstoffmetabolismus und Pathogenität in M. pneumoniae}

Die Pathogenitätsmechanismen und die Virulenzfaktoren sind bisher in M. pneumoniae kaum untersucht worden. In dieser Arbeit sollte gezeigt werden, dass es einen Zusammenhang zwischen dem Kohlenstoffmetabolismus und Pathogenität gibt. In vorherigen Experimenten wurde bereits eine Verbindung zwischen dem Glycerolstoffwechsel und dem Phosphotransferasesystem festgestellt (Halbedel, 2006). Die Anwesenheit von Glycerol hat einen Einfluss auf die HPr-Kinase-Aktivität und somit auf den Phosphorylierungszustand des HPr. Das HPr(Ser-P) entsteht nur, wenn Glycerol im Medium ist. Diese C-Quelle scheint ein wichtiges Signal für die Zelle zu sein. In diesem Zusammenhang sollte nun die Zytotoxizität einer hprK-Mutante näher untersucht werden.

Des Weiteren sollte die Rolle des Glycerolmetabolismus von $M$. pneumoniae näher charakterisiert werden. Hierbei sollte gezeigt werden, dass ein Enzym des Glycerolstoffwechsels maßgeblich an der Produktion des Virulenzfaktors Wasserstoffperoxid beteiligt ist und welchen Einfluss das $\mathrm{H}_{2} \mathrm{O}_{2}$ auf eukaryotische Wirtszellen hat.

\subsection{Der Glycerolstoffwechsel und seine Rolle bei der Virulenz}

Glycerol ist eine der wenigen Kohlenstoffquellen, die $M$. pneumoniae verwerten kann (Halbedel et al., 2004). Es scheint auch ein wichtiges Signal für die HPr-Kinase zu sein, da nur in Anwesenheit von Glycerol $\operatorname{HPr}($ Ser-P) gebildet wird (Halbedel et al., 2004). Das $\operatorname{HPr}($ His $\sim$ P) hat in E. faecalis einen aktivierenden Effekt auf die Glycerolkinase. Sie wird von $\operatorname{HPr}($ His $\sim$ P) phosphoryliert und zeigt eine zehnfach höhere Aktivität als die unphosphorylierte Glycerolkinase (Deutscher und Sauerwald, 1986).

In $M$. pneumoniae konnte bereits gezeigt werden, dass die Aktivität der Glycerolkinase weder durch $\operatorname{HPr}($ His $\sim$ P) noch durch $\operatorname{HPr}($ His $\sim$ P)(Ser-P) beeinflusst wird (Hames, 2006). Es wurde jedoch auch schon ein Fall beschrieben, in dem die Glycerolkinase phosphoryliert wird, wobei diese Phosphorylierung kaum Einfluss auf 
die Aktivität hat ((Darbon et al., 1999). Daher wurde untersucht, ob die Glycerolkinase aus $M$. pneumoniae von HPr phosphoryliert werden kann. Es stellte sich jedoch heraus, dass weder $\operatorname{HPr}($ His $\sim \mathrm{P})$, $\operatorname{HPr}($ Ser-P) noch $\operatorname{HPr}($ His $\sim \mathrm{P})($ Ser-P) in der Lage sind, die Kinase am Histidin zu phosphorylieren (Kapitel 4.3.1). Die Glycerolkinase wird weder auf Transkriptionsebene noch auf posttranslationaler Ebene reguliert. Auch in anderen Mykoplasmen scheint die Glycerolkinaseaktivität nicht reguliert zu sein.

M. capricolum besitzt als einziger unter den Mykoplasmen ein lösliches EIIA, wie es auch bei Gram-negativen Bakterien vorkommt. Hier wird jedoch die Glycerolkinase nicht durch EIIA inhibiert, wie es in E. coli der Fall ist (Zhu, 1997). Die Regulation der Glycerolkinaseaktivität scheint also in Mykoplasmen nicht so verbreitet zu sein wie in Gram-positiven und Gram-negativen Bakterien.

Da bei B. subtilis die Expression der Glyceroldehydrogenase reguliert wird, sollte untersucht werden, ob dies auch bei M. pneumoniae der Fall ist. Ein Western Blot hat jedoch gezeigt, dass unter verschiedenen Nährstoffbedingungen die Menge an dem Enzym GlpD nicht variiert und demnach nicht reguliert wird. Dies ist verwunderlich, da in B. subtilis durch die Regulation verhindert wird, dass unnötig Enzyme für den Abbau von C-Quellen synthetisiert werden, wenn diese gar nicht im Medium vorhanden sind. Eine Proteomanalyse von $M$. pneumoniae hat gezeigt, dass alle Enzyme für die Aufnahme und den Abbau der C-Quellen, die dieser Organismus verwerten kann, also Glukose, Fruktose und Glycerol, detektiert werden können (Jaffe et al., 2004). Dies könnte ein Hinweis darauf sein, dass den Mykoplasmen in ihrem natürlichen Lebensraum verschiedene Kohlenstoffquellen ständig zur Verfügung stehen und sie deshalb auf eine Kohlenstoffkatabolitenrepression verzichten.

Glycerol scheint neben seiner Rolle als Energielieferant auch eine wichtige Rolle in der Pathogenität von M. pneumoniae zu spielen. In der Anwesenheit von Glycerol im Medium werden bis zu $5 \mu \mathrm{g} / \mathrm{ml}$ Wasserstoffperoxid freigesetzt, während bei der Zugabe von Glukose nur $2 \mu \mathrm{g} / \mathrm{ml}$ produziert werden (Kapitel 4.1.7). Der hochvirulente M. mycoides subsp. mycoides SC Afadé Stamm, der in Afrika weit verbreitet ist und in Rindern die Lungenseuche hervorruft, kann bis zu 6,5 $\mu \mathrm{g} / \mathrm{ml}$ Wasserstoffperoxid bei der Verwertung von Glycerol in das Medium abgeben (Vilei und Frey, 2001). M. pneumoniae setzt, wie M. mycoides, große Mengen Wasserstoffperoxid frei, wenn Glycerol als C-Quelle zur Verfügung steht. Wahrscheinlich ist dies auch in M. pneumoniae ein primärer Virulenzfaktor. 
In M. mycoides ist die Glycerol-3-phosphat-Oxidase, welche Glycerol-3-phosphat zu Dihydroxyacetonphosphat umsetzt, für die Produktion von Wasserstoffperoxid zuständig. Dieses Enzym nutzt dabei Sauerstoff als Elektronenakzeptor. Bei der Sequenzierung des Genoms von $M$. pneumoniae wurde eine Glycerol-3-phosphatDehydrogenase annotiert (Himmelreich et al., 1996). Dehydrogenasen nutzen im Gegensatz zu Oxidasen NAD ${ }^{+}$als Elektronenakzeptor. Die Wasserstoffperoxidmessung von M. pneumoniae in Gegenwart von Glycerol gab bereits einen Hinweis darauf, dass glpD eventuell doch für eine Oxidase kodieren könnte (Kapitel 4.1.7).

Es stellte sich heraus, dass die rekombinante Glycerol-3-phosphat-Dehydrogenase $\mathrm{NAD}^{+}$nicht als Elektronenakzeptor verwenden kann und auch kein Wasserstoffperoxid bilden kann (Kapitel 4.1.2). Wenn man jedoch das Enzym für eine Stunde mit dem Substrat Glycerol-3-phosphat inkubiert hat, war es möglich Wasserstoffperoxid zu messen (Kapitel 4.1.3). Dies zeigt, dass $g l p D$ aus $M$. pneumoniae für eine Glycerol-3phosphat-Oxidase kodiert.

Glycerol-3-phosphat-Oxidasen scheinen unter den Milchsäurebakterien weit verbreitet zu sein. Sie wurden bereits in Pediococcus, Enterococcus, Aerococcus, Leuconostoc, Propionibacterium und Lactobacillus beschrieben und liegen als lösliches Protein im Cytoplasma vor (Esders und Michrin, 1979; Ince et al., 1987; Suchová et al., 1992, Parsonage et al., 1998). Somit ist auch die Fähigkeit, Wasserstoffperoxid zu produzieren, in Milchsäurebakterien weit verbreitet (Anders et al., 1970). Die Glycerol3-phosphat-Dehydrogenasen scheinen hingegen bei den anderen Bakterien verbreitet zu sein. Viele, darunter E. coli, B. subtilis, Streptomyces coelicolor und Staphylococcus aureus, besitzen eine membrangebundene Dehydrogenase (Mindich, 1968; Lascelles, 1978; Seno und Chater, 1983; Schweizer und Larson, 1987; Walz et al., 2002). In Mykoplasmen wurde der Glycerolstoffwechsel bisher nur in $M$. sp. bovine group 7 (Djordjevic et al., 2003) und in M. mycoides näher untersucht, wo zum ersten Mal eine Glycerol-3-phosphat-Oxidase beschrieben wurde (Wadher et al., 1990; Pilo et al., 2005). Auch in dieser Arbeit konnte gezeigt werden, dass M. pneumoniae ein solches Enzym exprimiert. Da Mykoplasmen und die Milchsäurebakterien einem gemeinsamen Vorfahren entstammen, scheinen sie die Glycerol-3-phosphat-Oxidase und somit die Wasserstoffperoxidproduktion von diesem beibehalten $\mathrm{zu}$ haben (Ciccarelli et al., 2006). 
Obwohl die beschriebenen Glycerol-3-phosphat-Oxidasen löslich sind und sich im Zytoplasma befinden, scheint die Oxidase von M. mycoides eine Ausnahme zu bilden (Pilo et al., 2005). Dieses Enzym ist in der Membran verankert und gibt das Wasserstoffperoxid direkt in die Umgebung ab. Bei M. pneumoniae ist dies jedoch nicht der Fall. Es konnte mit elektronenmikroskopischen Aufnahmen gezeigt werden, dass nur wenige Proteinmoleküle an der Oberfläche zu detektieren sind (Kapitel 4.1.5). Ein Western Blot hat bestätigt, dass die Glycerol-3-phosphat-Oxidase von M. pneumoniae größtenteils im Cytoplasma vorliegt und nur wenig Protein in der Membran verankert ist (Kapitel 4.1.5). Hier muss das gebildete Wasserstoffperoxid wohl erst durch die Zellmembran diffundieren, um an die Wirtszellen zu gelangen und diese zu schädigen.

M. mycoides setzt das Wasserstoffperoxid als Virulenzfaktor gegen die Wirtszellen ein. Die Blockierung der GlpO mit Antikörpern an der Zelloberfläche inhibiert die Zytotoxizität der Mykoplasmen gegenüber den nasalen Epithelzellen aus Kälbern (Pilo et al., 2005; Bischof et al., 2008). Obwohl die Glycerol-3-phosphatOxidase von $M$. pneumoniae größtenteils intrazellulär ist, konnte gezeigt werden, dass dieses Enzym auch in diesem Organismus eine wichtige Rolle bei der Virulenz spielt. Eine $g l p D:: t n-M u t a n t e$ ist weniger zytotoxisch als die Wildtypzellen (Kapitel 4.1.8). Wie bereits bei E. faecium beschrieben, hat der Glycerolstoffwechsel bzw. das von der Glycerol-3-phosphat-Oxidase produzierte Wasserstoffperoxid einen toxischen Effekt (Moy et al., 2004).

Bei den Milchsäurebakterien wird das gebildete Wasserstoffperoxid als Waffe eingesetzt. Es konnte gezeigt werden, dass viele Streptococcus-Arten durch die Produktion von Wasserstoffperoxid in der Lage sind, C. elegans zu töten (Bolm et al., 2004). Die pathogenen Milchsäurebakterien verfolgen dabei die Strategie, die konkurrierenden Krankheitserreger von dem gleichen Standort zu verdrängen. In der Mundhöhle kommen bis zu 500 verschiedene mikrobielle Arten vor (Kroes et al., 1999; Paster et al., 2001). Hier herrscht ein hoher Konkurrenzdruck. S. mutans bildet zur Abwehr von anderen Mikroorganismen Milchsäure, wodurch der $\mathrm{pH}$-Wert in der Umgebung absinkt und die Konkurrenten schädigt. S. oligofermentans, der sich in der gleichen Nische wie S. mutans aufhält, hat eine Strategie entwickelt, die es ihm ermöglicht dem zu entgehen. Er setzt das Laktat mit Hilfe einer Laktat-Oxidase um und bildet dabei Wasserstoffperoxid. Das Wasserstoffperoxid hat dann eine inhibierende Wirkung auf S. mutans (Tong et al., 2007). Streptococcen, die im Urogenitaltrakt 
vorkommen, sind mit Hilfe dieses Virulenzfaktors in der Lage, das Wachstum von Neisseria gonorrhoeae zu inhibieren (Dubreuil et al., 1984).

Auch S. pneumoniae nutzt Wasserstoffperoxid, um das Wachstum anderer pathogener Erreger zu unterbinden. Dieser Organismus kommt vor allem in der Nase und im Pharynx vor. S. aureus fühlt sich ebenfalls in der Nase sehr wohl und ist somit der Hauptkonkurrent von S. pneumoniae. Die Streptococcen bilden mit Hilfe der Pyruvat-Oxidase Wasserstoffperoxid und können somit das Wachstum von den Staphylococcen inhibieren (Spellerberg et al., 1996; Regev-Yochay et al., 2006). Bei den Milchsäurebakterien sind wie bei $M$. pneumoniae auch Enzyme des Kohlenstoffwechsels für die Produktion von Wasserstoffperoxid zuständig. Womöglich kann dieser Virulenzfaktor auch von $M$. pneumoniae zum Bekämpfen von konkurrierenden pathogenen Organismen genutzt werden, wie dies bei S. pneumoniae der Fall ist. Dies könnte vor allem den Mykoplasmen das Überleben im Wirt erleichtern, da sie doch recht langsam wachsen und eine lange Latenzzeit haben.

Jedoch nutzen nicht nur die pathogenen Milchsäurebakterien Wasserstoffperoxid zu ihrem Vorteil. Auch die Milchsäurebakterien, die in der Nahrungsmittelindustrie eingesetzt werden, setzen $\mathrm{H}_{2} \mathrm{O}_{2}$ frei und sind dabei in der Lage das Wachstum von Bakterien, die Lebensmittelvergiftungen hervorrufen können, zu inhibieren (Batdorj et al., 2007). Da sie oft als Starterkulturen für die Käse- und Joghurtherstellung verwendet werden, müssen sie ihre Nische vor anderen Bakterien verteidigen. Dies hat dann auch einen positiven Effekt für den Menschen, weil dabei die Kontamination mit pathogenen Bakterien verhindert wird.

Neben dem toxischen Effekt auf andere Bakterien bewirkt das Wasserstoffperoxid von S. pneumoniae bei alveolaren Epithelzellen von Ratten die Autolyse (Duane et al., 1993). Auch die bewimperten Epithelzellen der Lunge werden geschädigt, in dem die Schlagfrequenz herabgesetzt wird und es zur Lyse dieser Zellen kommt (Yoshitsugu et al., 1995; Feldman et al., 2002). Dies passt zu dem Krankheitsbild, welches S. pneumoniae hervorruft, nämlich der schweren Lungenentzündung. Wahrscheinlich hat der Virulenzfaktor von $M$. pneumoniae den gleichen Effekt auf die Lungenepithelzellen wie dies bei $S$. pneumoniae zu beobachten ist. Die Freisetzung von Wasserstoffperoxid durch die Mykoplasmen führt dann ebenfalls zu der Entstehung einer Lungenentzündung. 
Wenn die Lungenentzündung, welche von S. pneumoniae hervorgerufen wird, nicht behandelt wird, kommt es oft zu weiteren Entzündungen und vor allem zu einer Hirnhautentzündung, die bei Kindern meist tödlich verläuft oder schwere Hirnschäden verursacht (Bohr et al., 1984; Quagliarello und Scheld, 1992; deGans et al., 2002). Auch bei der Meningitis spielt das Wasserstoffperoxid eine wichtige Rolle. Es bewirkt eine Blutgefäßerweiterung im Gehirn, der Blutfluss wird erhöht und es kommt zu einer zerebralen Hyperämie, einem übermäßigen Blutangebot (Hoffmann et al., 2007). Auch die Ependymzellen, welche die Hirnflüssikeit von dem eigentlichen Hirngewebe abtrennen werden massiv geschädigt. Diese Zellen besitzen, wie die Zellen in der Lunge, Flimmerhärchen. Das Wasserstoffperoxid inhibiert die Schlagfrequenz dieser Härchen und es kommt zur Lyse der Zellen (Hirst et al., 2000). Die Freisetzung von $\mathrm{H}_{2} \mathrm{O}_{2}$ durch $E$. faecalis bewirkt Schäden der DNA in Darmepithelzellen und kann somit die Entstehung von Darmkrebs fördern (Huycke et al., 2002). Auch eine Infektion mit M. pneumoniae ruft oftmals neben der Lungenentzündung weitere Komplikationen bei den Patienten hervor. Unter anderem treten bei Mykoplasmeninfektionen auch Hirnhautentzündungen auf (Taylor et al., 1967). Wie bei S. pneumoniae könnte auch hier die Wasserstoffperoxidproduktion von M. pneumoniae einen negativen Einfluss auf das Hirngewebe haben und zur Entstehung der Meningitis beitragen. Des Weiteren konnte gezeigt werden, dass Zellextrakte von $M$. pneumoniae einen inhibierenden Effekt auf die Wimpernaktivität von Trachealzellen haben, was wahrscheinlich auf die $\mathrm{H}_{2} \mathrm{O}_{2}$-Produktion zurückzuführen ist (Chandler und Barile, 1980).

Diese Beispiele zeigen, dass Wasserstoffperoxid ein vielseitiger Virulenzfaktor ist, der auch von anderen Organismen genutzt wird. Es entsteht immer als Nebenprodukt wichtiger Stoffwechselenzyme, die oftmals am Abbau von Kohlenstoffquellen beteiligt sind. Wie genau $M$. pneumoniae das gebildete Wasserstoffperoxid einsetzt, bleibt noch unklar. Der lysierende Effekt der Mykoplasmen auf die HeLa-Zellen konnte jedoch klar gezeigt werden (Kapitel 4.1.8).

\subsection{Die $\mathrm{NADH}_{2}$-Oxidase von $M$. pneumoniae}

Eine $\mathrm{NADH}_{2}$-Oxidase (Nox) ist in allen Mollicutes vorhanden und befindet sich fast ausschließlich im Cytoplasma (Pollack, 1975; Pollack, 1986; Pollack et al., 1989; Pollack et al., 1996). Die Ausnahme bilden hierbei die Acholeplasma Arten, bei denen 
dieses Enzym in der Membran verankert ist (Pollack, 1975). In Bakterien wurden zwei verschiedene $\mathrm{NADH}_{2}$-Oxidasen beschrieben. Die Nox von Leuconostoc mesenteroides, Streptococcus pyogenes oder E. faecalis sind Beispiele für $\mathrm{H}_{2} \mathrm{O}$-bildende Oxidasen, während Thermus thermophilus, Amphibacillus xylanus oder Salmonella thyphimurium $\mathrm{H}_{2} \mathrm{O}_{2}$-bildende $\mathrm{NADH}_{2}$-Oxidasen besitzen (Koike et al., 1985; Ross und Claiborne, 1992; Park et al., 1992; Niimura et al., 1993; Niimura et al., 1995; Gibson et al., 2000). Sequenzvergleiche haben gezeigt, dass die $\mathrm{NADH}_{2}-\mathrm{Oxidase}$ von $M$. pneumoniae am meisten Ähnlichkeit mit den $\mathrm{H}_{2} \mathrm{O}$-bildenden Oxidasen von E. faecalis und S. pyogenes besitzt (Schmidt et al., 1986; Gibson et al., 2000).

In der Anwesenheit von Glukose ist $M$. pneumoniae in der Lage, Wasserstoffperoxid freizusetzen (Cohen und Somerson, 1969). Es konnte ebenfalls in dieser Arbeit gezeigt werden, dass dieser Organismus bis zu $2 \mu \mathrm{g} / \mathrm{ml} \mathrm{H}_{2} \mathrm{O}_{2}$ freisetzt, wenn man Glukose zu den Zellen gibt (Kapitel 4.1.7). Jedoch war bisher nicht klar, welches Enzym hierfür zuständig ist. In $M$. gallisepticum ist die $\mathrm{NADH}_{2}$-Oxidase in der Lage, Sauerstoff zu Wasserstoffperoxid zu reduzieren (Smith et al., 1963). Daher sollte in dieser Arbeit untersucht werden, ob auch in $M$. pneumoniae die Nox diese Reaktion katalysieren kann. Das Protein wurde aufgereinigt und in einem Enzymassay näher charakterisiert, wobei sich herausstellte, dass die Nox enzymatisch aktiv ist (Kapitel 4.1.9). Es war jedoch nicht möglich, die Freisetzung von Wasserstoffperoxid zu messen. Dies könnte zum einen daran liegen, dass der Assay für die Messung von $\mathrm{H}_{2} \mathrm{O}_{2}$ nicht geeignet war. Es besteht jedoch auch die Möglichkeit, dass M. pneumoniae zwei verschiedene $\mathrm{NADH}_{2}$-Oxidasen besitzt, nämlich eine die Wasser und eine die Wasserstoffperoxid produziert, obwohl in dem Genom nur eine Nox annotiert wurde. Erste Hinweise auf die Anwesenheit von zwei Oxidasen in Zellextrakten von M. pneumoniae wurden bereits veröffentlicht (Low und Zimkus, 1973).

Eine phylogenetische Studie der $\mathrm{H}_{2} \mathrm{O}$-bildenden Nox aus S. pneumoniae zeigt, dass die Nox aus M. pneumoniae nah mit diesem Enzym verwandt ist (Auzat et al., 1999; Yu et al., 2001). Demnach könnte es sich bei der aufgereinigten $\mathrm{NADH}_{2}-\mathrm{Oxidase}$ um eine wasserbildende Oxidase handeln.

Bereits in S. mutans, die wie M. pneumoniae ebenfalls keine Katalase besitzen, konnte gezeigt werden, dass zwei verschiedene $\mathrm{NADH}_{2}$-Oxidasen exprimiert werden (Higuchi et al., 1993). Die Oxidase Nox-2, welche Sauerstoff zu Wasser reduziert, wird für die Regenerierung des $\mathrm{NAD}^{+}$für die Glykolyse verwendet (Higuchi, 1992). Bei 
oxidativem Stress hingegen scheint die Oxidase Nox-1 eine wichtige Rolle zu spielen. Dieses Protein ist homolog zu der Flavoproteinkomponente AhpF der Alkylhydroperoxidreduktase (AhpR), welche aus AhpF und AhpC besteht. Die Nox-1 kann mit einem AhpC-Homolog bei Anwesenheit von Sauerstoff Wasserstoffperoxid zu Wasser umwandeln und ist damit ein Zweikomponenten Peroxidasesystem in S. mutans (Poole et al., 2000).

Die wasserbildende $\mathrm{NADH}_{2}$-Oxidase Nox-2 spielt in S. agalactiae eine wichtige Rolle. Es konnte gezeigt werden, dass eine Nox-2 Mutante Defekte in der Fettsäurebiosynthese aufweist und in Mäusen eine schwächere Virulenz aufweist (Yamamoto et al., 2006). Auch nox-Mutanten von S. pneumoniae, E. faecium und dem Spirochet Brachyspira hyodysenteriae sind weniger pathogen als die Wildtyp-Zellen (Stanton et al., 1999; Yu et al., 2001; Moy et al., 2004). Bei dem fakultativ anaeroben Humanpathogen S. pneumoniae wird die Kompetenz durch eine Deletion der $\mathrm{NADH}_{2}$ Oxidase stark reduziert und man nimmt an, dass die Oxidase in diesem Organismus als Sauerstoffsensor dient und dieses Signal weiterleitet (Auzat et al., 1999). In S. pyogenes sind nox-Mutanten nicht mehr in der Lage, in Anwesenheit von hohen Sauerstoffkonzentrationen zu wachsen (Gibson et al., 2000).

Zur näheren Charakterisierung der $\mathrm{NADH}_{2}$-Oxidase aus M. pneumoniae wäre die Isolierung einer nox-Mutante sehr hilfreich. Es stellte sich jedoch heraus, dass es keine Mutante in der Transposonbank gibt und das Gen demnach wohl, im Gegensatz zu anderen Organismen, essentiell ist. In einer nox-Mutante hätte man sehen können, ob das Wasserstoffperoxid bei Zugabe von Glukose von diesem Enzym produziert wird. Des Weiteren hätte man untersuchen können, ob eine solche Mutante, wie bereits in anderen Organismen beschrieben, weniger pathogen ist.

Obwohl die Möglichkeit besteht, dass in M. pneumoniae zwei verschiedene $\mathrm{NADH}_{2}$-Oxidasen vorhanden sind, lässt sich dies bisher nicht beweisen. Es nicht möglich eine nox-Mutante zu isolieren und es wurde keine weitere $\mathrm{NADH}_{2}$-Oxidase im Genom annotiert. Sequenzuntersuchungen konnten ebenfalls keine weitere $\mathrm{NADH}_{2}-$ Oxidase, die Ähnlichkeiten mit $\mathrm{H}_{2} \mathrm{O}_{2}$-bildenden $\mathrm{NADH}_{2}$-Oxidasen aufweist, identifizieren. Auch gibt es offensichtlich kein Protein, welches ähnlich zu AhpF von S. mutans ist. Daher kann es auch sein, dass ein anderes Enzym in Anwesenheit von Glukose im Medium Wasserstoffperoxid produziert. 


\subsection{Proteinphosphorylierung: ein wichtiger Regulationsmechanismus in M. pneumoniae?}

Die Proteinphosphorylierung ist eine weit verbreitete posttranslationale Modifikation, die sowohl bei Eukaryoten als auch bei Prokaryoten weit verbreitet ist. Die Ser/Thr/TyrKinasen und die dazugehörenden Phosphatasen wurden zuerst in Eukaryoten beschrieben (Ben-David et al., 1991; Rossomando et al., 1992).

Der MAP-Kinase Signalweg ist von den Hefezellen bis zum Menschen hochkonserviert und besteht aus mehreren Kinasen und inaktivierenden Phosphatasen (Ferrell, 1996; Morrison und Davis, 2003). Bei den Hefen regulieren die MAP-Kinasen die Bildung von diploiden Zellen (Choi et al., 1994), das filamentöse Wachstum (Gagiano et al., 2002), den High Osmolarity Glycerol (HOG) Weg (Han et al., 1994), die Translation, die Transkription und viele andere wichtige Prozesse in der Zelle (Chen et al., 2001; Kyriakis und Avruch, 2001). Die MAP-Kinasen und Phosphatasen kommen jedoch nicht in Prokaryoten vor.

In Bakterien wurde vor kurzem die Phosphatase PrpC, welche Ähnlichkeiten zu PP2C, einer Phosphatase aus dem Menschen, aufweist, beschrieben (Obuchowski et al., 2000). Die Phosphatase wird in Hefen und Säugerzellen bei Umweltstress aktiviert und bewirkt die Umkehrung der Proteinkinasekaskade (Gaits et al., 1997; Hanada et al., 1998). Auch in Mykoplasmen wurde diese Phosphatase beschrieben (Bork et al., 1996; Fraser et al., 1995). Interessanterweise ist diese Phosphatase in M. pneumoniae in der Lage, das $\operatorname{HPr}($ Ser-P) zu dephosphorylieren. Diese Aufgabe wird in anderen Bakterien, wie zum Beispiel in B. subtilis, von der HPrK/P übernommen (Halbedel et al., 2006). Es bleibt unklar, welche weiteren Prozesse die Phosphatase in Bakterien reguliert.

Eine Untersuchung der Operonstruktur in B. subtilis hat gezeigt, dass hinter dem Gen für die Phosphatase eine Kinase kodiert wird (Obuchowski et al., 2000; Iwanicki et al., 2005). Diese Kinase weist Ähnlichkeiten zu der Hanks-Kinase-Familie aus Eukayroten auf (Hanks und Hunter, 1995). Die Phosphatase und die Kinase findet man in vielen anderen Bakterien und sie bilden immer ein Operon (Abb. 5.1.). Über die Funktion der Phosphatase und der Kinase ist bisher jedoch nur wenig bekannt. 


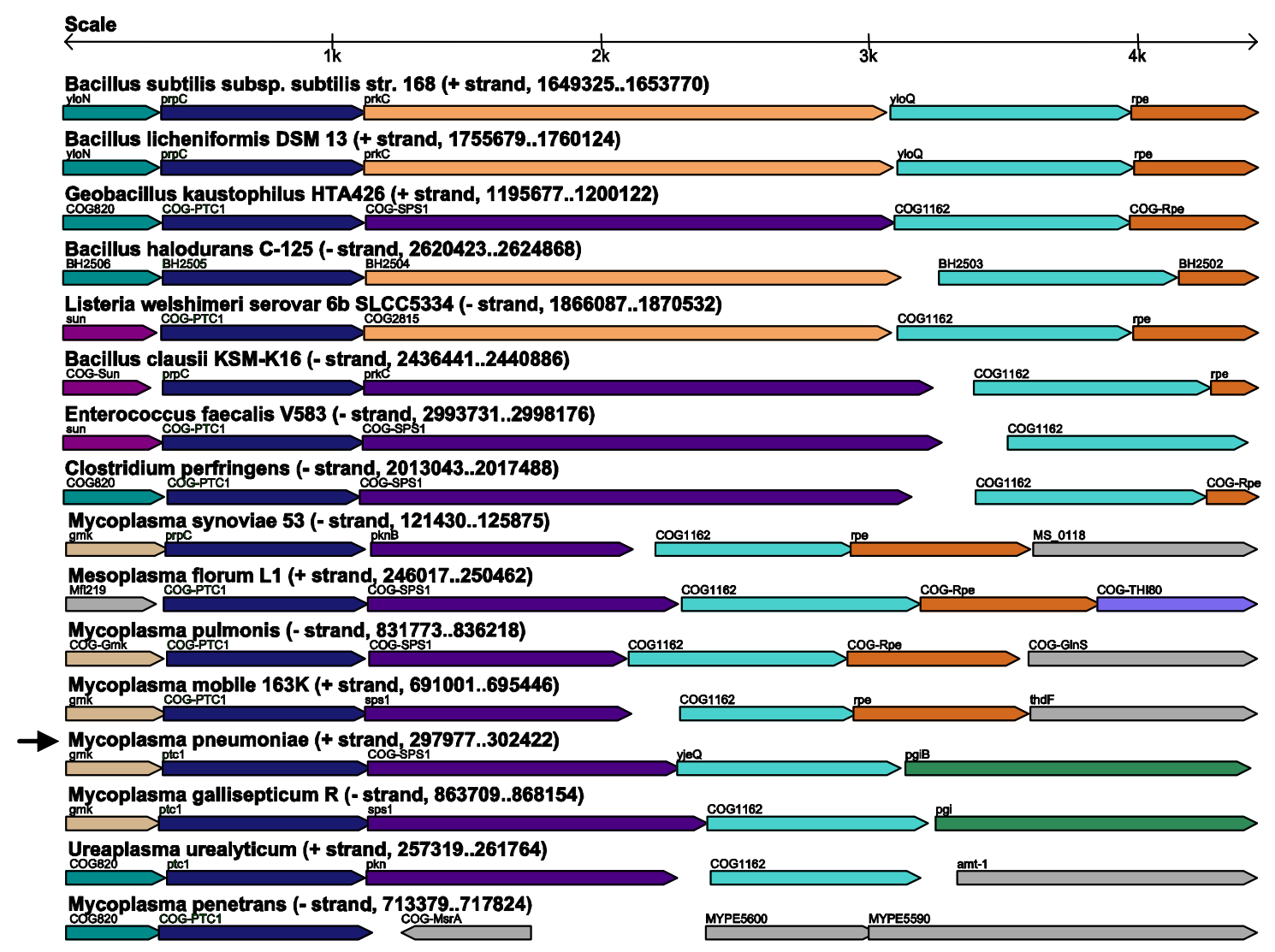

Abb. 5.1. Alignment des prpC-prkC-Operons (dunkelblau und lila) in verschiedenen Bakterien

Es fällt auf, dass die Gene für die Phosphatase und die Kinase nur in Gram-positiven Bakterien zu finden sind. Nur M. penetrans bildet hier eine Ausnahme (Abb. 5.1). Man sieht auch, dass die Gene der Kinase bei den Mykoplasmen deutlich kleiner sind als bei den anderen Organismen. Die Mykoplasmen haben im Gegensatz zu allen anderen Gram-positiven Bakterien keine Zellwand. Schaut man sich nun in Abb. 5.2. die Domänen von prkC in B. subtilis, M. pneumoniae und $M$. genitalium genauer an, so wird klar, dass es einen Zusammenhang zwischen Zellwand und Genlänge gibt. 
B. subtilis
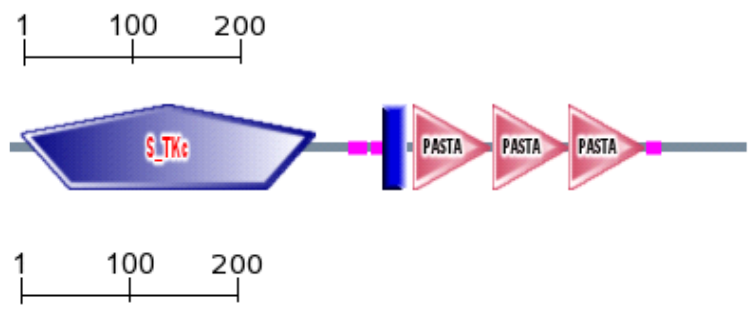

M. pneumoniae
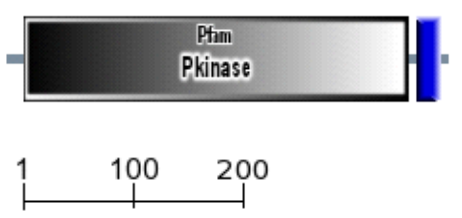

M. genitalium

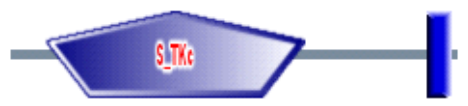

Abb. 5.2. Domänen von PrkC aus B. subtilis, M. pneumoniae und M. genitalium.

PrkC von B. subtilis besitzt 4 verschiedene Domänen: Das Kästchen gibt die Kinase-Domäne an, die kleinen pinken Kästchen sind Regionen mit niedriger Komplexität, der blaue Balken stellte eine Transmembran-Domäne dar und die Dreiecke sind PASTA-Domänen. Bei M. pneumoniae und M. genitalium sind die Kinase-Domäne und die Transmembran-Domäne vorhanden.

Bei den Mykoplasmen sind eine Kinase-Domäne und eine Transmembran-Domäne vorhanden. Dies deutet darauf hin, dass das Protein in der Cytoplasmamembran verankert ist. Damit kann die Kinase vielleicht ein Signal aus der Umwelt wahrnehmen und durch Phosphorylierung von Substraten eine Antwort in der Zelle hervorrufen. Bis auf die so genannten PASTA-Domänen sind die Kinasen von B. subtilis und den Mykoplasmen gleich. Die PASTA-Domäne steht für Penicillin-bindendes Protein und zugehörige Serin/Threonin Kinase Domäne. Dieser Proteinteil ist wohl in der Lage, nicht vernetztes Peptidoglykan schwach zu binden. Man vermutet, dass die PASTADomäne Zellwandschäden detektiert und das Signal an den Zellwand-Biosynthese-Weg weiterleitet (Yeats et al., 2002). Da die Mykoplasmen jedoch keine Zellwand besitzen, benötigen sie auch keine PASTA-Domäne und die Kinase scheint hier eine andere Funktion zu übernehmen. Daher sind die prkC-Gene in allen Mykoplasmen kürzer als bei den anderen Gram-positiven Bakterien.

Eine wichtige Eigenschaft von PrkC ist die Autophosphorylierung, die bei $B$. subtilis gezeigt werden konnte (Obuchowski et al., 2000). Die in-vitro Phosphorylierung der Kinase aus M. pneumoniae hat gezeigt, dass in Anwesenheit von ATP ebenfalls eine Autophosphorylierung stattfindet (Kapitel 4.3.2).

Die Untersuchung des Phosphoproteoms von M. pneumoniae hat gezeigt, dass viele Proteine phosphoryliert werden (Su et al., 2007). Darunter waren zum Beispiel die 
Laktatdehydrogenase und viele Adhäsionsproteine. In dieser Arbeit wurde untersucht, ob PrkC in der Lage ist, die Laktatdehydrogenase oder HPr zu phosphorylieren. Es stellte sich heraus, dass keines dieser Proteine durch die Kinase phosphoryliert wird (Kapitel 4.3.2). PrkC aus B. subtilis kann im Gegensatz zu dem Protein aus M. pneumoniae HPr am Serin12 phosphorylieren (Pietack, 2007). Die Kinasen scheinen demnach unterschiedliche Substratspezifitäten zu haben.

Es bleibt auch unklar, welche Kinase die Phosphorylierung der Laktatdehydrognase übernimmt und welche Funktion diese hat. Außer PrkC ist bisher nur die HPr-Kinase in M. pneumoniae beschrieben worden. Diese wurde ebenfalls bei einem in-vitro Assay eingesetzt, um herauszufinden, ob die Kinase Ldh phosphoryliert. Da die HPr-Kinase und die Laktatdehydrogenase die gleiche molekulare Größe haben, kann man nicht sagen, ob man nur die Autophosphorylierung der Kinase sieht oder auch die Phosphorylierung der Ldh (Kapitel 4.3.2). Hier müssten weitere Experimente durchgeführt werden, um die entsprechende Kinase zu finden.

Die Isolierung der prkC-Mutante zeigte, dass diese Mutante nicht mehr in der Lage ist, adhäsiv an Oberflächen zu wachsen. Dies ist ein Hinweis darauf, dass die Kinase möglicherweise die Phosphorylierung der Adhäsionsproteine direkt oder indirekt steuert (Su et al., 2007). Ein vermindertes Wachstum der prkC-Mutante mit Glukose als C-Quelle nicht festgestellt werden. In B. subtilis bewirkt die Deletion der Kinase eine stark verminderte Zelldichte in der späten stationären Phase, was eventuell daran liegt, dass die Aktivität des Elongationsfaktors EF-G nicht mehr reguliert wird und die Translationsrate unkontrolliert ansteigt (Gaidenko et al., 2002). Hier scheint PrkC auch an der Sporulation und der Biofilmbildung beteiligt zu sein (Madec et al, 2002). In unserer Arbeitsgruppe konnte gezeigt werden, dass PrkC zumindest in-vitro Enzyme aus dem Zitratzyklus, dem GOGAT-Zyklus, dem Pentose-Phosphat-Weg und dem Überfluss-Stoffwechsel phosphorylieren kann. Auch in anderen Organismen scheint die Kinase eine wichtige Rolle zu spielen. Vor kurzem hat man herausgefunden, dass eine prkC-Mutante von E. faecalis wesentlich sensitiver auf Antibiotika reagiert und die Persistenz in Mäusen ist wesentlich herabgesetzt (Kristich et al., 2007). Obwohl PrkC in keinem der bisher untersuchten Organismen essentiell ist, scheint es jedoch in allen wichtige physiologische Prozesse zu regulieren. Vor allem in Mykoplasmen, bei denen bisher nur die Transkriptionsregulation durch HrcA beschrieben wurde, scheint die posttranslationale Modifikation in Form von Phosphorylierung eine wichtige Rolle zu 
übernehmen (Fehri et al., 2005; Musatovova et al., 2006; Chang et al., 2008). Offensichtlich wird hier der komplexe Aufbau des Zytoskeletts durch Proteinmodifikation gesteuert.

Da die Transposoninsertion in PrkC bewirkt, dass die Zellen sich nicht mehr auf Oberflächen anlagern, wurde untersucht, ob dies auch einen Effekt auf die Zytotoxizität hat (Kapitel 4.2.11). Es stellte sich heraus, dass die prkC-Mutante nicht mehr zytotoxisch auf die HeLa-Zellen wirkt. Dies ist wahrscheinlich darauf zurückzuführen, dass die Mykoplasmen nicht mehr in der Lage sind, sich an die Wirtszellen anzuheften. Bei M. mycoides konnte bereits gezeigt werden, dass der enge Kontakt zu den eukaryotischen Zellen wichtig ist, um die Zellschäden hervorzurufen (Pilo et al., 2005).

Wie bereits erwähnt, spielt die Kinase auch eine wichtige Rolle bei der Persistenz von E. faecalis in Mäusen (Kristich et al., 2007). Die Kinase in S. pyogenes scheint einen Einfluss auf die Oberflächenproteine zu haben. Zum einen ist die Zellmorphologie verändert und zum anderen sind Mutanten nicht mehr in der Lage, an humane Pharynxzellen zu adhärieren (Jin und Pancholi, 2006). S. pneumoniae und S. agalactiae besitzen ebenfalls Homologe zu PrkC und deren Funktion wurde ebenfalls bereits untersucht. Die Kinase aus S. pneumoniae hat neben seiner aktivierenden Rolle der Kompetenzgene offensichtlich auch einen Einfluss auf die Etablierung der Virulenz (Echenique et al., 2004). Vor allem die Invasion der Blutbahn, aber auch der Lunge scheinen durch eine Deletion von prkC beeinträchtigt zu sein. In S. agalactiae bewirkt eine prkC-Mutante die Bildung von Ketten, was ein Hinweis darauf ist, dass nach der Teilung die Trennung der Zellen nicht mehr stattfinden kann. Bei diesen Mutanten war ebenfalls die Virulenz herabgesetzt. Jedoch konnte man nicht genau sagen, ob dies ein Effekt der fehlerhaften Trennung der Zellen ist oder ob die Kinase ein unbekanntes Substrat reguliert, welches für die Virulenz wichtig ist (Rajagopal et al., 2003). Man hat später herausgefunden, dass die Kinase einen Regulator phosphoryliert, der dann nicht mehr in der Lage ist, die Expression von Zytotoxinen zu reprimieren (Rajagopal et al., 2006). In vitro-Phosphorylierungen haben gezeigt, dass diese Kinase in der Lage ist, eine Mangan-abhängige anorganische Pyrophosphatase zu phosphorylieren (Rajagopal et al., 2003). Diese Pyrophosphatasen sind wohl für die Regulierung des intrazellulären $\mathrm{PP}_{\mathrm{i}}$-Spiegels zuständig und die Veränderung ihrer Aktivität hat globale Effekte auf den Zellmetabolismus, das Wachstum und die Teilung der Zellen (Lahti, 1983). Ein Homolog dieser Pyrophosphatase ist in S. gordonii an der Regulation der Expression 
von Adhäsinen beteiligt, die für die Koaggregation zuständig sind (Whittaker et al., 1996).

Die Ser/Thr/Tyr-Kinasen und die entsprechende Phosphatase scheinen in den Gram-positiven Bakterien unterschiedliche Funktionen zu übernehmen. Es wird jedoch deutlich, dass in den pathogenen Bakterien das Fehlen der Kinase immer einen negativen Effekt auf die Virulenz hat. Mal können die Bakterien nicht mehr adhärieren, mal sind sie sensitiver gegenüber Antibiotika und können nicht im Wirt überleben. Die regulatorische Funktion ist zwar nicht essentiell, da immer Mutanten isoliert werden können, aber das Wachstum und die Morphologie sind sichtbar verändert. Es bleibt herauszufinden, welche Prozesse in M. pneumoniae von PrkC beeinflusst werden und welches Signal aus der Umwelt an die Zelle weitergegeben wird.

\subsection{Das PTS und die Virulenz}

Das Phosphotransferasesystem dient den Bakterien zur Aufnahme und gleichzeitigen Phosphorylierung von Zuckern. Wie bereits in der Einleitung (Kapitel 2.3) beschrieben, kann die HPr-Kinase in diesem System regulatorische Aufgaben übernehmen. In M. pneumoniae konnte die Funktion der HPr-Kinase bzw. des $\operatorname{HPr}(\mathrm{Ser}-\mathrm{P})$ bisher nicht näher charakterisiert werden. Daher wurde die Zytotoxizität einer hprK-Mutante untersucht, um herauszufinden, ob die Kinase eine regulatorische Rolle bei der Pathogenität übernimmt (Kapitel 4.2.8). Es stellte sich heraus, dass die hprK-Mutante nicht mehr toxisch gegenüber den HeLa-Zellen ist. Auch in anderen pathogenen Bakterien spielt die HPr-Kinase-Aktivität eine wichtige Rolle bei der Etablierung der Pathogenität. Im Gegensatz zu M. pneumoniae ist in diesen Organismen die Transkriptionsregulation der Virulenzgene durch den HPr(Ser-P)/CcpA-Komplex von großer Bedeutung für die Expression von Virulenzfaktoren oder Anhaftungsmechanismen.

Bei S. pyogenes wird die Expression des Responseregulators Mga durch CcpA aktiviert (Almengor et al., 2007). Der Regulator Mga ist an der Regulation verschiedener Virulenzgene beteiligt, die es den Bakterien ermöglichen, an das Gewebe zu adhärieren, in die Wirtszellen einzudringen und das Immunsystem zu umgehen. Auch die Expression des Oberflächenproteins M, welches die Phagozytose inhibiert und die Invasion der Wirtszelle erleichtert, wird von Mga aktiviert. Die Proteinproduktion 
ist dabei zuckerabhängig (Pine und Reeves, 1978). Man geht davon aus, dass bei der Besiedlung von neuem Gewebe eine gute Kohlenstoffquelle zur Verfügung steht, die es S. pyogenes ermöglicht, in die exponentielle Wachstumsphase überzugehen. Dabei tritt die Kohlenstoffkatabolitenrepression ein, die die Expression des Virulenzregulators Mga aktiviert und so die Virulenzgene anschaltet. Der Kohlenstoffwechsel scheint demnach im Zusammenhang mit der Virulenz zu stehen.

In Clostridium perfringens wird die Ausbildung der Pili und somit die Gleitbewegung durch Glukose bzw. die Kohlenstoffkatabolitenrepression inhibiert. Interessanterweise wird bei Abwesenheit von Glukose die Expression der Piligene durch den $\operatorname{HPr}($ Ser-P)/CcpA-Komplex induziert (Mendez et al., 2008). In dem Darmlumen des Menschen ist nur wenig Glukose vorhanden (Ferraris et al., 1990). Hier sind die Clostridien also in der Lage, zu gleiten und Toxine freizusetzen.

Eine ccpA-Mutante von S. pneumoniae ist nicht mehr in der Lage, den Nasopharynx zu besiedeln und Lungenentzündung in Mäusen hervorzurufen (Iyer et al., 2005). In diesem Organismus reguliert HPr(Ser-P)/CcpA-Komplex nicht die Expression von Virulenzgenen, sondern Gene die für die Synthese von Polysacchariden der Kapsel zuständig sind (Giammarinaro und Paton, 2002). Ohne diese Polysaccharide können sich die Streptococcen nicht mehr an die Wirtszellen anlagern.

Demnach zeigen Mutanten des regulatorischen Weges des PTS oftmals eine verringerte Pathogenität. Dies bestätigt die Ergebnisse, die mit der hprK-Mutante aus M. pneumoniae erhalten wurden. Es bleibt jedoch noch herauszufinden, welche Gene oder Proteine durch die HPr-Kinase bzw. HPr(Ser-P) beeinflusst werden, damit die Mykoplasmen ihre Zytotoxizität entfalten können.

\subsection{Ausblick}

Die posttranslationale Modifikation bzw. Proteinphosphorylierung scheint, im Gegensatz zur Transkriptionsregulation, eine wichtige Rolle in M. pneumoniae zu spielen. Es wird daher interessant sein, mit Hilfe von Proteomanalysen die Substrate der PrkC näher zu charakterisieren. Dabei sollte herausgefunden werden, wie die Kinase zum Aufbau der Tipstruktur beiträgt. Auch der Zusammenhang zwischen der HPrKinase aus dem PTS und der Zytotoxizität sollte weiter untersucht werden. Hier würde sich ebenfalls eine Proteomanalyse anbieten. Bei dieser Untersuchung könnte auch 
geklärt werden, ob die HPr-Kinase auch für die Phosphorylierung der Laktatdehydrogenase zuständig ist.

Des Weiteren können mit Hilfe des etablierten Infektionsmodels weitere Mutanten auf ihre Zytotoxizität untersucht werden. Die Virulenzmechanismen und die Regulation der Virulenz kann somit besser untersucht und in einen Zusammenhang gestellt werden. 


\section{Literaturverzeichnis}

Abdallah, A.M., Gey van Pittius, N.C., Champion, P.A., Cox, J., Luirink, J., Vandenbroucke-Grauls, C.M., Appelmelk, B.J. \& Bitter, W. (2007): Type VII secretion--mycobacteria show the way. Nat Rev Microbiol 5(11), 883-891.

Aizawa, S.I. (2001): Bacterial flagella and type III secretion systems. FEMS Microbiol Lett 202(2), 157-164.

Almengor, A.C., Kinkel, T.L., Day, S.J. \& McIver, K.S. (2007): The catabolite control protein CcpA binds to Pmga and influences expression of the virulence regulator Mga in the Group A streptococcus. J Bacteriol 189(23), 8405-8416.

Anders, R.F., Hogg, D.M. \& Jago G.R. (1970): Formation of hydrogen peroxide by group $\mathrm{N}$ streptococci and its effect on their growth and metabolism. Appl Microbiol 19(4), 608-612.

Andreev, J., Borovsky, Z., Rosenshine, I. \& Rottem, S. (1995): Invasion of HeLa cells by Mycoplasma penetrans and the induction of tyrosine phosphorylation of a 145kDa host cell protein. FEMS Microbiol Lett 132(3), 189-194.

Armstrong, J.A. \& Hart, P.D. (1971): Response of cultured macrophages to Mycobacterium tuberculosis, with observations on fusion of lysosomes with phagosomes. J Exp Med

34, 713-740.

Asnis, R.E. \& Brodie, A.F. (1953): A glycerol dehydrogenase from Escherichia coli. $J$ Biol Chem 203(1), 153-159.

Auzat, I., Chapuy-Regaud, S., Le Bras, G., Dos Santos, D., Ogunniyi, A.D., Le Thomas, I., Garel, J.R., Paton, J.C. \& Trombe, M.C. (1999): The NADH oxidase of Streptococcus pneumoniae: its involvement in competence and virulence. Mol Microbiol 34(5), 1018-1028.

Balish, M.F., Santurri, R.T., Ricci, A.M., Lee, K.K. \& Krause, D.C. (2003): Localization of Mycoplasma pneumoniae cytadherence-associated protein HMW2 by fusion with green fluorescent protein: implications for attachment organelle structure. Mol Microbiol 47(1), 49-60.

Batdorj, B., Trinetta, V., Dalgalarrondo, M., Prévost, H., Dousset, X., Ivanova, I., Haertlé, T. \& Chobert, J.M. (2007): Isolation, taxonomic identification and hydrogen peroxide production by Lactobacillus delbrueckii subsp. lactis T31, isolated from Mongolian yoghurt: inhibitory activity on food-borne pathogens. J Appl Microbiol 103(3), 584-593.

Beckwith, J.R. (1967): Regulation of the lac operon. Recent studies on the regulation of lactose metabolism in Escherichia coli support the operon model. Science 156(3775), 597-604. 
Behrens, A., Heller, M., Kirchhoff, H., Yogev, D. \& Rosengarten, R. (1994): A family of phase- and size-variant membrane surface lipoprotein antigens (Vsps) of Mycoplasma bovis.

Infect Immun 62(11), 5075-5084.

Ben-David, Y., Letwin, K., Tannock, L., Bernstein, A. \& Pawson, T. (1991): A mammalian protein kinase with potential for serine/threonine and tyrosine phosphorylation is related to cell cycle regulators. EMBO J 10(2), 317-325.

Berman, M. \& Lin, E. C. (1971). Glycerol-specific revertants of a phosphoenolpyruvate phosphotransferase mutant: suppression by the desensitization of glycerol kinase to feedback inhibition. J Bacteriol 105, 113-120.

Bhakdi, S., Muhly, M., Mannhardt, U., Hugo, F., Klapettek, K., Mueller-Eckhardt, C. \& Roka, L. (1988): Staphylococcal alpha toxin promotes blood coagulation via attack on human platelets. J Exp Med 168(2), 527-542.

Bhakdi, S. \& Tranum-Jensen, J. (1988): Damage to cell membranes by pore-forming bacterial cytolysins. Prog Allergy 40, 1-43.

Bhakdi, S. \& Tranum-Jensen, J. (1991): Alpha-toxin of Staphylococcus aureus. Microbiol Rev 55(4), 733-751.

Bi, W. \& Stambrook, P. J. (1998). Site-directed mutagenesis by combined chain reaction. Anal Biochem 256, 137-140.

Bischof, D.F., Janis, C., Vilei, E.M., Bertoni, G. \& Frey, J. (2008): Cytotoxicity of Mycoplasma mycoides subsp. mycoides small colony type to bovine epithelial cells. Infect Immun 76(1), 263-269.

Bohr, V., Paulson, O.B. \& Rasmussen, N. (1984): Pneumococcal meningitis. Late neurologic sequelae and features of prognostic impact. Arch Neurol 41(10), 1045-1049.

Bolm, M., Jansen, W.T., Schnabel, R. \& Chhatwal, G.S. (2004): Hydrogen peroxidemediated killing of Caenorhabditis elegans: a common feature of different streptococcal species. Infect Immun 72(2), 1192-1194.

Bork, P., Brown, N.P., Hegyi, H. \& Schultz, J. (1996): The protein phosphatase 2C (PP2C) superfamily: detection of bacterial homologues. Protein Sci 5(7), 1421-1425.

Boyer, M.J. \& Wise, K.S. (1989): Lipid-modified surface protein antigens expressing size variation within the species Mycoplasma hyorhinis. Infect Immun 57(1), 245-254.

Bradford, M. M. (1976). A rapid and sensitive method for the quantitation of microgram quantities of protein utilizing the principle of protein-dye binding. Anal Biochem 72, 248-254.

Brennan, P.C. \& Feinstein, R.N. (1968): Secretion of hydrogen peroxide as a virulence factor for Mycoplasma pulmonis. ANL-7535. ANL Rep 181-183. 
Brückner, R. \& Titgemeyer, F. (2002): Carbon catabolite repression in bacteria: choice of the carbon source and autoregulatory limitation of sugar utilization. FEMS Microbiol Lett 209(2):141-8

Brunner, H., Feldner, J. \& Bredt, W. (1984): Effect of monoclonal antibodies to the attachment-tip on experimental Mycoplasma pneumoniae infection of hamsters. A preliminary report. Isr J Med Sci 20(9), 878-881.

Burns, D.L. (2003): Type IV transporters of pathogenic bacteria. Curr Opin Microbiol 6(1), 29-34.

Burton, R.M. \& Kaplan, N.O. (1953): A Dpn Specific Glycerol Dehydrogenase from Aerobacter-Aerogenes. J Am Chem Soc 75(4), 1005-1006.

Chandler, D.K. \& Barile, M.F. (1980): Ciliostatic, hemagglutinating, and proteolytic activities in a cell extract of Mycoplasma pneumoniae. Infect Immun 29(3), 1111-1116.

Chang LJ, Chen WH, Minion FC \& Shiuan D. (2008): Mycoplasmas regulate the expression of heat-shock protein genes through CIRCE-HrcA interactions. Biochem Biophys Res Commun 367(1), 213-218.

Chanock, R. M., Mufson, M. A., Somerson, N. L. \& Couch, R. B. (1963). Role of Mycoplasma (Pplo) in Human Respiratory Disease. Am Rev Respir Dis 88, SUPPL 21839.

Charrier, V., Buckley, E., Parsonage, D., Galinier, A., Darbon, E., Jaquinod, M., Forest, E., Deutscher, J. \& Claiborne, A. (1997). Cloning and sequencing of two enterococcal glpK genes and regulation of the encoded glycerol kinases by phosphoenolpyruvate-dependent, phosphotransferase system-catalyzed phosphorylation of a single histidyl residue. J Biol Chem 272, 14166-14174.

Chen, Z., Gibson, T.B., Robinson, F., Silvestro, L., Pearson, G., Xu, B., Wright, A., Vanderbilt, C. \& Cobb, M.H. (2001): MAP kinases. Chem Rev 101(8), 2449-2476.

Cherry, J.D. \& Taylor-Robinson, D. (1970): Growth and Pathogenesis of Mycoplasma mycoides var. capri in Chicken Embryo Tracheal Organ Cultures. Infect Immun 2(4):431-438.

Choe, S., Bennett, M.J., Fujii, G., Curmi, P.M., Kantardjieff, K.A., Collier, R.J. \& Eisenberg, D. (1992): The crystal structure of diphtheria toxin. Nature 357(6375):216222.

Choi, K.Y., Satterberg, B., Lyons, D.M. \& Elion, E.A. (1994): Ste5 tethers multiple protein kinases in the MAP kinase cascade required for mating in S. cerevisiae. Cell 78(3), 499-512. 
Christie, P.J. (1997): Agrobacterium tumefaciens T-complex transport apparatus: a paradigm for a new family of multifunctional transporters in eubacteria. $J$ Bacteriol 179(10), 3085-3094.

Ciccarelli, F.D., Doerks, T., von Mering, C., Creevey, C.J., Snel, B. \& Bork, P. (2006): Toward automatic reconstruction of a highly resolved tree of life. Science 311(5765), 1283-1287.

Cirillo, V.P. \& Razin, S. (1973): Distribution of a phosphoenolypyruvate-dependent sugar phosphotransferase system in mycoplasms. J Bacteriol 113(1), 212-217.

Cochu, A., Roy, D., Vaillancourt, K., Lemay, J.D., Casabon, I., Frenette, M., Moineau, S. \& Vadeboncoeur, C. (2005): The doubly phosphorylated form of HPr, $\operatorname{HPr}($ Ser P)(His-P), is abundant in exponentially growing cells of Streptococcus thermophilus and phosphorylates the lactose transporter LacS as efficiently as HPr(His P). Appl Environ Microbiol 71(3), 1364-1372.

Cohen, G. \& Somerson, N.L. (1967). Mycoplasma pneumoniae: hydrogen peroxide secretion and its possible role in virulence. Ann N Y Acad Sci 143, 85-87.

Cohen, G. \& Somerson, N.L. (1969): Glucose-dependent secretion and destruction of hydrogen peroxide by Mycoplasma pneumoniae. J Bacteriol 98(2), 547-551.

Dallo, S.F. \& Baseman, J.B. (2000): Intracellular DNA replication and long-term survival of pathogenic mycoplasmas. Microb Pathog 29(5), 301-309.

Dandekar, T., Huynen, M., Regula, J. T., Ueberle, B., Zimmermann, C. U., Andrade, M. A., Doerks, T., Sanchez-Pulido, L., Snel, B., Suyama, M. et al. (2000). Re-annotating the Mycoplasma pneumoniae genome sequence: adding value, function and reading frames. Nucleic Acids Res 28, 3278-3288.

Darbon, E., Ito, K., Huang, H. S., Yoshimoto, T., Poncet, S. \& Deutscher, J. (1999). Glycerol transport and phosphoenolpyruvate-dependent enzyme I- and HPr-catalysed phosphorylation of glycerol kinase in Thermus flavus. Microbiology 145 ( Pt 11), 32053212.

Darbon, E., Servant, P., Poncet, S. \& Deutscher, J. (2002): Antitermination by GlpP, catabolite repression via CcpA and inducer exclusion triggered by P-GlpK dephosphorylation control Bacillus subtilis glpFK expression. Mol Microbiol 43(4), 1039-1052.

de Boer, M., Broekhuizen, C. P. \& Postma, P. W. (1986). Regulation of glycerol kinase by enzyme IIIGlc of the phosphoenolpyruvate:carbohydrate phosphotransferase system. J Bacteriol 167, 393-395.

de Gans, J. \& van de Beek, D. (2002): European Dexamethasone in Adulthood Bacterial Meningitis Study Investigators. Dexamethasone in adults with bacterial meningitis. N Engl J Med 347(20), 1549-1556. 
de Verdier, C.H. (1952): Isolation of phosphothreonine from bovine casein. Nature 170(4332), 804-805.

Deutscher, J. \& Saier M.H. (2005): Ser/Thr/Tyr protein phosphorylation in bacteria for long time neglected, now well established. J Mol Microbiol Biotechnol 9(3-4), 125131.

Deutscher, J. \& Sauerwald, H. (1986). Stimulation of dihydroxyacetone and glycerol kinase activity in Streptococcus faecalis by phosphoenolpyruvate-dependent phosphorylation catalyzed by enzyme I and HPr of the phosphotransferase system. $J$ Bacteriol 166, 829-836.

Dhandayuthapani, S., Blaylock, M.W., Bebear, C.M., Rasmussen, W.G. \& Baseman, J.B. (2001): Peptide methionine sulfoxide reductase (MsrA) is a virulence determinant in Mycoplasma genitalium. J Bacteriol 183(19):5645-5650.

Dirksen, L.B., Krebes, K.A. \& Krause, D.C. (1994): Phosphorylation of cytadherence-accessory proteins in Mycoplasma pneumoniae. J Bacteriol 176(24):74997505.

Djordjevic, S.P., Vilei, E.M. \& Frey, J. (2003): Characterization of a chromosomal region of Mycoplasma sp. bovine group 7 strain PG50 encoding a glycerol transport locus (gtsABC).

Microbiology 149(Pt 1):195-204.

Duane, P.G., Rubins, J.B., Weisel, H.R. \& Janoff, E.N. (1993): Identification of hydrogen peroxide as a Streptococcus pneumoniae toxin for rat alveolar epithelial cells. Infect Immun 61(10), 4392-4397.

Dubreuil, D., Bisaillon, J.G. \& Beaudet, R. (1984): Inhibition of Neisseria gonorrhoeae growth due to hydrogen peroxide production by urogenital streptococci. Microbios 39, 159-167.

Dybvig, K. (1993): DNA rearrangements and phenotypic switching in prokaryotes. $\mathrm{Mol}$ Microbiol 10(3), 465-471.

Echenique, J., Kadioglu, A., Romao, S., Andrew, P.W. \& Trombe, M.C. (2004): Protein serine/threonine kinase StkP positively controls virulence and competence in Streptococcus pneumoniae. Infect Immun 72(4), 2434-2437.

Esders, T.W. \& Michrina, C.A. (1979): Purification and properties of L-alphaglycerophosphate oxidase from Streptococcus faecium ATCC 12755. J Biol Chem 254(8), 2710-2715.

Farizo, K.M., Fiddner, S., Cheung, A.M. \& Burns, D.L. (2002): Membrane localization of the S1 subunit of pertussis toxin in Bordetella pertussis and implications for pertussis toxin secretion. Infect Immun 70(3), 1193-1201. 
Fehri, L.F., Sirand-Pugnet, P., Gourgues, G., Jan, G., Wróblewski, H. \& Blanchard, A. (2005): Resistance to antimicrobial peptides and stress response in Mycoplasma pulmonis. Antimicrob Agents Chemother 49(10), 4154-4165.

Feldman C, Anderson R, Cockeran R, Mitchell T, Cole P, Wilson R. (2002): The effects of pneumolysin and hydrogen peroxide, alone and in combination, on human ciliated epithelium in vitro. Respir Med 96(8), 580-585.

Ferraris, R.P., Yasharpour, S., Lloyd, K.C., Mirzayan, R. \& Diamond, J.M. (1990): Luminal glucose concentrations in the gut under normal conditions. Am J Physiol 259, G822-837.

Ferrell ,J.E. Jr. (1996): Tripping the switch fantastic: how a protein kinase cascade can convert graded inputs into switch-like outputs. Trends Biochem Sci 21(12),460-466.

Fraser, C. M., Gocayne, J. D., White, O., Adams, M. D., Clayton, R. A., Fleischmann, R. D., Bult, C. J., Kerlavage, A. R., Sutton, G., Kelley, J. M. et al. (1995). The minimal gene complement of Mycoplasma genitalium. Science 270, 397403.

Fujita, Y., Miwa, Y., Galinier, A. \& Deutscher, J. (1995). Specific recognition of the Bacillus subtilis gnt cis-acting catabolite-responsive element by a protein complex formed between CcpA and seryl-phosphorylated HPr. Mol Microbiol 17, 953-960.

Gagiano, M., Bauer, F.F. \& Pretorius, I.S. (2002): The sensing of nutritional status and the relationship to filamentous growth in Saccharomyces cerevisiae. FEMS Yeast Res 2(4), 433-470.

Gaidenko, T.A., Kim, T.J. \& Price, CW. (2002): The PrpC serine-threonine phosphatase and PrkC kinase have opposing physiological roles in stationary-phase Bacillus subtilis cells.

J Bacteriol 184(22):6109-6114.

Gaillard, J.L., Berche, P., Mounier, J., Richard, S. \& Sansonetti, P. (1987): In vitro model of penetration and intracellular growth of Listeria monocytogenes in the human enterocyte-like cell line Caco-2. Infect Immun 55(11), 2822-2829.

Gaits, F., Shiozaki, K. \& Russell, P. (1997): Protein phosphatase 2C acts independently of stress-activated kinase cascade to regulate the stress response in fission yeast. J Biol Chem 272(28), 17873-17879.

Galinier, A., Haiech, J., Kilhoffer, M.C., Jaquinod, M., Stülke, J., Deutscher, J. \& Martin-Verstraete, I. (1997): The Bacillus subtilis crh gene encodes a HPr-like protein involved in carbon catabolite repression. Proc Natl Acad Sci U S A 94(16), 8439-8444.

Garnak, M. \& Reeves, H.C. (1979): Phosphorylation of Isocitrate dehydrogenase of Escherichia coli. Science 203(4385), 1111-1112. 
Gey Van Pittius, N.C., Gamieldien, J., Hide, W., Brown, G.D., Siezen, R.J. \& Beyers, A.D. (2001): The ESAT-6 gene cluster of Mycobacterium tuberculosis and other high G+C Gram-positive bacteria. Genome Biol 2(10).

Giammarinaro, P. \& Paton, J.C. (2002): Role of RegM, a homologue of the catabolite repressor protein CcpA, in the virulence of Streptococcus pneumoniae. Infect Immun 70(10), 5454-5461.

Gibson, C.M., Mallett, T.C., Claiborne, A. \& Caparon, M.G. (2000): Contribution of NADH oxidase to aerobic metabolism of Streptococcus pyogenes. J Bacteriol 182(2), 448-455.

Glatz, E., Nilsson, R.P., Rutberg, L. \& Rutberg, B. (1996): A dual role for the Bacillus subtilis glpD leader and the GlpP protein in the regulated expression of glpD: antitermination and control of mRNA stability. Mol Microbiol 19(2), 319-328.

Glatz, E., Farewell, A. \& Rutberg, B. (1998): The Bacillus subtilis glpD leader and antiterminator protein GlpP provide a target for glucose repression in Escherichia coli. FEMS Microbiol Lett 162(1), 93-96.

Goldkorn, T., Balaban, N., Shannon, M., Chea, V., Matsukuma, K., Gilchrist, D., Wang, H. \& Chan, C. (1998): $\mathrm{H}_{2} \mathrm{O}_{2}$ acts on cellular membranes to generate ceramide signaling and initiate apoptosis in tracheobronchial epithelial cells. J Cell Sci 11( Pt 21), 3209-3220.

Guérout-Fleury, A.M., Shazand, K., Frandsen, N. \& Stragier, P.(1995): Antibioticresistance cassettes for Bacillus subtilis. Gene 167(1-2), 335-336.

Gunsalus, I.C. \& Umbreit, W.W. (1945): The Oxidation of Glycerol by Streptococcus faecalis. J Bacteriol 49(4), 347-357.

Halbedel, S., Hames, C. \& Stülke, J. (2004). In vivo activity of enzymatic and regulatory components of the phosphoenolpyruvate:sugar phosphotransferase system in Mycoplasma pneumoniae. J Bacteriol 186, 7936-7943.

Halbedel, S., Busse, J., Schmidl, S.R. \& Stülke, J. (2006): Regulatory protein phosphorylation in Mycoplasma pneumoniae. A PP2C-type phosphatase serves to dephosphorylate HPr(Ser-P). J Biol Chem 281(36):26253-26259.

Halbedel, S. (2006): Regulation of HPr phosphorylation in Mycoplasma pneumoniae.

Halbedel, S., Eilers, H., Jonas, B., Busse, J., Hecker, M., Engelmann, S. \& Stülke, J. (2007): Transcription in Mycoplasma pneumoniae: analysis of the promoters of the ackA and ldh genes. J Mol Biol 371(3), 596-607.

Hames, C. (2005): Etablierung eines Systems zur ortsgerichteten Mutagenese in Mycoplasma pneumoniae. 
Hames, C., Halbedel, S., Schilling, O. \& Stülke, J. (2005): Multiple-mutation reaction: a method for simultaneous introduction of multiple mutations into the $g l p K$ gene of Mycoplasma pneumoniae. Appl Environ Microbiol 71(7), 4097-4100.

Han, J., Lee, J.D., Bibbs, L. \& Ulevitch, R.J. (1994): A MAP kinase targeted by endotoxin and hyperosmolarity in mammalian cells. Science 265(5173), 808-811.

Hanada, M., Kobayashi, T., Ohnishi, M., Ikeda, S., Wang, H., Katsura, K., Yanagawa, Y., Hiraga, A., Kanamaru, R. \& Tamura S. (1998): Selective suppression of stress-activated protein kinase pathway by protein phosphatase 2C in mammalian cells. FEBS Lett 437(3); 172-176.

Hanks, S.K. \& Hunter, T. (1995): Protein kinases 6. The eukaryotic protein kinase superfamily: kinase (catalytic) domain structure and classification. FASEB J 9(8), 576596.

Heller, K.B., Lin, E.C. \& Wilson, T.H. (1980). Substrate specificity and transport properties of the glycerol facilitator of Escherichia coli. J Bacteriol 144(1), 274-278.

Higuchi, M. (1992): Reduced nicotinamide adenine dinucleotide oxidase involvement in defense against oxygen toxicity of Streptococcus mutans. Oral Microbiol Immunol 7(5), 309-314.

Higuchi, M., Shimada, M., Yamamoto, Y., Hayashi, T., Koga, T. \& Kamio, Y. (1993): Identification of two distinct NADH oxidases corresponding to H2O2-forming oxidase and H2O-forming oxidase induced in Streptococcus mutans. J Gen Microbiol 139(10), 2343-2351.

Himmelreich, R., Hilbert, H., Plagens, H., Pirkl, E., Li, B. C. \& Herrmann, R. (1996). Complete sequence analysis of the genome of the bacterium Mycoplasma pneumoniae. Nucleic Acids Res 24, 4420-4449.

Hirst, R.A., Sikand, K.S., Rutman, A., Mitchell, T.J., Andrew, P.W. \& O'Callaghan, C. (2000): Relative roles of pneumolysin and hydrogen peroxide from Streptococcus pneumoniae in inhibition of ependymal ciliary beat frequency. Infect Immun 68(3), 1557-1562.

Hoffmann, O.M., Becker, D. \& Weber, J.R. (2007): Bacterial hydrogen peroxide contributes to cerebral hyperemia during early stages of experimental pneumococcal meningitis. J Cereb Blood Flow Metab 27(11), 1792-1797.

Holmberg, C. \& Rutberg, B. (1991): Expression of the gene encoding glycerol-3phosphate dehydrogenase $(\mathrm{glpD})$ in Bacillus subtilis is controlled by antitermination. Mol Microbiol 5(12), 2891-2900.

Holmberg, C. \& Rutberg, L. (1992): An inverted repeat preceding the Bacillus subtilis glpD gene is a conditional terminator of transcription. Mol Microbiol 6(20), 2931-2938. 
Honjo, T., Nishizuka, Y. \& Hayaishi, O. (1968): Diphtheria toxin-dependent adenosine diphosphate ribosylation of aminoacyl transferase II and inhibition of protein synthesis.

J Biol Chem 243(12), 3553-3555.

Hummel, W. \& Riebel, B. (2003): Isolation and biochemical characterization of a new NADH oxidase from Lactobacillus brevis. Biotechnol Lett 25(1), 51-54.

Hurley, J.H., Faber, H.R., Worthylake, D., Meadow, N.D., Roseman, S., Pettigrew, D.W. \& Remington, S.J. (1993): Structure of the regulatory complex of Escherichia coli IIIGlc with glycerol kinase. Science 259(5095), 673-677.

Huycke, M.M., Abrams, V. \& Moore, D.R. (2002): Enterococcus faecalis produces extracellular superoxide and hydrogen peroxide that damages colonic epithelial cell DNA. Carcinogenesis 23(3), 529-536.

Iglewski, B.H. \& Kabat, D. (1975): NAD-dependent inhibition of protein synthesis by Pseudomonas aeruginosa toxin. Proc Natl Acad Sci U S A 72(6), 2284-2288.

Ince, J. E., Macadam, A.M. \& Knowles, C.J. (1987): L-glycerol phosphate oxidase from Propionibacterium freudenreichii. FEMS Microbiol Lett 44, 185-191.

Iwanicki, A., Hinc, K., Seror, S., Wegrzyn, G. \& Obuchowski, M. (2005): Transcription in the prpC-yloQ region in Bacillus subtilis. Arch Microbiol 183(6), 421430.

Iyer, R., Baliga, N.S. \& Camilli, A. (2005): Catabolite control protein A (CcpA) contributes to virulence and regulation of sugar metabolism in Streptococcus pneumoniae. J Bacteriol 187(24), 8340-8349.

Jaffe, J.D., Stange-Thomann, N., Smith, C., DeCaprio, D., Fisher, S., Butler, J., Calvo, S., Elkins, T., FitzGerald, M.G., Hafez, N., Kodira, C.D., Major, J., Wang, S., Wilkinson, J., Nicol, R., Nusbaum, C., Birren, B., Berg, H.C. \& Church, G.M. (2004): The complete genome and proteome of Mycoplasma mobile. Genome Res 14(8), $1447-1461$.

Jault, J. M., Fieulaine, S., Nessler, S., Gonzalo, P., Di Pietro, A., Deutscher, J. \& Galinier, A. (2000). The HPr kinase from Bacillus subtilis is a homo-oligomeric enzyme which exhibits strong positive cooperativity for nucleotide and fructose 1,6bisphosphate binding. J Biol Chem 275, 1773-1780.

Jenkinson, E.J., Kingston, R., Smith, C.A., Williams, G.T. \& Owen J.J. (1989): Antigen-induced apoptosis in developing T cells: a mechanism for negative selection of the T cell receptor repertoire. Eur J Immunol 19(11), 2175-2177.

Jensen, J.S., Blom, J. \& Lind, K. (1994): Intracellular location of Mycoplasma genitalium in cultured Vero cells as demonstrated by electron microscopy. Int $J$ Exp Pathol 75(2), 91-98. 
Jin, H. \& Pancholi, V. (2006): Identification and biochemical characterization of a eukaryotic-type serine/threonine kinase and its cognate phosphatase in Streptococcus pyogenes: their biological functions and substrate identification. J Mol Biol 357(5), 1351-1372.

Kannan, T.R. \& Baseman, J.B. (2006): ADP-ribosylating and vacuolating cytotoxin of Mycoplasma pneumoniae represents unique virulence determinant among bacterial pathogens.

Proc Natl Acad Sci U S A 103(17), 6724-6729.

Kappler, J., Kotzin, B., Herron, L., Gelfand, E.W., Bigler, R.D., Boylston, A., Carrel, S., Posnett, D.N., Choi, Y. \& Marrack, P. (1989): V beta-specific stimulation of human T cells by staphylococcal toxins. Science 244(4906): 811-813.

Kenri, T., Taniguchi, R., Sasaki, Y., Okazaki, N., Narita, M., Izumikawa, K., Umetsu, M. \& Sasaki, T. (1999): Identification of a new variable sequence in the P1 cytadhesin gene of Mycoplasma pneumoniae: evidence for the generation of antigenic variation by DNA recombination between repetitive sequences. Infect Immun 67(9), 4557-4562.

Koike, K., Kobayashi, T., Ito, S. \& Saitoh, M. (1985): Purification and characterization of NADH oxidase from a strain of Leuconostoc mesenteroides. J Biochem 97(5), 1279-1288.

Kormann, A.W., Hurst, R.O. \& Flynn, T.G. (1972): Purification and properties of an NADP + -dependent glycerol dehydrogenase from rabbit skeletal muscle. Biochim Biophys Acta 258(1), 40-55.

Krause, D.C. (1996): Mycoplasma pneumoniae cytadherence: unravelling the tie that binds.

Mol Microbiol 20(2), 247-253.

Krause, D.C. \& Balish, M.F. (2001): Structure, function, and assembly of the terminal organelle of Mycoplasma pneumoniae. FEMS Microbiol Lett 198(1), 1-7.

Kravanja, M., Engelmann, R., Dossonnet, V., Bluggel, M., Meyer, H. E., Frank, R., Galinier, A., Deutscher, J., Schnell, N. \& Hengstenberg, W. (1999). The hprK gene of Enterococcus faecalis encodes a novel bifunctional enzyme: the HPr kinase/phosphatase. Mol Microbiol 31, 59-66.

Krebes, K.A., Dirksen, L.B. \& Krause, D.C. (1995): Phosphorylation of Mycoplasma pneumoniae cytadherence-accessory proteins in cell extracts. $J$ Bacteriol 177(15), 45714574.

Kristich, C.J., Wells, C.L. \& Dunny, G.M. (2007): A eukaryotic-type Ser/Thr kinase in Enterococcus faecalis mediates antimicrobial resistance and intestinal persistence. Proc Natl Acad Sci U S A 104(9), 3508-3513. 
Kroes, I., Lepp, P.W. \& Relman, D.A. (1999): Bacterial diversity within the human subgingival crevice. Proc Natl Acad Sci U S A 96(25), 14547-14552.

Krueger, K.M. \& Barbieri, J.T. (1995): The family of bacterial ADP-ribosylating exotoxins. Clin Microbiol Rev 8(1), 34-47.

Kubori, T., Sukhan, A., Aizawa, S.I. \& Galán J.E. (2000): Molecular characterization and assembly of the needle complex of the Salmonella typhimurium type III protein secretion system. Proc Natl Acad Sci U S A 97(18), 10225-10230.

Kyriakis, J.M. \& Avruch, J. (2001): Mammalian mitogen-activated protein kinase signal transduction pathways activated by stress and inflammation. Physiol Rev 81(2), 807-869.

Laemmli, U. K. (1970). Cleavage of structural proteins during the assembly of the head of bacteriophage T4. Nature 227, 680-685.

Lahti, R. (1983): Microbial inorganic pyrophosphatases. Microbiol Rev 47(2), 169-178.

Lascelles, J. (1978): sn-Glycerol-3-phosphate dehydrogenase and its interaction with nitrate reductase in wild-type and hem mutant strains of Staphylococcus aureus. $J$ Bacteriol 133(2), 621-625.

Leith, D. K. \& Baseman, J. B. (1984). Purification of a Mycoplasma pneumoniae adhesin by monoclonal antibody affinity chromatography. J Bacteriol 157, 678-680.

Lewis, K.N., Liao, R., Guinn, K.M., Hickey, M.J., Smith, S., Behr, M.A. \& Sherman, D.R. (2003): Deletion of RD1 from Mycobacterium tuberculosis mimics bacille Calmette-Guérin attenuation. J Infect Dis 187(1), 117-123.

Lin, E.C. (1976). Glycerol dissimilation and its regulation in bacteria. Annu Rev Microbiol 30, 535-578.

Lin, Y.S., Lei, H.Y., Low, T.L., Shen, C.L., Chou, L.J. \& Jan, M.S. (1992): In vivo induction of apoptosis in immature thymocytes by staphylococcal enterotoxin B. $J$ Immunol 149(4), 1156-1163.

Low, I.E. (1971): Effect of Medium on $\mathrm{H}(2) \mathrm{O}(2)$ Levels and Peroxidase-Like Activity by Mycoplasma pneumoniae. Infect Immun 3(1), 80-86.

Low, I.E. \& Zimkus, S.M. (1973): Reduced nicotinamide adenine dinucleotide oxidase activity and $\mathrm{H} 2 \mathrm{O} 2$ formation of Mycoplasma pneumoniae. J Bacteriol 116(1), 346-354.

Mackay, A. D., Watt, J. B. \& Jones, G. R. (1975). Myocarditis associated with Mycoplasma pneumoniae infection. Practitioner 214, 390-392.

Madec, E., Laszkiewicz, A., Iwanicki, A., Obuchowski, M. \& Séror, S. (2002): Characterization of a membrane-linked Ser/Thr protein kinase in Bacillus subtilis, implicated in developmental processes. Mol Microbiol 46(2), 571-586. 
Majlessi, L., Brodin, P., Brosch, R., Rojas, M.J., Khun, H., Huerre, M., Cole, S.T. \& Leclerc, C. (2005): Influence of ESAT-6 secretion system 1 (RD1) of Mycobacterium tuberculosis on the interaction between mycobacteria and the host immune system. J Immunol 174(6), 3570-3579.

Mangan, D.F., Taichman, N.S., Lally, E.T. \& Wahl, S.M. (1991): Lethal effects of Actinobacillus actinomycetemcomitans leukotoxin on human $\mathrm{T}$ lymphocytes. Infect Immun 59(9), 3267-3272.

Maniloff, J. (1992). Phylogeny of mycoplasmas In Mycoplasmas: molecular biology and pathogenesis. American Society for Microbiology, Washington, D.C., 549-559.

Marples, R.R. \& Wieneke, A.A. (1993): Enterotoxins and toxic-shock syndrome toxin-1 in non-enteric staphylococcal disease. Epidemiol Infect 110(3), 477-488.

Meiklejohn, G., Beck, M.D. \& Eaton, M.D. (1944): Atypical pneumonia caused by psittacosis-like viruses. J Clin Invest 23(2), 167-175.

Mendez, M., Huang, I.H., Ohtani, K., Grau, R., Shimizu, T. \& Sarker, M.R. (2008): Carbon catabolite repression of type IV pilus-dependent gliding motility in the anaerobic pathogen Clostridium perfringens. J Bacteriol 190(1), 48-60.

Merzbacher, M., Detsch, C., Hillen, W. \& Stülke, J. (2004). Mycoplasma pneumoniae HPr kinase/phosphorylase. Eur J Biochem 271, 367-374.

Meseguer, M.A., Alvarez, A., Rejas, M.T., Sánchez, C., Pérez-Díaz, J.C. \& Baquero, F. (2003): Mycoplasma pneumoniae: a reduced-genome intracellular bacterial pathogen.

Infect Genet Evol 3(1), 47-55.

Miles, R.J. (1992). Catabolism in mollicutes. J Gen Microbiol 138, 1773-1783.

Mindich, L. (1968): Pathway for oxidative dissimilation of glycerol in Bacillus subtilis. J Bacteriol 96(2), 565-566.

Morimoto, H. \& Bonavida, B. (1992): Diphtheria toxin- and Pseudomonas A toxinmediated apoptosis. ADP ribosylation of elongation factor-2 is required for DNA fragmentation and cell lysis and synergy with tumor necrosis factor-alpha. J Immunol 149(6), 2089-2094.

Morrison, D.K. \& Davis, R.J. (2003): Regulation of MAP kinase signaling modules by scaffold proteins in mammals. Annu Rev Cell Dev Biol 19, 91-118.

Mougous, J.D., Cuff, M.E., Raunser, S., Shen, A., Zhou, M., Gifford, C.A., Goodman, A.L., Joachimiak, G., Ordoñez, C.L., Lory, S., Walz, T., Joachimiak, A. \& Mekalanos, J.J. (2006): A virulence locus of Pseudomonas aeruginosa encodes a protein secretion apparatus. Science 312(5779), 1526-1530. 
Moy, T. I., Mylonakis, E., Calderwood, S. B. \& Ausubel, F. M. (2004). Cytotoxicity of hydrogen peroxide produced by Enterococcus faecium. Infect Immun 72, 4512-4520.

Musatovova, O., Dhandayuthapani, S. \& Baseman, J.B. (2006): Transcriptional heat shock response in the smallest known self-replicating cell, Mycoplasma genitalium. $J$ Bacteriol 188(8), 2845-2855.

Myllykallio, H., Lipowski, G., Leduc, D., Filee, J., Forterre, P. \& Liebl, U. (2002): An alternative flavin-dependent mechanism for thymidylate synthesis. Science 297(5578), 105-107.

Neimark, H. \& Lemcke, R.M. (1972): Occurrence and properties of lactic dehydrogenases of fermentative mycoplasmas. J Bacteriol 111(3), 633-640.

Nester, E.W. \& Jensen, R.A. (1966): Control of aromatic acid biosynthesis in Bacillus subtilis: sequenial feedback inhibition. J Bacteriol 91(4), 1594-1598.

Neuhard, J. \& Kelln, R.A. (1996): Escherichia coli and Salmonella. American Society for Microbiology, Washington D.C. 580-599.

Niimura, Y., Ohnishi, K., Yarita, Y., Hidaka, M., Masaki, H., Uchimura, T., Suzuki, H., Kozaki, M. \& Uozumi, T. (1993): A flavoprotein functional as NADH oxidase from Amphibacillus xylanus Ep01: purification and characterization of the enzyme and structural analysis of its gene. J Bacteriol 175(24), 7945-7950.

Niimura, Y., Poole, L.B. \& Massey, V. (1995): Amphibacillus xylanus NADH oxidase and Salmonella typhimurium alkyl-hydroperoxide reductase flavoprotein components show extremely high scavenging activity for both alkyl hydroperoxide and hydrogen peroxide in the presence of $S$. typhimurium alkyl-hydroperoxide reductase 22-kDa protein component. J Biol Chem 270(43), 25645-25650.

Obuchowski M, Madec E, Delattre D, Boël G, Iwanicki A, Foulger D \& Séror SJ. (2000): Characterization of PrpC from Bacillus subtilis, a member of the PPM phosphatase family.

J Bacteriol 182(19), 5634-5638.

Pallen, M.J. (2002): The ESAT-6/WXG100 superfamily -- and a new Gram-positive secretion system? Trends Microbiol 10(5), 209-212.

Papazisi, L., Frasca, S. Jr., Gladd, M., Liao, X., Yogev, D. \& Geary, S.J. (2002): GapA and CrmA coexpression is essential for Mycoplasma gallisepticum cytadherence and virulence. Infect Immun 70(12), 6839-6845.

Park, H.J., Reiser, C.O., Kondruweit, S., Erdmann, H., Schmid, R.D. \& Sprinzl, M. (1992): Purification and characterization of a NADH oxidase from the thermophile Thermus thermophilus HB8. Eur J Biochem 205(3), 881-885.

Parsonage, D., Luba, J., Mallett, T.C. \& Claiborne, A. (1998): The soluble alphaglycerophosphate oxidase from Enterococcus casseliflavus. Sequence homology with 
the membrane-associated dehydrogenase and kinetic analysis of the recombinant enzyme. J Biol Chem 273(37), 23812-23822.

Paster, B.J., Boches, S.K., Galvin, J.L., Ericson, R.E., Lau, C.N., Levanos, V.A., Sahasrabudhe, A. \& Dewhirst, F.E. (2001): Bacterial diversity in human subgingival plaque. J Bacteriol 183(12), 3770-3783.

Pettigrew, D. W., Liu, W. Z., Holmes, C., Meadow, N. D. \& Roseman, S. (1996). A single amino acid change in Escherichia coli glycerol kinase abolishes glucose control of glycerol utilization in vivo. $J$ Bacteriol 178, 2846-2852.

Pietack, N. (2007): Phosphorylierung von Enzymen des Kohlenstoffmetabolismus von Bacillus subtilis.

Pilo, P., Vilei, E.M., Peterhans, E., Bonvin-Klotz, L., Stoffel, M.H., Dobbelaere, D. \& Frey, J. (2005): A metabolic enzyme as a primary virulence factor of Mycoplasma mycoides subsp. mycoides small colony. J Bacteriol 187(19), 6824-6831.

Pine, L. \& Reeves, M.W. (1978): Regulation of the synthesis of M protein by sugars, Todd Hewitt broth, and horse serum, in growing cells of Streptococcus pyogenes. Microbios (85-86), 185-212.

Pollack, J.D. (1975): Localization of reduced nicotinamide adenine dinucleotide oxidase activity in Acholeplasma and Mycoplasma species. Int J Syst Bacteriol 25, 108113.

Pollack, J.D. (1986): Metabolic distinctiveness of ureaplasmas. Pediatr Infect Dis 5, 305-307.

Pollack, J.D., McElwain, M.C., Desantis, D., Manolukas, J.T., Tully, J.G., Chang, C.-J., Whitcomb, R.F., Hackett, K.J. \& Williams, M.V. (1989): Metabolism of members of the Spiroplasmataceae. Int J Syst Bacteriol 39, 406-412.

Pollack, J.D., Williams, M.V., Banzon, J., Jones, M.A., Harvey, L. \& Tully, J.G. (1996): Comparative metabolism of Mesoplasma, Entomoplasma, Mycoplasma, and Acholeplasma. Int J Syst Bacteriol 46(4), 885-890.

Pollack, J.D., Myers, M.A., Dandekar, T. \& Herrmann, R. (2002): Suspected utility of enzymes with multiple activities in the small genome Mycoplasma species: the replacement of the missing "household" nucleoside diphosphate kinase gene and activity by glycolytic kinases. OMICS 6(3), 247-258.

Poole, L.B., Higuchi, M., Shimada, M., Calzi, M.L. \& Kamio, Y. (2000): Streptococcus mutans H2O2-forming NADH oxidase is an alkyl hydroperoxide reductase protein. Free Radic Biol Med 28(1), 108-120.

Pukatzki, S., Ma, A.T., Sturtevant, D., Krastins, B., Sarracino, D., Nelson, W.C., Heidelberg, J.F. \& Mekalanos, J.J. (2006): Identification of a conserved bacterial 
protein secretion system in Vibrio cholerae using the Dictyostelium host model system. Proc Natl Acad Sci U S A 103(5), 1528-1533.

Pukatzki, S., Ma, A.T., Revel, A.T., Sturtevant, D. \& Mekalanos, J.J. (2007): Type VI secretion system translocates a phage tail spike-like protein into target cells where it cross-links actin. Proc Natl Acad Sci U S A 104(39), 15508-15513.

Pym, A.S., Brodin, P., Brosch, R., Huerre, M. \& Cole, S.T. (2002): Loss of RD1 contributed to the attenuation of the live tuberculosis vaccines Mycobacterium bovis BCG and Mycobacterium microti. Mol Microbiol 46(3), 709-717.

Quagliarello, V. \& Scheld, W.M. (1992): Bacterial meningitis: pathogenesis, pathophysiology, and progress. N Engl J Med 327(12), 864-872.

Rajagopal, L., Clancy, A. \& Rubens, C.E. (2003): A eukaryotic type serine/threonine kinase and phosphatase in Streptococcus agalactiae reversibly phosphorylate an inorganic pyrophosphatase and affect growth, cell segregation, and virulence. $J$ Biol Chem 278(16), 14429-14441.

Rajagopal, L., Vo, A., Silvestroni, A. \& Rubens, C.E. (2006): Regulation of cytotoxin expression by converging eukaryotic-type and two-component signalling mechanisms in Streptococcus agalactiae. Mol Microbiol 62(4), 941-957

Ramirez, A. S., Rosas, A., Hernandez-Beriain, J. A., Orengo, J. C., Saavedra, P., de la Fe, C., Fernandez, A. \& Poveda, J. B. (2005). Relationship between rheumatoid arthritis and Mycoplasma pneumoniae: a case-control study. Rheumatology (Oxford) 44(7), 912-914.

Razin, S., Yogev, D. \& Naot, Y. (1998): Molecular biology and pathogenicity of mycoplasmas. Microbiol Mol Biol Rev 62(4), 1094-1156.

Regev-Yochay, G., Trzcinski, K., Thompson, C.M., Malley, R. \& Lipsitch, M. (2006): Interference between Streptococcus pneumoniae and Staphylococcus aureus: In vitro hydrogen peroxide-mediated killing by Streptococcus pneumoniae. J Bacteriol 188(13), 4996-5001.

Reizer, J., Novotny, M. J., Stuiver, I. \& Saier, M. H., Jr. (1984). Regulation of glycerol uptake by the phosphoenolpyruvate-sugar phosphotransferase system in Bacillus subtilis. J Bacteriol 159, 243-250.

Reizer, J., Sutrina, S. L., Saier, M. H., Stewart, G. C., Peterkofsky, A. \& Reddy, P. (1989). Mechanistic and physiological consequences of $\operatorname{HPr}($ ser) phosphorylation on the activities of the phosphoenolpyruvate:sugar phosphotransferase system in gram-positive bacteria: studies with site-specific mutants of HPr. Embo J 8, 2111-2120.

Reizer, J., Hoischen, C., Titgemeyer, F., Rivolta, C., Rabus, R., Stulke, J., Karamata, D., Saier, M. H., Jr. \& Hillen, W. (1998). A novel protein kinase that controls carbon catabolite repression in bacteria. Mol Microbiol 27, 1157-1169. 
Renaudin, J., Pascarel, M. C., Saillard, C., Chevalier, C., Laigret, F. \& Bove, J. M. (1987). Spiroplasmas: gene structure and expression. Isr J Med Sci 23, 676-677.

Rosqvist, R., Magnusson, K.E. \& Wolf-Watz, H. (1994): Target cell contact triggers expression and polarized transfer of Yersinia YopE cytotoxin into mammalian cells. EMBO J 13(4), 964-972.

Ross, R.P. \& Claiborne, A. (1992): Molecular cloning and analysis of the gene encoding the NADH oxidase from Streptococcus faecalis 10C1. Comparison with NADH peroxidase and the flavoprotein disulfide reductases. $J$ Mol Biol 227(3), 658671.

Rossomando, A., Wu, J., Weber, M.J. \& Sturgill, T.W. (1992): The phorbol esterdependent activator of the mitogen-activated protein kinase p42mapk is a kinase with specificity for the threonine and tyrosine regulatory sites. Proc Natl Acad Sci U S A 89(12), 5221-5225.

Rutberg, B. (1997): Antitermination of transcription of catabolic operons. Mol Microbiol 23(3), 413-421.

Sanger, F., Nicklen, S. \& Coulson, A. R. (1977). DNA sequencing with chainterminating inhibitors. Proc Natl Acad Sci U S A 74, 5463-5467.

Sambrook, J., Fritsch, E. F. \& Maniatis (1989). Molecular cloning: A laboratory manual. 2. Edition. Cold Spring Harbor Laboratory Press, Cold Spring Harbor, NY.

Sasaki, Y., Ishikawa, J., Yamashita, A., Oshima, K., Kenri, T., Furuya, K., Yoshino, C., Horino, A., Shiba, T., Sasaki, T. \& Hattori, M. (2002): The complete genomic sequence of Mycoplasma penetrans, an intracellular bacterial pathogen in humans. Nucleic Acids Res 30(23), 5293-5300.

Schaper, U., Chapman, J. S. \& Hu, P. C. (1987). Preliminary indication of unusual codon usage in the DNA coding sequence of the attachment protein of Mycoplasma pneumoniae. Isr J Med Sci 23, 361-7.

Schmidl, S. (2007): Kontrolle der HPrK-Aktivität aus M. pneumoniae.

Schmidt, H.L., Stöcklein, W., Danzer, J., Kirch, P. \& Limbach, B. (1986): Isolation and properties of an $\mathrm{H} 2 \mathrm{O}$-forming NADH oxidase from Streptococcus faecalis. Eur $J$ Biochem 156(1), 149-155.

Schirmer, F., Ehrt, S. \& Hillen, W. (1997). Expression, inducer spectrum, domain structure, and function of MopR, the regulator of phenol degradation in Acinetobacter calcoaceticus NCIB8250. J Bacteriol 179, 1329-1336.

Schweizer, H. \& Larson, T.J. (1987): Cloning and characterization of the aerobic snglycerol-3-phosphate dehydrogenase structural gene glpD of Escherichia coli K-12. J Bacteriol 169(2), 507-513. 
Seno, E.T. \& Chater, K.F. (1983): Glycerol catabolic enzymes and their regulation in wild-type and mutant strains of Streptomyces coelicolor A3(2). J Gen Microbiol 129(5), 1403-1413.

Singh, K.D., Halbedel, S., Görke, B. \& Stülke, J. (2007): Control of the phosphorylation state of the HPr protein of the phosphotransferase system in Bacillus subtilis: implication of the protein phosphatase PrpC. J Mol Microbiol Biotechnol 13(13), 165-171.

Smith, S.L., Vandemark, P.J. \& Fabricant, J. (1963): Respiratory pathways in the Mycoplasma. I. Lactate oxidation by Mycoplasma gallisepticum. J Bacteriol 86, 893897.

Somerson, N. L., Taylor-Robinson, D. \& Chanock, R. M. (1963). Hemolyin production as an aid in the identification and quantitation of Eaton agent (Mycoplasma pneumoniae). Am J Hyg 77, 122-128.

Somerson, N. L., James, W. D., Walls, B. E. \& Chanock, R. M. (1967). Growth of Mycoplasma pneumoniae on a glass surface. Ann N Y Acad Sci 143, 384-389.

Spellerberg, B., Cundell, D.R., Sandros, J., Pearce, B.J., Idanpaan-Heikkila, I., Rosenow, C. \& Masure, H.R. (1996): Pyruvate oxidase, as a determinant of virulence in Streptococcus pneumoniae. Mol Microbiol 19(4), 803-813.

Stanton, T.B., Rosey, E.L., Kennedy, M.J., Jensen, N.S. \& Bosworth, B.T. (1999): Isolation, oxygen sensitivity, and virulence of NADH oxidase mutants of the anaerobic spirochete Brachyspira (Serpulina) hyodysenteriae, etiologic agent of swine dysentery. Appl Environ Microbiol 65(11), 5028-5034.

Steinhauer, K., Jepp, T., Hillen, W. \& Stülke, J. (2002). A novel mode of control of Mycoplasma pneumoniae HPr kinase/phosphatase activity reflects its parasitic lifestyle. Microbiology 148, 3277-3284.

Strittmatter, C.F. (1959): Flavin-linked oxidative enzymes of Lactobacillus casei. $J$ Biol Chem 234, 2794-2800.

Stülke, J. \& Hillen, W. (1999). Carbon catabolite repression in bacteria. Curr Opin Microbiol 2, 195-201.

Su, C.J. \& Baseman, J.B. (1990): Genome size of Mycoplasma genitalium. J Bacteriol 172(8), 4705-4707.

Su, H.C., Hutchison, C.A. $3^{\text {rd }}$. \& Giddings, M.C. (2007): Mapping phosphoproteins in Mycoplasma genitalium and Mycoplasma pneumoniae. BMC Microbiol 7, 63.

Suchová, M., Demnerová, K. Valentová, O. \& Ruml, T. (1993): Purification of glycerophosphate oxidase isolated from mutant strain of Aerococcus viridans. Biotechnol Tech 7, 435-438. 
Suttorp, N., Seeger, W., Dewein, E., Bhakdi, S. \& Roka, L. (1985): Staphylococcal alpha-toxin-induced PGI2 production in endothelial cells: role of calcium. Am J Physiol 248(1Pt1), C127-134.

Taichman, N.S., Dean, R.T. \& Sanderson, C.J. (1980): Biochemical and morphological characterization of the killing of human monocytes by a leukotoxin derived from Actinobacillus actinomycetemcomitans. Infect Immun 28(1), 258-268.

Taylor, M. J., Burrow, G. N., Strauch, B. \& Horstmann, D. M. (1967). Meningoencephalitis associated with pneumonitis due to Mycoplasma pneumoniae. Jama 199, 813-816.

Taylor-Robinson, D., Davies, H.A., Sarathchandra, P. \& Furr, P.M. (1991): Intracellular location of mycoplasmas in cultured cells demonstrated by immunocytochemistry and electron microscopy. Int J Exp Pathol 72(6), 705-714.

Tesh, V.L. \& O'Brien, A.D. (1991): The pathogenic mechanisms of Shiga toxin and the Shiga-like toxins. Mol Microbiol 5(8), 1817-1822.

Thomas, C.B. \& Sharp, P. (1988): Detection of antigenic variation among strains of Mycoplasma gallisepticum by enzyme-linked immunosorbent inhibition assay (ELISA) and Western blot analysis. Avian Dis 32(4), 748-756.

Titgemeyer, F. \& Hillen, W. (2002): Global control of sugar metabolism: a grampositive solution. Antonie Van Leeuwenhoek 82(1-4), 59-71.

Tong, H., Chen, W., Merritt, J., Qi, F., Shi, W. \& Dong, X. (2007): Streptococcus oligofermentans inhibits Streptococcus mutans through conversion of lactic acid into inhibitory $\mathrm{H}_{2} \mathrm{O}_{2}$ : a possible counteroffensive strategy for interspecies competition. $\mathrm{Mol}$ Microbiol 63(3), 872-880.

Tsai, C.C., McArthur, W.P., Baehni, P.C., Hammond, B.F. \& Taichman, N.S. (1979): Extraction and partial characterization of a leukotoxin from a plaque-derived Gram-negative microorganism. Infect Immun 25(1), 427-439.

Vancini, R.G., Pereira-Neves, A., Borojevic, R. \& Benchimol, M. (2008): Trichomonas vaginalis harboring Mycoplasma hominis increases cytopathogenicity in vitro. Eur J Clin Microbiol Infect Dis

Vilei, E. M. \& Frey, J. (2001). Genetic and biochemical characterization of glycerol uptake in mycoplasma mycoides subsp. mycoides SC: its impact on $\mathrm{H}(2) \mathrm{O}(2)$ production and virulence. Clin Diagn Lab Immunol 8, 85-92.

Vogl, G., Plaickner, A., Szathmary, S., Stipkovits, L., Rosengarten, R. \& Szostak, M.P. (2008): Mycoplasma gallisepticum invades chicken erythrocytes during infection. Infect Immun 76(1), 71-77. 
Wadher, B. J., Henderson, C. L., Miles, R. J. \& Varsani, H. (1990). A mutant of Mycoplasma mycoides subsp. mycoides lacking the H2O2- producing enzyme L-alphaglycerophosphate oxidase. FEMS Microbiol Lett 60, 127-130.

Walz, A.C., Demel, R.A., de Kruijff, B. \& Mutzel, R. (2002): Aerobic sn-glycerol-3phosphate dehydrogenase from Escherichia coli binds to the cytoplasmic membrane through an amphipathic alpha-helix. Biochem J 365, 471-479.

Warner, J. B. \& Lolkema, J. S. (2003). CcpA-dependent carbon catabolite repression in bacteria. Microbiol Mol Biol Rev 67, 475-490.

Watson, H.L., McDaniel, L.S., Blalock, D.K., Fallon, M.T. \& Cassell, G.H. (1988): Heterogeneity among strains and a high rate of variation within strains of a major surface antigen of Mycoplasma pulmonis. Infect Immun 56(5), 1358-1363.

Way, S.S. \& Wilson, C.B. (2005): The Mycobacterium tuberculosis ESAT-6 homologue in Listeria monocytogenes is dispensable for growth in vitro and in vivo. Infect Immun 73(9), 6151-6153.

Welch, RA. (1991): Pore-forming cytolysins of gram-negative bacteria. Mol Microbiol 5(3):521-528

Whittaker, C.J., Clemans, D.L. \& Kolenbrander, P.E. (1996): Insertional inactivation of an intrageneric coaggregation-relevant adhesin locus from Streptococcus gordonii DL1 (Challis). Infect Immun 64(10), 4137-4142.

White, J., Herman, A., Pullen, A.M., Kubo, R., Kappler, J.W. \& Marrack, P. (1989): The $V$ beta-specific superantigen staphylococcal enterotoxin B: stimulation of mature $\mathrm{T}$ cells and clonal deletion in neonatal mice. Cell 56(1), 27-35.

Wiame, J.M., Bourgeois, S. \& Lambion, R. (1954): Oxidative dissimilation of glycerol studied with variants of Bacillus subtilis. Nature 174(4418), 37-38.

Wilson, M. H. \& Collier, A. M. (1976). Ultrastructural study of Mycoplasma pneumoniae in organ culture. J Bacteriol 125, 332-339.

Wilson, M.L., Menjivar, E., Kalapatapu, V., Hand, A.P., Garber, J. \& Ruiz, M.A. (2007): Mycoplasma pneumoniae associated with hemolytic anemia, cold agglutinins, and recurrent arterial thrombosis. South Med J 100(2), 215-217.

Winans, S.C., Burns, D.L. \& Christie, P.J. (1996): Adaptation of a conjugal transfer system for the export of pathogenic macromolecules. Trends Microbiol 4(2), 64-68.

Winner F, Rosengarten R, Citti C. (2000): In vitro cell invasion of Mycoplasma gallisepticum. Infect Immun 68(7), 4238-4244.

Woese, C.R., Maniloff, J. \& Zablen, L.B. (1980): Phylogenetic analysis of the mycoplasmas. Proc Natl Acad Sci U S A 77(1), 494-498. 
Yamamoto, Y., Pargade, V., Lamberet, G., Gaudu, P., Thomas, F., Texereau, J., Gruss, A., Trieu-Cuot, P. \& Poyart, C. (2006): The Group B Streptococcus NADH oxidase Nox-2 is involved in fatty acid biosynthesis during aerobic growth and contributes to virulence. Mol Microbiol 62(3), 772-785.

Yavlovich, A., Higazi, A.A. \& Rottem, S. (2001): Plasminogen binding and activation by Mycoplasma fermentans. Infect Immun 69(4), 1977-1982.

Yavlovich, A., Katzenell, A., Tarshis, M., Higazi, A.A. \& Rottem, S. (2004): Mycoplasma fermentans binds to and invades HeLa cells: involvement of plasminogen and urokinase. Infect Immun 72(9), 5004-5011.

Yavlovich, A. \& Rottem, S. (2007): Binding of host extracellular matrix proteins to Mycoplasma fermentans and its effect on adherence to, and invasion of HeLa cells.

FEMS Microbiol Lett 266(2), 158-162.

Yeats, C., Finn, R.D. \& Bateman, A. (2002): The PASTA domain: a beta-lactambinding domain. Trends Biochem Sci 27(9), 438-440.

Yoshitsugu, M., Matsunaga, S., Hanamure, Y., Rautiainen, M., Ueno, K., Miyanohara, T., Furuta, S., Fukuda, K. \& Ohyama, M. (1995): Effects of oxygen radicals on ciliary motility in cultured human respiratory epithelial cells. Auris Nasus Larynx 22(3), 178-185.

Yu, J., Bryant, A.P., Marra, A., Lonetto, M.A., Ingraham, K.A., Chalker, A.F., Holmes, D.J., Holden, D., Rosenberg, M. \& McDevitt, D. (2001): Characterization of the Streptococcus pneumoniae $\mathrm{NADH}$ oxidase that is required for infection. Microbiology 147, 431-438.

Zhu, P.P., Nosworthy, N., Ginsburg, A., Miyata, M., Seok, Y.J. \& Peterkofsky, A. (1997): Expression, purification, and characterization of enzyme IIA(glc) of the phosphoenolpyruvate:sugar phosphotransferase system of Mycoplasma capricolum.

Biochemistry 36(23), 6947-6953.

Zimmerman, C.U. \& Herrmann, R. (2005): Synthesis of a small, cysteine-rich, 29 amino acids long peptide in Mycoplasma pneumoniae. FEMS Microbiol Lett 253(2), 315-321. 
7. Anhang

\subsection{Materialien}

\subsubsection{Chemikalien}

Ampicillin

BSA

CDP*

Desthiobiotin

DMEM

Fötales Kälberserum

$\gamma$-ATP

Gentamycin

sn-Glycerol-3-Phosphat

HABA

Hydrazin

Imidazol

IPTG

Kanamycin

$\mathrm{NAD}^{+}$

$\mathrm{NADH} / \mathrm{H}^{+}$

Na-Pyruvat

Nicht essentielle Aminosäuren

$\mathrm{Ni}^{2+}$-NTA Superflow

Penicillin G

PEP

Phenolrot

Pferdeserum

PPLO broth

Strep-Tactin Sepharose

X-Gal
Sigma, München

MBI Fermentas, St. Leon-Rot

Roche Diagnostics, Mannheim

IBA, Göttingen

Biochrom, Berlin

Biochrom, Berlin

Hartmann Analytic GmbH

Sigma, München

Fluka, Buchs

IBA, Göttingen

Sigma, München

Serva, Heidelberg

Peqlab, Erlangen

Sigma, München

Sigma, München

Sigma, München

Biochrom, Berlin

Biochrom, Berlin

Qiagen, Hilden

Serva, Heidelberg

Sigma, München

Roth, Karlsruhe

Invitrogen, Karlsruhe

Becton, Dickinson and Company, France

IBA, Göttingen

Peqlab, Erlangen

Alle sonstigen verwendeten allgemeinen Chemikalien wurden von Merck, Serva, Fluka, Sigma oder Roth in p.a. Qualität bezogen. 


\subsubsection{Hilfsmittel}

Dialyseschläuche

Einmalspritzen $(5 \mathrm{ml}, 10 \mathrm{ml})$

Eppendorfgefäße

Gene Amp Reaction Tubes (PCR)

Pipettenspitzen

Glaspipetten

Halbmikroküvetten aus Kunststoff

Kulturflaschen

Kunststoffpetrischalen

Membranfilter NC 45

$(0,2 \mu \mathrm{m}$ Porengröße)

Mikroliterpipetten

$(2 \mu 1,20 \mu 1,200 \mu 1,1000 \mu 1)$

Polyethylenröhrchen

Poly-Prep Chromatography Columns

Polyvinylidendifluorid-Membran

(PVDF)

Quarzküvetten aus Kunststoff

Zentrifugenbecher
Serva, Heidelberg

Becton Dickinson Drogheda, Irland

Greiner, Nürtingen

Perkin Elmer, Weiterstadt

Greiner, Nürtingen

Eppendorf, Hamburg

Sarstedt, Nümbrecht

Brand, Wertheim

Sarstedt, Nümbrecht

Renner, Dannstadt

Nunc, Wiesbaden

Greiner, Nürtingen

Schleicher und Schüll, Dassel

Gilson, Düsseldorf

Eppendorf, Hamburg

Greiner, Nürtingen

Bio-Rad Laboratories GmbH, München

Bio-Rad Laboratories GmbH, München

Brand, Wertheim

Beckmann, München

\subsubsection{Geräte und Apparaturen}

Autoklav

Biofuge fresco

Chemilumineszenzsystem

ChemiSmart

$\mathrm{CO}_{2}$-Inkubator

Elektronenmikroskop

Feinwaage Sartorius
Zirbus, Bad Grund

Heraeus Christ, Osterode

Peqlab, Erlangen

Labotect, Göttingen

Philips, Amsterdam

Sartorius, Göttingen 
French Press

Gelelektrophoreseapparaturen

Heizblock

Horizontalschüttler 3006

Kühlzentrifuge PrimoR

Kulturschüttler Innova 2300

Magnetrührer

Mikroprozessor pH-Meter Calimatic

Mikroskop

Spannungsgerät

Spektralphotometer Ultrospec

2100pro

TE70 SemiPhor Semi-Dry Transfer

Unit

Thermocycler Tpersonal

Ultraschallgerät UP200S

Ultrazentrifuge Optima Max-E

Vertikalgelelektrophoreseapparatur

Mini-Protean III System

Waage Sartorius universal

Wasservollentsalzungsanlage
Spectonic Unicam, England

EasyCast $^{\mathrm{TM}}$ Minigelsystem, Peqlab,

Erlangen

Waasetec, Göttingen

GFL, Burgwedel

Heraeus Christ, Osterode

New Brunswick, Neu-Isenburg

JAK Werk, Staufen

Knick, Berlin

Zeiss, Jena

Bio-Rad Laboratories California USA

Amersham, Freiburg

Amersham, Freiburg

Biometra, Göttingen

Dr. Hielscher GmbH, Teltow

Beckman, München

Bio-Rad Laboratories, California USA

Sartorius, Göttingen

Millipore, Schwalbach

\subsubsection{Kommerziell erhältliche Systeme}

Gene Ruler DNA Ladder Mix

Nucleospin Plasmid

Protein Molecular Weight Marker SM0431

Prestainded Protein Marker

QIAquick PCR Purification Kit
MBI Fermentas, St. Leon-Rot Macherey-Nagel, Düren

MBI Fermentas, St. Leon-Rot

MBI Fermentas, St. Leon-Rot

Qiagen, Hilden 


\subsubsection{Antikörper und Enzyme}

Ampligase

Anti-Digoxigenin-AP, Fab Fragmente

Pfu-DNA-Polymerase

Polyklonaler Antikörper gegen

M .pneumoniae Strep-tag-GlpD

Polyklonaler Antikörper gegen

M.pneumoniae Strep-tag-GlpK

Polyklonaler Antikörper gegen

M. pneumoniae $\mathrm{P} 01$

Restriktionsendonukleasen

Sekundärer AK Anti-Kaninchen IgG-AP gekoppelt

Taq-DNA-Polymerase
Epicentre, Madison, USA

Roche Diagnostics, Mannheim

MBI Fermentas, St. Leon-Rot

Institut für Veterinär-Bakteriologie, Bern

Seqlab, Göttingen

ZMBH, Heidelberg

NEB Biolabs, Frankfurt am Main

MBI Fermentas, St. Leon-Rot

Promega, Mannheim

MBI Fermentas, St. Leon-Rot

\subsection{Oligonukleotide}

Die 5'-phosphorylierten Oligonukleotide und die restlichen Oligonukleotide wurden von der Firma Operon Köln bezogen.

Tab. 7.1. Oligonukleotide

\begin{tabular}{|c|c|c|}
\hline Name & Sequenz $\left(5^{\prime} \rightarrow 3^{\prime}\right)^{1}$ & Verwendung \\
\hline $\mathrm{CH} 32$ & GGGCGAAAATTCTTTTTACTAATATG & glpF-Mutantenscreen \\
\hline $\mathrm{CH} 33$ & $\begin{array}{l}\text { GTAACTATTAATTAGTTAAGCCTTTAT } \\
\text { GG }\end{array}$ & glpD-Mutantenscreen \\
\hline $\mathrm{CH} 34$ & $\begin{array}{l}\text { GCAATTTTACTAGCTGAATTTAATTAA } \\
\text { TG }\end{array}$ & $\begin{array}{l}\text { Protein Phosphatase } 2 \mathrm{c} \text { homolog } \\
\text { (MPN247)-Mutantenscreen }\end{array}$ \\
\hline $\mathrm{CH} 35$ & $\begin{array}{l}\text { GCTCAACTTGATTAATTTAAAACAATG } \\
\text { G }\end{array}$ & $\begin{array}{l}\text { Ser/thr/tyr Protein Kinase } \\
(M P N 248) \text {-Mutantenscreen }\end{array}$ \\
\hline $\mathrm{CH} 36$ & GCACCTCTATGGTTTTGATGAAG & Sonde für $p g i$ fw \\
\hline
\end{tabular}




\begin{tabular}{|c|c|c|}
\hline Name & Sequenz $\left(5^{\prime} \rightarrow 3^{\prime}\right)^{1}$ & Verwendung \\
\hline $\mathrm{CH} 37$ & $\begin{array}{l}\text { CTAATACGACTCACTATAGGGAGAG } \\
\text { CTAACTCTTGTTTGGCTGTC }\end{array}$ & Sonde für pgi rev \\
\hline $\mathrm{CH} 38$ & GCCATTTTAACCTCTGGTGGTG & Sonde für $p f k$ fw \\
\hline $\mathrm{CH} 39$ & $\begin{array}{l}\text { CTAATACGACTCACTATAGGGAGAC } \\
\text { AGTGGTTTTGGTGTTGCAAGATC }\end{array}$ & Sonde für $p f k$ rev \\
\hline $\mathrm{CH} 40$ & CAACACGCTAAGCAACACCAC & Sonde für $f b a$ fw \\
\hline $\mathrm{CH} 41$ & $\begin{array}{l}\text { CTAATACGACTCACTATAGGGAGAC } \\
\text { CACCATGGAGCACTAAGGG }\end{array}$ & Sonde für $f b a$ rev \\
\hline $\mathrm{CH} 42$ & GGATTTACACCAAGCGTTGGC & Sonde für tpi fw \\
\hline $\mathrm{CH} 43$ & $\begin{array}{l}\text { CTAATACGACTCACTATAGGGAGAG } \\
\text { CAACCGAACCACCATAGAG }\end{array}$ & Sonde für tpi rev \\
\hline $\mathrm{CH} 44$ & GACTATCCGTGTTGCTATCAATG & Sonde für gap fw \\
\hline $\mathrm{CH} 45$ & $\begin{array}{l}\text { CTAATACGACTCACTATAGGGAGAC } \\
\text { CAGTGGTGGTAGGTACAATG }\end{array}$ & Sonde für gap rev \\
\hline $\mathrm{CH} 46$ & CCCACTGTTGCTTGTGTTGTG & Sonde für eno fw \\
\hline $\mathrm{CH} 47$ & $\begin{array}{l}\text { CTAATACGACTCACTATAGGGAGAG } \\
\text { CTACATCCAGTGCAATCGC }\end{array}$ & Sonde für eno rev \\
\hline $\mathrm{CH} 48$ & $\begin{array}{l}\text { AAAAGGATCCATGGAAACAAGAGATG } \\
\text { TTTTAATAG }\end{array}$ & glpD fw (BamHI) \\
\hline $\mathrm{CH} 49$ & $\begin{array}{l}\text { P-GGTAAAAAGCTCTGGTTAAATACC } \\
\text { TAC }\end{array}$ & glpD Mutageneseprimer A219 G \\
\hline $\mathrm{CH} 50$ & P-GAAGGTAGCTGGGCAATTGATC & glpD Mutageneseprimer A447G \\
\hline $\mathrm{CH} 51$ & $\begin{array}{l}\text { P-GGACTTATTTAGTTTGGACTAACAAC } \\
\text { GAAAC }\end{array}$ & glpD Mutageneseprimer A573G \\
\hline CH52 & $\begin{array}{l}\text { P-CTAAAAAGCCGAACTGGAACGGAA } \\
\text { AG }\end{array}$ & glpD Mutageneseprimer A1125G \\
\hline $\mathrm{CH} 53$ & $\begin{array}{l}\text { TATAATGCATTTAGATCCATGGCAGAT } \\
\text { TG }\end{array}$ & $\begin{array}{l}\text { glpD rev (AvaIII/Mph1103I/ } \\
\text { NsiI) }\end{array}$ \\
\hline $\mathrm{CH} 54$ & $\begin{array}{l}\text { AAAAGTCGACATGAAGAAA } \\
\text { GTGATTGTTATCG }\end{array}$ & nox fw (SalI) \\
\hline CH55 & P-CTGGAGCTTGGCCGATTTG & nox Mutageneseprimer A115G \\
\hline $\mathrm{CH} 56$ & P-CAGAAGCGGCTTGGCAGTG & nox Mutageneseprimer A187G \\
\hline $\mathrm{CH} 57$ & P-CTTTCGTGGAACACCAACCACAG & nox Mutageneseprimer A1257G \\
\hline CH58 & $\begin{array}{l}\text { TATAAAGCTTTTATTTATTTTTAGGGGT } \\
\text { ATAGTAAC }\end{array}$ & nox rev (HindIII) \\
\hline
\end{tabular}




\begin{tabular}{|c|c|c|}
\hline Name & Sequenz $\left(5^{\prime} \rightarrow 3^{\prime}\right)^{1}$ & Verwendung \\
\hline CH59 & $\begin{array}{l}\text { AAAAGGATCCAGATAGATGGATGTGA } \\
\text { GACAAACATGGAAACAAGAGATGTTT } \\
\text { TAATAGGC }\end{array}$ & $\begin{array}{l}\text { RBS von Gltc } \\
\text { Amplifikation von glpD fw } \\
\text { (Expression in B. subtilis) } \\
\text { (BamHI) }\end{array}$ \\
\hline $\mathrm{CH} 60$ & $\begin{array}{l}\text { TATAGTCGACCTATTAGATCCATGGCA } \\
\text { GATTGTACTTTC }\end{array}$ & $\begin{array}{l}\text { Amplifikation von glpD rev } \\
\text { (zusätzliches Stopcodon) } \\
\text { (SalI) }\end{array}$ \\
\hline CH61 & ATGCCAAATCCTGTTAGATTTGTTTAC & MPN372 Mutantenscreen fw \\
\hline CH62 & CAGTGACGTTAAAGCTTAATCGC & MPN372 Mutantenscreen rev \\
\hline $\mathrm{CH} 63$ & $\begin{array}{l}\text { CTAATACGACTCACTATAGGGAGAG } \\
\text { CCGGGTGGTGAGCATG }\end{array}$ & MPN372 rev (bis 492 bp) \\
\hline CH64 & CCATGCTCCCTGAAGTGAAGCCG & $\begin{array}{l}\text { glpK fw intern ( } 1000 \mathrm{bp}) \text { für LI } \\
(\Delta g l p D \text { Mutante } B . \text { subtilis })\end{array}$ \\
\hline $\mathrm{CH} 65$ & $\begin{array}{l}\text { CCTATCACCTCAAATGGTTCGCTGTAC } \\
\text { GTTTCCTCCTTGTTGTCACGG }\end{array}$ & $\begin{array}{l}\text { glpK rev für LFH mit Schwanz } \\
\text { für Spec-Kassette (Kan } \\
\text { kompatibel) } \\
\text { ( } \Delta \text { glpD Mutante B. subtilis) }\end{array}$ \\
\hline CH66 & $\begin{array}{l}\text { CGAGCGCCTACGAGGAATTTGTATCGT } \\
\text { AAATCATAACGGGCTGTCTGCAGCCC }\end{array}$ & $\begin{array}{l}y h x B \text { fw für LFH mit Schwanz } \\
\text { für Spec-Kassette (Kan } \\
\text { kompatibel) } \\
(\triangle g l p D \text { Mutante B. subtilis) }\end{array}$ \\
\hline CH67 & CAGGATCTGTCGCGATGAGAATATCTG & $\begin{array}{l}y h x B \text { rev intern }(1000 \mathrm{bp}) \text { für } \\
\text { LFH } \\
(\Delta g l p D \text { Mutante B. subtilis })\end{array}$ \\
\hline CH68 & $\begin{array}{l}\text { TATACCCGGGCTATTAGATCCATGGCA } \\
\text { GATTGTACTTTC }\end{array}$ & $\begin{array}{l}\text { Amplifikation von glpD rev } \\
\text { (zusätzliches Stopcodon) } \\
\text { (SmaI) }\end{array}$ \\
\hline CH69 & $\begin{array}{l}\text { GGCGTTTAAATGAGCTTTAAAATAACC } \\
\text { G }\end{array}$ & $\begin{array}{l}\text { MPN320 thyA Mutantenscreen } \\
\text { fw }\end{array}$ \\
\hline $\mathrm{CH} 70$ & $\begin{array}{l}\text { TTAAACTGCTACCTCTCCTTTAATTGTA } \\
\text { G }\end{array}$ & $\begin{array}{l}\text { MPN320 thyA Mutantenscreen } \\
\text { rev }\end{array}$ \\
\hline $\mathrm{CH} 71$ & $\begin{array}{l}\text { ATGGAAACGCAAAACCAAATAGAAAC } \\
\text { G }\end{array}$ & $\begin{array}{l}\text { MPN358 thyX Mutantenscreen } \\
\text { fw }\end{array}$ \\
\hline $\mathrm{CH} 72$ & TTAGTTGAGGTACTTCAACGCTGC & $\begin{array}{l}\text { MPN358 thyX Mutantenscreen } \\
\text { rev }\end{array}$ \\
\hline $\mathrm{CH} 73$ & $\begin{array}{l}\text { CTAATACGACTCACTATAGGGAGAC } \\
\text { CAGCGCAATTGCAAACACCG }\end{array}$ & MPN358 rev (bis Base 592) \\
\hline $\mathrm{CH} 74$ & $\begin{array}{l}\text { CTAATACGACTCACTATAGGGAGAG } \\
\text { GTGTTCAAAACTGTGGAGG }\end{array}$ & MPN248 rev (bis Base 475) \\
\hline
\end{tabular}




\begin{tabular}{|c|c|c|}
\hline Name & Sequenz $\left(5^{\prime} \rightarrow 3^{\prime}\right)^{1}$ & Verwendung \\
\hline SH29 & ATGAGTGAGCTAACTCACAG & $\begin{array}{l}\text { Sequenzierungsprimer für } \\
\text { pMT85-Transposanten, 60 bp } \\
\text { vor IR } 1 \text { (1-26) }\end{array}$ \\
\hline SH30 & CAATACGCAAACCGCCTC & $\begin{array}{l}\text { Sequenzierungsprimer für } \\
\text { pMT85-Transposanten, } \sim 60 \mathrm{bp} \\
\text { vor IR } 2 \text { (3413-3438) }\end{array}$ \\
\hline SH80 & $\begin{array}{l}\text { ATGGATCCTTACGAATGGACAACTACC } \\
\text { C }\end{array}$ & MPN248 rev (BamHI) \\
\hline SH81 & P-GATTTGGCGCAATGGCAAACCG & $\begin{array}{l}\text { MPN248 Mutageneseprimer } \\
\text { A969G }\end{array}$ \\
\hline SH89 & $\begin{array}{l}\text { TAGAGCTCGATGGCACTAAATTTAAAG } \\
\text { ATTGG }\end{array}$ & MPN248 fw (SacI) \\
\hline TM0141 & $\begin{array}{l}\text { CAGCGAACCATTTGAGGTGATAGGGA } \\
\text { CTGGCTCGCTAATAACGTAACGTGACT } \\
\text { GGCAAGAG }\end{array}$ & $\begin{array}{l}\text { Amplifikation der spec-Kassette } \\
\text { fw }\end{array}$ \\
\hline TM0142 & $\begin{array}{l}\text { CGATACAAATTCCTCGTAGGCGCTCGG } \\
\text { CGTAGCGAGGGCAAGGGTTTATTGTTT } \\
\text { TCTAAAATCTG }\end{array}$ & $\begin{array}{l}\text { Amplifikation der spec-Kassette } \\
\text { rev }\end{array}$ \\
\hline
\end{tabular}

${ }^{1}$ Die angefügten Schnittstellen sind unterstrichen, die T7-Promotoren sind fett, $\mathrm{P}$ steht für eine 5'-Phosphorylierung, wichtige Sequenzen sind rot und Mutationen fett gedruckt.

\subsection{Plasmide}

Tab. 7.2. Plasmide

\begin{tabular}{llll}
\hline Plasmid & Resistenz & Referenz bzw. Konstruktion & Verwendung \\
\hline pWH844 & Amp $^{\mathrm{R}}$ & Schirmer et al., 1997 & Überexpressionsvektor \\
pGP172 & Amp $^{\mathrm{R}}$ & Merzbacher et al., 2004 & Überexpressionsvektor \\
pDG1727 & Spc $^{\mathrm{R}}$ & Guérout-Fleury et al., 1995 & $\begin{array}{l}\text { Isolierung der Spc- } \\
\text { Resistenzkassette }\end{array}$ \\
& & Zimmermann und Herrmann, & Mini-Transposon \\
pMT85 & Gent $^{\mathrm{R}}$ & 2005 & \\
& & Galinier et al, 1997 & Überexpression von His $6^{-}$ \\
pAG3 & Amp $^{\mathrm{R}}$ & & EI aus B. subtilis
\end{tabular}




\begin{tabular}{|c|c|c|c|}
\hline Plasmid & Resistenz & Referenz bzw. Konstruktion & Verwendung \\
\hline pGP217 & $A m p^{R}$ & Steinhauer et al., 2002 & $\begin{array}{l}\text { Überexpression von } \text { His }_{6-} \\
\text { HPr aus } M . \text { pneumoniae }\end{array}$ \\
\hline pGP611 & $A m p^{R}$ & Merzbacher et al, 2004 & $\begin{array}{l}\text { Überexpression von Strep- } \\
\text { HPrK aus } M \text {. pneumoniae }\end{array}$ \\
\hline pGP255 & $A m p^{R}$ & Claudine Hames, 2005 & $\begin{array}{l}\text { Überexpression von } \\
\text { Strep-GlpK aus } \\
\text { M. pneumoniae }\end{array}$ \\
\hline
\end{tabular}

In dieser Arbeit konstruiert

\begin{tabular}{|c|c|c|c|}
\hline pGP263 & $\mathrm{Amp}^{\mathrm{R}}$ & $\begin{array}{l}1440 \text { bp PCR-Produkt Nox aus } \\
\text { chromosomaler M. pneumoniae }\end{array}$ & Template für die MMR \\
\hline & & DNA (Primer CH54/CH58) über & \\
\hline & & SalI und HindIII in pWH844 & \\
\hline pGP264 & $A m p^{R}$ & $\begin{array}{l}1440 \text { bp MMR-Produkt nox mit } \\
\text { pGP263 (CH54-58) über SalI } \\
\text { und HindIII in pWH844 }\end{array}$ & $\begin{array}{l}\text { Überexpression von } \\
\text { His }_{6} \text {-Nox aus } \\
\text { M. pneumoniae }\end{array}$ \\
\hline pGP265 & $A m p^{R}$ & $\begin{array}{l}1155 \text { bp PCR-Produkt glpD aus } \\
\text { chromosomaler M. pneumoniae } \\
\text { DNA (Primer CH48/CH53) über } \\
\text { BamHI und PstI/Mph1103I in } \\
\text { pWH844 }\end{array}$ & Template für die MMR \\
\hline pGP266 & $A m p{ }^{R}$ & $\begin{array}{l}1155 \text { bp MMR-Produkt glpD aus } \\
\text { pGP265 (CH48-CH53) über } \\
\text { BamHI und PstI/Mph1103I in } \\
\text { pWH844 }\end{array}$ & $\begin{array}{l}\text { Überexpression von } \\
\text { His,-GlpD aus } \\
\text { M. pneumoniae }\end{array}$ \\
\hline pGP267 & $\begin{array}{l}\text { E. coli: } \\
\text { Kan }^{\mathrm{R}} \\
\text { B. subtilis: } \\
\text { Erm }^{\mathrm{R}}\end{array}$ & $\begin{array}{l}1155 \text { bp MMR-Produkt glpD aus } \\
\text { pGP266 + RBS von gltC } \\
\text { CH59/CH60 über BamHI und } \\
\text { SalI in pBQ200 }\end{array}$ & $\begin{array}{l}\text { Expression von GlpD aus } \\
\text { M. pneumoniae in } \\
\text { B. subtilis }\end{array}$ \\
\hline
\end{tabular}




\begin{tabular}{|c|c|c|c|}
\hline Plasmid & Resistenz & Referenz bzw. Konstruktion & Verwendung \\
\hline pGP268 & $\begin{array}{l}\text { E. coli: } \\
\text { Amp }^{\mathrm{R}} \\
\text { B. subtilis: } \\
\mathrm{Cm}^{\mathrm{R}}\end{array}$ & $\begin{array}{l}1155 \text { bp MMR-Produkt glpD aus } \\
\text { pGP267 + RBS von gltC } \\
\text { CH59/CH68 über BamHI und } \\
\text { SmaI in pHCMC02 }\end{array}$ & $\begin{array}{l}\text { Expression von GlpD aus } \\
\text { M. pneumoniae in } \\
\text { B. subtilis }\end{array}$ \\
\hline pGP269 & $\begin{array}{l}\text { E. coli: } \\
\text { Amp }^{\mathrm{R}} \\
\text { B. subtilis: } \\
\mathrm{Cm}^{\mathrm{R}}\end{array}$ & $\begin{array}{l}1155 \text { bp MMR-Produkt glpD aus } \\
\text { pGP267 + RBS von gltC } \\
\text { CH59/CH68 über BamHI und } \\
\text { SmaI in pHCMC04 }\end{array}$ & $\begin{array}{l}\text { Expression von GlpD aus } \\
\text { M. pneumoniae in } \\
\text { B. subtilis }\end{array}$ \\
\hline pGP270 & $A m p^{R}$ & $\begin{array}{l}1170 \text { bp PCR-Produkt MPN248 } \\
\text { (prkC) aus chrom. DNA von } \\
\text { M.pneumoniae (SH89/SH80) } \\
\text { über BamHI und SacI in pGP172 }\end{array}$ & Template für die MMR \\
\hline pGP271 & $A m p^{R}$ & $\begin{array}{l}1170 \text { bp CCR-Produkt MPN248 } \\
(\text { prkC) aus pGP270 } \\
\text { (SH89/SH80/SH81) über BamHI } \\
\text { und SacI in pGP172 }\end{array}$ & $\begin{array}{l}\text { Überexpression von Strep- } \\
\text { PrkC aus } M . \text { pneumoniae }\end{array}$ \\
\hline
\end{tabular}

\subsection{Stämme}

Tab. 7.3. Bakterienstämme

\begin{tabular}{lll}
\hline Stamm & relevanter Genotyp & Referenz bzw. \\
& & Konstruktion \\
\hline
\end{tabular}

E. coli

DH $5 \alpha$

recA1 endA1 gyrA96 thi hsdR17 $\mathrm{r}_{\mathrm{K}^{-}} \quad$ Sambrook et al., 1989

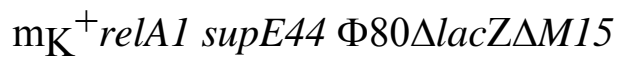

$\Delta($ lacZYA-argF)U169

BL21 $\quad \mathrm{F}^{-}$,lon ompT $r_{B} m_{B}$ hsdS gal $\left(\mathrm{cI}_{\mathrm{ts} 857}\right.$ ind1 $\quad$ Sambrook et al., 1989

(DE3) Sam7 nin5 lacUV5-T7 gene1) 


\begin{tabular}{lll}
\hline Stamm & relevanter Genotyp & $\begin{array}{l}\text { Referenz bzw. } \\
\text { Konstruktion }\end{array}$ \\
\hline M. pneumoniae & & \\
M129 & Wildtyp & Somerson et al., 1963 \\
GPM51 & hprK::Tn4001m & Halbedel et al., 2006 \\
GPM52 & glpD::Tn4001m & Halbedel, 2006 \\
GPM68 & prpC::Tn4001m & Halbedel, 2006 \\
GPM69 & Idh::Tn4001m & Halbedel, 2006 \\
GPM70 & mpn474::Tn4001m & Halbedel, 2006 \\
in dieser Arbeit isoliert bzw. konstruiert: & \\
M. pneumoniae & mpn372::Tn4001m & \\
GPM8 & thyA::Tn4001m & pMT85 $\rightarrow$ M129 \\
GPM9 & $m p n 358:: T n 4001 \mathrm{~m}$ & pMT85 $\rightarrow$ M129 \\
GPM10 & mpn248::Tn4001m & pMT85 $\rightarrow$ M129 \\
GPM11 & & pMT85 $\rightarrow$ M129 \\
\hline
\end{tabular}

${ }^{1}$ Der Pfeil $(\rightarrow)$ steht für eine Transformation

\subsection{Proteine}

Tab. 7.4. Verwendete Proteine

\begin{tabular}{lll}
\hline Protein & Organismus & Referenz \\
\hline Enzym I & B. subtilis & pAG3 \\
HPr & M. pneumoniae & pGP217 \\
HPrK & M. pneumoniae & pGP611 \\
GlpK & M. pneumoniae & pGP255 \\
Nox & M. pneumoniae & pGP264 \\
GlpD & M. pneumoniae & pGP266 \\
PrkC & M. pneumoniae & pGP271 \\
\hline
\end{tabular}




\subsection{Verwendete Internetangebote und Computerprogramme}

Tab. 7.5. Genutzte Internetangebote

\begin{tabular}{|c|c|c|}
\hline URL & Anbieter & Anwendung \\
\hline $\begin{array}{l}\text { http://www.zmbh.uni- } \\
\text { heidelberg.de/M_pneumoniae/ge } \\
\text { nome/Results.html }\end{array}$ & $\begin{array}{l}\text { ZMBH, Uni } \\
\text { Heidelberg }\end{array}$ & $\begin{array}{l}\text { Recherchen zum Genom } \\
\text { von } M . \text { pneumoniae }\end{array}$ \\
\hline http://www.ncbi.nlm.nih.gov/ & $\begin{array}{l}\text { National Institutes of } \\
\text { Health, Bethesda, } \\
\text { USA }\end{array}$ & Literaturrecherche \\
\hline $\begin{array}{l}\text { http://www.genome.jp/kegg/kegg } \\
\text {.html }\end{array}$ & Kanehisa Laboratories & Sequenzrecherche \\
\hline $\begin{array}{l}\text { http://cmr.tigr.org/tigr- } \\
\text { scripts/CMR/CmrHomePage.cgi }\end{array}$ & $\begin{array}{l}\text { The Institute for } \\
\text { Genomic Research }\end{array}$ & Sequenzrecherche \\
\hline http://au.expasy.org/tools/ & $\begin{array}{l}\text { Swiss Institute of } \\
\text { Bioinformatics }\end{array}$ & $\begin{array}{l}\text { Recherchen } \mathrm{zu} \\
\text { Proteineigenschaften }\end{array}$ \\
\hline http://smart.embl-heidelberg.de/ & EMBL & $\begin{array}{l}\text { Recherchen } \mathrm{zu} \\
\text { Proteindomänen }\end{array}$ \\
\hline http://www.microbesonline.org/ & $\begin{array}{l}\text { Virtual Institute for } \\
\text { Microbial Stress and } \\
\text { Survival }\end{array}$ & $\begin{array}{l}\text { Recherche und Vergleiche } \\
\text { von Operons }\end{array}$ \\
\hline http://www.ebi.ac.uk/clustalw/ & $\begin{array}{l}\text { European } \\
\text { Bioinformatics } \\
\text { Institute }\end{array}$ & Erstellen von Alignments \\
\hline
\end{tabular}

Tab. 7.6. Genutzte Computerprogramme

$\begin{array}{lll}\text { Programm Hersteller Anwendung } & \text { An }\end{array}$

ChemiCapt Version 11.07

SeqMan $^{\text {TM }}$ II 5.07

Swift II Time Drive
Aufnahme von

Chemilumineszenzsignalen

DNASTAR

Auswertung von

Sequenzierdateien

Biochrom Ltd. Enzymmessung 
Microsoft Office XP

Microsoft Inc.

Text- und

Datenverarbeitung 


\section{Lebenslauf}

\section{Persönliche Daten}

$\begin{array}{ll}\text { Name } & \text { Claudine Anne Lydia Hames } \\ \text { Geburtsdatum,-ort } & \text { 03.04.1981, Luxemburg } \\ \text { Staatsangehörigkeit } & \text { luxemburgisch } \\ \text { Familienstand } & \text { ledig } \\ \text { Eltern } & \text { Georgette Hames-Bertemes } \\ & \text { Dipl. Ing. Alphonse Hames }\end{array}$

\section{Schulausbildung}

1987-1993

Besuch der Grundschule in Bascharage, Luxemburg

1993-2000

Besuch des Lycée Hubert Clément in Esch/Alzette,

Luxemburg

\section{Studium}

2000-2005

2002

2005

2005-2008

Studium der Biologie an der Georg-August Universität

Göttingen

Vordiplom

Diplom, Göttingen im Mai 2005

Promotion an der Georg-August Universität Göttingen im Mai 2008 